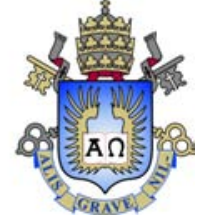

Rodrigo Araujo Cardoso Dias

\title{
Produtividade de poços em reservatórios de alta heterogeneidade de permeabilidade
}

Tese apresentada ao Programa de Pós-graduação em Engenharia Mecânica da PUC-Rio como requisito parcial para obtenção do grau de Doutor em Engenharia Mecânica.

Orientadora : Profa. Angela Ourivio Nieckele

Coorientador: Dr. Paulo Dore Fernandes 


\section{Rodrigo Araujo Cardoso Dias}

\section{Produtividade de poços em reservatórios de alta heterogeneidade de permeabilidade}

Tese apresentada como requisito parcial para obtenção do grau de Doutor pelo Programa de Pós-graduação em Engenharia Mecânica da PUC-Rio. Aprovada pela Comissão Examinadora abaixo assinada.

Profa. Angela Ourivio Nieckele

Orientadora

Departamento de Engenharia Mecânica - PUC-Rio

Dr. Paulo Dore Fernandes

Coorientador

PUC-Rio

Dr. Luiz Otavio Schmall dos Santos

Petrobras

Prof. Philippe Remy Bernard Devloo

UNICAMP

Prof. Luis Glauber Rodrigues

Departamento de Engenharia Mecânica - PUC-Rio

Dr. Antonio Luiz Serra de Souza

Petrobras

Prof. Márcio da Silveira Carvalho

Coordenador Setorial do Centro

Técnico Científico - PUC-Rio

Rio de Janeiro, 12 de Maio de 2017 
Todos os direitos reservados. É proibida a reprodução total ou parcial do trabalho sem autorização da universidade, do autor e do orientador.

\section{Rodrigo Araujo Cardoso Dias}

Engenheiro Mecânico e Mestre em Engenharia Mecânica pela Universidade Federal Fluminense.

Ficha Catalográfica

Dias, Rodrigo Araujo Cardoso

Produtividade de poços em reservatórios de alta heterogeneidade de permeabilidade / Rodrigo Araujo Cardoso Dias; orientadora: Angela Ourivio Nieckele; co-orientador: Paulo Dore Fernandes. - 2017.

v., 229 f: il. color. ; $30 \mathrm{~cm}$

Tese (doutorado) - Pontifícia Universidade Católica do Rio de Janeiro, Departamento de Engenharia Mecânica.

Inclui bibliografia

1. Engenharia Mecânica - Teses. 2. Poços de petróleo; 3. Reservatório;. 4. Heterogeneidade;. 5. Fluido dinâmica computacional;. 6. OpenFoam;. I. Nieckele, Angela Ourivio. II. Fernandes, Paulo Dore. III. Pontifícia Universidade Católica do Rio de Janeiro. Departamento de Engenharia Mecânica. IV. Título. 
Dedico essa tese a minha amada esposa, Lorena Dias, e ao meu pequeno Luccas, meus maiores presentes nessa vida. 


\section{Agradecimentos}

Para mim, essa é a parte mais importante da tese. Não posso esquecer das pessoas que me acompanharam durante todos esses anos de estudo. Primeiro, sem dúvida alguma, eu preciso agradecer a Deus, Ele tem me acompanhado em todas as frentes da minha vida, inclusive nessa. A escolha da Universidade, as pessoas que encontrei ao longo do caminho, a força, perseverança, a motivação, os obstáculos ultrapassados, as provas que passei e as pequenas conquistas que obtive, são mérito dEle e não meus. Talvez alguns não consigam entender, mas eu não consigo não registrar. Agradeço a Deus por não deixar eu percorrer o caminho sozinho e estar ao meu lado em todas situações.

Agradeço a minha esposa, Lorena Dias, que continuamente me incentivou e não deixou eu desistir. No meio de tantas atividades profissionais, pessoais e acadêmicas, ela estava sempre ali. Torcendo, ajudando e absorvendo as outras atividades da nossa vida que precisei me ausentar devido ao projeto do doutorado.

Agradeço aos meus pais, José Cardoso e Marta Cardoso que me apoiaram, investiram, se dedicaram para que esse sonho se tornasse realidade. Sem as orações dos dois, muito provável eu não terminaria.

Agradeço ao meu amigo, coordenador, co-orientador, Paulo Dore. Divido com ele os resultados encontrados. Sempre acreditou no meu trabalho, me orientou, me ajudou e esteve nos momentos mais importantes da minha carreira profissional e acadêmica.

À minha orientadora Angela Nieckele, que aceitou o desafio de me orientar em meio a tantas atividades que ela precisa estar presente. Ela sempre tirou o melhor de mim. Suas percepções, comentários e acréscimos a tese foram fundamentais. Sem ela, eu não teria terminado meu doutorado.

Aos amigos do CENPES, Sylvio Dermeval, meu agradecimento por desbravar parte do caminho comigo. Tive a oportunidade de trabalhar alguns anos ao seu lado e juntos descobrimos bastantes novidades na área. Ao amigo de escola, de CENPES, Thiago Judson, por trabalharmos juntos e pelo incentivo do desenvolvimento de CFD na área de estimulação de poços. A amiga Francileide Gomes que acreditou no trabalho desenvolvido na tese e possibilitou que essa pesquisa fosse até o fim. Ao amigo Umberto Sansoni pelas conversas e por estar sempre disposto em ajudar.

A companheiro e amigo, Antonio Samel (gênio), é um privilégio trabalhar ao seu lado e poder ver quantas áreas podemos desbravar juntos! Suas aulas sempre serão uma inspiração.

Aos amigos Carlos Fontes e Karolline Ropelato, quando trabalhavamos juntos, vocês acreditaram no desenvolvimento dessa pesquisa. Foi muito bom 
trabalhar com vocês. Aos colegas Fernando Motta, Mayk Caldas e Paulo Costa, a ajuda de vocês na fase final foi muito importante.

A minha outra família, Josiani Trindade, Marcos Tindade, Nicea Trindade e todos os Trindades! Obrigado pelo carinho, pelas orações e incentivo! Aos amigos pessoais que torceram, incentivarm e oraram por mim, Pedro Barros e Saulo Vieira. Obrigado pela amizade de vocês. Um agradecimento especial ao meu Pastor Valdomiro Alves, que orou por mim na fase mais importante do meu doutorado e que nesse período (acreditem), eu encontrei os resultados esperados.

Todos vocês escreveram um pouco da tese. Todos vocês de alguma forma construiram esse estudo comigo. A tese também é um pouco de cada um de vocês. Muito obrigado. 


\section{Resumo}

Dias, Rodrigo Araujo Cardoso; Nieckele, Angela Ourivio; Fernandes, Paulo Dore. Produtividade de Poços em Reservatórios de Alta Heterogeneidade de Permeabilidade. Rio de Janeiro, 2017. 229p. Tese de Doutorado - Departamento de Engenharia Mecânica, Pontifícia Universidade Católica do Rio de Janeiro.

A previsão da produção de poços tem um papel crucial na engenharia de petróleo. Logo, a modelagem do escoamento no reservatório e no poço é fundamental em diversos problemas nessa área. Na maioria esmagadora dos problemas, a equação de Darcy é a escolha para prever o comportamento do fluxo em rochas petrolíferas. O grande sucesso do uso da equação de Darcy, infelizmente, levou sua aplicação para fora do âmbito dos problemas para os quais esta se aplica. A equação clássica de Darcy apresenta limitações quando aplicadas em meios porosos altamente heterogêneos, por exemplo com cavidades conectadas por redes de fraturas, com vugs e cavernas. Ao longo dos anos, outras modelagens foram propostas e derivadas de outros pontos de vista para tratar o escoamento em meios porosos, por exemplo, através do processo de média de volume ou através de teoria de mistura. $\mathrm{O}$ presente trabalho utiliza as equações médias em meios porosos. O modelo desenvolvido contabiliza termos adicionais para a equação de quantidade de movimento linear que são relevantes em várias situações práticas, e envolve a solução conjunta das equações de conservação. No modelo desenvolvido neste trabalho, o escoamento no reservatório é resolvido de forma acoplada ao escoamento ao longo do poço, considerando a possibilidade de utilização de diferentes tipos de completação. As previsões dos campos de pressão e velocidade, assim como a produtividade de poços de petróleo utilizando o modelo desenvolvido são comparadas com as previsões do modelo baseado na equação de Darcy. Mostra-se que para determinadas situações, em especial em reservatórios carbonáticos, altamente heterogêneos, grandes diferenças podem ser obtidas. A previsão da produtividade de um poço a partir da equação de Darcy pode ser significativamente super-estimada.

\section{Palavras-chave}

Poços de Petróleo; Reservatório; Heterogeneidade; Fluido Dinâmica Computacional; OpenFoam. 


\section{Abstract}

Dias, Rodrigo Araujo Cardoso; Nieckele, Angela Ourivio (Advisor); Fernandes, Paulo Dore (Co-Advisor). Wells Productivity in High Heterogeneity Reservoirs. Rio de Janeiro, 2017. 229p. Tese de Doutorado - Departamento de Engenharia Mecânica, Pontifícia Universidade Católica do Rio de Janeiro.

Predicting wellbore production plays a crucial role in petroleum engineering. Therefore, the modeling of the flow in reservoir and in wellbore is fundamental in several problems in this area. In the overwhelming majority problems, Darcy's equation is the choice to predict the behavior of flow in reservoirs. The great success of Darcy's equation, unfortunately, took its application out of the scope of the problems for which it applies. The classic Darcy's equation presents limitations when applied in highly heterogeneous porous media, for example with cavities connected by fracture networks, with vugs and caves. Over the years, other models have been proposed and derived from other points of view to treat flow in porous media, for example through the average volume process or through mixture theory. The present work considers the average volume process in porous media. The developed model includes additional terms for the linear momentum equation that are relevant in several practical situations, and involves the joint solution of conservation equations. In the model developed in this work, the flow in the reservoir is solved coupled to the wellbore flow, considering the possibility of using different completion types. The pressure and velocity fields predictions as well as the productivity of oil wellbores using the developed model are compared with the predictions of the model based on the Darcy's equation. It is shown that for certain situations, especially in highly heterogeneous carbonate reservoirs, large differences can be obtained. The prediction of the productivity of a wellbore from the Darcy's equation can be significantly overestimated.

\section{Keywords}

Wellbore; Reservoir; Heterogeneus; Computational Fluid Dynamics; OpenFoam. 


\section{Sumário}

1 Introdução $\quad 27$

1.1 Motivação 28

Simulação na Região Próxima ao Poço $\quad 29$

Produção de Poços Acidificados $\quad 31$

Produção de Poços Horizontais 33

Modelo de Produtividade Babu-Odeh 35

Modelo de Economides Brand Frick 36

Produtividade de Poços Estimulados por Fraturamento Hidráulico $\quad 37$

Modelo de McGuire e Sikora 40

Modelo de Prats 41

Modelo de Cinclo-Ley e Samaniego 42

Reservatórios Carbonáticos - Altamente Heterogêneos 43

1.2 Limitações das Modelagens Tradicionais 46

1.3 Organização do Trabalho 48

2 Revisão Bibliografica $\quad 50$

3 Teoria de Média $\quad 59$

3.1 Volume Elementar Representativo 61

3.2 Definições das Médias $\quad 62$

Decomposição do Campo em Macroscópico e Microscópico 63

3.3 Teoremas Relacionados ao Método de Alteração de Escala 64

Teorema Temporal 64

Teorema Espacial $\quad 64$

Relações Importantes $\quad 65$

3.4 Processo de Alteração de Escala 66

Equações Microscópicas $\quad 66$

Aplicação da Média na Pequena Escala $\quad 67$

Equação da Conservação de Massa 67

Equação da Conservação da Quantidade de Movimento Linear 68

3.5 Equações Macroscópicas 73

Análise de Ordem de Grandeza $\quad 73$

Conservação de Massa $\quad 74$

Conservação da Quantidade de Movimento Linear $\quad 75$

$\begin{array}{lll}3.6 & \text { Problema de Fechamento } & 77\end{array}$

3.7 Equações Macroscópicas Formato Final 79 
4 Equação da Difusividade Hidráulica $\quad 80$

4.1 Derivação da Equação da Difusividade Hidráulica 82

4.2 Equações de Estado para Fluidos e Rochas 84

Líquidos e Rochas Levemente Compressiveis 84

Gases e Rocha Levemente Compressivel 85

Modelo Black-Oil para o Fluido e Rocha Levemente Compressível 86

5 Escoamento no Poço $\quad 88$

5.1 Modelos Simplificados de Poço $\quad 89$

Modelo Simplificado para o Índice do Poço 89

$\begin{array}{lll}5.2 & \text { Fator Skin } & 91\end{array}$

5.3 Tipos de Completação $\quad 92$

Poço Aberto $\quad 92$

Poço com Liner $\quad 93$

Poço Revestido Canhoneado $\quad 94$

Modelos de Completação Implementados $\quad 95$

Completação Poço Aberto Não Revestido 95

Completação Poço Aberto Stand Alone 95

Completação Poço Aberto com Gravel-Pack 96

Completação Revestido Cimentado Canhoneado 96

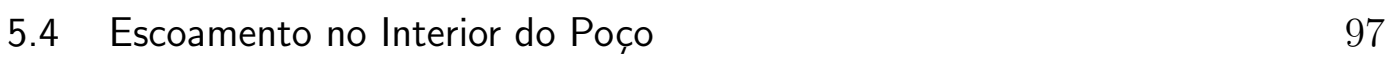

Fator de Atrito no Interior do Poço 98

Modelagem das Completações do Poço 99

Modelagem Poço Aberto Não Revestido 100

Modelagem para Poço Aberto Stand Alone 101

Modelagem para Poço Aberto com Gravel-Pack 102

Modelagem para Poço Revestido Cimentado Canhoneado 104

6 Metodologia Numérica 105

$\begin{array}{lll}6.1 & \text { OpenFOAM } & 105\end{array}$

6.2 Discretização das Equações para o Reservatório 108

Discretização do Termo Transiente 110

Discretização do Fluxo Convectivo 111

Discretização do Termo Advectivo 112

Discretização do Fluxo Difusivo 113

Discretização do Termo Difusivo 114

Discretização do Termo Fonte $\quad 116$

6.3 Metodologia de Solução - Difusividade Hidráulica 120

6.4 Metodologia de Solução - Teoria de Média para Meios Porosos 124

6.5 Discretização e Metodologia de Solução da Equação no Poço 127

Discretização do Poço Aberto com Liner sem Gravel 128

Discretização do Poço Aberto com Liner com Gravel 132

Metodologia de solução $\quad 135$

7 Testes de Verificação e Validação 137

$\begin{array}{lll}7.1 & \text { Verificação do Código } & 138\end{array}$ 
Verificação do Código HDF 139

Verificação do Código RPPF 141

7.2 Validação do Código 143

Teste 1.1: Escoamento 1D em Regime Permanente 143

Teste 1.2: Escoamento 1D em Regime Transiente 144

7.3 Comparação do Modelo de Difusidade Hidráulica com o Software IMEX - Escala de Poço. 147

Teste 2.1: Poço Vertical em um Reservatório Homogêneo Circular 148

Teste 2.2: Poço Vertical em um Reservatório Homogêneo Quadrado 151

Teste 2.3: Poço Vertical em um Reservatório Homogêneo Circular 154

Teste 2.4: Poço vertical em um Reservatório Heterogêneo Quadrado 157

Teste 2.5: Poço Horizontal em um Reservatório Heterôgeneo Retangular 160

Teste 2.6: Poço Horizontal em Reservatório Heterogêneo Retangular com Acoplamento Poço Reservatório 165

7.4 Comparação do Modelo de Média com o Modelo de Darcy. 167

Teste 3.1: Poço Horizontal em um Reservatório Homogêneo 167

Teste 3.2: Poço Horizontal em um Reservatório Heterogêneo 173

Teste 3.3: Poço vertical com uma Fratura em um Reservatório Homogêneo 176

Teste 3.4: Poço Vertical com uma Fratura de Altíssima Permeabilidade em um $\begin{array}{ll}\text { Reservatório Homogêneo } & 179\end{array}$

8 Resultados 182

8.1 Cálculo Analítico 183

Modelo de Darcy 184

Modelo de Média $\quad 184$

8.2 Plug com Heterogeneidade Simplificada 188

8.3 Plug com Heterogeneidade Complexa 198

Caso 2.1 - Plug 2D pouco permeável, com fratura natural 199

Caso 2.2 - Plug 2D pouco permeável, com heterogeneidades distintas em série 201

Caso 2.3 - Plug 2D pouco permeável, com heterogeneidade distintas em série e fratura

Caso 2.4 - Rocha heterogênea 3D 206

Comparação da Produção do Plug 212

9 Conclusões $\quad 214$

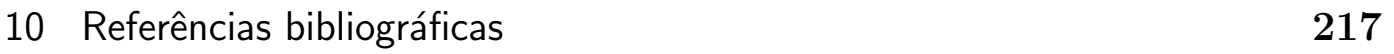




\section{Lista de Figuras}

1.1 Modelo para simulação na região do poço. Figura retirada de Karimi (2011).

$1.2 \quad$ Imagem reconstruída de wormholes. 32

1.3 Poço vertical e horizontal interceptando o reservatório. 33

1.4 Diferentes arquiteturas de poços multilaterais. 34

1.5 Esquema de poço e reservatório (Babu, 1989). 35

1.6 Modificação do padrão de fluxo devido ao fraturamento hidráulico (Nolte, 2000).

1.7 Modificação do padrão de fluxo devido ao fraturamento hidráulico (Nolte, 2000).

1.8 Curvas de produtividade de fratura em função da condutividade adimensional (McGuire, 1960).

1.9 Curva de raio efetivo adimensional do modelo de Prats (1961). 41

1.10 Fator skin de poço fraturado em função da condutividade adimensional para fluxo transiente (Cinclo-Ley, 1981).

1.11 Corredor de fraturas em afloramento carbonático.

3.1 Diferentes escalas do problema de escoamento em meios porosos. Figura retirada de Whitaker (1996).

3.2 Volume elementar representativo. Figura retirada de Whitaker (1996).

3.3 Exemplo didático para a decomposição de um campo em um valor médio e sua flutuação. Figura retirada de Soulaine (2012).

5.1 Geometria da região modelada pelo fator skin.

5.2 Geometria de completação a poço aberto (Garcia, 2010).

5.3 Geometria de completação de poço com liner (Garcia, 2010).

5.4 Geometria de completação de poço revestido canhoneado (Garcia, 2010).

5.5 Malha detalhando a geometria dos canhoneios em CFD. 96

5.6 Modelos de resistência devido a perda de carga na seção do poço. Figura retirada de Johansen (2007).

5.7 Modelos de resistência devido a perda de carga no poço. Figura retirada de Johansen (2007).

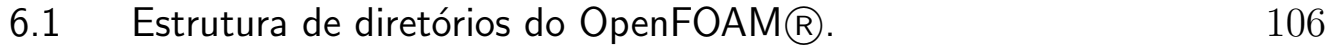

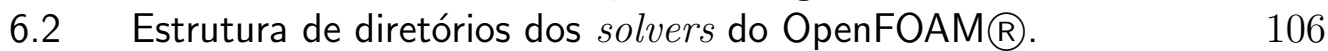

6.3 Estrutura de diretórios para um caso de simulação no OpenFOAM $\cap$.

6.4 Ilustração de duas células poliédricas, $P$ e $N$ compartilhando uma face poligonal $f$, para discretização por volumes finitos. Adaptada de Rushe (2002). 
6.5 Não ortogonalidade entre os vetores que liga os centróides dos elementos e o vetor normal de área. Figura extraída de Jasak (1996).

6.6 Trecho de código do programa principal para solução da equação de difusividade hidráulica.

6.7 Modelos de acoplamento poço-reservatório implementados e disponíveis para uso com o hydraulicDiffusivityFoam.

6.8 Trecho de código do programa principal contendo solução da equação da pressão e avanço do campo de velocidades.

6.9 Modelos termofísicos disponíveis para uso com o hydraulicDiffusivityFoam.

6.10 Trecho de código do programa principal para solução das equações de conservação de média em meios porosos.

6.11 Modelo de segmentos do poço. 128

6.12 Numeração para poço aberto com liner sem Gravel. 129

6.13 Trecho genérico de poço aberto com liner sem Gravel. 130

6.14 Numeração para poço aberto com liner com gravel. 132

6.15 Trecho genérico para poço aberto com liner com gravel. 133

7.1 Campo do erro para diferentes malhas - HDF. 140

7.2 Índice de convergência em função do número de elementos de malha - HDF.

7.3 Campo do erro para diferentes malhas - RPPF 142

7.4 Índice de convergência em função do número de elementos de malha - RPPF.

7.5 Perfil de pressão. Teste 1.1: 1D regime permanente.

7.6 Comparação da variação temporal da vazão volumétrica de HDF com RPPF. Teste 1.2: $1 \mathrm{D}$ regime transiente.

7.7 Perfil axial de pressão para o tempo de $50 \mathrm{~s}$. Teste 1.2: $1 \mathrm{D}$ regime transiente.

7.8 Dois ângulos de visão com amplificação do refino da malha no poço para metodologia de CFD.

7.9 Dois ângulos de visão da malha em uma região mais afastada do poço. Refino da malha no poço para metodologia de CFD.

7.10 Dois âgulos de visão diferentes da mesma malha - Teste 2.1. 149

7.11 Dois níveis de amplificação daregião de refino da malha na região do poço - Teste 2.1.

7.12 Plano central - pressão após dez dias de produção para Teste 2.1.

(a) IMEX a esquerda (b) HDF Fluent a direita.

7.13 Campo de pressão após dez dias de produção para Teste 2.1. (a) IMEX a esquerda (b) HDF Fluent a direita.

7.14 Comparação da variação temporal da vazão volumétrica obtida com Fluent e IMEX, para um poço vertical em um reservatório circular. Teste 2.1.

7.15 Malha do Teste 2.2.

7.16 Refino da malha na região do poço. Teste 2.2. IMEX a esquerda (b) HDF Fluent a direita. 
7.18 Vista de topo - Campo de pressão após dez dias de produção para Teste 2.2. (a) IMEX a esquerda (b) HDF Fluent a direita.

7.19 Comparação da variação da vazão volumétrica obtida com Fluent e IMEX, para poço vertical em um reservatório quadrado. Teste 2.2 .

7.20 Malha de CFD para Teste 2.3. (a) reservatório circular (b) detalhe do poço

7.21 Campo de pressão após quatro dias de produção para Teste 2.3. HDF OpenFOAM $R$.

7.22 Produtividade do poço ao longo do tempo calculada pelos softwares HDF OpenFOAM $\cap$, HDF Fluent e IMEX. Teste 2.3.

7.23 Mapeamento de uma propriedade qualquer do software IMEX para software CFD.

7.24 Componente $K_{x x}$ do tensor de permeabilidade. (a) IMEX à

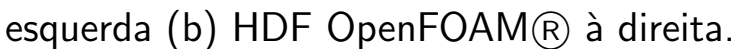

7.26 Campo de pressões no reservatório após 400 (quatrocentos) dias

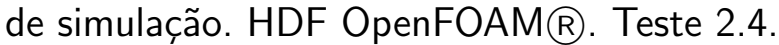

7.27 Variação temporal da vazão obtida com os softwares hydraulicDiffusivityFoam e IMEX, para um poço vertical em um reservatório circular heterogêneo. Teste 2.4 .

7.28 Campo de permeabilidade $K_{y y}$ para poço horizontal em reservatório retangular.

7.29 Malha para o cálculo de CFD - Teste 2.5.

7.30 Campo de pressão para poço horizontal em reservatório retangular, heterogêoneo, após após 1 e 3 dias de produção. Teste 2.5. (a) HDF OpenFOAM $\cap$ à esquerda (b) HDF Fluent à direita.

7.31 Campo de pressão para poço horizontal em reservatório retangular, após 3 dias. Teste 2.5. IMEX.

7.32 Plano central - Pressão para poço horizontal em reservatório retangular heterogêoneo, após 10 dias de produção. Teste 2.5. (a) IMEX à esquerda (b) HDF Fluent à direita.

7.33 Produtividade do poço horizontal ao longo do tempo para a simulação do reservatório heterogêneo com propriedades variáveis. Teste 2.5

7.34 Produtividade do poço horizontal em um reservatório heterogêneo. Poço horizontal com liner com a presença de gravel no anular. Teste 2.6.

7.35 Vazão volumétrica ao longo do comprimento do poço para 10 dias. Poço horizontal com liner com gravel no anular.Teste 2.6. 166

7.36 Refino da malha na região do poço. Teste 3.1. 169

7.37 Refino ao redor poço. Teste 3.1.

7.38 Campo de pressão após dois dias de produção. corte horizontal. Teste 3.1. Acima HDF e abaixo RPPF.

7.39 Campo de pressão após dois dias de produção - corte transversal. Teste 3.1. Acima HDF e Abaixo RPPF

7.40 Campo de pressão. Teste 3.1. (a) vinte dias de produção (b) 60 dias de produção. Acima HDF e Abaixo RPPF 
7.41 Campo de velocidade. Teste 3.1. (a) 2 dias de produção (b) 40 dias de produção. Acima HDF e Abaixo RPPF

7.42 Produtividade do poço em reservatório homogêneo. Teste 3.1. Comparação entre malhas - (a) HDF à esquerda (b) à direita.

7.43 Campo de Permeabilidade para poço horizontal com reservatório heterogêneo. Teste 3.2.

7.44 Campo de pressão após 4 horas de produção. Teste 3.2. Acima HDF e Abaixo RPPF.

7.45 Campo de pressão. Teste 3.2. (a) 8 horas de produção. (b) 16 horas de produção. Acima HDF e Abaixo RPPF.

7.46 Campo de velocidade superficial. Teste 3.2 (a) 4 horas (b) 20 horas (c) 1,6 dias (d) 3,3 dias. HDF

7.47 Campo de velocidade superficial. Teste 3.2 (a) 4 horas (b) 20 horas (c) 1,6 dias (d) 3,3 dias. HDF

7.48 Produtividade do poço em reservatório heterogêneo. Teste 3.2. Comparação HDF e RPPF.

7.49 Campo de permeabilidade - Poço vertical fraturado. Teste 3.3. 177

7.50 Refino da malha na região do poço. Teste 3.3. 177

7.51 Refino da malha ao redor do poço. Teste 3.3. 177

7.52 Campo de pressão em poço vertical fraturado. Teste 3.3. (a) 1,6 horas de produção (b) 33 horas de produção. Acima HDF e abaixo RPPF.

7.53 Campo de velocidade em poço vertical fraturado. Teste 3.3. (a) 1,6 horas de produção (b) 60 horas de produção. Acima HDF e abaixo RPPF.

7.54 Produtividade do poço vertical fraturado - Comparação HDF e RPPF - Teste 3.3.

7.55 Campo de permeabilidade agressivo - Poço vertical fraturado. Teste 3.4

7.56 Campo de pressão em poço vertical fraturado agressivo. Teste 3.4. (a) 1,6 horas de produção (b) 33 horas de produção. Acima HDF e abaixo RPPF.

7.57 Campo de velocidade em poço vertical fraturado agressivo. Teste 3.4. (a) 1,6 horas de produção (b) 33 horas de produção. Acima HDF e abaixo RPPF.

7.58 Produtividade do poço vertical fraturado agressivo. Teste 3.4. Comparação HDF e RPPF.

8.1 Variação da pressão em função da vazão para várias permeabilidades diferentes.

8.2 Campo de permeabilidade do plug de $10^{8} \mathrm{D}$. Caso 1.1

8.3 Caso 1.1. $\Delta p=10 \mathrm{k} \mathrm{Pa}, K_{p l g}=10^{8} \mathrm{D}$. (a) Campo de pressão (b) Campo de velocidade superfical. Acima HDF e abaixo RPPF. 190

8.4 Caso 1.1. Perfil de velocidade superficial (HDF) ao longo da vertical no centro do plug. $\Delta p=10 \mathrm{k} \mathrm{Pa}, K_{\text {plug }}=10^{8} \mathrm{D}$.

8.5 Caso 1.1. Perfil de velocidade superficial (RPPF) ao longo da vertical no centro do plug. $\Delta p=10 \mathrm{k} \mathrm{Pa}, K_{\text {plug }}=10^{8} \mathrm{D}$.

8.6 Caso 1.1. Perfil de velocidade superficial ao longo da vertical no centro do plug. $\Delta p=10 \mathrm{k} \mathrm{Pa}, K_{\text {plug }}=10^{8} \mathrm{D}$. 
8.7 Caso 1.2. $\Delta p=10 \mathrm{k} \mathrm{Pa}, K_{\text {plug }}=10^{7}$ D. (a) Campo de pressão (b) Campo de velocidade superfical. Acima HDF e abaixo RPPF. 193

8.8 Caso 1.3. $\Delta p=10 \mathrm{k} \mathrm{Pa}, K_{p l u g}=10^{6} \quad$ D. (a) Campo de pressão (b) Campo de velocidade superfical. Acima HDF e abaixo RPPF. 193

8.9 Caso 1.2. Perfil de velocidade superficial ao longo da vertical no centro do plug. $\Delta p=10 \mathrm{k} \mathrm{Pa}, K_{\text {plug }}=10^{7} \mathrm{D}$.

8.10 Caso 1.3. Perfil de velocidade superficial ao longo da vertical no centro do plug. $\Delta p=10 \mathrm{k} \mathrm{Pa}, K_{\text {plug }}=10^{6} \mathrm{D}$.

8.11 Caso 1.4. $\Delta p=1 \mathrm{M} \mathrm{Pa}, K_{\text {plug }}=10^{7}$ D. (a) Campo de pressão (b) Campo de velocidade superfical.

8.12 Caso 1.4. Perfil de velocidade superficial ao longo da vertical no centro do plug. $\Delta p=1 \mathrm{M} \mathrm{Pa}, K_{\text {plug }}=10^{7} \mathrm{D}$.

8.13 Campo de permeabilidade com fratura natural. Caso 2.1.

8.14 Caso 2.1. (a) Campo de pressão (b) Campo de velocidade superficial. Acima HDF e abaixo RPPF.

8.15 Caso 2.1. Perfil de velocidade superficial ao longo da vertical no centro para plug.

8.16 Campo de permeabilidade com heterogeneidade distintas em série. Caso 2.2.

8.17 Caso 2.2. (a) Campo de pressão (b) Campo de velocidade superficial. Acima HDF e abaixo RPPF.

8.18 Caso 2.2. Perfil de velocidade superficial ao longo da vertical no centro para plug.

8.19 Campo de permeabilidade com heterogeneidade distintas em série com fratura. Caso 2.3 .

8.20 Caso 2.3. (a) Campo de pressão (b) Campo de velocidade superficial. Acima HDF e abaixo RPPF.

8.21 Caso 2.3. Perfil de velocidade superficial ao longo da vertical no centro para plug.

8.22 Campo de permeabilidade complexo do plug 3D. Caso 2.4 - Vista 1 e 2 .

8.23 Campo de permeabilidade complexo do plug 3D. Caso 2.4 - Vista 3 e 4.

8.24 Caso 2.4 - Plug 3D. Campo de pressão - Corte longitudinal 1. Acima HDF e abaixo RPPF.

8.25 Caso 2.4 - Plug 3D. Campo de pressão - Corte longitudinal 2. Acima HDF e abaixo RPPF.

8.26 Caso 2.4 - Plug 3D. Campo de pressão nas paredes laterais. Acima HDF e abaixo RPPF.

8.27 Caso 2.4 - Plug 3D. Campo de pressão - Corte transveral. Acima HDF e abaixo RPPF.

8.28 Caso 2.4 - Plug 3D. Campo de velocidade superficial - Corte longitudinal 1. Acima HDF e abaixo RPPF.

8.29 Caso 2.4 - Plug 3D. Campo de velocidade superficial - Corte longitudinal 2. Acima HDF e abaixo RPPF.

8.30 Caso 2.4 - Plug 3D. Campo de velocidade superficial visto pelas laterais. Acima HDF e abaixo RPPF. 
8.31 Caso 2.4 - Plug 3D. Campo de velocidade superficial (a) Corte transversal 1 (b) Corte transversal 2. Acima HDF e abaixo RPPF. 211 


\section{Lista de Tabelas}

6.1 Parâmetros globais para difusividade hidráulica e equação de média de continuidade. 109

6.2 Parâmetros globais equação de média de momento. 109

7.1 Propriedades do fluido e reservatório. Teste 1.1: 1D permanente. 143

7.2 Produção: vazão mássica. Teste 1.1: 1D Regime permanente. 144

7.3 Propriedades do fluido e reservatório. Teste 1.2: 1D regime transiente. 145

7.4 Dimensões do poço vertical em reservatório circular. Teste 2.1. 148

7.5 Propriedades do fluido e reservatório para o Teste 2.1. 149

7.6 Dimensões do poço vertical em reservatório circular. Teste 2.2. 151

7.7 Propriedades do fluido e reservatório para o Teste 2.2. 152

7.8 Dimensões do caso de poço vertical em reservatório circular. Teste $2.3 \quad 155$

7.9 Propriedades do fluido e reservatório para o Teste 2.3. 155

7.10 Dimensões do caso de poço vertical em reservatório heterogêneo circular. Teste 2.4. 158

7.11 Propriedades do fluido e reservatório para o Teste $2.4 \quad 158$

7.12 Dimensões do caso de poço horizontal em reservatório retangular. Teste 2.5

7.13 Propriedades do fluido e reservatório para o caso de poço horizontal em reservatório retangular. Teste 2.5 .

7.14 Dimensões do caso de poço vertical em reservatório circular. Teste 2.6.

7.15 Dimensões do poço horizontal em um reservatório homogêneo. Teste 3.1.

7.16 Propriedades do fluido e reservatório em poço horizontal em um reservatório homogêneo. Teste 3.1.

7.17 Dimensões do poço vertical em um reservatório homogêneo. Teste 3.3.

8.1 Diferença de previsão perda de carga entre Darcy e média para diferentes permeabilidades

8.2 Plug com Heterogeneidade Simplificada 189

8.3 Propriedades do fluido e plug. Caso 1.1 a $1.4 \quad 189$

8.4 Produção no Plug. Casos 1.1, 1.2 e $1.3 \quad 195$

8.5 Produção no Plug. Caso $1.4 \quad 197$

8.6 Propriedades do fluido e plug. Caso 2.1 a 2.4

8.7 Produção no Plug. Casos 2.1 a 2.4 


\section{Nomenclatura}

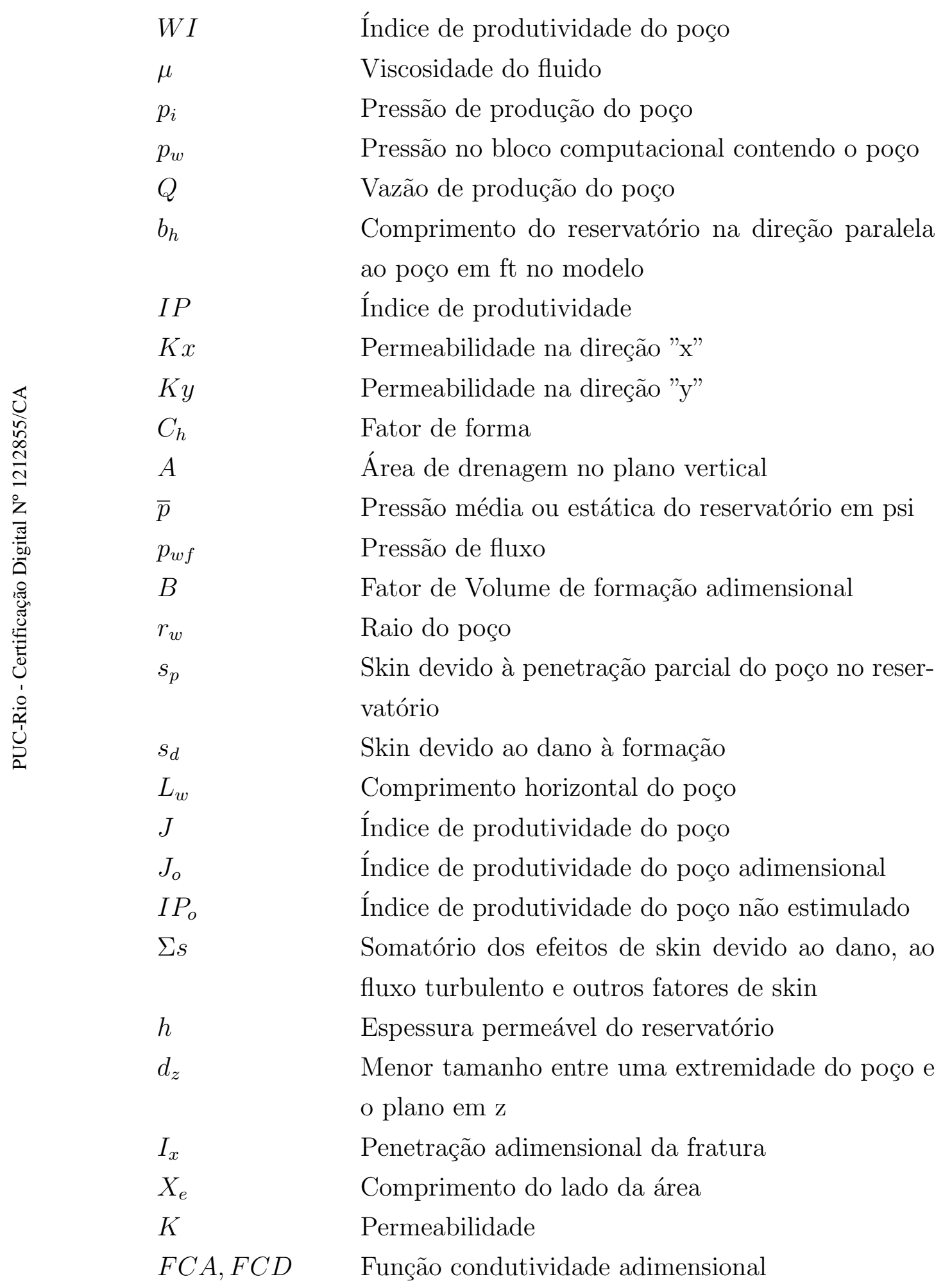




\begin{tabular}{|c|c|c|}
\hline & $w$ & Espessura da fratura \\
\hline & $L$ & Comprimento da asa da fratura \\
\hline & $K_{f}$ & Permeabilidade da fratura \\
\hline & $r_{w}^{\prime}$ & Raio efetivo do poço \\
\hline & $a$ & Capacidade relativa \\
\hline & $h_{f}$ & Altura da fratura \\
\hline & $p$ & Pressão \\
\hline & $v$ & Vetor velocidade \\
\hline & $b$ & Força de campo por unidade \\
\hline & $\rho$ & Massa específica \\
\hline & $\alpha$ & Arraste do fluido \\
\hline & $\beta$ & Índice da fase \\
\hline & $k$ & Condutividade hidráulica \\
\hline & $D_{C}$ & Força de forma \\
\hline & $D_{\mu}$ & Força viscosa \\
\hline & $\mu_{e}$ & Viscosidade efetiva \\
\hline & $L$ & Comprimento característico da macro-escala \\
\hline & $l_{\beta}$ & Menor escala para hipótese do Continuum \\
\hline & $\forall_{\beta}$ & Volume ocupado pelo fluido (fase $\beta$ ) \\
\hline${ }_{2}^{\circ}$ & $\forall$ & Volume representativo \\
\hline 7 & $\phi$ & Porosidade de formação \\
\hline (6) & $\psi$ & $\begin{array}{l}\text { Campo microscópico tensorial de uma variável } \\
\text { física qualquer associada a fase } \beta\end{array}$ \\
\hline & $\langle\psi\rangle$ & Média superficial do campo tensorial $\psi$ \\
\hline & $\langle\psi\rangle^{\beta}$ & Média intríseca do campo tensorial $\psi$ \\
\hline & $\tilde{\psi}$ & Flutuação no tempo do campo tensorial $\psi$ \\
\hline & $\lambda$ & Segundo coeficiente da viscosidade \\
\hline & $g$ & Vetor gravidade \\
\hline & $O()$ & Ordem de grandeza da variável entre parênteses \\
\hline & $\mathbf{I}$ & Tensor identidade \\
\hline & $\mathbf{K}_{\beta}$ & Tensor permeabilidade da fase $\beta$ \\
\hline & $c_{\rho}$ & $\begin{array}{l}\text { Coeficiente de compressibilidade para a massa es- } \\
\text { pecífica }\end{array}$ \\
\hline & $c_{\phi}$ & Coeficiente de compressibilidade para a porosidade \\
\hline & $\tilde{\mathbf{K}}$ & $\begin{array}{l}\text { Tensor de permeabilidade dividido pela viscosidade } \\
\text { cinemática }\end{array}$ \\
\hline & $\nu$ & Viscosidade cinemática \\
\hline & $D$ & Parte deviatórica do tensor $\tilde{\boldsymbol{K}}$ \\
\hline & $\gamma$ & Parte isotŕopica do tensor $\tilde{\boldsymbol{K}}$ \\
\hline
\end{tabular}




\begin{tabular}{|c|c|}
\hline$S_{w c}$ & Valor de saturação de água conata \\
\hline$z$ & Fator de compressibilidade \\
\hline$T$ & Temperatura na qual o escoamento ocorre \\
\hline$c_{\rho}^{s t d}$ & $\begin{array}{l}\text { Coeficiente de compressibilidade para a massa es- } \\
\text { pecífica, referência }\end{array}$ \\
\hline$c_{\phi}^{r e f}$ & $\begin{array}{l}\text { Coeficiente de compressibilidade para a porosidade, } \\
\text { referência }\end{array}$ \\
\hline$\rho^{s t d}$ & massa específica, referência \\
\hline$\phi^{r e f}$ & porosidade, referência \\
\hline$p^{r e f}$ & Pressão, referência \\
\hline$B_{o}$ & $\begin{array}{l}\text { Volume da fase óleo(óleo + gás dissolvido) dividido } \\
\text { pelo volume do óleo nas condições padrão }\end{array}$ \\
\hline$R_{s}$ & $\begin{array}{l}\text { Volume de gás dissolvido na fase óleo, dividido pelo } \\
\text { volume do óleo, ambos nas condições padrão }\end{array}$ \\
\hline$\forall_{o}^{s t d}$ & Volume de óleo nas condições padrão \\
\hline$\forall_{o+g d}^{p, T}$ & $\begin{array}{l}\text { Volume de óleo }+ \text { gás dissolvido nas condições } \\
(\mathrm{p}, \mathrm{T})\end{array}$ \\
\hline$\forall_{g d}^{s t d}$ & Volume de gás dissolvido nas condições padrão \\
\hline$\rho_{o}^{s t d}$ & Densidade de óleo nas condições padrão \\
\hline$\rho_{g}^{s t d}$ & Densidade de gás dissolvido nas condições padrão \\
\hline$B_{o b}$ & Bo avaliado na pressão de bolha \\
\hline$p_{b}$ & Pressão de bolha \\
\hline$\mu_{o b}$ & Viscosidade do fluido avaliada na pressão de bolha \\
\hline$R e$ & Número de Reynolds \\
\hline$f_{\text {laminar }}$ & Fator de atrito para escomaento laminar \\
\hline$f_{\text {turbulento }}$ & Fator de atrito para escoamento turbulento \\
\hline$\dot{m}_{p 1}$ & Vazão em massa antes de um trecho do poço \\
\hline$\dot{m}_{p 2}$ & Vazão em massa após um trecho do poço \\
\hline$\dot{m}_{\text {perp }}$ & $\begin{array}{l}\text { Vazão de massa adicionada devido ao fluxo perpen- } \\
\text { dicular ao poço }\end{array}$ \\
\hline$\dot{m}_{C F D}$ & $\begin{array}{l}\text { Vazão em massa adicionada devido ao fluxo vindo } \\
\text { do reservatório através do CFD }\end{array}$ \\
\hline$\dot{m}_{\text {furos }}$ & $\begin{array}{l}\text { Vazão em massa adicionada devido ao fluxo vindo } \\
\text { do anular através dos furos }\end{array}$ \\
\hline$\dot{m}_{\text {anular }}$ & $\begin{array}{l}\text { Vazão em massa adicionada devido ao fluxo vindo } \\
\text { do anular }\end{array}$ \\
\hline$f_{p}$ & Fator de atrito dentro do poço \\
\hline$A_{p}, A_{r p}$ & Área transversal ao escoamento \\
\hline$D_{p}$ & Diâmetro do poço \\
\hline
\end{tabular}




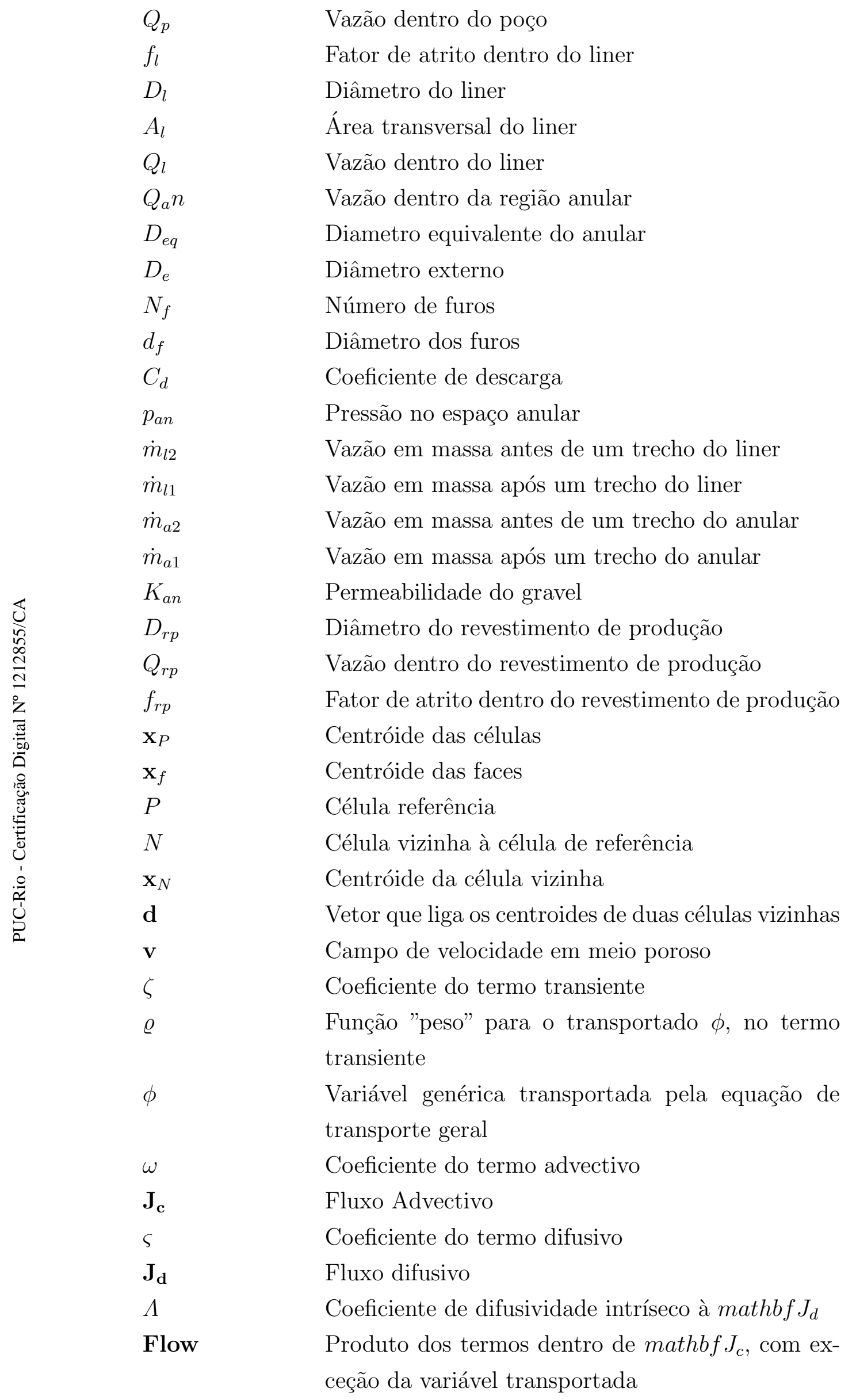


Flow $_{n}$

$S_{n}$ $\Gamma(p)_{n}$

$a_{P}$

$a_{P}^{0}$

H

$\zeta_{P}$

$\varrho_{P}$

$\phi_{P}$
Termo fonte

Volume da célula em análise

Coeficiente do termo transiente, tomado no instante de tempo $\mathrm{n}$

Função "peso" para o transportado $\phi$, no termo transiente, tomado no instante de tempo $\mathrm{n}$

Variável genérica transportada pela equação de transporte geral, tomado no instante de tempo $\mathrm{n}$

Coeficiente do termo advectivo, tomado no instante de tempo $n$

Fluxo Advectivo, tomado no instante de tempo n

Coeficiente do termo difusivo, tomado no instante de tempo $\mathrm{n}$

Fluxo difusivo, tomado no instante de tempo $\mathrm{n}$

Coeficiente de difusividade intríseco à mathbf $J_{d}$, tomado no instante de tempo $\mathrm{n}$

Produto dos termos dentro de mathbf $J_{c}$, com exceção da variável transportada, tomado no instante de tempo $n$

Termo fonte, tomado no instante de tempo $\mathrm{n}$

Coeficiente do termo transiente da equação de difusividade hidráulica, tomado no instante de tempo n Coeficientes da diagonal principal da matriz de discretização das equações governantes Coeficientes da diagonal principal da matriz de discretização das equações governantes, avaliada no tempo inicial

Vetor que contém os termos tratados explicamente na discretização e os termos implícitos associados a parte não diagonal da matriz de quantidade de movimento

Coeficiente do termo transiente, avaliado no centro da célula em análise

Função "peso" para o transportado $\phi$, no termo transiente, avaliado no centro da célula em análise Variável genérica transportada pela equação de transporte geral, avaliado no centro da célula em análise 
$\omega_{P} \quad$ Coeficiente do termo advectivo, avaliado no centro da célula em análise

$\mathbf{J}_{\mathbf{c} P} \quad$ Fluxo Advectivo, avaliado no centro da célula em análise

$\varsigma_{P} \quad$ Coeficiente do termo difusivo, avaliado no centro da célula em análise

$\mathbf{J}_{\mathbf{d} P} \quad$ Fluxo difusivo, avaliado no centro da célula em análise

$\Lambda_{P} \quad$ Coeficiente de difusividade intríseco à mathbf $J_{d}$, avaliado no centro da célula em análise

Flow $_{P} \quad$ Produto dos termos dentro de mathbf $J_{c}$, com exceção da variável transportada, avaliado no centro da célula em análise

$S_{P} \quad$ Termo fonte, avaliado no centro da célula em análise

$\Gamma(p)_{P} \quad$ Coeficiente do termo transiente da equação de difusividade hidráulica, avaliado no centro da célula em análise

$\zeta_{f}$ Coeficiente do termo transiente, avaliado no centroide da face em análise

$\varrho_{f} \quad$ Função "peso" para o transportado $\phi$, no termo transiente, avaliado no centroide da face em análise Variável genérica transportada pela equação de transporte geral, avaliado no centroide da face em análise

$\omega_{f} \quad$ Coeficiente do termo advectivo, avaliado no centroide da face em análise

$\mathbf{J}_{\mathbf{c} f} \quad$ Fluxo Advectivo, avaliado no centroide da face em análise

$\varsigma_{f} \quad$ Coeficiente do termo difusivo, avaliado no centroide da face em análise

$\mathbf{J}_{\mathbf{d} f} \quad$ Fluxo difusivo, avaliado no centroide da face em análise

$\Lambda_{f} \quad$ Coeficiente de difusividade intríseco à mathbf $J_{d}$, avaliado no centroide da face em análise

Flow $_{f} \quad$ Produto dos termos dentro de mathbf $J_{c}$, com exceção da variável transportada, avaliado no centroide da face em análise 


$\begin{array}{ll}S_{f} & \text { Termo fonte, avaliado no centroide da face em } \\ & \text { análise } \\ \mathbf{n}_{f} & \text { Vetor normal unitário à face em análise } \\ \overline{f N} & \begin{array}{l}\text { Distância entre o centroide da face f e o centroide } \\ \text { da célula vizinha }\end{array} \\ \overline{P N}, \mathbf{d}_{f} & \text { Distância entre os centroides dos elementos em } \\ & \text { análise e vizinho } \\ \mu_{e f f} & \text { Viscosidade efetiva do fluido } \\ \mu_{t u r b} & \text { Viscosidade turbulenta } \\ \psi & \text { Função de estado genérica que relaciona a densi- } \\ & \text { dade e a pressão do fluido }\end{array}$


"If you can't fly, then run.

If you can't run, then walk.

If you can't walk, then crawl,

but by all means, keep moving."

Martin Luther King Jr., . 


\section{Introdução}

Materiais porosos podem ser encontrados em diferentes lugares da natureza, como em rochas, minerais, madeira e no solo, em tecidos biológicos, como a pele, os ossos, membranas e em materiais feitos pelo homem, tais como cimentos, cerâmicas e polímeros. Todos esses materiais podem ser considerados como meios porosos. O estudo do escoamento de fluidos através de meios porosos surge naturalmente como um campo específico de pesquisa, onde a interação entre fluido e o meio se torna um importante aspecto dentro do desenvolvimento.

Quando um fluido escoa e encontra um objeto sólido como uma rocha, por exemplo, é natural imaginar que o fluido passe ao redor do objeto e a rocha seja considerada impermeável ou impenetrável. A impermeabilidade de um material é, na verdade, uma hipótese. Dependendo da escala em que o observador analise o problema, os poros através da estrutura rochosa, dita impermeável, podem ser considerados meios para o fluido escoar.

Logo, o significado da impermeabilidade ou impenetrabilidade está mais relacionado com a percepção do objeto, do que com algo intrínseco ao próprio objeto. Um objeto pode ser descrito como impermeável se na escala de tempo de observação, uma quantidade insignificante de fluido escoar através dele. Por exemplo, quando uma massa de água é drenada em um solo argiloso, ao longo de meses ou anos, a permeabilidade da argila não pode ser negligenciada, mas ao armazenar água em um compartimento de argila, é natural considerar a argila como impermeável (Srinivasan, 2013b).

O estudo de escoamentos através de meios porosos encontra relevância em uma infinidade de problemas de engenharia como no caso de filtração, como na mecânica de solo e rocha, no movimento das águas subterrâneas e contaminantes de solos, no fluxo de óleo através de um reservatório de petróleo, na difusão de fluidos através de polímeros sintéticos e em materiais biológicos.

Alguns exemplos de problemas interessantes e tecnologicamente importantes são aqueles que tratam do escoamento através de meios porosos envolvendo pressões e gradientes de pressão muito elevados. Os problemas de engenharia relacionados ao escoamento de óleo através de reservatórios de petróleo 
são exemplos práticos desses casos. O presente trabalho tem como foco o escoamento de fluidos em reservatórios de petróleo, para diversas condições de operação, incluindo estas situações.

A equação de Darcy se tornou o modelo de escolha mais comum para o estudo do escoamento de fluidos em meios porosos. O grande sucesso do uso da equação de Darcy, infelizmente, levou sua aplicação para fora do âmbito dos problemas para os quais esta se aplica. No presente trabalho analisa-se a equação completa de quantidade de movimento linear para o movimento do fluido. Uma avaliação das hipóteses tradicionalmente utilizadas na obtenção das equações de transporte para este tipo de escoamento é realizada. É apresentado que a equação de Darcy prevê resultados não satisfatórios para alguns casos na área de simulação de reservatórios de petróleo. Por exemplo, quando as pressões e gradientes de pressão são extremamente altos (Srinivasan, 2016d), quando os efeitos da inércia são importantes no escoamento (Hill, 2016b) ou até mesmo para rochas com alta variação de permeabilidade (Srinivasan, 2016b). Uma equação de quantidade de movimento linear mais completa será apresentada, sendo esta, a escolha mais apropriada para a modelagem do escoamento no meio poroso em determinados casos de engenharia de reservatórios.

Ou seja, apesar da equação de Darcy continuar ocupando um lugar central no estudo de escoamentos através de meios porosos, esta equação só é válida para uma classe especial de escoamentos, sendo necessário o desenvolvimento de diferentes aproximações que são aplicáveis a outras situações na área de simulação de reservatórios. A teoria de média (Whitaker, 1967; Slattery, 1967; Whitaker, 1999), será apresentada no presente trabalho como uma metodologia de abordar o problema de escoamento em meios porosos de forma consistente. As equações de quantidade de movimento linear e continuidade pela teoria de média foram implementadas em um novo solver no software OpenFOAM $®$ sendo resolvidas através do método de volumes finitos. A equação da difusividade hidráulica também foi programada em um novo solver no software OpenFOAM@. Alguns exemplos serão apresentados com o objetivo de mostrar a relevância e importância do uso da equação completa de quantidade de movimento linear para meios porosos.

\section{1}

\section{Motivação}

O petróleo se apresenta como a principal fonte de energia primária no mundo. O aumento do consumo de óleo e gás e a perspectiva do declínio de descobertas de grandes reservatórios faz com que a indústria petrolífera volte seus interesses para a exploração de novos reservatórios de petróleo e também para um melhor 
aproveitamento das reservas já existentes. Logo, volumosos investimentos são feitos em projetos exploratórios ou em estudos de novas tecnologias que tornem comerciais reservatórios antes considerados inviáveis.

A previsão da produção de poços de petróleo tem um papel crucial na engenharia de petróleo. Logo, a modelagem do escoamento em meios porosos é fundamental em diversos problemas nessa área. Na maioria esmagadora dos problemas, a equação de Darcy é a escolha para prever o comportamento do fluxo em rochas petrolíferas.

A grande questão é que a equação de Darcy é válida apenas se diversas condições forem atendidas. Por exemplo, a abordagem de Darcy é incapaz de prever as tensões do meio poroso, fornecendo somente a vazão volumétrica como função do gradiente de pressão. Além das deformações do sólido serem ignoradas e o sólido ser tratado como um meio poroso rígido, as equações que governam o sólido são completamente ignoradas. Além disso, os efeitos de fricção nos poros são assumidos com uma estrutura muito especial e específica e os efeitos friccionais dentro do fluido também são esquecidos (Nakshatrala, 2011; Srinivasan, 2013a; Rajagopal, 2014).

Alguns problemas práticos relacionados à produtividade de poços de petróleo na área de simulação são apresentadas no presente capítulo. Nos capítulos posteriores alguns casos de cada área serão resolvidos através de fluidodinâmica computacional com o objetivo de dar base para os argumentos do presente trabalho. A motivação principal desse estudo é apresentar uma modelagem geral para o escoamento de um fluido em meios porosos. O presente trabalho mostra que em alguns casos, a contabilização dos termos adicionais da equação de quantidade de movimento linear leva a resultados diferentes da equação de Darcy. Ressalta-se portanto, algumas limitações do uso da equação de Darcy.

\subsection{1}

\section{Simulação na Região Próxima ao Poço}

A previsão da produditividade de um poço de petróleo é extremamente importante para o projeto do poço. Na maioria das vezes, para prever a produção dos poços, realiza-se uma simulação na região próxima ao poço (near well simulation), sendo comum a utilização de soluções analíticas ou semi-analíticas. Estas soluções são obtidas através da introdução de diversas aproximações, juntamente com o uso de geometrias simplificadas para o poço e reservatório. Dentre as simplificações introduzidas, geralmente desprezam-se os efeitos não darcianos. Também é comum adaptar o caso real, para ser possível aplicar a solução aproximada do modelo. Este tipo de solução é relativamente 
fácil e barata de ser utilizada, portanto altamente desejável. Porém, possui aplicação limitada.

O cálculo preciso do desempenho de um poço é muito importante para a gestão e otimização de um reservatório. Por esta razão, modelos mais realistas em relação aos analíticos e semi-analíticos são muitas vezes utilizados na avaliação de campos que apresentam vários poços de petróleo produzindo simultaneamente. Os simuladores de reservatórios mais tradicionais são baseados no método de diferenças finitas, utilizando domínios aproximadamente regulares. Apesar de mais realistas que os modelos analíticos, estes simuladores são limitados com relação a representação detalhada do poço, pois a malha geralmente não se adapta a todos os detalhes de sua geometria e completação. Adicionalmente, o escoamento no poço não é contabilizado de forma acoplada ao escoamento no reservatório, característica importante, principalmente na modelagem para casos de poços horizontais longos.

A modelagem empregada nos simuladores tradicionais de reservatórios, devido ao tamanho da malha, também despreza parâmetros físicos importantes da região próxima ao poço. As heterogeneidades do reservatório perto do poço, os componentes de completação do poço, o dano da formação, a geometria dos canhoneios e de fraturas hidráulicas são alguns exemplos de fenômenos físicos normalmente pouco detalhadas em simuladores convencionais. Estes efeitos ocorrem em escalas que são muito pequenas em comparação com os elementos de malha dos simuladores de reservatórios típicos. Essas variáveis têm um grande impacto sobre a produtividade dos poços. Para avaliar esse impacto, uma modelagem adequada da região próxima ao poço leva a cenários de produção mais reais (Karimi, 2012; Chandra, 2013; Sun, 2013).

Para determinar a vazão através do poço, comumente, os simuladores de reservatórios tradicionais utilizam a seguinte expressão para o cálculo da produção.

$$
Q=\frac{W I}{\mu}\left(p_{i}-p_{w}\right)
$$

onde $Q$ é a vazão volumétrica entrando ou saindo do poço, $p_{w}$ e $p_{i}$ são as pressões do poço e do bloco computacional contendo o poço, respectivamente, $\mu$ é a viscosidade molecular e $W I$ é o índice de produtividade do poço.

Para casos particulares, como por exemplo em reservatórios homogêneos, na região junto ao poço é possível exprimir a solução para a pressão perto do poço analiticamente. É importante ressaltar que o índice de produtividade do poço WI depende dos detalhes da configuração do poço e do reservatório. No 
caso particular de reservatório discretizado utilizando uma malha cartesiana, sendo a trajetória do poço alinhada com a malha, expressões analíticas para o índice de produtividade do poço também podem ser derivadas. Com o objetivo de aumentar os tipos de casos para o cálculo do $W I$, dentro da metodologia de modelo de poço, métodos semi-analíticos tem sido utilizados. Essas abordagens são muitas vezes úteis, mas são limitadas em termos de sua aplicabilidade, por exemplo, quando o reservatório exibe alta heterogeneidade de permeabilidade na região perto dos poços.

Simulações mais modernas de fluidodinâmica computacional (CFD), utilizam malhas irregulares e não estruturadas, e apresentam vantagens em relação aos simuladores tradicionais quando aplicadas para casos de avaliação da produtividade de poços. A geração de malha é flexível permitindo a descrição em detalhes das geometrias do poço e da completação. Estes simuladores também permitem o acoplamento do domínio fluido referente ao poço com o meio poroso referente ao reservatório. A figura 1.1 apresenta uma região próxima ao poço com detalhes da geometria do poço e de uma fratura hidráulica.
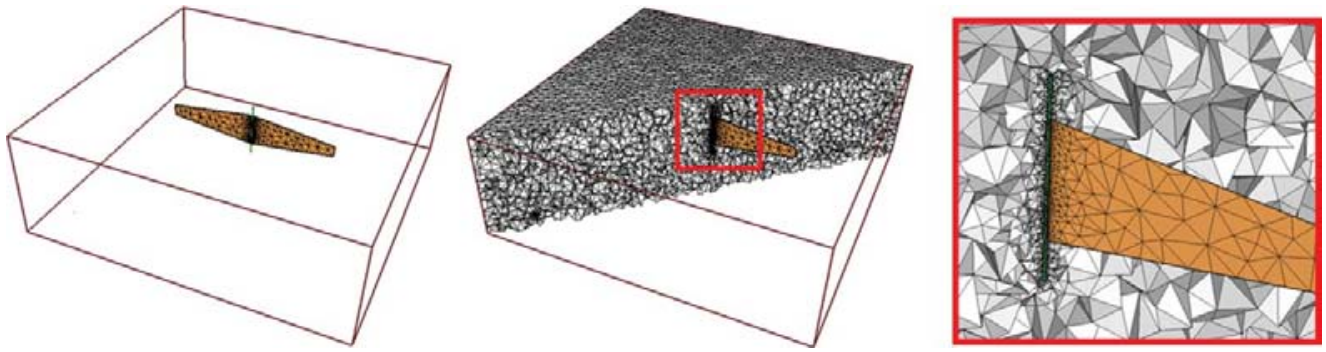

Figura 1.1: Modelo para simulação na região do poço. Figura retirada de Karimi (2011).

A principal motivação do presente estudo é a representação mais realista dos cenários de produção, através de uma modelagem adequada da região próxima ao poço. Não só os detalhes da heterogeneidade de permeabilidade próxima do poço são bem descritas, mas a geometria do poço é modelada, ou seja, não utiliza a consideração de modelo de poço, com a utilização de soluções aproximadas analíticas.

\subsection{2}

\section{Produção de Poços Acidificados}

Na região do pré-sal no Brasil pode-se encontrar vários tipos de reservatórios, sendo os principais compostos por formações carbonáticas. As acumulações de petróleo se estendem ao longo da costa, do Nordeste para o Sul, onde a maior parte delas são offshore. Estas formações são longas e complexas, naturalmente fraturadas, muito heterogêneas com intensas variações de propriedades 
petrofísicas. As formações de carbonato consistem em uma rocha de calcário as vezes com baixa permeabilidade, podendo ter uma porosidade secundária, contribuindo de certa forma para uma permeabilidade maior (Weng, 2011).

O resultado dessas características é uma escala de permeabilidade que pode chegar a mais de quatro ordens de grandeza de diferença. Os reservatórios carbonáticos do pré-sal representam uma nova fronteira em quase todas as áreas de interesse na exploração de campos petrolíferos. Uma dessas áreas é a estimulação de poços que se torna extremamente importante para o melhor aproveitamento das reservas, aumentando o fator de recuperação. Na área de estimulação de poços, pode-se destacar, por exemplo o processo de acidificação que é uma das metodologias mais antigas de estimulação.

O processo de acidificação consiste na injeção de um sistema ácido com o objetivo de criar canais de alta condutividade, os chamados wormholes, para retirar o dano induzido durante as operações de perfuração e completação. Logo, o objetivo principal do processo de acidificação é criar uma conexão do poço com o reservatório através dos wormholes (Kalia, 2007; Kalia N.; Balakotaiah, 2009; Liang, 2015). A Figura 1.2 apresenta uma imagem reconstruída de wormhole após a injeção do ácido em uma amostra de carbonato.

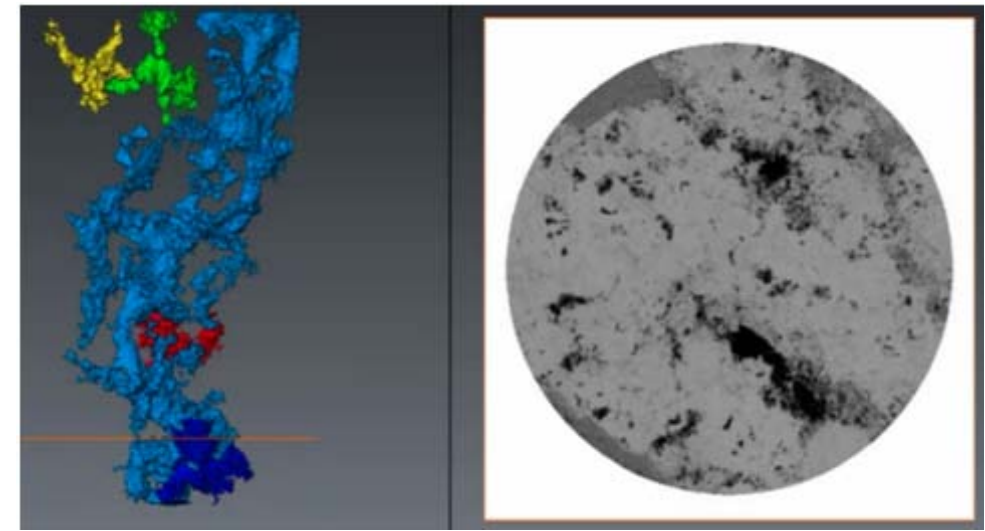

Figura 1.2: Imagem reconstruída de wormholes.

Em experimentos, o ácido é injetado em plugues de rochas para que a alteração da porosidade local seja compreendida. Assim, processos mais eficientes de fluxo são desenvolvidos para diferentes rochas carbonáticas. Um dos objetivos desses tipos de experimentos é estudar o comportamento da rocha após a injeção do ácido, avaliando o fluxo do ácido e o tipo de wormhole formado.

A acidificação matricial é aplicada principalmente para remover danos causados pela perfuração e completação. A remoção do dano em reservatórios de carbonato pode resultar em grande aumento na produtividade do poço. 
Por outro lado, se não houver nenhum dano, a acidificação raramente aumenta muito a produção natural do poço.

A região próxima ao poço, após o tratamento de acidificação tem alta heterogeneidade devido a presença dos canais de alta condutividade. A equação de Darcy sendo utilizada para a estimativa da produção de um poço, ou seja, para o cálculo do índice de produtividade $(I P)$, após acidificação pode levar a resultados não acurados devido a alta heterogeneidade imposta pelo ácido e às limitações da equação de Darcy. Um modelo mais adequado é portanto desejável para a melhor contabilização do escoamento nos meios porosos acidificados.

\subsection{3}

\section{Produção de Poços Horizontais}

Pode-se definir um poço através de sua posição em relação ao reservatório. Um poço horizontal é perfurado paralelamente ao leito do reservatório, enquanto que um poço vertical intercepta o plano de alinhamento do reservatório a 90 graus. Já um poço inclinado seria aquele que intercepta o reservatório sob qualquer ângulo intermediário entre zero e 90. A figura 1.3 apresenta um esquema de poço vertical e horizontal.

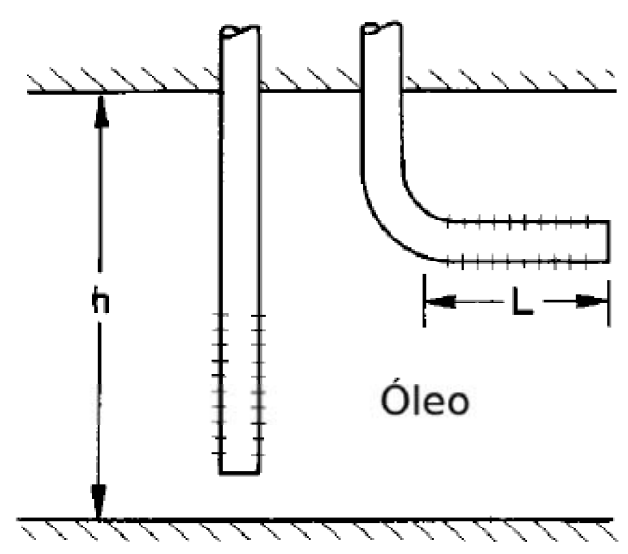

Figura 1.3: Poço vertical e horizontal interceptando o reservatório.

Outros tipos de poços perfurados são os multilaterais. A construção de poços multilaterais envolve a perfuração de dois ou mais poços a partir do mesmo trecho vertical como mostrado na figura 1.4. O objetivo principal dos poços horizontais e multilaterais é produzir maiores vazões de óleo ou gás e reduzir o custo total de produção de cada barril de petróleo ou metro cúbico de gás. Isto ocorre devido, principalmente, ao fato de que esses poços apresentam grande área de contato com o reservatório, além de promover a linearização de fluxo numa grande porção do reservatório ao redor do poço. 


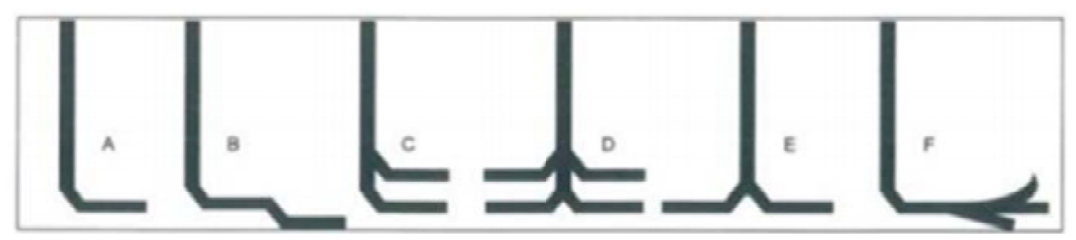

Figura 1.4: Diferentes arquiteturas de poços multilaterais.

Geralmente, a produtividade de um poço horizontal é de duas a cinco vezes a produtividade de um poço vertical, dependendo da permeabilidade do reservatório, da viscosidade do fluido, das anisotropias permo-porosas e da geometria do poço (extensão e diâmetro).

Outro fator importante para a perfuração dos poços horizontais é que os reservatórios de óleo e gás variam muito em espessura, podendo apresentar poucos metros de espessura permeável até centenas de metros. Assim, com um poço vertical convencional, a área de contato entre o poço e o reservatório fica limitado à sua espessura permeável. Em um poço horizontal, a área de contato entre o poço e o reservatório pode ser muito longa, dependendo da extensão horizontal do poço.

Embora o comprimento comum de um poço horizontal seja de $600 \mathrm{~m}$ a $900 \mathrm{~m}$, há casos de poços horizontais de até $8 \mathrm{~km}$ de extensão. Esses poços longos proporcionam alta produtividade, reduzindo o custo de desenvolvimento do campo.

A aplicação da tecnologia de perfuração horizontal no desenvolvimento de reservatórios de óleo e gás tornou-se comum em todo o mundo ao longo do último quarto de século. Desde 1980, mais de 50.000 poços horizontais e 1000 poços multilaterais foram perfurados ao redor do mundo (Joshi, 2007).

Somente nos Estados Unidos, mais de 30 mil poços horizontais foram perfurados, sendo a maioria no Texas, principalmente nos reservatórios de carbonato Austin Chalk e nas formações de folhelho em Barnett Shale. Fora dos EUA, muitos poços horizontais foram perfurados em arenitos, sendo que em vários campos a técnica de poços horizontais é utilizada para retardar o aparecimento de cones de gás e água.

Nos Estados Unidos, milhares de poços horizontais têm sido perfurados em campos de gás não-convencional (folhelhos), a exemplo dos Campos de Bakken, em Dakota do Norte, Barnett no Texas e Fayetteville em Oklahoma e Arkansas.

Nesta seção, são discutidos dois modelos de produtividade que se mostram úteis na prática. O primeiro, publicado por Babu (1989), é limitado 
a poços horizontais simples. O segundo, publicado por Economides (1996), é mais geral e é útil para poços multilaterais.

\section{Modelo de Produtividade Babu-Odeh}

Babu (1989) obtiveram uma solução precisa para a equação de difusividade hidráulica de um poço em um reservatório em forma de "caixa de sapato", sujeito às seguintes hipóteses simplificadoras:

1. O fluido escoa para o poço uniformemente em todos os pontos ao longo da extensão horizontal (fluxo uniforme);

2. As arestas do volume de drenagem do poço estão alinhados com as direções principais do tensor de permeabilidades;

3. O poço é paralelo aos lados da área de drenagem e é orientado paralelamente a uma direção de permeabilidade principal e perpendicular aos outros dois componentes principais de permeabilidade;

4. Os limites do reservatório são fechados e o poço produz em regime de fluxo pseudo-permanente;

5. O dano de formação em torno do poço é uniforme ao longo da extensão horizontal do poço.

A figura 1.5 mostra a geometria de poço e reservatório utilizada na solução de Babu (1989). A solução é bastante complexa, mas apresenta precisão comparável à equação de fluxo pseudo-permanente monofásico para um poço vertical.

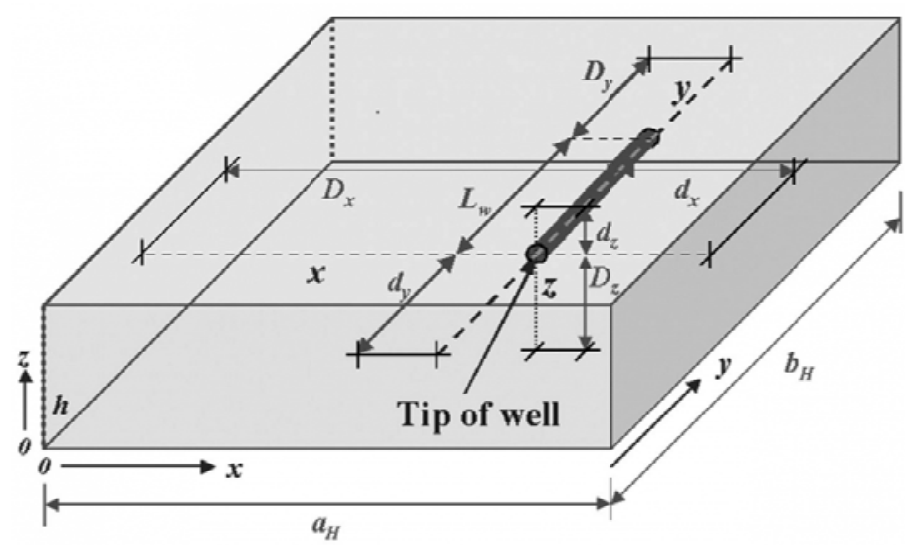

Figura 1.5: Esquema de poço e reservatório (Babu, 1989).

O valor de vazão do poço é dada pela equação 1.2 e o índice de produtividade do poço é dado pela equação 1.3 


$$
\begin{gathered}
Q=\frac{0,00708 b_{h}\left(K_{x} K_{z}\right)^{1 / 2}\left(\bar{p}-p_{w f}\right)}{B \mu\left[\ln \left(\frac{A^{1 / 2}}{r_{w}}\right)+\ln C_{H}-0,75+s_{p}+\frac{b_{h}}{L_{w}} s_{d}\right]} \\
J=\frac{Q}{\left(\bar{p}-p_{w f}\right)}=\frac{0,00708 b_{h}\left(K_{x} K_{z}\right)^{1 / 2}}{B \mu\left[\ln \left(\frac{C_{h} A^{1 / 2}}{r_{w}}\right)-0,75+s_{p}+\frac{b_{h}}{L_{w}} s_{d}\right]}
\end{gathered}
$$

onde $b_{h}$ é o comprimento do reservatório na direção paralela ao poço em ft, $K_{x}$ a permeabilidade na direção "x" em md, $K_{x}$ e $K_{z}$ a permeabilidade na direção "x" e "z", respectivamente, em $\mathrm{mD}, C_{h}$ o fator de forma, $A$ a área de drenagem no plano vertical em ft, $\bar{p}$ a pressão média ou estática do reservatório em psi, $p_{w f}$ a pressão de fluxo em psi, $B$ o fator volume de formação unidimensional, $\mu$ a viscosidade em $\mathrm{cp}, r_{w}$ o raio de poço em ft, $s_{p}$ o skin devido à penetração parcial do poço no reservatório, adimensional, $b_{h}$ o comprimento do reservatório na direção paralela ao poço em ft, $L_{w}$ o comprimento horizontal do poço em $\mathrm{ft}$ e $s_{d}$ o skin devido ao dano à formação adimensional.

\section{Modelo de Economides Brand Frick}

Economides (1996) apresentaram um modelo mais genérico para estimar o índice de produtividade de um poço horizontal. O método tem a vantagem de ser aplicável a poços multilaterais no mesmo plano horizontal e não está limitado a poços alinhados com permeabilidades principais. Inclui soluções para poços sem queda de pressão no poço (condutividade infinita, em oposição aos poços com fluxo uniforme). Tem a desvantagem da necessidade de interpolação de dados em um tabela onde certas formas de área de drenagem são encontradas para a determinação do fator de forma do reservatório.

A equação básica para o índice de produtividade neste modelo é dada pela equaçã 1.4

$$
J=\frac{K b_{h}}{887,22 B \mu\left(p_{D}+\frac{b_{h}}{2 \pi L_{w}} \Sigma s\right)}
$$

onde 


$$
\begin{gathered}
p_{D}=\frac{b_{h} C_{h}}{4 \pi h}+\frac{b_{h}}{2 \pi L_{w}} s_{c} \\
s_{c}=\ln \left(\frac{h}{2 \pi r_{w}}\right)+\frac{h}{6 L_{w}}+s_{e} \\
s_{e}=\frac{h}{L_{w}}\left[\frac{2 d_{z}}{h}+\frac{1}{2}\left(\frac{2 d_{z}}{h}\right)^{2}-\frac{1}{2}\right]+\ln \left[\sin \left(\frac{\pi d_{z}}{h}\right)\right]
\end{gathered}
$$

onde $J$ é o índice de produtividade do poço, $K$ a permeabilidade do reservatório, $\Sigma s$ refere ao somatório dos efeitos de skin devido ao dano, ao fluxo turbulento e outros fatores de skin, $L_{w}$ o comprimento horizontal do poço em $\mathrm{ft}, h$ a espessura permeável do reservatório em ft, $b_{h}$ é o comprimento do reservatório na direção paralela ao poço em $\mathrm{ft}, r_{w}$ o raio de poço em $\mathrm{ft}, d_{z}$ o menor tamanho entre a extremidade do poço e o plano em z, em ft. As equações 1.4 e 1.5 são válidas para reservatórios isotrópicos.

\subsection{4}

\section{Produtividade de Poços Estimulados por Fraturamento Hidráulico}

O Fraturamento Hidráulico é uma técnica de estimulação de poços na qual, por meio de um fluido submetido a alta pressão, é iniciada e propagada uma fratura, de forma a criar um canal de alta condutividade para o escoamento de fluidos entre o poço e o reservatório. A fratura induzida por estimulação é preenchida com um material granular, de alta permeabilidade, caracterizando o reservatório como um meio de dupla porosidade no raio de ação da fratura.

A técnica do fraturamento hidráulico é bastante utilizada para a viabilização econômica de campos onde as rochas-reservatório têm baixa permeabilidade, podendo ser utilizada em qualquer litologia de rocha. Assim, é comum a aplicação da técnica em arenitos, carbonatos e folhelhos, sendo que, neste último cenário, dito reservatório não-convencional, o fraturamento é a única técnica capaz de promover a produção de óleo ou gás de forma comercial.

O fraturamento aumenta a capacidade de fluxo entre reservatório e poço, melhorando a produtividade ou injetividade, pela ação de diferentes mecanismos:

1. melhoria da conectividade hidráulica entre poço e reservatório. No caso de existência de dano, a região danificada é ultrapassada pela fratura;

2. modifica o padrão de fluxo reservatório-poço. O fluxo passa a ser linear na fratura e radial nos pontos mais distantes;

3. promove maior área de contato entre poço e reservatório; 
4. pode atingir áreas do reservatório com melhores características permoporosas;

5. pode conectar zonas hidraulicamente isoladas;

6. pode conectar fraturas naturais do reservatório.

A figura 1.6 ilustra a influência da fratura no padrão de fluxo entre reservatório e poço, supondo um poço vertical drenando uma área circular do reservatório.

Na situação de poço não-fraturado, o fluxo é predominantemente radial em toda a extensão do reservatório. Após o fraturamento, há um pequeno período de tempo em que o raio de investigação do poço é menor do que o comprimento de fratura, caracterizando um padrão de fluxo bi-linear, ou seja, linear do reservatório para a fratura e da fratura para o poço.

Findo o período inicial transiente, à medida que o raio de investigação do poço aumenta, o fluxo se torna radial longe da fratura e linear nas proximidades da fratura e poço. A este tipo de escoamento dá-se o nome de fluxo pseudoradial.

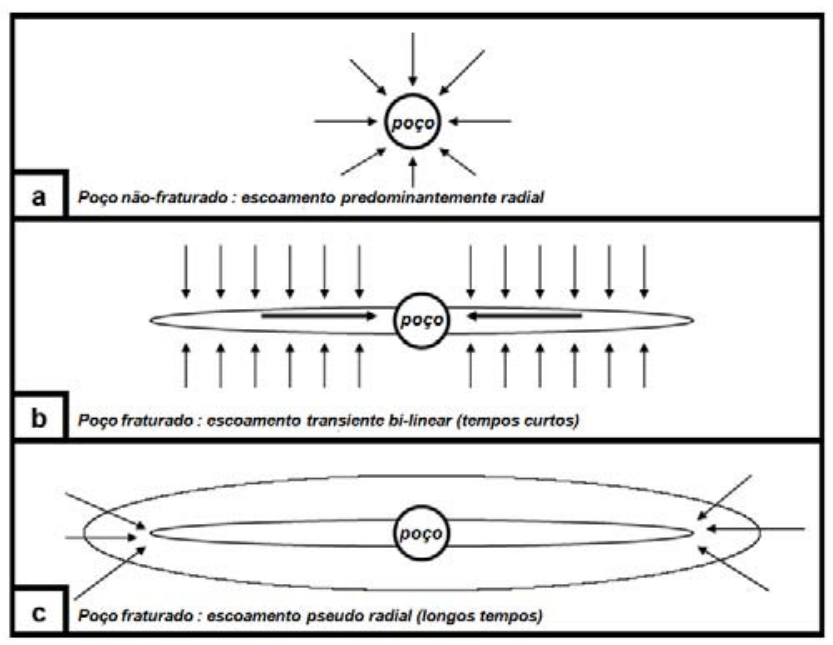

Figura 1.6: Modificação do padrão de fluxo devido ao fraturamento hidráulico (Nolte, 2000).

Para o planejamento da operação de fraturamento hidráulico, é imprescindível uma simulação precisa do ganho de produtividade, uma vez que a viablidade econômica da técnica depende desta estimativa. De forma geral, quanto menor for a permeabilidade do reservatório, maiores serão os ganhos relativos proporcionados pelo fraturamento. Porém, nem sempre isso garante poços com vazões econômicas. Desta forma, a estimativa do ganho de produtividade resultante do fraturamento é uma etapa crítica do planejamento 
da operação. A figura 1.7 mostra o fluxograma do planejamento de uma operação de fraturamento hidráulico.

No planejamento da operação, deve ser feita uma estimativa do custo da operação, que depende da geometria de fratura que se pretende estabelecer. Por outro lado, é feita uma estimativa do benefício gerado pela fratura, através de uma simulação de produtividade do poço fraturado. O ganho de produtividade promovido pelo poço fraturado vai depender, dentre outros fatores, do comprimento e condutividade de fratura, da permeabilidade do reservatório e da viscosidade do fluido a ser produzido. Ao final do planejamento, a relação custo-benefício vai definir a geometria ótima de fratura para um dado reservatório.
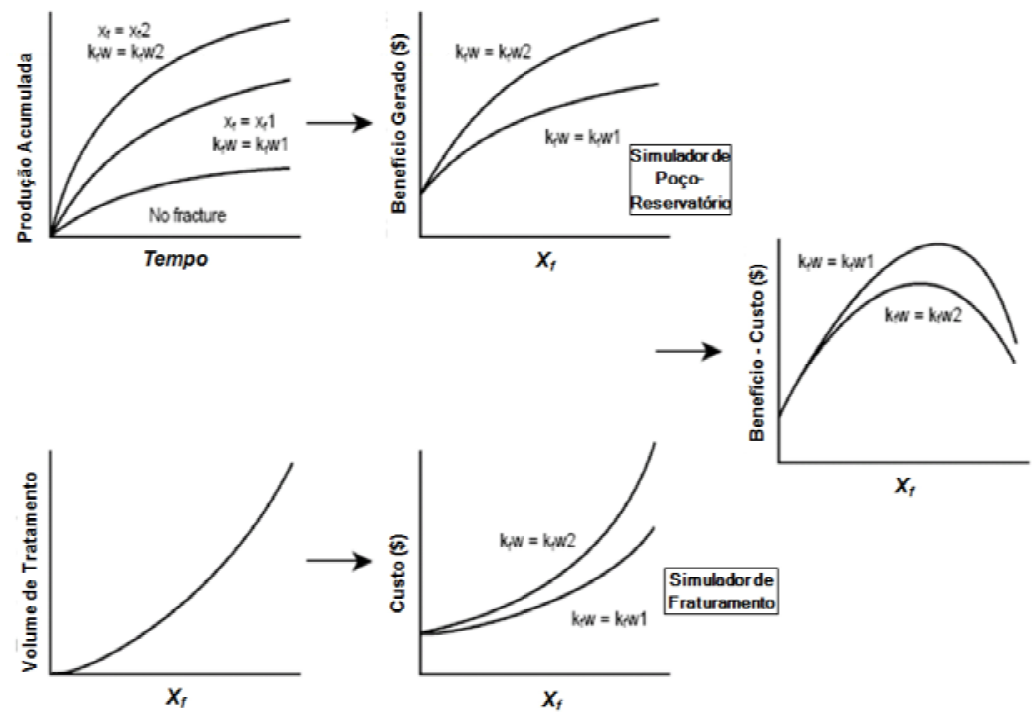

Figura 1.7: Modificação do padrão de fluxo devido ao fraturamento hidráulico (Nolte, 2000).

A estimativa de ganho de produtividade é, geralmente feita por meio de simuladores de reservatório, nem sempre apropriados à esta finalidade, uma vez que nem sempre representam a fratura de forma adequada. Como os simuladores de reservatório trabalham com elementos de malha muito grandes, compatíveis com o tamanho do reservatório, acabam perdendo a resolução da geometria de fratura, que apresenta aberturas da ordem de alguns milímetros.

Outra maneira de se obter uma estimativa da produtividade de poços fraturados é através de modelos analíticos clássicos. Esses modelos, bastante conhecidos pelos profissionais da área, fazem boas estimativas, desde que as condições do poço e reservatório tenham concordância com as hipóteses básicas, as quais introduzem grande simplificação aos modelos. Neste trabalho são apresentados, de forma resumida, os três modelos mais conhecidos da literatura técnica. 


\section{Modelo de McGuire e Sikora}

O trabalho de McGuire (1960), propõe a previsão de produtividade de poços verticais fraturados, produzindo em regime de fluxo-pseudo permanente. Portanto, o modelo adota reservatório fechado, ou seja, sem manutenção de pressão, com a vazão no poço constante. O modelo considera, ainda, área de drenagem do poço com geometria quadrada.

Utilizando-se de modelos elétricos análogos aos modelos de fluxo entre meio poroso e poço, McGuire (1960) publicaram uma solução para o escoamento em poços fraturados, figura 1.8, que foi a primeira ferramenta desenvolvida para determinar o comprimento e a condutividade de fratura necessários para atingir um certo aumento no índice de produtividade de um poço vertical.

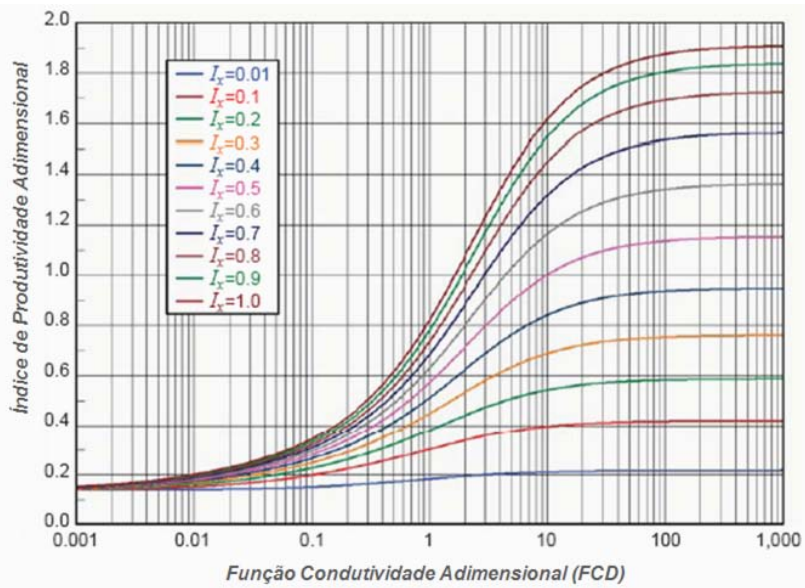

Figura 1.8: Curvas de produtividade de fratura em função da condutividade adimensional (McGuire, 1960).

No desenvolvimento do modelo, são definidos os seguintes parâmetros: a penetração adimensional da fratura $I_{x}$, o comprimento da asas da fratura $L$ e o comprimento do lado da área de drenagem quadrada $X_{e}$. A equação 1.6. relaciona os parâmetros.

$$
I_{x}=\frac{2 L}{X_{e}}
$$

O índice de produtividade adimensional é dado pela equação 1.7.

$$
J_{0}=\frac{J}{2 \pi K h / \mu}
$$


onde $J$ é o indice de produtividade do poço, $K$ a permeabilidade do reservatório, $h$ a altura do reservatório e $\mu$ a viscosidade do fluido. A função condutividade adimensional é dada pela equação 1.8 .

$$
F C A=\frac{K_{f} w}{K L}
$$

onde $K_{f}$ a permeabilidade da fratura, $w$ a espessura da fratura, $K$ a permeabilidade do reservatório e $L$ o comprimento da asa da fratura.

\section{Modelo de Prats}

O modelo de Prats é o mais simples dos modelos de predição de produtividade de poços fraturados. Proposto por Prats (1961) para um regime de fluxo permanente incompressível, em um reservatório de geometria circular drenado por um poço vertical.

O modelo de Prats (1961) se baseia no conceito de raio efetivo de poço, definido da forma $r_{w}^{\prime}=r_{w} e^{-s}$. Sendo $r_{w}^{\prime}$ o raio efetivo de poço, $r_{w}$ o raio geométrico e $s$ o fator skin.

O fator skin é um parâmetro utilizado para definir o dano de poço, sendo positivo para poços danificados e negativo para poços estimulados. O raio efetivo, em termos físicos, significa o raio geométrico equivalente do poço, para que ele tenha a mesma produtividade de um poço estimulado com um fator skin. Desta forma, a relação entre a produtividade do poço estimulado e a produtividade do poço não-estimulado pode ser expressa pela equação 1.9.

$$
\frac{I P}{I P_{0}}=\frac{\ln \left(r_{e} / r_{w}\right)}{\ln \left(r_{e} / r_{w}^{\prime}\right)}
$$

O raio efetivo de poço $r_{w}^{\prime}$ é obtido através da curva tipo mostrada na figura 1.9 .

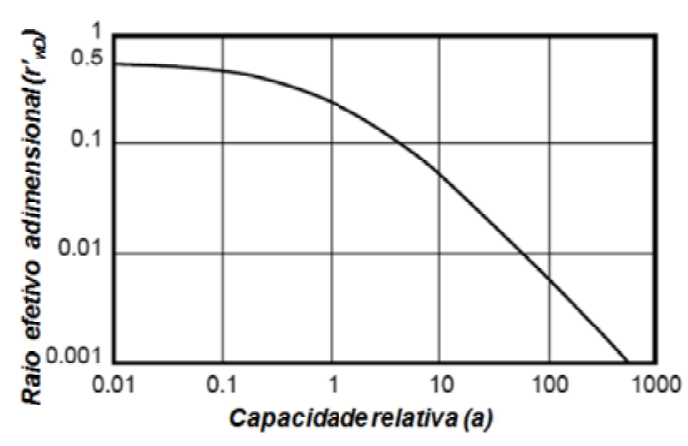

Figura 1.9: Curva de raio efetivo adimensional do modelo de Prats (1961). 
O raio efetivo adimensional é definido como a relação entre o raio efetivo $r_{w}^{\prime}$ e o comprimento de asa da fratura $L$. O parâmetro $a$, dito capacidade relativa, é definido pela equação 1.10 .

$$
a=\frac{\pi K x_{f}}{2 k_{f} w}
$$

\section{Modelo de Cinclo-Ley e Samaniego}

Cinclo-Ley (1981) propuseram um modelo para análise de produtividade de poços verticais fraturados, em regime de fluxo transiente. Nesse trabalho, foi apresentada uma nova modelagem analítica, para análise de dados de transientes de pressão em poços verticais interceptados por uma fratura de condutividade finita. Este método baseia-se na teoria do fluxo bilinear, que considera o fluxo linear transitório tanto na fratura quanto na formação. Demonstra-se que um gráfico de pressão de fluxo versus $t^{1 / 4}$, onde $t$ é o tempo, produz uma reta cuja inclinação é inversamente proporcional ao produto $h_{f}\left(k_{f} w_{f}\right)^{1 / 2}$.

Para o cálculo da produtividade de poços verticais fraturados, em regime de fluxo transiente, Cinclo-Ley (1981) introduziram uma correção no cálculo de raio efetivo de poço proposto pelo trabalho de Prats (1961) para fluxo permanente.

A figura 1.10 mostra a curva do fator skin de fratura corrigido, em função da condutividade adimensional, sendo $F C D=K_{f} w / K L$, onde o produto $K_{f} w$ é a condutividade de fratura, $K$ é a permeabilidade da formação e $L$ é o comprimento da fratura. A partir do fator skin corrigido, calcula-se o raio efetivo de poço e o ganho de produtividade proporcionado pela fratura.

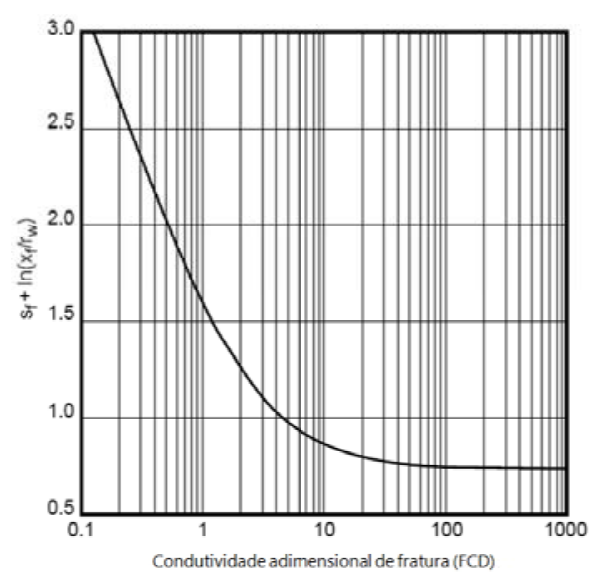

Figura 1.10: Fator skin de poço fraturado em função da condutividade adimensional para fluxo transiente (Cinclo-Ley, 1981). 


\subsection{5}

\section{Reservatórios Carbonáticos - Altamente Heterogêneos}

O fator de recuperação médio, considerando rochas-reservatório das mais diversas litologias em variadas províncias produtoras ao redor do mundo, é de cerca de 35\%. No entanto, é reconhecido que os fatores de recuperação são maiores para os reservatórios areníticos do que para os carbonáticos. Os reservatórios carbonáticos apresentam várias características específicas que apresentam desafios tecnológicos complexos, sejam na caracterização, na produção e no gerenciamento do reservatório.

Os carbonatos são rochas sedimentares depositadas normalmente em ambientes marinhos com águas claras, superficiais e quentes e são na sua maioria de origem biológica. São compostos por fragmentos de organismos marinhos, microorganismos, esqueletos, corais e algas, e consistem, principalmente, de carbonato de cálcio, que é quimicamente ativo em comparação com a areia que forma os arenitos. Outra diferença chave entre as rochas siliciclásticas e os carbonatos é a distância entre o local onde o sedimento foi criado e onde foi depositado. Enquanto os sedimentos areníticos podem viajar centenas de quilômetros abaixo dos sistemas fluviais antes da deposição e da litificação, os grãos que compõem os sedimentos de carbonatos são geralmente depositados muito perto do local onde foram criados. Esta deposição local contribui significativamente para a heterogeneidade dos grãos de carbonato.

Uma vez formada a rocha carbonática, uma série de processos químicos e físicos começa a alterar a estrutura da rocha, estabelecendo as suas características fundamentais, tais como porosidade e permeabilidade. Isso é conhecido como diagênese. $\mathrm{Na}$ deposição, os sedimentos de carbonatos têm frequentemente porosidades muito elevadas (35\% -75\%), mas esta diminui acentuadamente à medida que o sedimento é soterrado nas profundidades do reservatório. Como resultado, os reservatórios de carbonato exibem variações grandes e abruptas na distribuição do tipo de rocha, podendo apresentar grandes falhas, fraturas naturais, cavernas e vugs, traduzidos em altas heterogeneidades e anisotropias.

Os carbonatos podem exibir propriedades altamente variáveis (por exemplo, porosidade, permeabilidade) dentro de pequenas secções do reservatório, tornando-as difíceis de caracterizar. Uma abordagem específica é necessária para entender melhor a natureza heterogênea da rocha e as propriedades de fluxo nos meios porosos freqüentemente fraturados. Isso envolve compreensão detalhada da saturação de fluidos, distribuição de tamanho de poros, permeabilidade, textura da rocha, tipo de rocha reservatório e sistemas de fraturas naturais em diferentes escalas. 
Os reservatórios carbonáticos, de uma forma geral, apresentam grandes variações texturais e estruturais devido à natureza de processos deposicionais (tamanho de grão, grau de seleção, mineralogia, ciclos deposicionais), diagênese (lixiviação, cimentação) e fraturas naturais, que causam grandes heterogeneidades e anisotropias de propriedades permo-porosas e mecânicas. Desta forma, para simplificar o entendimento da estrutura dessas rochas, a caracterização de reservatórios carbonáticos é categorizada em classificação textural, petrofísica e caracterização de sistemas fraturados. A classificação textural e petrofísica têm como base a textura deposicional e alterações texturais devido aos efeitos diagenéticos. A caracterização de sistemas fraturados aborda os tipos de reservatórios fraturados, origem e conformação de fraturas (Correia, 2014).

A porosidade das rochas carbonáticas pode ser agrupada em três tipos: porosidade conectada, existente entre os grãos de carbonato; vugs, que são poros não ligados resultantes da dissolução da calcita por água durante a diagênese, e porosidade de fratura, que é causada pela redistribuição de tensões sobre a rocha, após a deposição. A diagênese pode criar estruturas estilolíticas que formam barreiras horizontais de fluxo, grandes fraturas e cavernas que, às vezes, se estendem por quilômetros dentro do reservatório, tendo um efeito dominante na produtividade do campo. As fraturas podem ser responsáveis pela produção prematura de água, aparecimento de cones de gás e problemas durante a perfuração dos poços, tais como perdas de fluido e prisão de coluna. Juntas, essas três formas de porosidade criam um caminho muito complexo para os fluidos e afetam diretamente a produtividade dos poços, sendo de difícil modelagem para simulação de reservatórios.

Os sistemas de porosidade vugular são inerentemente mais complexos do que os sistemas de porosidade intergranular-intercristalinos ou de matriz de fratura. A estrutura original dos poros é normalmente alterada pela formação de cavidades e canais de dissolução. As estruturas de poros em muitos reservatórios carbonáticos geralmente pertencem a esta categoria. As rochas carbonáticas formadas por acúmulos orgânicos, submetidos a apenas uma ligeira ruptura durante a sedimentação são os principais candidatos para o desenvolvimento da porosidade vugular. Essa porosidade consiste em vugs de escala que varia de micro a macroscópica. A permeabilidade direcional pode ser muito acentuada, caracterizando uma direção preferencial de fluxo.

Embora as fraturas normalmente existam, nem sempre elas dominam a mecânica do fluxo no meio poroso. O desempenho dos reservatórios de carbonato com porosidade vugular pode ser muito parecido com o desempenho de reservatórios areníticos, mas comumente difere consideravelmente devido a uma distribuição muito mais ampla dos tamanhos de garganta dos poros 
(Ferreira, 2016).

Um sistema de dupla porosidade caracteriza os reservatórios com porosidade de fratura-matriz. Neste caso, também pode existir forte permeabilidade direcional. A matriz é geralmente de baixa permeabilidade e contém a maioria dos hidrocarbonetos. As fraturas contribuem apenas com uma pequena fração do volume poroso, mas permitem que o reservatório produza a vazões comerciais. O desempenho do reservatório é marcadamente diferente daquele dos reservatórios de arenito. O tamanho dos blocos de rocha-matriz varia de alguns centímetros a vários metros, criando heterogeneidades de diferentes escalas.

Além das variações na porosidade, a molhabilidade é outra característica altamente heterogênea em carbonatos. A maturação da rocha carbonática contendo água e óleo pode inverter a molhabilidade da rocha. Isto significa que o óleo pode aderir à superfície da rocha carbonática e tornar seu escoamento muito mais difícil. Acredita-se que a maioria dos reservatórios carbonáticos tenha molhabilidade mista. De fato, em alguns reservatórios carbonáticos, os fatores de recuperação podem ser muito pequenos, se comparados a arenitos, chegando a menos de 10\%. Caracterizar as heterogeneidades e anisotropias, bem como a distribuição da molhabilidade e compreender seus efeitos sobre o fluxo de fluidos dentro de um reservatório carbonático complexo é crucial para estimar as reservas e determinar estratégias de produção para maximizar a recuperação de óleo. A figura 1.11 apresenta um corredor de Fraturas em um afloramento carbonático.

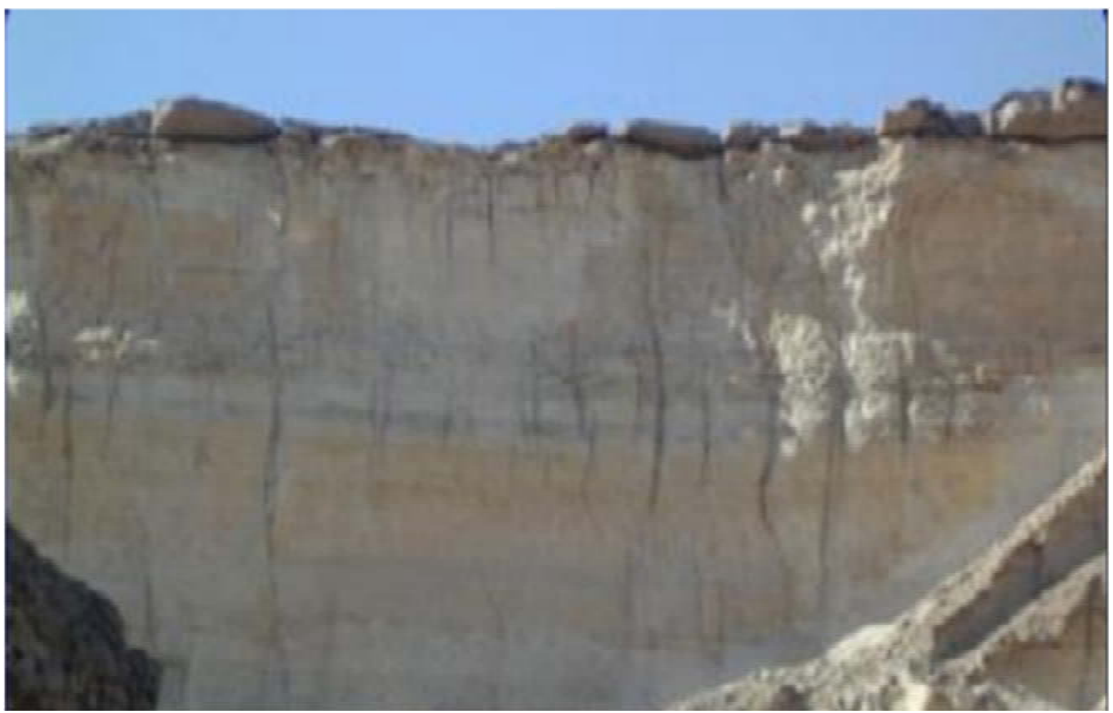

Figura 1.11: Corredor de fraturas em afloramento carbonático. 


\section{2}

\section{Limitações das Modelagens Tradicionais}

Em princípio, pode-se escrever as leis de equilíbrio para o movimento do fluido através do meio poroso a partir do conhecimento da distribuição espacial dos poros, e então determinar o campo de velocidade depois de aplicar condições de contorno apropriadas na interface fluido-poro. Praticamente, esta é uma tarefa impossível, pois mesmo que a distribuição espacial fosse conhecida, como o número de poros é muito elevado, com distribuição aleatória, o problema torna-se intratável. Por isso, modelos são desenvolvidos, abandonando a visão microscópica para uma nova perspectiva, sob um ponto de vista macroscópico, onde se pode lidar com determinadas quantidades médias que representam o comportamento macroscópico.

A seguir, apresentam-se alguns dos modelos mais populares para determinar o escoamento de fluidos em meios porosos.

A equação clássica de Darcy (1856) considerando também a ação da gravidade é apresentada pela equação 1.11:

$$
\nabla p+\alpha \mathbf{v}=\rho \mathbf{b}
$$

onde $p$ é a pressão, $\mathbf{v}$ é o vetor velocidade, $\rho \mathbf{b}$ é força de corpo for unidade de volume, onde geralmente $\mathbf{b}=\mathbf{g}$, sendo $\mathbf{g}$ o vetor aceleração da gravidade e $\rho$ é a massa específica. O termo $\alpha \mathbf{v}$ representa o arraste no fluido no meio, sendo o coeficiente de arrasto definido pela equação 1.12 onde $\mu$ a viscosidade molecular e $K$ a permeabilidade do meio.

$$
\alpha=\frac{\mu}{K}
$$

A equação de Forchheimer (1901), apresentada pela equação 1.13, é uma modificação do modelo de Darcy clássico, onde o coeficiente de arrasto já não é uma constante.

$$
\nabla p+\alpha \mathbf{v}+\beta(\mathbf{v}) \mathbf{v}=\rho \mathbf{b}
$$

A equação de Brinkman (1947a,b, 1952) incorpora efeitos difusivos, sendo dada pela equação 1.14 . 


$$
\nabla p+\alpha \mathbf{v}-2 \mu \nabla^{2} \mathbf{v}=\rho \mathbf{b}
$$

Rajagopal (2007) mostrou que a equação de Darcy pode ser obtida depois de fazer um grande número de suposições sobre o sólido e o fluido. As restrições para a utilização da equação de Darcy são bastante específicas.

1. O sólido é um corpo poroso rígido saturado cujo equilíbrio da quantidade de movimento linear pode ser ignorado.

2. O fluxo é suficientemente lento de modo que os efeitos de inércia no fluido podem ser negligenciados.

3. O efeito de atrito no fluido devido à viscosidade do próprio fluido pode ser negligenciado.

4. A única interação entre o sólido e o líquido é devido à fricção nos poros e é proporcional à velocidade relativa entre o sólido e o líquido.

5. O escoamento é permanente.

6. O fluido é incompressível.

7. A escala de pressão em que o fluido está sujeito não conduz a alterações na viscosidade do fluido.

8. A tensão parcial no fluido se comporta como um fluido de Euler.

Subramanian (2007) e Kannan (2008) introduziram algumas modificações na restrições iniciais na equação de Darcy para permitir que reservatórios heterogêneos, fluidos com viscosidade variável e fluidos compressíveis fossem considerados.

O modelo Forchheimer é obtido se o item (4) for modificado para permitir que o coeficiente de arrasto dependa da magnitude da velocidade relativa entre o sólido e o líquido. O modelo de Brinkman clássico é obtido através do relaxamento das hipóteses (3) e (8) e assumindo a hipótese clássica constitutiva de Navier-Stokes para a tensão parcial do fluido levando em consideração os efeitos viscosos no fluido.

É fácil perceber que as imposições para o uso da equação de Darcy são muito restritivas e que em alguns problemas físicos reais esta equação pode violar uma ou mais premissas da lista apresentada. 


\section{3 \\ Organização do Trabalho}

Nesta seção, apresenta-se como o presente trabalho encontra-se estruturado.

O capítulo 2 apresenta a revisão bibliográfica da tese. Apresenta-se o histórico do desenvolvimento das equações para o escoamento em meios porosos ao longo dos anos. Os autores que utilizam a modelagem do fenômeno físico em meios porosos pela teoria de média, modelo escolhido no presente trabalho, são apresentados. Diversos artigos aplicados em reservatórios de carbonatos utilizando a equação mais completa de quantidade de movimento linear são discutidos, assim como artigos evidenciando a importância da utilização da equação completa para a determinação do escoamento.

Tendo por objetivo analisar o comportamento médio do sistema, podese aplicar um método matemático de alteração de escala ao problema físico na pequena escala, gerando modelos macroscópicos. O capítulo 3 apresenta de forma detalhada este procedimento, como a aplicação da teoria de médias nas equações de conservação, visando deixar clara todas as simplicações utilizadas no processo.

No capítulo 4 é apresentada a equação de Darcy como uma simplificação da equação de quantidade de movimento linear e o desenvolvimento para a construção da equação de difusividade hidráulica. Além da equação de Darcy, modelos para equação de estado para o fluido, desenvolvidos nos presentes solvers, são apresentados.

No capítulo 5 é apresentada a modelagem para o escoamento unidimensional no poço para a contabilização da perda de carga considerando diferentes completações. A importância da não utilização da hipótese de modelo de poço devido ao refino de malha ao redor do poço também é apresentada. Outra hipótese não imposta e apresentada no capítulo 5 é a não utilização do fator skin devido a versatilidade da geração de malha no processo de CFD.

No capítulo 6 é apresentado o método dos volumes finitos aplicados na solução do problema de escoamento em meios porosos considerando as duas equações no reservatório: a equação de quantidade de movimento linear média e a equação da difusividade hidráulica. A discretização da equação no poço também é apresentada.

O capítulo 7 apresenta os resultados de validação do modelo proposto. Os solvers desenvolvidos são comparados com soluções analíticas e com softwares comerciais conhecidos na área de simulação de reservatório. No caso da comparação com software comercial, os casos são preparados de forma que ambos os softwares, comercial e desenvolvido, tenham as mesmas condições e hipóteses simplificadoras. 
O capítulo 8 apresenta os resultados de casos de aplicações onde os solvers desenvolvidos são utilizados. Eles serão apresentados com o objetivo de mostrar a relevância e importância do uso da equação completa de quantidade de movimento linear para meios porosos. Fica claro que a equação de Darcy não pode ser utilizada para rochas que contenham um campo de permeabilidade altamente heterogêneo.

O capítulo 9 apresenta a conclusão do presente trabalho mostrando as vantagens da utilização de uma equação mais geral de conservação de quantidade de movimento linear para meios porosos ressaltando as limitações do uso da equação de Darcy em simulação de reservatório e os impactos nas previsões de produtividades de poços estudados no capítulo 8. No capítulo 9 , recomendações de trabalhos futuros também são apresentadas. 


\section{2 \\ Revisão Bibliografica}

Em 1856, Henry Philibert Gaspard Darcy, publicou seu artigo que teve, sem dúvida, grande contribuição na área de sistemas hidráulicos de filtros com a descoberta de uma lei empírica que leva seu nome até hoje. Em seu relatório sobre as fontes públicas de Dijon, Darcy (1856) apresentou uma fórmula para usar no projeto e construção de sistemas de distribuição e filtragem de água. Os resultados experimentais foram apresentados por Darcy em termos de vazão volumétrica $(Q=U A)$, sendo $U$ a velocidade média e $A$ a área da seção transversal, e diferença de pressão $(\Delta p)$ em metros de coluna de água. Ele definiu um coeficiente $k$ chamado condutividade hidráulica e usou a altura da camada de areia $h$. O $\Delta p$ é a diferença entre a pressão acima da camada de areia (pressão atmosférica aumentada pela leitura do manômetro) e a pressão debaixo da camada de areia para determinar seus resultados.

A equação de Darcy é válida, essencialmente, para escoamentos muito lentos, incompressíveis e isotérmicos, para fluidos Newtonianos através de um meio poroso relativamente longo, uniforme e isotrópico de baixa condutividade hidráulica. Além disso, a condutividade hidráulica $k$, conforme definida por Darcy, é de fato dependente do fluido, além de ser afetada pela matriz sólida do meio poroso. A equação 2.1 apresenta a equação de Darcy.

$$
k=U \frac{h}{\Delta p}
$$

Anos após a publicação da equação de Darcy, o efeito de viscosidade de fluido foi observado indiretamente e incluído na equação de Darcy. Hazen (1893), parece ter sido o primeiro a perceber o efeito de viscosidade em ligação com a equação de fluxo original proposta por Darcy. A Lei de Darcy apresentada em alguns livros didáticos modernos, na verdade, foi proposta por Hazen. A equação de Hazen-Darcy possui a condutividade hidráulica $k$ da equação de Darcy original substituía por $K / \mu$, onde $K$ é chamado de permeabilidade específica e $\mu$ é a viscosidade dinâmica fluida como mostra a equação 2.2 . 


$$
U=\frac{K}{\mu} \frac{\Delta p}{h}
$$

A evolução inicial da equação original de Darcy para uma fórmula dependente de viscosidade foi puramente empírica e indireta, isto é, relacionada à temperatura de fluido e não à viscosidade diretamente. Não foi ainda muito tarde que a viscosidade de fluido apareceu como um parâmetro individual na equação de Darcy (Kruger, 1927). Nutting (1930), apresentou um método simples para medir permeabilidade específica já considerando a viscosidade de fluido na equação de Darcy.

Szekely (1968) estudaram fluxo de gás não isotérmico através de um meio permeável. A variação de pressão ao longo de um meio, que está em acordo com os dados experimentais, é obtida com um esquema interativo seguindo uma equação de equilíbrio de energia.

Ling (1992) apresentaram uma investigação teórica numérica da influência da viscosidade de fluido dependente de temperatura na convecção forçada estável sobre uma placa plana isotérmica delimitando um meio poroso infinito.

Pomeala (1997) demonstraram a validade da equação de Hazen-Darcy para o caso de convecção forçada de um líquido com viscosidade dependente de temperatura entre placas planas paralelas uniformemente aquecidas. Subsequentemente, Nield (1997) propuseram um modelo teórico para levar em conta a variação de temperatura do fluido ao longo da direção transversa à direção de fluxo, e o efeito desta variação de temperatura na viscosidade de fluido, velocidade, e queda de pressão total.

Lage (1998) mostrou como os dados apresentados por Darcy são afetados pela variação da viscosidade com a temperatura.

Foi Arsène Jules Emite Juvénal Dupuit, o primeiro cientista a usar princípios teóricos para derivar e explicar fisicamente a equação de Darcy. Dupuit, contemporâneo de Darcy, teve uma segunda edição de seu relatório Dupuit (1963) sobre os estudos teóricos e práticos de fluxo de água em canais descobertos e através de terreno permeável. O que Dupuit fez, de fato, foi visualizar mentalmente a contribuição de fluxo de cada poro (nível microscópico) para a caracterizar o fluxo da camada inteira (nível global). Dupuit propôs então a equação 2.3

$$
0=\frac{\Delta p}{L}-\alpha U-\beta U^{2}+\rho g
$$

É surpreendente ver a equação 2.3 nomeada a Philipp Forchheimer 
em vários artigos e livros didáticos. Forchheimer, em seu artigo original, Forchheimer (1901) indica que ele não foi o primeiro a verificar que a proposta por Darcy (linear) era inapropriada para correlacionar dados experimentais. Existia então um grupo de cientistas defendendo a equação linear de Darcy e outro defendendo a equação quadrática de Dupuit. O artigo de Forchheimer foi escrito principalmente para declarar e defender sua posição com relação ao modelo existente mais apropriado para prever a queda de pressão através da equação quadrática.

O fenômeno físico responsável pelo termo quadrático é conhecido como a força de forma imposta a um fluido por qualquer superfície sólida obstruindo o trajeto de fluxo. Esta força resistiva (para fluxo unidirecional) foi proposta por Newton sendo proporcional à velocidade média do fluido ao quadrado. Usando este conceito, a equação 2.3 é reescrita e é chamada de equação de HazenDupuit-Darcy. A equação 2.4 é idêntica à equação 2.3, exceto pela inclusão da: permeabilidade, viscosidade de fluido, densidade e coeficiente de forma. Os dois últimos termos da equação 2.4 representam os efeitos viscosos e de forma dentro do meio permeável, respectivamente.

$$
0=\frac{\Delta p}{\Delta x}-\frac{\mu}{K} U+\rho g-C \rho U^{2}
$$

Ward (1964) propôs substituir parâmetro $C$ da fórmula na equação 2.4 por $c / K^{1 / 2}$, onde o parâmetro $c$ sem dimensão foi acreditado por ser uma constante universal. A sugestão de Ward resulta de uma análise dimensional que envolve apenas quatro parâmetros básicos, isto é, ele assumiu que a queda de pressão versus a velocidade dependeria apenas de $U, K, \rho$ e $\mu$.

É importante ressaltar que se o lado esquerdo da equação 2.4 é zero, o fluido dentro e fora de uma seção de meio permeável retém sua quantidade de movimento. Vemos no lado direito da equação 2.4 os termos que representam todas as forças consideradas que atuam sobre o fluido. De interesse especial é o termo mais a direita da equação 2.4, ou seja o termo de forma, que é geralmente referido como a força de inércia ou o termo inércia. Esta terminologia é obviamente errônea e confusa. É errônea porque, com momentum constante, o fluxo tem zero de inércia. A confusão é criada porque a força de forma é proporcional a velocidade ao quadrado e em certos casos especiais o termo inércia de fluxo é também escrito como quadrado da velocidade. Sabemos, entretanto, que o termo mais à direita da equação 2.4 representa uma força, que ocorre em função do quadrado da velocidade.

Zhang (1997) relacionaram a contribuição individual dos termos viscosos e de forma com a resistência total de fluxo causada por aletas em fila. 
A transição do regime de fluxo linear, para o regime quadrático, pode ser entendida pela comparação entre a força $D_{C}$ de forma e a força $D_{\mu}$ viscosa.

$$
\frac{D_{C}}{D_{\mu}}=\frac{C \rho U^{2}}{\frac{\mu}{K} U}=\frac{\rho C K}{\mu} U
$$

A equação 2.5 provê um equilíbrio global de forças que atuam em um volume permeável finito completamente saturado com fluxo constante unidirecional de um fluido incompressível. A transformação da equação $2.4 \mathrm{em}$ uma formulação diferencial pode ser realizada heuristicamente ou formulável através da ponderação de volume, por exemplo, em Bear (1990).

Uma extensão heurística do modelo de Hazen-Dupuit-Darcy, na fórmula diferencial, para fluxo multidimensional foi apresentada por Stanek (1974). Knupp (1995) também estendeu o modelo considerando a permeabilidade como um tensor para um meio anisotrópico.

Brinkman (1947a) estudou a limitação da equação de Hazen-Darcy com relação à tensão de cisalhamento viscosa causada pelas superfícies de um meio permeável em um elemento de volume adjacente de fluido. Brinkman sugeriu uma modificação adicionando simplesmente o termo Laplaciano na equação Hazen-Darcy considerando a equação tridimensional como mostrado na equação 2.6 .

$$
0=\nabla p-\frac{\mu}{K} U+\mu \nabla^{2} U+\rho g
$$

Fazendo isso, a nova equação suportaria um fluxo através de um meio poroso de alta permeabilidade. Brinkman reconheceu a origem física diferente de cada termo viscoso, isto é, a tensão de cisalhamento viscoso do fluido, e o arrasto viscoso imposto pelo meio poroso. Ele percebeu que o efeito da tensão de cisalhamento viscosa do fluido deve se tornar desprezível quando comparada com o arrasto viscoso quando a permeabilidade for pequena.

Seguindo o raciocínio por Brinkman, pode-se substituir a equação 2.6 em fórmula multidimensional e diferencial, para obter a equação de BrinkmanHazen-Dupuit-Darcy, equação 2.7, onde $\phi$ é a porosidade do meio e $\mu_{e}$ a viscosidade efetiva. Uma contribuição fundamental de Brinkman é o reconhecimento da capacidade do fluido de transmitir força por cisalhamento viscoso de maneira indepedente ao arrasto viscoso.

$$
0=\nabla(\phi p)+\mu_{e} \nabla^{2} U-\frac{\mu}{K} U+C \rho \phi^{2}|U| U+\rho \phi g
$$


Hsu (1990) usou a ideia da viscosidade efetiva de Brinkman, e agrupou as forças que atuam na fase de fluido do meio permeável em forças viscosas efetivas e de forma, usando o modelo de Hazen-Dupuit-Darcy com a sugestão de Ward. A equação final equivalente para fluido incompressível é uma extensão da equação 2.7 com o termo inércia incluído.

$$
\rho\left[\frac{\partial U}{\partial t}+U \cdot \nabla U\right]=\nabla(\phi p)+\mu_{e} \nabla^{2} U-\frac{\mu}{K} U+C \rho \phi^{2}|U| U+\rho \phi g
$$

Observa-se que a equação 2.8 tem seis propriedades físicas: densidade do fluido $\rho$, viscosidade dinâmica fluida $\mu$, viscosidade efetiva $\mu_{e}$, permeabilidade $K$, porosidade $\phi$ e coeficiente de forma $C$. Os parâmetros $\rho, \mu$ e $\phi$ podem ser medidos independentemente, mas os outros três, a saber, $\mu_{e}, K$, e $C$, dependem da geometria do meio permeável. Eles não podem ser medidos diretamente, nem calculados analiticamente, porque não existe modelo relacionando-os a quantidades mais básicas (mensuráveis) válidas para todos os meios porosos. Em princípio, estas quantidades devem ser obtidas combinando os resultados obtidos a partir da resolução da equação 2.8 com dados experimentais.

Givler (1994) estimou a viscosidade efetiva seguindo a determinação da permeabilidade e o coeficiente de forma a partir de medições globais experimentais.

O modelo clássico de Darcy deve ser aplicado apenas para escoamentos muito lentos. Outras modelagens foram propostas e derivadas de outros pontos de vista, por exemplo, através do processo de média de volume em Hassanizadeh (1980) ou através de teoria de mistura em Rajagopal (2007).

A teoria das misturas apresenta uma descrição conveniente do escoamento de fluidos através de meios porosos. Pode-se demonstrar que o modelo de Darcy pode ser obtido a partir da estrutura da teoria da mistura, fazendo uma série de suposições sobre o sólido e o fluido Munaf (1993). A teoria de mistura apresenta a equação de Darcy como uma aproximação para o equilíbrio de quantidade de movimento linear para o fluido. A equação de Darcy supõe que esta resistência de fricção é diretamente proporcional à velocidade relativa entre o fluido e o sólido poroso. A constante de proporcionalidade, comumente referida como o coeficiente de arrasto depende da viscosidade do fluido. Enquanto a equação de Darcy leva em conta a resistência de fricção ao fluxo do fluido, esta não leva em consideração outros efeitos importantes para o escoamento. A derivação da equação de Darcy pela teoria das misturas pode ser encontrada em vários artigos Bowen (1976), Atkin (1976), Rajagopal (World Scientific), Crochet (1967), Adkins (1963b), Adkins (1963a) e Green (1964). 
Outro caminho proposto para a modelagem do escoamento em meios porosos é através de conceitos estatísticos com o objetivo de provisionar um suporte teórico para a equação de Darcy. A maior parte deles usaram hipóteses constitutivas para o fechamento das equações encontradas. Vafai (1981), Whitaker (1986), Hsu (1990) e Whitaker (1996) apresentaram uma derivação analítica de uma equação geral para fluxo de fluido através de um meio poroso isotrópico, rígido e homogêneo. A técnica de ponderação de volume leva a um problema de fechamento, isto é, algumas das forças que atuam em um volume permeável representativo precisam ser modeladas. Whitaker (1986) derivou a equação de Darcy para o escoamento de um fluido incompressível em um meio poroso. Um refinado tratamento das equações de conservação de massa e de quantidade de movimento linear baseados no procedimento de média volumétrica foi apresentado por Altevogt (2003).

O processo de upscale a partir de média volumétricas em meios porosos é considerado por vários pesquisadores com o objetivo de obter as equações macroscópicas médias para o escoamento de um fluido em meios porosos. Como apresentado na literatura, Anderson (1967), Whitaker (1967), Slattery (1967), Whitaker (1973), Gray (1975), Miller (2005) e Gray (2013), entre outros autores desenvolveram teoremas para o método de teoria de média.

Até a presente data, muitos pesquisadores tem expandido os teoremas de média para diferentes aplicações em meios porosos como por exemplo Gray (1989), Hassanizadeh (1989), Bennethum (2004), Miller (2005), Gray (2009), Jackson (2012), Gray (2013) e Wang (2015).

Alguns autores utilizam a velocidade superficial nas equações de conservação para escoamento em meios porosos como Ni (1991), Ganesan (1991),Hsu (1990), Whitaker (1973). A velocidade real também é utilizada para descrever as equações de conservação na literatura como em Whitaker (1986), Yang (2013) e Smit (2011).

Vários autores tem apresentado a importância da contabilização dos termos adicionais da equação completa para o escoamento de fluido em meios porosos. A modelagem de Darcy é bem definida para pequenos gradientes de pressão, sendo razoável que modelos diferentes precisem ser utilizados para aplicações ou processos diferentes, por exemplo, onde os gradientes de pressão são extremamente grandes. Uma aplicação de importância industrial, onde pressões altíssimas são utilizadas em meios porosos, é a recuperação avançada de petróleo Kovscek (2011) e Stauffer (2008).

O modelo clássico de Darcy não prevê um fluxo limitante para grandes pressões, na verdade, este prevê uma proporcionalidade entre fluxo e pressão. As armadilhas de usar um modelo clássico de Darcy foram demonstradas 
computacionalmente em Nakshatrala (2009), onde os autores propuseram um modelo de Darcy generalizado cujo coeficiente pode depender da pressão. Além disso, Nakshatrala (2009) mostra que para os casos estudados, o fluxo calculado pela equação de Darcy apresenta uma sobreprevisão.

Posteriormente, foi demonstrado em Srinivasan (2014) que o modelo de Darcy pode ser derivado a partir de uma equação completa através de considerações puramente termodinâmicas. Uma discussão detalhada das várias suposições impostas no desenvolvimento da equação de Brinkman e de Darcy podem ser encontradas no artigo Rajagopal (2007); Hubbert (n.d.).

Como mostrado em Rajagopal (2014), Srinivasan (2016c), Srinivasan (2016a), apenas a alteração do modelo de Brinkman (1947a) na equação de Darcy não é suficiente e não resulta numa relação não linear entre a queda de pressão e o fluxo, onde fluxo limite deve ser previsto.

Subramanian (2007) investigaram o fluxo de fluidos em altas pressões sob a suposição de que tanto a viscosidade como o "coeficiente de arrasto" dependiam da pressão. Eles encontraram vazões muito diferentes quando compararam as vazões previstas pelo modelo clássico de Darcy. Mais tarde, Kannan (2008) estudaram o fluxo de fluidos através de um meio poroso inclinado a altas pressões na presença dos efeitos da gravidade. Subramanian (2007) e Kannan (2008) não levam em consideração o termo transiente e convectivo na equação de movimento linear. Além disso, os escoamentos considerados nestes e em vários outros estudos ocorrem em um meio poroso onde o fluxo é unidirecional.

É importante reconhecer que os fluxos através de meios porosos são inerentemente transientes e, portanto, sendo necessário, em alguns casos, incluir o termo inercial. Além disso, os fluxos através de meios porosos não são unidimensionais à medida que os fluxos ocorrem através de poros tortuosos e, portanto, não se pode negligenciar o termo não-linear de inércia nesse contexto. Em Hill (2016a) o termo de inércia é considerado em um estudo de estabilidade de escoamentos utilizando a equação completa para escoamentos em meios porosos. Wood (2007) também apresentou a importância dos efeitos de inércia no escoamento e transporte de fluidos em meios porosos, onde esses devem ser considerados em várias aplicações práticas.

Outra limitação da aplicação da equação de Darcy é em meios porosos com cavidades conectadas por redes de fraturas. Os reservatórios de carbonato naturalmente fraturados são comumente encontrados em todo o mundo Dabbouk (2002), Khvatova (2012) e Peng (2009). A modelagem e a simulação numérica desses reservatórios são um problema desafiador devido à presença de vugs (cavidades de pequeno a médio porte) e de cavernas (cavidades de 
grandes dimensões) que normalmente são interligadas por fraturas naturais. Os vugs e cavernas são encontrados em tamanhos variando de um centímetro a vários metros Huang (2010b), Peng (2009) e Zhang (2004).

Várias abordagens contínuas foram desenvolvidas para a modelagem do fluxo de fluidos em reservatórios de carbonatos naturalmente fraturados. Métodos baseados no modelo conceitual de múltiplas fraturas e vugs como meios porosos com altos valores de permeabilidade foram propostos em Abdassah (1986), Camacho (1986), Kang (2006), Wu (2006) e Wu (2007).

Outra abordagem contínua que modela o meio poroso como uma combinação entre a rocha, fraturas e cavidades é apresentada em Wu (2013), Sitharam (2001), Oda (1986). Esses autores utilizam a porosidade e permeabilidade efetivas para aproximar o comportamento de armazenamento e transporte de fluidos nos reservatórios de fraturados e com vugs.

Outra abordagem para a modelagem do fluxo de fluidos em reservatórios de carbonatos fraturados é baseada sistema Darcy-Stokes Arbogast (2007), Arbogast (2006) e Yao (2010). O sistema Darcy-Stokes consiste no cálculo de escoamento livre nas cavidades e fraturas modelado pela equação de Stokes e o cálculo do fluxo de fluido em meios porosos pela Lei de Darcy.

A equação de Brinkman (1947a) fornece uma abordagem unificada que evita alguns dos problemas encontrados no sistema Darcy-Stokes. Esta abordagem é unificada no sentido de que utiliza uma única equação em vez de um sistema acoplado para descrever o fluxo de fluido em todo o reservatório de carbonato fraturado. Gulbransen (2009) e Popov (2007) mostram que a equação de Brinkman permite uma transição perfeita entre os vugs e os meios porosos, evitando uma modelagem explícita da interface.

Muitos trabalhos em simulação de reservatório são dedicados a formulação numérica e a solução da equação de Stokes-Brinkman, como por exemplo em Gulbransen (2009), Popov (2007), Popov (2009), Qin (2011), (Ingeborg, 2010), Bi (2009), Laptev (2003), Gulbransen (2009), Popov (2007), mas todos eles consideram apenas o fluxo em regime estacionário e são aplicados em simulações 2D. He (2015) propôs um modelo de fluxo transiente monofásico para o transporte de fluidos em reservatórios de carbonatos naturalmente fraturados.

Mesmo nos mais recentes artigos, quer seja aplicados à simulação de reservatórios de carbonatos ou avaliando a modelagem através da importância dos termos adicionais da equação de quantidade de movimento linear em meios porosos, ainda encontra-se uma lacuna que o presente trabalho pretende colaborar. A contabilização na equação de quantidade de movimento linear dos termos transiente, de inércia, de dilatação e de cisalhamento em meios porosos é realizada, a qual não encontra-se disponível, assim como a aplicação 
da mesma em meios porosos altamente heterogêneos. A implementação de tais termos possibilitou a avaliação de fluidos levemente compressíveis no presente trabalho. As equações foram implementadas de tal forma que os novos solvers não se limitam a tais hipóteses de fluidos, ou seja, os escoamentos de gás e fluidos com maiores compressibilidades também podem ser simulados. A comparação da previsão das vazões entre o presente modelo e a equação clássica de Darcy também contribui para uma reflexão e avaliação da utilização da equação de Darcy em meios porosos altamente heterogêneos como por exemplo em reservatórios de carbonatos. 


\section{3}

\section{Teoria de Média}

Um meio poroso possui uma geometria complexa, envolvendo diferentes escalas, conforme ilustrado na figura 3.1. A escala do domínio de interesse é $L$, no entanto, a escala característica do poro, por onde o fluido escoa é $l_{\beta}$. A ordem de grandeza do comprimento típico do fluxo microscópico em uma rocha porosa é inferior a milímetros, enquanto a magnitude da escala macroscópica do reservatório é de quilometros. O desafio da modelagem do escoamento de fluidos em meios porosos é evidente já que a estrutura geométrica das interfaces entre fluido e meio poroso é indeterminada, devido sua complexa e aleatória estrutura. É preciso saber distinguir as propriedades microscópicas e macroscópicas definidas para cada material individualmente, a fim de chegar a uma descrição satisfatória do comportamento do escoamento.

Para a descrição do escoamento de fluidos na escala de poro, é necessário conhecer os detalhes da estrutura porosa. Apesar do crescente desenvolvimento

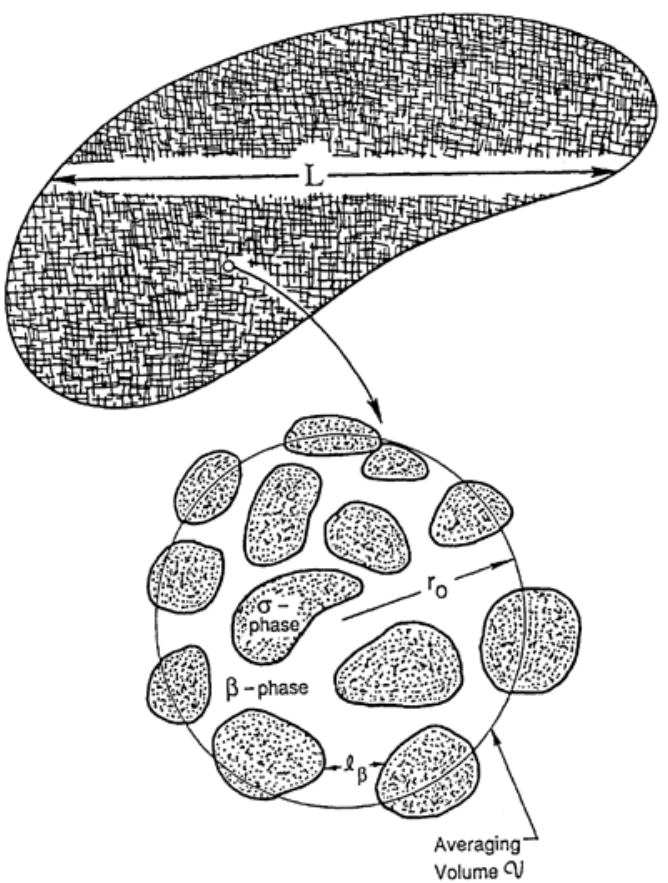

Figura 3.1: Diferentes escalas do problema de escoamento em meios porosos. Figura retirada de Whitaker (1996). 
da área computacional, tal nível de detalhe é limitado a domínios muito pequenos e consequentemente, muito caro computacionalmente para simulações em grandes áreas. Uma alternativa possível para estudar os fenômenos de transporte em meios porosos é através da modelagem do comportamento médio do sistema considerando modelos macroscópicos. Estes modelos podem ser obtidos aplicando um método matemático de alteração de escala ao problema físico na pequena escala.

Para a realização do procedimentos de média é essencial que os elementos de volume e superfície considerados sejam suficientemente grandes para garantir procedimentos de média sem demasiada dispersão. Ao mesmo tempo, os elementos precisam ser escolhidos suficientemente pequenos para representar as dependências locais das quantidades médias.

A definição de um comprimento característico para cada escala do problema é fundamental para o processo de mudança de escala. O comprimento característico da macro-escala $L$ é a dimensão do reservatório de interesse, já a escala característica da micro-escala, $l_{\beta}$ é a menor escala a partir da qual um sistema pode ser visto como um processo contínuo.

Conforme ilustrado na figura 3.1, na escala macroscópica o comportamento médio de um elemento volumétrico de meio poroso é um ponto do domínio. Os detalhes da estrutura porosa dentro do volume médio são desprezados, e as informações na escala de poro devem ser repassadas para o domínio maior.

As medições experimentais em laboratório, ou cálculo de vazões e queda de pressão em meios porosos geralmente correspondem a escala macroscópica. Logo, é importante ressaltar que a previsão da vazão e da queda de pressão ou de qualquer outra variável em um problema de escoamento em meios porosos é tão boa quanto a modelagem macroscópica aplicada ao problema.

Uma informação relevante para o processo de alteração de escala é que os comprimentos característicos das duas escalas, $l_{\beta}$ e $L$, diferem geralmente por várias ordens de grandeza, i.e.,

$$
L \gg l_{\beta}
$$

Esta diferença na ordem de grandeza das dimensões características da macro e micro escala do meio poroso, permite introduzir simplificações na modelagem do meio, através de simplificações das equações de conservação.

Nas seções seguintes diversas definições são introduzidas para que o processo de média possa ser aplicado nas equações microscópicas de forma a gerar equações que descrevam o comportamento médio do escoamento na escala macroscópica. 


\section{1}

\section{Volume Elementar Representativo}

A escolha de um elemento de volume representativo do meio poroso é essencial para o processo de média, o qual deve ser específico para a geometria do meio e os fenômenos que querem ser estudados. A figura 3.2 apresenta o elemento volumétrico representativo (REV) como uma esfera de raio $r_{0}$. O centro desta esfera é identificado pelo vetor $\mathbf{X}$ definido na escala maior pelo sistema de coordenadas.

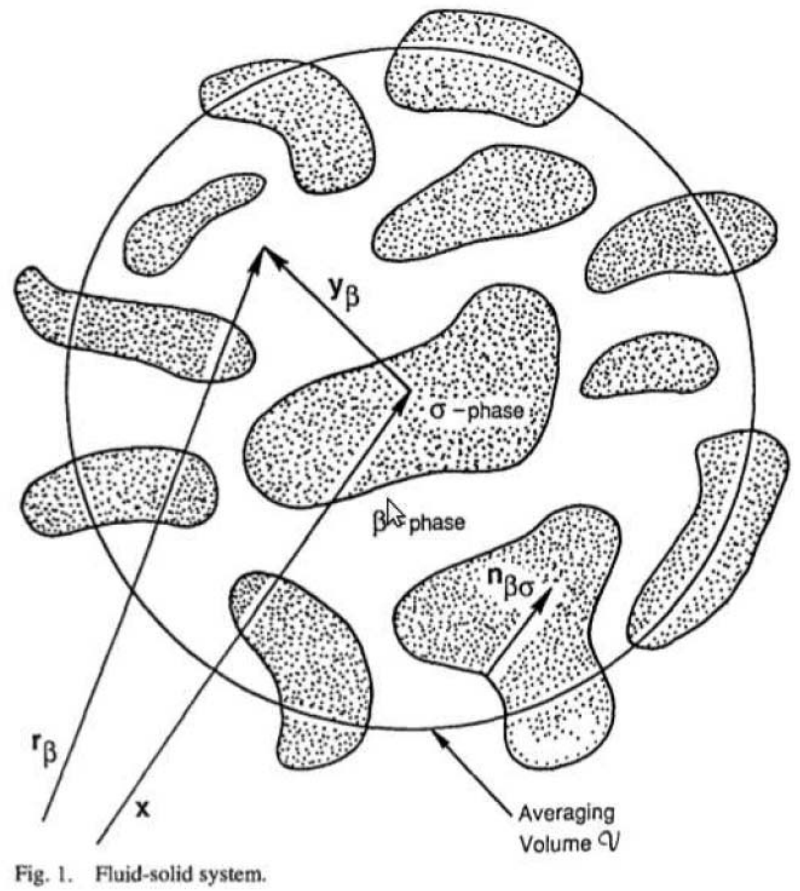

Figura 3.2: Volume elementar representativo. Figura retirada de Whitaker (1996).

A posição de um ponto qualquer dentro do volume pode ser determinado de duas formas diferentes: através do referencial global pelo vetor $r_{\beta}$ ou por um vetor $y_{\beta}$ expressado em um sistema de coordenadas cuja origem é o centro do REV. As variáveis macroscópicas são expressas no sistema de coordenadas global, e são definidas a partir da integração de campos microscópicos no volume REV.

Para caracterizar o meio poroso, é conveniente introduzir os conceitos de fração volumétrica e porosidade. A definição dessas grandezas é baseada na utilização de uma função indicadora da fase, a qual é igual a 1 na região do meio poroso ocupado pelo fluido e zero na região sólida, de acordo com 


$$
\gamma_{\beta}(r)=\left\{\begin{array}{lll}
1, & \text { se } & r \in \forall_{\beta} \\
0, & \text { se } & r \notin \forall_{\beta}
\end{array}\right.
$$

onde $\forall_{\beta}$, corresponde ao volume ocupado pelo fluido (fase $\beta$ ) no interior do volume representativo $\forall$. A fração do volume da fase $\beta$, isto é, a fração do volume ocupado pela fase fluida no volume total do REV é definido por

$$
\phi=\frac{1}{\forall} \int_{\forall} \gamma_{\beta} d \forall=\frac{\forall_{\beta}}{\forall}
$$

Para um fluxo monofásico, esta fração volumétrica é a fração de vazio no REV e, por conseguinte, representa a porosidade do meio poroso. Apesar de não ser uma restrição da metodologia a ser apresentada neste trabalho, para facilitar a análise, considerou-se escoamento monofásico através do meio poroso.

\section{2}

\section{Definições das Médias}

Os campos e propriedades macroscópicas do problema de maior escala, devem ser obtidos a partir de médias de campos e propriedades microscópicas no volume elementar representativo, através da utilização do método de alteração de escala.

Definindo um campo microscópico tensorial $\psi$ de uma variável física qualquer associado a fase $\beta$, pode-se definir dois tipos de médias: média superficial e média intrínseca da fase.

A média superficial denotada por \langle\rangle , corresponde ao valor médio de $\psi$, se todo o volume fosse ocupado pela fase $\beta$, i.e.,

$$
\langle\psi\rangle=\frac{1}{\forall} \int_{\forall_{\beta}} \psi d \forall
$$

Note que a média superfícial de 1 pode ser obtida se substituirmos $\psi=1$ na equação 3.4, resultando na seguinte definição alternativa da porosidade

$$
\langle 1\rangle=\frac{1}{\forall} \int_{\forall_{\beta}} 1 d \forall=\frac{\forall_{\beta}}{\forall}=\phi
$$

A média intrínseca do campo tensorial $\psi$ na fase $\beta$ é designada por \langle\rangle$^{\beta}$. Neste caso, a média é ponderada pelo volume ocupado pela fase fluido $\forall_{\beta}$ do 
REV

$$
\langle\psi\rangle^{\beta}=\frac{1}{\forall_{\beta}} \int_{\forall_{\beta}} \psi d \forall
$$

Essas duas médias são relacionadas através da porosidade, $\phi$, por:

$$
\langle\psi\rangle=\phi\langle\psi\rangle^{\beta}
$$

\subsection{1}

\section{Decomposição do Campo em Macroscópico e Microscópico}

Como parte do procedimento de aplicação da média volumétrica, um campo tensorial de qualquer ordem $\psi$ pode ser decomposto em um valor médio e um desvio, denotado por $\widetilde{\psi}$. A abordagem é semelhante a utilizada na análise de escoamentos turbulentos em que uma variável é decomposta em uma média e uma flutuação no tempo. Utilizando a decomposição:

$$
\psi=\langle\psi\rangle^{\beta}+\widetilde{\psi}
$$

Esta decomposição é ilustrada na figura 3.3.

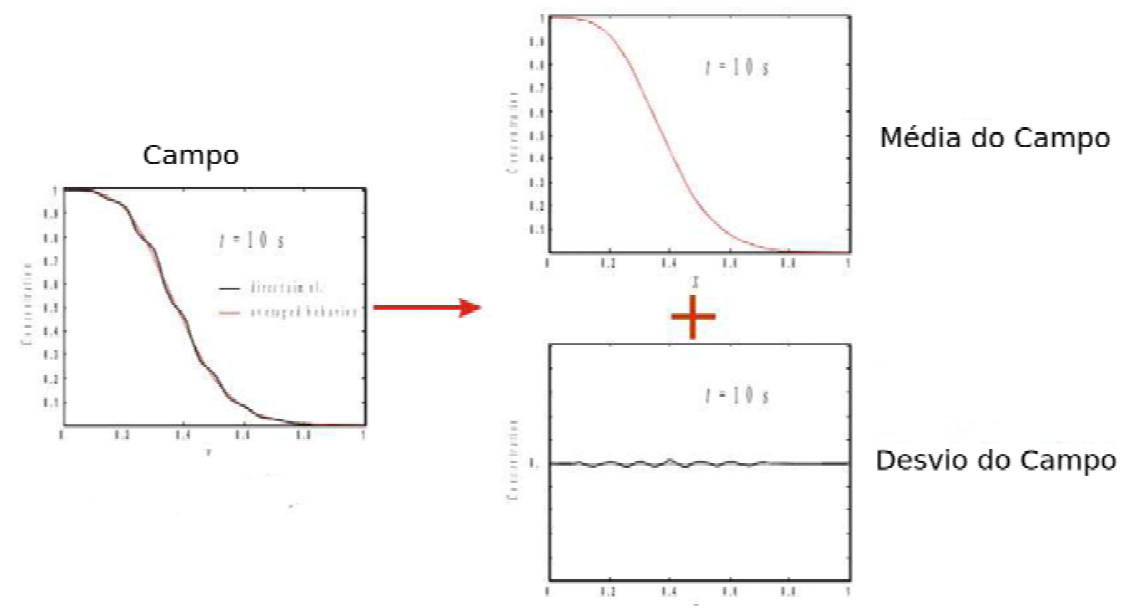

Figura 3.3: Exemplo didático para a decomposição de um campo em um valor médio e sua flutuação. Figura retirada de Soulaine (2012).

Para que a relação dada pela equação 3.8 seja consistente, a seguinte aproximação deve ser satisfeita (Whitaker, 1967, 1996, 1999). 


$$
\langle\widetilde{\psi}\rangle^{\beta}=0
$$

\section{3}

\section{Teoremas Relacionados ao Método de Alteração de Escala}

O primeiro passo para a aplicação do método de alteração de escala é a aplicação do operador média \langle\rangle nas equações diferenciais do problema da pequena escala. Esse processo tem como objetivo final a obtenção da equação diferencial macroscópica do modelo. A aplicação do operador em uma função $\psi_{\beta}$ é simples, mas sua aplicação é mais complicada no que se refere as suas derivadas espaciais e temporais, sendo apresentada a seguir.

\subsection{1}

\section{Teorema Temporal}

A média de operadores temporais pode ser obtida considerando as interfaces do meio poroso sendo estáticas, logo, a média superficial do termo transiente é a derivada temporal da média superficial:

$$
\left\langle\frac{\partial \psi}{\partial t}\right\rangle=\frac{\partial\langle\psi\rangle}{\partial t}
$$

\subsection{2}

\section{Teorema Espacial}

Para avaliar a média de operadores espaciais, é necessário considerar efeitos interfaciais entre o fluido e matriz sólida, como resultado, frequentemente, o gradiente do campo médio é diferente da média do gradiente do campo (Marle, 1965; Gray, 1993; Quintard, 1994a). A inversão do operador média supercicial $\langle>$ nos operadores gradiente e divergente deve ser realizada pelas equações 3.11 e 3.12 .

$$
\begin{gathered}
\langle\nabla \psi\rangle=\nabla\langle\psi\rangle+\frac{1}{\forall} \int_{A_{i}} \psi \mathbf{n} d S \\
\langle\nabla \cdot \psi\rangle=\nabla \cdot\langle\psi\rangle+\frac{1}{\forall} \int_{A_{i}} \psi \cdot \mathbf{n} d S
\end{gathered}
$$


onde $A_{i}$ é a área interfacial sólido-fluido e $\mathbf{n}$ é o vetor normal orientado para fora do fluido em direção a fase sólida. A integral avalia o campo na grande escala. Existem várias provas deste teorema na literatura, alguns começam a partir do teorema de Gauss, como por exemplo em Howes (1985) e outros usam a teoria de distribuição de Schwartz como Quintard (1994c).

\subsection{3}

\section{Relações Importantes}

Aplicando o teorema espacial, equação 3.11, para $\psi=1$, e utilizando a equação 3.5, obtém-se o gradiente da porosidade, o qual é não nulo

$$
\nabla \phi=-\frac{1}{\forall} \int_{A_{i}} \mathbf{n} d S \neq 0
$$

Esta relação é de grande utilidade nesse procedimento matemático de alteração de escala, permitindo simplificar as equações macroscópicas.

Outra relação útil no processo de alteração de escalas é a determinação da média do gradiente de campos de flutuações. Aplicando a equação $3.11 \mathrm{em}$ um campo de flutuações

$$
\langle\nabla \widetilde{\psi}\rangle=\nabla\langle\widetilde{\psi}\rangle+\frac{1}{\forall} \int_{A_{i}} \widetilde{\psi} \mathbf{n} d S
$$

e lembrando que a média de flutuações é nula, equação 3.9, tem-se

$$
\langle\nabla \widetilde{\psi}\rangle=\frac{1}{\forall} \int_{A_{i}} \widetilde{\psi} \mathbf{n} d S
$$

A alteração da ordem do operador média intrínseca com operadores espaciais pode ser obtida, utilizando a relação dada pela equação 3.7, juntamente com a Eq. 3.13 e aplicando na equação 3.11

$$
\langle\nabla \psi\rangle^{\beta}=\nabla\langle\psi\rangle^{\beta}+\frac{1}{\forall} \int_{A_{i}} \widetilde{\psi} \mathbf{n} d S
$$

A média de um produto de campos locais $\beta_{\beta}$ e $\psi_{\beta}$, não é o produto das médias destas funções devendo ser obtida com

$$
\left\langle\psi_{\beta} \beta_{\beta}\right\rangle=\phi\left\langle\psi_{\beta}\right\rangle^{\beta}\left\langle\beta_{\beta}\right\rangle^{\beta}+\left\langle\widetilde{\psi}_{\beta} \widetilde{\beta}_{\beta}\right\rangle
$$


A média do produto das flutuações que aparece nesta relação nem sempre é insignificante. Um exemplo é o termo que reflete a dispersão generalizada no caso de transporte de um composto químico em um meio poroso (Quintard, 1994b).

Da mesma forma, estima-se a média do produto de um campo $\beta_{\beta}$ e da derivada espacial de um campo $\psi_{\beta}$ com:

$$
\left\langle\beta_{\beta} \nabla \psi_{\beta}\right\rangle=\phi\left\langle\beta_{\beta}\right\rangle^{\beta} \nabla\left\langle\psi_{\beta}\right\rangle^{\beta}+\left\langle\widetilde{\beta}_{\beta} \nabla \widetilde{\psi}_{\beta}\right\rangle+\frac{1}{\forall} \int_{A_{i}}\left\langle\beta_{\beta}\right\rangle^{\beta} \widetilde{\psi} \mathbf{n} d S
$$

\section{4}

\section{Processo de Alteração de Escala}

O método de alteração de escala (upscale) (Whitaker, 1999) através da média de volume visa encontrar equações macroscópicas correspondentes a um problema definido em uma escala menor. O procedimento do método é feito em vários passos. O procedimento aqui descrito é utilizado na maioria dos artigos da literatura.

\subsection{1}

\section{Equações Microscópicas}

Após a definição da pequena escala e do volume REV, o primeiro passo do processo de mudança de escala é a definição do problema matemático que governa o fenômeno que se pretende estudar. Especial atenção deve ser dada à escolha das condições de contorno, porque estas determinam a forma do modelo macroscópico.

O presente desenvolvimento considera escoamento monofásico compressível de um fluido Newtoniano em um meio poroso saturado. Considera-se ainda que as escalas do domínio microscópico são suficientemente pequenos para que o escoamento possa ser governado pelas equações de Navier-Stokes.

A equação da conservação de massa microscópica para a fase $\beta$ é

$$
\frac{\partial \rho_{\beta}}{\partial t}+\nabla \cdot\left(\rho_{\beta} \mathbf{v}_{\beta}\right)=0
$$

onde o subscrito $\beta$ refere-se a propriedade do fluido no interior do poro. $\rho$ é a massa específica e $\mathbf{v}$ é o vetor velocidade.

A equação da conservação da quantidade de movimento linear para o fluido no interior do poro é 


$$
\begin{array}{r}
\frac{\partial\left(\rho_{\beta} \mathbf{v}_{\beta}\right)}{\partial t}+\nabla \cdot\left(\rho_{\beta} \mathbf{v}_{\beta} \mathbf{v}_{\beta}\right) \\
=-\nabla p+\rho_{\beta} \mathbf{g}+\nabla \cdot\left[\mu_{\beta}\left(\nabla \mathbf{v}_{\beta}+\nabla \mathbf{v}_{\beta}^{\mathbf{T}}\right)\right]+\nabla\left(\lambda_{\beta} \nabla \cdot \mathbf{v}_{\beta}\right)=\mathbf{0}
\end{array}
$$

onde $p$ é a pressao, $\mu$ e $\lambda$ correspondem ao primeiro e segundo coeficiente da viscosidade, respectivamente, e $\mathbf{g}$ é vetor aceleração da gravidade. No presente trabalho, utilizou-se o valor de $\lambda=-2 / 3 \mu$ para o segundo coeficiente de viscosidade (Bird, n.d.).

A condição de contorno necessária para a solução destas equações acopladas é de não deslizamento nas fronteiras do poro, i.e,

$$
\mathbf{v}_{\beta}=0 \quad \text { em } A_{\beta \sigma}
$$

3.4.2

\section{Aplicação da Média na Pequena Escala}

O segundo passo consiste na aplicação da média considerando um volume de controle representativo nas equações diferenciais que governam o sistema na pequena escala, aplicando o operador média \langle\rangle .

O processo físico sob consideração é de um único fluido newtoniano, compressível que escoa em um meio poroso rígido, como ilustrado na figura 3.1. A seguir a média superficial é aplicada às equações de conservação.

\subsection{3}

\section{Equação da Conservação de Massa}

Aplicando o processo de média na equação da continuidade, equação 3.19, tem-se:

$$
\left\langle\frac{\partial \rho_{\beta}}{\partial t}\right\rangle+\left\langle\nabla \cdot\left(\rho_{\beta} \mathbf{v}_{\beta}\right)\right\rangle=\frac{\partial\left\langle\rho_{\beta}\right\rangle}{\partial t}+\nabla \cdot\left\langle\rho_{\beta} \mathbf{v}_{\beta}\right\rangle+\frac{1}{\forall} \int_{A_{i}} \mathbf{v}_{\beta} \cdot \mathbf{n} d S=0
$$

Uma vez que a fase sólida é impermeável, o último termo da equação anterior é nulo, e a equação da continuidade usando a média superficial se torna

$$
\frac{\partial\left\langle\rho_{\beta}\right\rangle}{\partial t}+\nabla \cdot\left\langle\rho_{\beta} \mathbf{v}_{\beta}\right\rangle=0
$$


A equação da continuidade baseada na média intrínseca pode ser obtida combinando a decomposição em valor médio e perturbação, equação3.8, com as relações de médias, equação 3.7, com as limitações de escala $l \ll R \ll L$ e utilizando relações termodinâmicas (Whitaker, 1986).

A parcela não linear pode ser escrita como

$$
\rho_{\beta} \mathbf{v}_{\beta}=\left\langle\rho_{\beta}\right\rangle^{\beta}\left\langle\mathbf{v}_{\beta}\right\rangle^{\beta}+\left\langle\rho_{\beta}\right\rangle^{\beta} \widetilde{\mathbf{v}}_{\beta}+\widetilde{\rho}_{\beta}\left\langle\widetilde{\mathbf{v}}_{\beta}\right\rangle^{\beta}+\widetilde{\rho}_{\beta} \widetilde{\mathbf{v}}_{\beta}
$$

Aplicando a média:

$$
\left\langle\rho_{\beta} \mathbf{v}_{\beta}\right\rangle=\left\langle\left\langle\rho_{\beta}\right\rangle^{\beta}\left\langle\mathbf{v}_{\beta}\right\rangle^{\beta}\right\rangle+\left\langle\widetilde{\rho}_{\beta} \widetilde{\mathbf{v}}_{\beta}\right\rangle=\phi\left\langle\rho_{\beta}\right\rangle^{\beta}\left\langle\mathbf{v}_{\beta}\right\rangle^{\beta}+\left\langle\widetilde{\rho}_{\beta} \widetilde{\mathbf{v}}_{\beta}\right\rangle
$$

Substituindo os termos desenvolvidos na equação da continuidade, obtém-se a seguinte equação macroscópica de conservação de massa:

$$
\frac{\partial\left(\phi\left\langle\rho_{\beta}\right\rangle^{\beta}\right)}{\partial t}+\nabla \cdot\left[\phi\left\langle\rho_{\beta}\right\rangle^{\beta}\left\langle\mathbf{v}_{\beta}\right\rangle^{\beta}\right]+\nabla \cdot\left[\left\langle\widetilde{\rho}_{\beta} \widetilde{\mathbf{v}}_{\beta}\right\rangle\right]=0
$$

\subsection{4}

\section{Equação da Conservação da Quantidade de Movimento Linear}

O mesmo procedimento aplicado na conservação da massa será repetido para a equação da conservação de quantidade de movimento linear considerando um único fluido newtoniano, compressível escoando através dos poros de um meio poroso.

Avaliando inicialmente a média no termo de aceleração na conservação do movimento linear, lado esquerdo da equação 3.20 tem-se

$$
\begin{array}{r}
\left\langle\frac{\partial\left(\rho_{\beta} \mathbf{v}_{\beta}\right)}{\partial t}\right\rangle+\left\langle\nabla \cdot\left(\rho_{\beta} \mathbf{v}_{\beta} \mathbf{v}_{\beta}\right)\right\rangle= \\
\frac{\partial\left\langle\rho_{\beta} \mathbf{v}_{\beta}\right\rangle}{\partial t}+\frac{\partial\left(\phi\left\langle\rho_{\beta}\right\rangle^{\beta}\left\langle\mathbf{v}_{\beta}\right\rangle^{\beta}\right)}{\partial t}+\frac{\partial\left\langle\widetilde{\rho}_{\beta} \widetilde{\mathbf{v}}_{\beta}\right\rangle}{\partial t}+\nabla \cdot\left\langle\rho_{\beta} \mathbf{v}_{\beta} \mathbf{v}_{\beta}\right\rangle+\frac{1}{\forall} \int_{A_{i}} \rho_{\beta} \mathbf{v}_{\beta} \mathbf{v}_{\beta} \cdot \mathbf{n} d S
\end{array}
$$

Como as velocidades na parede da rocha são zero, o último termo da equação anterior é nulo. Para avaliar a média do produto triplo, vamos introduzir a definição de uma variável auxiliar para facilitar o desenvolvimento: $\psi_{\beta}=\mathbf{v}_{\beta} \mathbf{v}_{\beta}$, sendo a média de $\psi_{\beta}$ igual a $\left\langle\psi_{\beta}\right\rangle=\phi\left\langle\mathbf{v}_{\beta}\right\rangle^{\beta}\left\langle\mathbf{v}_{\beta}\right\rangle^{\beta}+\left\langle\widetilde{\mathbf{v}}_{\beta} \widetilde{\mathbf{v}}_{\beta}\right\rangle$. Aplicando a equação 3.17 e 3.7 no produto triplo tem-se: 


$$
\begin{array}{r}
\left\langle\rho_{\beta} \psi_{\beta}\right\rangle=\phi\left\langle\psi_{\beta}\right\rangle^{\beta}\left\langle\rho_{\beta}\right\rangle^{\beta}+\left\langle\widetilde{\psi}_{\beta} \widetilde{\rho}_{\beta}\right\rangle=\left\langle\psi_{\beta}\right\rangle\left\langle\rho_{\beta}\right\rangle^{\beta}+\left\langle\widetilde{\psi}_{\beta} \widetilde{\rho}_{\beta}\right\rangle= \\
\phi\left\langle\rho_{\beta}\right\rangle^{\beta}\left\langle\mathbf{v}_{\beta}\right\rangle^{\beta}\left\langle\mathbf{v}_{\beta}\right\rangle^{\beta}+\left\langle\rho_{\beta}\right\rangle^{\beta}\left\langle\widetilde{\mathbf{v}}_{\beta} \widetilde{\mathbf{v}}_{\beta}\right\rangle+\left\langle\widetilde{\rho}_{\beta} \widetilde{\mathbf{v}_{\beta} \mathbf{v}_{\beta}}\right\rangle
\end{array}
$$

Logo, a média do termo de aceleração é:

$$
\frac{\partial\left(\phi\left\langle\rho_{\beta}\right\rangle^{\beta}\left\langle\mathbf{v}_{\beta}\right\rangle^{\beta}\right)}{\partial t}+\nabla \cdot\left[\phi\left\langle\rho_{\beta}\right\rangle^{\beta}\left\langle\mathbf{v}_{\beta}\right\rangle^{\beta}\left\langle\mathbf{v}_{\beta}\right\rangle^{\beta}\right]+\mathbf{A}_{\mathbf{1}}+\mathbf{A}_{\mathbf{2}}+\mathbf{A}_{\mathbf{3}}
$$

onde $\mathbf{A}_{1}, \mathbf{A}_{2}$ e $\mathbf{A}_{3}$ são

$$
\begin{gathered}
\mathbf{A}_{\mathbf{1}}=\frac{\partial\left\langle\widetilde{\rho}_{\beta} \widetilde{\mathbf{v}}_{\beta}\right\rangle}{\partial t} \\
\mathbf{A}_{\mathbf{2}}=\nabla \cdot\left[\left\langle\rho_{\beta}\right\rangle^{\beta}\left\langle\widetilde{\mathbf{v}}_{\beta} \widetilde{\mathbf{v}}_{\beta}\right\rangle\right] \\
\mathbf{A}_{\mathbf{3}}=\nabla \cdot\left[\left\langle\widetilde{\rho}_{\beta} \widetilde{\mathbf{v}_{\beta} \mathbf{v}_{\beta}}\right\rangle\right]
\end{gathered}
$$

Vamos avaliar agora a média dos termos de força da equação de quantidade de movimento linear, equação 3.20, i.e., lado direito da equação.

Aplicando o teorema espacial, equação 3.11 no termo de força de pressão, lembrando que a pressão pode ser decomposta em $p=\langle p\rangle^{\beta}+\widetilde{p}$, de acordo com a decomposição dada pela equação 3.8 e aplicando a equação 3.9 que relaciona média superficial com a intrísica, tem-se

$$
\langle\nabla p\rangle=\nabla\langle p\rangle+\frac{1}{\forall} \int_{A_{i}} p \mathbf{n} d S=\nabla\left(\phi\langle p\rangle^{\beta}\right)+\frac{1}{\forall} \int_{A_{i}}\langle p\rangle^{\beta} \mathbf{n} d S+\frac{1}{\forall} \int_{A_{i}} \tilde{p} \mathbf{n} d S
$$

Expandindo o gradiente do produto, utilizando a definição de gradiente da porosidade, equação 3.13, lembrando que $\langle p\rangle^{\beta}$ é constante na superfície do REV, podemos rescrever a média superficial da força de pressão como

$$
\langle\nabla p\rangle=\phi \nabla\langle p\rangle^{\beta}+\mathbf{P}_{\mathbf{1}}
$$

onde $\mathbf{P}_{1}$ : 


$$
\mathbf{P}_{\mathbf{1}}=\frac{1}{\forall} \int_{A_{i}} \tilde{p} \mathbf{n} d S
$$

O segundo termo de força de corpo é o termo gravitacional. A média superficial deste termo pode ser facilmente determinada, uma vez que a gravidade é constante, logo

$$
\left\langle\rho_{\beta} \mathbf{g}\right\rangle=\left\langle\rho_{\beta}\right\rangle \mathbf{g}=\phi\left\langle\rho_{\beta}\right\rangle^{\beta} \mathbf{g}
$$

Aplicando o teorema espacial, equação 3.11 no primeiro termo de força viscosa, tem-se

$$
\left\langle\nabla \cdot\left(\mu_{\beta} \nabla \mathbf{v}_{\beta}\right)\right\rangle=\nabla \cdot\left\langle\mu_{\beta} \nabla \mathbf{v}_{\beta}\right\rangle+\frac{1}{\forall} \int_{A_{i}} \mu_{\beta} \nabla \mathbf{v}_{\beta} \cdot \mathbf{n} d S
$$

O desenvolvimento do termo $\left\langle\mu_{\beta} \nabla \mathbf{v}_{\beta}\right\rangle$ pode ser feito usando a equação 3.18:

$$
\left\langle\mu_{\beta} \nabla \mathbf{v}_{\beta}\right\rangle=\phi\left\langle\mu_{\beta}\right\rangle^{\beta} \nabla\left\langle\mathbf{v}_{\beta}\right\rangle^{\beta}+\left\langle\widetilde{\mu}_{\beta} \nabla \widetilde{\mathbf{v}}_{\beta}\right\rangle+\frac{1}{\forall} \int_{A_{i}}\left\langle\mu_{\beta}\right\rangle^{\beta} \widetilde{\mathbf{v}}_{\beta} \mathbf{n} d S
$$

A equação anterior pode ser simplificada, ao rescrevermos $\widetilde{\mu}_{\beta}=\mu_{\beta}-$ $\left\langle\mu_{\beta}\right\rangle^{\beta}$. Lembrando que um valor médio no volume não varia ao longo da área, utilizando o teorema espacial, equação 3.11 juntamente com a relação dada pela equação 3.15 , tem-se que o último termo da equação anterior se simplifica para $\left\langle\mu_{\beta}\right\rangle^{\beta}\left\langle\nabla \widetilde{\mathbf{v}}_{\beta}\right\rangle$, resultando em

$$
\begin{array}{r}
\left\langle\mu_{\beta} \nabla \mathbf{v}_{\beta}\right\rangle=\phi\left\langle\mu_{\beta}\right\rangle^{\beta} \nabla\left\langle\mathbf{v}_{\beta}\right\rangle^{\beta}+\left\langle\left(\mu_{\beta}-\left\langle\mu_{\beta}\right\rangle^{\beta}\right) \nabla \widetilde{\mathbf{v}}_{\beta}\right\rangle+\left\langle\mu_{\beta}\right\rangle^{\beta}\left\langle\nabla \widetilde{\mathbf{v}}_{\beta}\right\rangle= \\
\phi\left\langle\mu_{\beta}\right\rangle^{\beta} \nabla\left\langle\mathbf{v}_{\beta}\right\rangle^{\beta}+\left\langle\mu_{\beta} \nabla \widetilde{\mathbf{v}}_{\beta}\right\rangle
\end{array}
$$

O segundo termo do lado direito da equação 3.37 pode ser desenvolvido aplicando a equação 3.8 para o gradiente de velocidade e para a viscocidade $\mu_{\beta}$. Considerando que $\left\langle\mu_{\beta}\right\rangle^{\beta}$ e $\nabla\left\langle\mathbf{v}_{\beta}\right\rangle^{\beta}$ são constantes ao longo da integral de área, aplicando as relações dadas pelas equações. 3.13 e 3.15, tem-se 


$$
\begin{array}{r}
\frac{1}{\forall} \int_{A_{i}} \mu_{\beta} \nabla \mathbf{v}_{\beta} \cdot \mathbf{n} d S=\frac{1}{\forall} \int_{A_{i}}\left(\left\langle\mu_{\beta}\right\rangle^{\beta}+\widetilde{\mu}_{\beta}\right) \nabla\left\langle\mathbf{v}_{\beta}\right\rangle^{\beta} \cdot \mathbf{n} d S+ \\
\frac{1}{\forall} \int_{A_{i}} \mu_{\beta} \nabla \widetilde{\mathbf{v}}_{\beta} \cdot \mathbf{n} d S=-\left\langle\mu_{\beta}\right\rangle^{\beta} \nabla\left\langle\mathbf{v}_{\beta}\right\rangle^{\beta} \cdot \nabla \phi+ \\
\left\langle\nabla \widetilde{\mu}_{\beta}\right\rangle \cdot \nabla\left\langle\mathbf{v}_{\beta}\right\rangle^{\beta}+\frac{1}{\forall} \int_{A_{i}} \mu_{\beta} \nabla \widetilde{\mathbf{v}}_{\beta} \cdot \mathbf{n} d S
\end{array}
$$

Aplicando o divergente em $\left\langle\mu_{\beta} \nabla \mathbf{v}_{\beta}\right\rangle$, combinando com a integral da equação 3.37 e explandindo a derivada de produto, obtém-se o seguinte resultado para a média superficial do primeiro termo viscoso da equação 3.20

$$
\phi \nabla \cdot\left[\left\langle\mu_{\beta}\right\rangle^{\beta} \nabla\left\langle\mathbf{v}_{\beta}\right\rangle^{\beta}\right]+\nabla \cdot\left\langle\mu_{\beta} \nabla \widetilde{\mathbf{v}}_{\beta}\right\rangle+\left\langle\nabla \widetilde{\mu}_{\beta}\right\rangle \cdot \nabla\left\langle\mathbf{v}_{\beta}\right\rangle^{\beta}+\frac{1}{\forall} \int_{A_{i}} \mu_{\beta} \nabla \widetilde{\mathbf{v}}_{\beta} \cdot \mathbf{n} d S
$$

O mesmo processo pode ser aplicado ao segundo termo viscoso (difusivo) referente ao gradiente transposto da velocidade

$$
\begin{aligned}
& \left\langle\nabla \cdot\left[\mu_{\beta}\left(\nabla \mathbf{v}_{\beta}+\nabla \mathbf{v}_{\beta}^{\mathbf{T}}\right)\right]\right\rangle=\phi \nabla \cdot\left[\left\langle\mu_{\beta}\right\rangle^{\beta}\left(\left\langle\nabla \mathbf{v}_{\beta}\right\rangle^{\beta}+\left(\left\langle\nabla \mathbf{v}_{\beta}\right\rangle^{\beta}\right)^{\mathbf{T}}\right)\right]+\mathbf{D}_{\mathbf{1}}+\mathbf{D}_{\mathbf{2}}+\mathbf{D}_{\mathbf{3}} \\
& \text { onde } \mathbf{D}_{\mathbf{1}}, \mathbf{D}_{\mathbf{2}} \text { e } \mathbf{D}_{\mathbf{3}} \text { são }
\end{aligned}
$$

$$
\mathbf{D}_{\mathbf{3}}=\frac{1}{\forall} \int_{A_{i}}\left(\left\langle\mu_{\beta}\right\rangle^{\beta}+\widetilde{\mu}_{\beta}\right)\left(\nabla \widetilde{\mathbf{v}}_{\beta}+\nabla \widetilde{\mathbf{v}}_{\beta}^{T}\right) \cdot \mathbf{n} d S=\hat{\mathbf{D}}_{\mathbf{3}}+\widetilde{\mathbf{D}_{\mathbf{3}}}
$$

O último termo da equação 3.20 corresponde a contribuição viscosa associada ao segundo coeficiente de viscosidade $\lambda$, o qual só é relevante quando o fluido é compressível. Aplicando exatamente o mesmo procedimento detalhado para os termos viscosos associados com o primeiro coeficiente de viscosidade (viscosidade molecular), tem-se

$$
\left\langle\nabla\left(\lambda_{\beta} \nabla \cdot \mathbf{v}_{\beta}\right)\right\rangle=\phi \nabla\left[\left\langle\lambda_{\beta}\right\rangle^{\beta} \nabla \cdot\left\langle\mathbf{v}_{\beta}\right\rangle^{\beta}\right]+\mathbf{C}_{\mathbf{1}}+\mathbf{C}_{\mathbf{2}}+\mathbf{C}_{\mathbf{3}}
$$


onde $\mathbf{C}_{1}, \mathbf{C}_{2}$ e $\mathbf{C}_{3}$ são

$$
\begin{gathered}
\mathbf{C}_{\mathbf{1}}=\nabla\left\langle\lambda_{\beta} \nabla \cdot \widetilde{\mathbf{v}}_{\beta}\right\rangle \\
\mathbf{C}_{\mathbf{2}}=\left\langle\nabla \widetilde{\lambda}_{\beta}\right\rangle \nabla \cdot\left\langle\mathbf{v}_{\beta}\right\rangle^{\beta} \\
\mathbf{C}_{\mathbf{3}}=\frac{1}{\forall} \int_{A_{i}}\left(\left\langle\lambda_{\beta}\right\rangle^{\beta}+\widetilde{\lambda}_{\beta}\right) \nabla \cdot \widetilde{\mathbf{v}}_{\beta} \mathbf{n} d S=\hat{\mathbf{C}}_{\mathbf{3}}+\widetilde{\mathbf{C}_{\mathbf{3}}}
\end{gathered}
$$

Finalmente, substiuindo todos os termos médios desenvolvidos, obtém-se a seguinte equação macroscópica de conservação de quantidade de movimento linear

$$
\begin{array}{r}
\frac{\partial\left(\phi\left\langle\rho_{\beta}\right\rangle^{\beta}\left\langle\mathbf{v}_{\beta}\right\rangle^{\beta}\right)}{\partial t}+\nabla \cdot\left[\phi\left\langle\rho_{\beta}\right\rangle^{\beta}\left\langle\mathbf{v}_{\beta}\right\rangle^{\beta}\left\langle\mathbf{v}_{\beta}\right\rangle^{\beta}\right] \\
=-\phi \nabla\langle p\rangle^{\beta}+\phi\left\langle\rho_{\beta}\right\rangle^{\beta} \mathbf{g}+ \\
\phi \nabla \cdot\left[\left\langle\mu_{\beta}\right\rangle^{\beta}\left(\nabla\left\langle\mathbf{v}_{\beta}\right\rangle^{\beta}+\left(\nabla\left\langle\mathbf{v}_{\beta}\right\rangle^{\beta}\right)^{T}\right)\right]+\phi \nabla\left[\left\langle\lambda_{\beta}\right\rangle^{\beta} \nabla \cdot\left\langle\mathbf{v}_{\beta}\right\rangle^{\beta}\right] \\
-\left(\mathbf{A}_{\mathbf{1}}+\mathbf{A}_{\mathbf{2}}+\mathbf{A}_{\mathbf{3}}\right)+\mathbf{D}_{\mathbf{1}}+\mathbf{D}_{\mathbf{2}}+\mathbf{C}_{\mathbf{1}}+\mathbf{C}_{\mathbf{2}}+\widetilde{\mathbf{S}_{\mathbf{1}}}+\left\langle\mathbf{S}_{\mathbf{1}}\right\rangle^{\beta}
\end{array}
$$

onde $\left\langle\mathbf{S}_{\mathbf{1}}\right\rangle^{\beta}=\hat{\mathbf{D}}_{\mathbf{3}}+\hat{\mathbf{C}}_{\mathbf{3}}$ é referente aos valores médios $\left\langle\mu_{\beta}\right\rangle^{\beta}$ e $\left\langle\lambda_{\beta}\right\rangle^{\beta}$ e $\widetilde{\mathbf{S}_{1}}=-\mathbf{P}_{1}+\widetilde{\mathbf{D}}_{\mathbf{3}}+\widetilde{\mathbf{C}}_{\mathbf{3}}$ é associado com os termos flutuantes $\widetilde{\mu}_{\beta}$ e $\widetilde{\lambda}_{\beta}$.

$$
\begin{aligned}
\left\langle\mathbf{S}_{\mathbf{1}}\right\rangle^{\beta} & =\frac{1}{\forall} \int_{A_{i}}\left[\left\langle\mu_{\beta}\right\rangle^{\beta}\left(\nabla \widetilde{\mathbf{v}}_{\beta}+\nabla \widetilde{\mathbf{v}}_{\beta}^{T}\right)+\left\langle\lambda_{\beta}\right\rangle^{\beta} \nabla \cdot \widetilde{\mathbf{v}}_{\beta}\right] \mathbf{n} d S \\
\widetilde{\mathbf{S}_{\mathbf{1}}} & =\frac{1}{\forall} \int_{A_{i}}\left[-\widetilde{p} \mathbf{I}+\widetilde{\mu}_{\beta}\left(\nabla \widetilde{\mathbf{v}}_{\beta}+\nabla \widetilde{\mathbf{v}}_{\beta}^{\mathbf{T}}\right)+\widetilde{\lambda}_{\beta} \nabla \cdot \widetilde{\mathbf{v}}_{\beta}\right] \mathbf{n} d S
\end{aligned}
$$

Posteriormente constataremos que a resistência devido a presença do meio poroso é contabilizada nos termos $\left\langle\mathbf{S}_{\mathbf{1}}\right\rangle^{\beta}$ e $\widetilde{\mathbf{S}_{\mathbf{1}}}$. Nesta fase do desenvolvimento, as equações de quantidade de movimento linear e continuidade médias não estão em uma forma fechada. As flutuações de velocidade e pressão ainda estão presentes nas integrais. A estratégia clássica é derivar um problema que governa o campo de flutuações, em seguida, representá-los em termos de quan- 
tidades médias, resolvendo o chamado problema de fechamento. Com a insersão dessas representações nas equações de conservação médias, obtém-se a formulação das equações médias macroscópicas de forma fechada.

\section{5}

\section{Equações Macroscópicas}

Para obter as equações de conservação macroscópicas (Whitaker, 1986), é necessário realizar uma análise de ordem de grandeza, identificando quais termos são relevantes nas equações de conservação. É importante ainda ressaltar qual a influência da pequena escala na grande escala, o que resulta em um problema de fechamento a ser resolvido.

\subsection{1}

\section{Análise de Ordem de Grandeza}

Podemos impor algumas simplificações com base no pressuposto da separação de escala de comprimento. Na verdade, se levarmos em consideração $l_{\beta}$ e $L$, respectivamente, como as dimensões características associadas às variações espaciais microscópica e macroscópica, temos a seguinte relação entre as escalas de comprimento:

$$
l_{\beta} \ll L
$$

A partir da diferenca das escalas espaciais, deve-se analisar qual a relação entre a ordem de grandeza de todas as grandezas relevantes.

Pode-se supor que o valor das propriedades da fase $\beta$ (massa específica $\rho$, primeiro e segundo coeficiente de viscosidade, $\mu$ e $\lambda$ ) são aproximadamente iguais aos valores médios das propriedades. Logo, pode-se assumir que a ordem de grandeza da flutuação da propriedades é inferior à ordem de grandeza do valor médio:

$$
\begin{aligned}
& O\left({\widetilde{\rho_{\beta}}}\right) \ll O\left(\left\langle\rho_{\beta}\right\rangle^{\beta}\right) \\
& O\left(\widetilde{\mu}_{\beta}\right) \ll O\left(\left\langle\mu_{\beta}\right\rangle^{\beta}\right) \\
& O\left(\widetilde{\lambda}_{\beta}\right) \ll O\left(\left\langle\lambda_{\beta}\right\rangle^{\beta}\right)
\end{aligned}
$$


Para relacionar a ordem de grandeza da média intrínsica da velocidade e de sua flutuação pode-se observar que como a velocidade $\mathbf{v}_{\beta}$ é zero nas paredes da rocha, a seguinte relação pode ser aplicada na parede:

$$
\left\langle\mathbf{v}_{\beta}\right\rangle^{\beta}=-\widetilde{\mathbf{v}}_{\beta}
$$

Portanto, a ordem de grandeza da média e de sua flutuação são equivalentes:

$$
O\left(\left\langle\mathbf{v}_{\beta}\right\rangle^{\beta}\right)=O\left(\widetilde{\mathbf{v}}_{\beta}\right)
$$

Para estimar a ordem de grandeza das variações no tempo, é preciso considerar se o transiente é associado à macrosescala (grandeza média superficial)

$$
O(t)=O\left(\frac{L}{\mathbf{v}_{\beta}}\right)
$$

ou à microsescala (flutuação).

$$
O(t)=O\left(\frac{l_{\beta}}{\mathbf{v}_{\beta}}\right)
$$

Uma análise de ordem de grandeza pode ser realizada nas equações macroscópicas visando simplificá-las. Neste caso, uma informação muito relevante nessa análise é que a perspectiva para a aplicação da ordem de grandeza para equação macroscópica é a do domínio da escala maior da figura 3.1 onde a $O\left(\left\langle\mathbf{v}_{\beta}\right\rangle^{\beta}\right) \gg O\left(\widetilde{\mathbf{v}}_{\beta}\right)$.

\subsection{2}

\section{Conservação de Massa}

Procedendo-se com a equação macroscópica de conservação de massa, equação 3.26, de forma análoga ao realizado com as equações microscópicas, i.e, estimando-se a ordem de grandeza de cada termo, tem-se

$$
\begin{array}{r}
\frac{\partial\left(\phi\left\langle\rho_{\beta}\right\rangle^{\beta}\right)}{\partial t}+\nabla \cdot\left[\phi\left\langle\rho_{\beta}\right\rangle^{\beta}\left\langle\mathbf{v}_{\beta}\right\rangle^{\beta}\right]+\nabla \cdot\left[\left\langle\widetilde{\rho}_{\beta} \widetilde{\mathbf{v}}_{\beta}\right\rangle\right]=0 \\
O\left[\frac{\left\langle\rho_{\beta}\right\rangle^{\beta} \mathbf{v}_{\beta}}{L}\right]+O\left[\frac{\left\langle\rho_{\beta}\right\rangle^{\beta} \mathbf{v}_{\beta}}{L}\right]+O\left[\frac{\widetilde{\rho}_{\beta} \widetilde{\mathbf{v}}_{\beta}}{L}\right]=0
\end{array}
$$


logo, pode-se concluir que o último termo é desprezível, resultando na seguinte equação macroscópica de continuidade

$$
\frac{\partial\left(\phi\left\langle\rho_{\beta}\right\rangle^{\beta}\right)}{\partial t}+\nabla \cdot\left[\phi\left\langle\rho_{\beta}\right\rangle^{\beta}\left\langle\mathbf{v}_{\beta}\right\rangle^{\beta}\right]=0
$$

\subsection{3}

\section{Conservação da Quantidade de Movimento Linear}

Da mesma forma, vamos analisar a ordem de grandeza de cada termo da equação de movimento linear a fim de simplificar esta equação. Analisando a ordem de grandeza de cada termo convectivo do lado esquerdo da equação 3.50, tem-se

$$
\begin{array}{r}
\frac{\partial\left(\phi\left\langle\rho_{\beta}\right\rangle^{\beta}\left\langle\mathbf{v}_{\beta}\right\rangle^{\beta}\right)}{\partial t}+\nabla \cdot\left[\phi\left\langle\rho_{\beta}\right\rangle^{\beta}\left\langle\mathbf{v}_{\beta}\right\rangle^{\beta}\left\langle\mathbf{v}_{\beta}\right\rangle^{\beta}\right]= \\
O\left[\frac{\left\langle\rho_{\beta}\right\rangle^{\beta} \mathbf{v}_{\beta}^{\mathbf{2}}}{L}\right]+O\left[\frac{\left\langle\rho_{\beta}\right\rangle^{\beta} \mathbf{v}_{\beta}^{2}}{L}\right]
\end{array}
$$

Os termos convectivos do lado direito da equação 3.50 são $\mathbf{A}_{\mathbf{1}}+\mathbf{A}_{\mathbf{2}}+\mathbf{A}_{\mathbf{3}}$. Analisando na equação 3.64, a ordem de grandeza deste termos, nota-se que estes podem ser desprezados na escala maior, quando comparados com os termos da equação 3.63 .

$$
\begin{array}{r}
\frac{\partial\left\langle\widetilde{\rho}_{\beta} \widetilde{\mathbf{v}}_{\beta}\right\rangle}{\partial t}+\nabla \cdot\left[\left\langle\rho_{\beta}\right\rangle^{\beta}\left\langle\widetilde{\mathbf{v}}_{\beta} \widetilde{\mathbf{v}}_{\beta}\right\rangle\right]+\nabla \cdot\left[\left\langle\widetilde{\rho}_{\beta} \widetilde{\mathbf{v}_{\beta} \mathbf{v}_{\beta}}\right\rangle\right]= \\
O\left[\frac{\widetilde{\rho}_{\beta} \widetilde{\mathbf{v}}_{\beta}^{2}}{L}\right]+O\left[\frac{\left\langle\rho_{\beta}\right\rangle^{\beta} \widetilde{\mathbf{v}}_{\beta}^{2}}{L}\right]+O\left[\frac{\widetilde{\rho}_{\beta} \widetilde{\mathbf{v}}_{\beta}^{2}}{L}\right]
\end{array}
$$

A seguir, a ordem de grandeza dos termos difusivos pode ser analisada:

$$
\begin{array}{r}
\phi \nabla \cdot\left[\left\langle\mu_{\beta}\right\rangle^{\beta}\left(\nabla\left\langle\mathbf{v}_{\beta}\right\rangle^{\beta}+\left(\nabla\left\langle\mathbf{v}_{\beta}\right\rangle^{\beta}\right)^{T}\right)\right]+\phi \nabla\left[\left\langle\lambda_{\beta}\right\rangle^{\beta} \nabla \cdot\left\langle\mathbf{v}_{\beta}\right\rangle^{\beta}\right]= \\
O\left[\frac{\left\langle\mu_{\beta}\right\rangle^{\beta} \mathbf{v}_{\beta}}{L^{2}}\right]+O\left[\frac{\left\langle\lambda_{\beta}\right\rangle^{\beta} \mathbf{v}_{\beta}}{L^{2}}\right]
\end{array}
$$

Nota-se que ambos os termos são da mesma ordem de grandeza. A seguir, a ordem de grandeza dos termos difusivos $\mathbf{D}_{1}+\mathbf{D}_{\mathbf{2}}+\mathbf{C}_{\mathbf{1}}+\mathbf{C}_{\mathbf{2}}$ é avaliada. $\mathrm{Na}$ 
grande escala, as derivadas espaciais devem ser calculadas na macro escala, $\log 0$

$$
\begin{array}{r}
\nabla \cdot\left\langle\mu_{\beta}\left(\nabla \widetilde{\mathbf{v}}_{\beta}+\nabla \widetilde{\mathbf{v}}_{\beta}^{T}\right)\right\rangle+\left\langle\nabla \widetilde{\mu}_{\beta}\right\rangle \cdot\left[\nabla\left\langle\mathbf{v}_{\beta}\right\rangle^{\beta}+\nabla\left(\left\langle\mathbf{v}_{\beta}\right\rangle^{\beta}\right)^{T}\right]+ \\
\nabla\left\langle\lambda_{\beta} \nabla \cdot \widetilde{\mathbf{v}}_{\beta}\right\rangle+\left\langle\nabla \widetilde{\lambda}_{\beta}\right\rangle \nabla \cdot\left\langle\mathbf{v}_{\beta}\right\rangle^{\beta}= \\
O\left[\frac{\left\langle\mu_{\beta}\right\rangle^{\beta} \widetilde{\mathbf{v}}_{\beta}}{L^{2}}\right]+O\left[\frac{\widetilde{\mu}_{\beta} \mathbf{v}_{\beta}}{L^{2}}\right]+O\left[\frac{\left\langle\lambda_{\beta}\right\rangle^{\beta} \widetilde{\mathbf{v}}_{\beta}}{L^{2}}\right]+O\left[\frac{\widetilde{\lambda}_{\beta} \mathbf{v}_{\beta}}{L^{2}}\right]
\end{array}
$$

Comparando a ordem de grandezas dos coeficientes difusivos da equação 3.66 com a ordem dos coeficientes da equação 3.65 observa-se que todos podem ser desprezados, pois envolvem flutuações no numerador.

Para finalizar a análise de ordem de grandeza da macro escala difusiva é preciso avaliar os termos $\mathbf{D}_{\mathbf{3}}+\mathbf{C}_{\mathbf{3}}=\hat{\mathbf{D}}_{\mathbf{3}}+\widetilde{\mathbf{D}}_{\mathbf{3}}+\hat{\mathbf{C}}_{\mathbf{3}}+\widetilde{\mathbf{C}}_{\mathbf{3}}$. Estes termos envolvem integral na micro escala, consequentemente a integral de área dividida pelo volume é da ordem de $1 / l_{\beta}$, resultando na seguinte ordem de grandeza para estes termos

$$
\begin{array}{r}
\frac{1}{\forall} \int_{A_{i}}\left[\left(\left\langle\mu_{\beta}\right\rangle^{\beta}+\widetilde{\mu}_{\beta}\right)\left(\nabla \widetilde{\mathbf{v}}_{\beta}+\nabla \widetilde{\mathbf{v}}_{\beta}^{T}\right)\right] \cdot \mathbf{n} d S+ \\
\frac{1}{\forall} \int_{A_{i}}\left[\left(\left\langle\lambda_{\beta}\right\rangle^{\beta}+\widetilde{\lambda}_{\beta}\right) \nabla \cdot \widetilde{\mathbf{v}}_{\beta}\right] \mathbf{n} d S= \\
O\left[\frac{\left\langle\mu_{\beta}\right\rangle^{\beta} \widetilde{\mathbf{v}}_{\beta}}{l_{\beta} L}\right]+O\left[\frac{\widetilde{\mu}_{\beta} \widetilde{\mathbf{v}}_{\beta}}{l_{\beta} L}\right]+O\left[\frac{\left\langle\lambda_{\beta}\right\rangle^{\beta} \widetilde{\mathbf{v}}_{\beta}}{l_{\beta} L}\right]+O\left[\frac{\widetilde{\lambda}_{\beta} \widetilde{\mathbf{v}}_{\beta}}{l_{\beta} L}\right]
\end{array}
$$

Analisando a equação 3.67, observa-se que os termos $\widetilde{\mathbf{D}}_{\mathbf{3}}+\widetilde{\mathbf{C}}_{\mathbf{3}}$ envolvem o produto de duas flutuações no numerador, sendo menores que $\hat{\mathbf{D}}_{\mathbf{3}}+\hat{\mathbf{C}}_{\mathbf{3}}$. Finalmente, comparando estes dois últimos termos com os termos difusivos da equação 3.65 conclui-se que possuem a mesma ordem de grandeza, pois $O\left[\left\langle\mathbf{v}_{\beta}\right\rangle^{\beta} / L\right] \approx O\left[\widetilde{\mathbf{v}}_{\beta} / l_{\beta}\right]$.

Usando o mesmo raciocínio com o termo de pressão, conclui-se que os dois termos possuem a mesma ordem

$$
\nabla\langle p\rangle^{\beta}+\frac{1}{\forall} \int_{A_{i}} \tilde{p} \mathbf{n} d S=O\left[\frac{\langle p\rangle^{\beta}}{L}\right]+O\left[\frac{\widetilde{p}}{l_{\beta}}\right]
$$


Após a análise de ordem de grandeza, a equação da conservação de quantidade de movimento linear, mantendo somente os termos mais relevantes, torna-se

$$
\begin{array}{r}
\frac{\partial\left(\phi\left\langle\rho_{\beta}\right\rangle^{\beta}\left\langle\mathbf{v}_{\beta}\right\rangle^{\beta}\right)}{\partial t}+\nabla \cdot\left[\phi\left\langle\rho_{\beta}\right\rangle^{\beta}\left\langle\mathbf{v}_{\beta}\right\rangle^{\beta}\left\langle\mathbf{v}_{\beta}\right\rangle^{\beta}\right]=-\phi \nabla\langle p\rangle^{\beta}+\phi\left\langle\rho_{\beta}\right\rangle^{\beta} \mathbf{g}+ \\
+\phi \nabla \cdot\left[\left\langle\mu_{\beta}\right\rangle^{\beta}\left(\nabla\left\langle\mathbf{v}_{\beta}\right\rangle^{\beta}+\left(\nabla\left\langle\mathbf{v}_{\beta}\right\rangle^{\beta}\right)^{T}\right)\right]+\phi \nabla\left[\left\langle\lambda_{\beta}\right\rangle^{\beta} \nabla \cdot\left\langle\mathbf{v}_{\beta}\right\rangle^{\beta}\right] \\
\frac{1}{\forall} \int_{A_{i}}\left[-\widetilde{p} \mathbf{I}+\left\langle\mu_{\beta}\right\rangle^{\beta}\left(\nabla \widetilde{\mathbf{v}}_{\beta}+\nabla \widetilde{\mathbf{v}}_{\beta}^{\mathbf{T}}\right)+\left\langle\lambda_{\beta}\right\rangle^{\beta} \nabla \cdot \widetilde{\mathbf{v}}_{\beta}\right] \mathbf{n} d S
\end{array}
$$

\section{6}

\section{Problema de Fechamento}

A equação 3.69 possui flutuações em sua formulação, especificamente no termo integral da equação. Essa equação ainda não está pronta para ser utilizada porque os termos que contém as flutuações precisam ser relacionados as variáveis macroscópicas. Como etapa seguinte do processo de obtenção das equações médias macrosópicas, é preciso determinar a solução do campo de flutuações e a relação desses com o campo macroscópico. Pode-se manipular as equações de conservação visando obter as equações. Ou seja, as equações para as flutuações podem ser obtidas subtraindo as equações de conservação pelas equações médias.

A equação que governa a equação da continuidade para as flutuações da fase $\beta$ pode ser obtida através da subtração da equação 3.19 pela equação 3.26. Após alguma rearrumação obtém-se

$$
\begin{array}{r}
\frac{\partial \widetilde{\rho}}{\partial t}+\nabla \cdot\left({\widetilde{\rho_{\beta}}}^{\widetilde{\mathbf{v}}_{\beta}}\right)+\left[\frac{\partial\left\langle\rho_{\beta}\right\rangle^{\beta}}{\partial t}+\nabla \cdot\left\langle\rho_{\beta}\right\rangle^{\beta}\left\langle\mathbf{v}_{\beta}\right\rangle^{\beta}\right] \\
+\nabla \cdot\left[\left\langle\rho_{\beta}\right\rangle^{\beta} \widetilde{\mathbf{v}}_{\beta}\right]+\nabla \cdot\left[{\widetilde{\rho_{\beta}}}_{\left.\left.\mathbf{v}_{\beta}\right\rangle^{\beta}\right]=0}\right.
\end{array}
$$

Procedendo de forma análoga com a equação de conservação de quantidade de movimento, subtrai-se da equação 3.20) a equação média, equação(3.50). Para facilitar o procedimento, trabalha-se com as equações na forma não conservativa, resultando em 


$$
\begin{array}{r}
\phi\left(\left\langle\rho_{\beta}\right\rangle^{\beta} \frac{\partial \widetilde{\mathbf{v}}_{\beta}}{\partial t}+{\widetilde{\rho_{\beta}}} \frac{\partial \widetilde{\mathbf{v}}_{\beta}}{\partial t}+{\widetilde{\rho_{\beta}}}_{\left.\frac{\partial\left\langle\mathbf{v}_{\beta}\right\rangle^{\beta}}{\partial t}\right)}+\right. \\
\phi\left(\left\langle\rho_{\beta}\right\rangle^{\beta}\left[\mathbf{v}_{\beta} \nabla \widetilde{\mathbf{v}}_{\beta}+\widetilde{\mathbf{v}}_{\beta} \nabla\left\langle\mathbf{v}_{\beta}\right\rangle^{\beta}\right]+{\widetilde{\rho_{\beta}}}_{\mathbf{v}} \nabla \mathbf{v}_{\beta}\right)+\left\langle\mathbf{v}_{\beta}\right\rangle^{\beta} \nabla \cdot\left\langle{\widetilde{\rho_{\beta}}}_{\mathbf{v}_{\beta}}\right\rangle= \\
\phi\left(\nabla \cdot\left[\mu_{\beta}\left(\nabla \widetilde{\mathbf{v}}_{\beta}+\left(\nabla \widetilde{\mathbf{v}}_{\beta}\right)^{T}\right)\right]+\nabla \widetilde{\mu}_{\beta} \cdot\left[\left(\nabla\left\langle\mathbf{v}_{\beta}\right\rangle^{\beta}+\left(\nabla\left\langle\mathbf{v}_{\beta}\right\rangle^{\beta}\right)^{T}\right)\right]\right)+ \\
\phi \widetilde{\mu}_{\beta}\left[\nabla^{2}\left\langle\mathbf{v}_{\beta}\right\rangle+\nabla \cdot\left(\nabla\left\langle\mathbf{v}_{\beta}\right\rangle^{\beta}\right)^{T}\right]+\phi \nabla\left(\lambda_{\beta} \nabla \cdot \widetilde{\mathbf{v}}_{\beta}\right)+\nabla\left(\widetilde{\lambda}_{\beta} \nabla \cdot\left\langle\mathbf{v}_{\beta}\right\rangle^{\beta}\right)+ \\
\widetilde{\rho} \mathbf{g}-\nabla \widetilde{p}+\left(\mathbf{A}_{\mathbf{1}}+\mathbf{A}_{\mathbf{2}}+\mathbf{A}_{\mathbf{3}}\right)-\left(\mathbf{D}_{\mathbf{1}}+\mathbf{D}_{\mathbf{2}}\right)-\left(\mathbf{C}_{\mathbf{1}}+\mathbf{C}_{\mathbf{2}}\right)-\left(\widetilde{\mathbf{S}_{\mathbf{1}}}+\left\langle\mathbf{S}_{\mathbf{1}}\right\rangle^{\beta}\right)
\end{array}
$$

A próxima etapa consiste em simplificar estas equações através de uma análise de ordem de grandeza, mantendo somente os termos dominantes. O processo de análise de ordem de grandeza das equações de flutuação pode ser visto em detalhes em Whitaker (1999). Aplicando a ordem de grandeza e desprezando os termos pequenos na equação 3.70, obtem-se a seguinte equação de continuidade para as flutuações:

$$
\nabla \cdot \widetilde{\mathbf{v}}_{\beta}=0
$$

A simplificação para a equação de conservação de quantidade de movimento linear 3.71 considerando o processo de ordem de grandeza se torna

$$
\begin{array}{r}
\left\langle\rho_{\beta}\right\rangle^{\beta} \frac{\partial \widetilde{\mathbf{v}}_{\beta}}{\partial t}+\left\langle\rho_{\beta}\right\rangle^{\beta} \mathbf{v}_{\beta} \nabla \widetilde{\mathbf{v}}_{\beta}=-\nabla \widetilde{\mathbf{p}}+\widetilde{\rho} \mathbf{g} \\
+\nabla \cdot\left[\left\langle\mu_{\beta}\right\rangle^{\beta}\left(\nabla \widetilde{\mathbf{v}}_{\beta}+\left(\nabla \widetilde{\mathbf{v}}_{\beta}\right)^{T}\right)\right]+\nabla\left(\left\langle\lambda_{\beta}\right\rangle^{\beta} \nabla \cdot \widetilde{\mathbf{v}}_{\beta}\right) \\
-\frac{1}{\phi}\left\langle S_{1}\right\rangle^{\beta}
\end{array}
$$

A solução desse problema precisa de condições de cotorno e pode ser encontrada utilizando $\mathbf{v}_{\beta}=\left\langle\mathbf{v}_{\beta}\right\rangle^{\beta}+\widetilde{\mathbf{v}}_{\beta}=\mathbf{0}$, logo

$$
\widetilde{\mathbf{v}}_{\beta}=-\left\langle\mathbf{v}_{\beta}\right\rangle^{\beta}
$$




\section{7}

\section{Equações Macroscópicas Formato Final}

A equação macroscópica de conservação da massa para o escoamento de fluidos em meios porosos é dada pela equação 3.75 .

$$
\frac{\partial\left(\phi\left\langle\rho_{\beta}\right\rangle^{\beta}\right)}{\partial t}+\nabla \cdot\left[\phi\left\langle\rho_{\beta}\right\rangle^{\beta}\left\langle\mathbf{v}_{\beta}\right\rangle^{\beta}\right]=0
$$

A solução do problema de fechamento pode ser encontrada em diversos trabalhos, como por exemplo em Whitaker (1999) e Soulaine (2012). Com a solução do campo de flutuações é possível determinar a solução da integral $\left\langle\mathbf{S}_{\mathbf{1}}\right\rangle^{\beta}$ e $\widetilde{\mathbf{S}_{\mathbf{1}}}$ da equação 3.69.

Edwards (1990) mostram diretamente a relação entre a integral da equação 3.69 com o tensor permeabilidade da forma

$$
\left\langle\mathbf{S}_{\mathbf{1}}\right\rangle^{\beta}+\widetilde{\mathbf{S}_{\mathbf{1}}}=-\mu_{\beta} \phi^{2} \mathbf{K}_{\beta}^{-\mathbf{1}} \cdot\left\langle\mathbf{v}_{\beta}\right\rangle^{\beta}
$$

Logo, a equação macroscópica para o escoamento de um fluido newtoniano levemente compressível com viscosidade variável é representada pela equação 3.77 .

$$
\begin{array}{r}
\frac{\partial\left(\phi\left\langle\rho_{\beta}\right\rangle^{\beta}\left\langle\mathbf{v}_{\beta}\right\rangle^{\beta}\right)}{\partial t}+\nabla \cdot\left[\phi\left\langle\rho_{\beta}\right\rangle^{\beta}\left\langle\mathbf{v}_{\beta}\right\rangle^{\beta}\left\langle\mathbf{v}_{\beta}\right\rangle^{\beta}\right] \\
=-\phi \nabla\langle p\rangle^{\beta}+\phi \nabla \cdot\left[\left\langle\mu_{\beta}\right\rangle^{\beta}\left(\nabla\left\langle\mathbf{v}_{\beta}\right\rangle^{\beta}+\left(\nabla\left\langle\mathbf{v}_{\beta}\right\rangle^{\beta}\right)^{T}\right)\right]+\phi \nabla\left[\left\langle\lambda_{\beta}\right\rangle^{\beta} \nabla \cdot\left\langle\mathbf{v}_{\beta}\right\rangle^{\beta}\right] \\
+\phi\left\langle\rho_{\beta}\right\rangle^{\beta} \mathbf{g}-\mu_{\beta} \phi^{2} \mathbf{K}_{\beta}^{-1} \cdot\left\langle\mathbf{v}_{\beta}\right\rangle^{\beta}
\end{array}
$$

A equação 3.77 contém apenas valores macroscópicos onde o termo com a permeabilidade modela a interação entre as pequenas e grandes escalas. Assim, a permeabilidade de um meio poroso é um parâmetro que descreve um efeito microscópico em uma escala macroscópica. Logo, a permeabilidade, que é uma variável macroscópica, é avaliada com base na geometria do espaço poroso que não é representado na escala maior. No método de alteração de escala através da média de volume, as variáveis que conectam as escalas micro e macro são avaliadas a partir das integrais das variáveis de fechamento. Portanto o conjunto final das equações macroscópicas que governam o escoamento de fluidos em meios porosos são 3.75 e 3.77 . 


\section{Equação da Difusividade Hidráulica}

Neste capítulo é apresentada a modelagem matemática da equação de difusividade hidráulica. Essa equação é muito utilizada em engenharia de reservatórios e é obtida a partir da associação de três equações básicas: a equação da conservação da massa, a equação de Darcy, que representa a conservação de quantidade de movimento linear, e uma equação de estado. Essa última pode ser uma lei dos gases ou a equação da compressibilidade para o caso de líquidos.

Na derivação da equação de difusividade hidráulica, deixa-se clara todas as hipóteses necessárias para sua utilização. É mostrado que a mesma pode ser considerada como um caso particular das equações de conservação de massa e quantidade de movimento para um meio poroso, derivadas no capítulo anterior. O primeiro passo para obter a equação de difusividade hidráulica consiste em derivar a equação de Darcy, o que é apresentado a seguir.

A equação de Darcy, amplamente utilizada até hoje, é uma das primeiras tentativas de descrever o fluxo de um único fluido através de um meio poroso rígido, devido a um gradiente de pressão. Rajagopal (2007) mostrou que o modelo de Darcy pode ser obtido a partir de uma série de suposições sobre o sólido e o fluido. As hipóteses incluem:

1. O sólido é um corpo poroso rígido saturado cujo equilíbrio da quantidade de movimento linear pode ser ignorado. Ou seja, a modelagem de Darcy não considera a equação de transporte para o movimento da rocha. A consideração da compressibilidade para a rocha vem através da conservação da massa. Não existe a previsão do movimento do meio. Esta é a única hipótese também considerada na modelagem apresentada no capítulo anterior, sendo empregada no presente trabalho.

2. O fluxo é suficientemente lento de modo que os efeitos de inércia no fluido podem ser negligenciados. Isso implica que o termo de inércia da equação 3.77 é desprezado. 


$$
\nabla \cdot\left[\phi\left\langle\rho_{\beta}\right\rangle^{\beta}\left\langle\mathbf{v}_{\beta}\right\rangle^{\beta}\left\langle\mathbf{v}_{\beta}\right\rangle^{\beta}\right] \approx 0
$$

3. Adicionalmente, como o escoamento é muito lento, a variação com o tempo da quantidade de movimento linear do fluido também é desprezada. Isso implica que o termo de transiente da equação 3.77 é negligenciado.

$$
\frac{\partial\left(\phi\left\langle\rho_{\beta}\right\rangle^{\beta}\left\langle\mathbf{v}_{\beta}\right\rangle^{\beta}\right)}{\partial t} \approx 0
$$

4. A difusão viscosa no fluido é desprezível, isto é, o efeito de atrito no fluido devido à viscosidade do próprio fluido é negligenciado. Isso implica que o termo viscoso da equação 3.77 é aproximadamente nulo

$$
\phi \nabla \cdot\left[\left\langle\mu_{\beta}\right\rangle^{\beta}\left(\nabla\left\langle\mathbf{v}_{\beta}\right\rangle^{\beta}+\left(\nabla\left\langle\mathbf{v}_{\beta}\right\rangle^{\beta}\right)^{T}\right)\right] \approx 0
$$

5. Apesar do fluido poder ser compressível, a difusão viscosa associada a dilatação do elemento de fluido também é nula, logo o termo de difusão associado ao segundo coeficiente de viscosidade referente a dilatação do fluido da equação 3.77 é desprezado

$$
\phi \nabla\left[\left\langle\lambda_{\beta}\right\rangle^{\beta} \nabla \cdot\left\langle\mathbf{v}_{\beta}\right\rangle^{\beta}\right]=0
$$

6. A interação entre o sólido e o líquido é devido à fricção nos poros, sendo representada pelo termo de fechamento referente as influências da pequena escala na escala macroscópica. Como mostrado no capítulo anterior, esse termo é proporcional à velocidade relativa entre o sólido e o líquido. Isso pode ser visto no termo fonte da equação 3.77

$$
-\mu_{\beta} \phi^{2} \mathbf{K}_{\beta}^{-1} \cdot\left\langle\mathbf{v}_{\beta}\right\rangle^{\beta}
$$


Após essa série de simplificações, a equação 3.77 pode ser escrita como:

$$
0=-\phi \nabla\langle p\rangle^{\beta}+\phi\left\langle\rho_{\beta}\right\rangle^{\beta} \mathbf{g}-\left\langle\mu_{\beta}\right\rangle^{\beta} \phi^{\mathbf{2}} \mathbf{K}_{\beta}^{-\mathbf{1}} \cdot\left\langle\mathbf{v}_{\beta}\right\rangle^{\beta}
$$

Pode-se reagrupar os termos da equação 4.6 para que a equação de Darcy seja obtida:

$$
\left\langle\mathbf{v}_{\beta}\right\rangle=-\frac{\mathbf{K}_{\beta}}{\left\langle\mu_{\beta}\right\rangle^{\beta}} \cdot\left(\nabla\langle p\rangle^{\beta}-\left\langle\rho_{\beta}\right\rangle^{\beta} \mathbf{g}\right)
$$

\section{1}

\section{Derivação da Equação da Difusividade Hidráulica}

A equação da difusividade hidráulica é baseada na conservação da massa, equação 3.75, em Darcy, equação 4.7, e na equação de estado. No presente trabalho modela-se um fluido compressível em um meio poroso compressível.

Simplicando a nomenclatura $\operatorname{com}\langle\rho\rangle^{\beta}=\rho,\left\langle\mu_{\beta}\right\rangle^{\beta}=\mu,\langle p\rangle^{\beta}=p$, $\left\langle\mathbf{v}_{\beta}\right\rangle^{\beta}=\mathbf{U}$ e $\mathbf{K}_{\beta}=\mathbf{K}$

$$
\begin{aligned}
& \frac{\partial(\rho \phi)}{\partial t}+\nabla \cdot[\rho \mathbf{U}]=0 \\
& \mathbf{U}=-\frac{\mathbf{K}}{\mu} \cdot(\nabla p-\rho \mathbf{g})
\end{aligned}
$$

Substituindo a equação de Darcy, equação 4.9, na equação de continuidade, equação 4.8, utilizando a definição de viscosidade cinemática, $\nu=$ $\mu / \rho$, e expandindo a derivada do termo transiente, obtém-se a seguinte equação

$$
\rho \frac{\partial \phi}{\partial t}+\phi \frac{\partial \rho}{\partial t}=\nabla \cdot\left[\frac{\mathbf{K} \cdot(\nabla p-\rho \mathbf{g})}{\nu}\right]
$$

Para escoamento isotérmico, pode-se assumir que a massa específica e a porosidade só dependem da pressão, e introduzindo a definição de coeficientes de compressibilidade para a massa específica e porosidade

$$
c_{\rho}=\frac{1}{\rho} \frac{\partial \rho}{\partial p} \quad ; \quad c_{\phi}=\frac{1}{\phi} \frac{\partial \phi}{\partial p}
$$


podemos reescrever as derivadas temporais de $\rho$ e $\phi$ em função da pressão como

$$
\frac{\partial \rho}{\partial t}=\frac{\partial \rho}{\partial p} \frac{\partial p}{\partial t}=\rho c_{\rho} \frac{\partial p}{\partial t} \quad ; \quad \frac{\partial \phi}{\partial t}=\frac{\partial \phi}{\partial p} \frac{\partial p}{\partial t}=\phi c_{\phi} \frac{\partial p}{\partial t}
$$

Substituindo as relações anteriores, na equação 4.10, obtém-se a seguinte equação em termos da pressão do fluido, a qual é denominada equação de difusividade hidráulica.

$$
\Gamma(p) \frac{\partial p}{\partial t}=\nabla \cdot\left[\left(\frac{1}{\nu}\right) \mathbf{K} \cdot \nabla p\right]-\nabla \cdot\left[\left(\frac{\rho}{\nu}\right) \mathbf{K} \cdot \mathbf{g}\right]
$$

onde a função $\Gamma(p)$ é dada por

$$
\Gamma(p) \equiv \rho \phi\left(c_{\rho}+c_{\phi}\right)
$$

A equação 4.13 é genérica em relação aos modelos que descrevem os estados do fluido e formação para escoamentos isotérmicos e com composição constante. Dessa maneira, para estes tipos de escoamentos, as únicas aproximações adicionais, em relação as hipóteses utilizadas para a derivação das equações gerais no capítulo anterior, no âmbito da mecânica do contínuo, a que a equação 4.13 está submetida são as hipóteses necessárias para a validade da equação de Darcy para descrição do escoamento no meio poroso.

Interpretando a equação de Darcy como uma simplificação da equação macroscópica de média, esta pode ser aplicada em escoamentos de fluidos Newtonianos, uma vez que a equação de Navier Stokes foi utilizada na microescala. Obviamente, uma vez especificados os modelos para descrição da densidade, viscosidade e porosidade, o modelo de difusividade hidráulica também estará submetido às suas respectivas aproximações.

A equação 4.13 pode ser reescrita em uma forma mais conveniente, se introduzirmos a variável $\tilde{\mathbf{K}} \equiv \mathbf{K} / \nu$, a qual corresponde ao tensor de permeabilidade dividido pela viscosidade cinemática $\nu$. Este tensor é de segunda ordem e anisotrópico, o qual pode ser separado em uma parte isotrópica e outra deviatórica de acordo com

$$
\tilde{\mathbf{K}}=\gamma \mathbf{I}+\mathbf{D}
$$

onde: 


$$
\gamma=\frac{1}{3} \operatorname{tr}(\tilde{\mathbf{K}}) \quad \text { e } \quad \mathbf{D}=[\tilde{\mathbf{K}}-\gamma \mathbf{I}]
$$

sendo D, por definição, a parte deviatórica do tensor $\tilde{\mathbf{K}}$. A equação da difusividade hidráulica pode entao ser escrita como

$$
\Gamma(p) \frac{\partial p}{\partial t}=\nabla \cdot[\gamma \nabla p]+\nabla \cdot[\mathbf{D} \cdot \nabla p-\rho \tilde{\mathbf{K}} \cdot \mathbf{g}]
$$

\section{2}

\section{Equações de Estado para Fluidos e Rochas}

Para completar a modelagem, equações de estado para o fluido e rocha precisam ser introduzidas, o que é apresentado a seguir.

\subsection{1}

\section{Líquidos e Rochas Levemente Compressíveis}

Quando os efeitos de compressibilidade são relativamente pequenos, os coeficientes de compressibilidade podem ser aproximados como constantes,

$$
c_{\rho} \approx c_{\rho}^{s t d} \quad ; \quad c_{\phi} \approx c_{\phi}^{r e f}
$$

A função $\Gamma$, neste caso, é dada de acordo com a equação 4.19

$$
\Gamma(p)=\rho \phi S_{w c}\left(c_{\rho}^{s t d}+c_{\phi}^{r e f}\right)
$$

onde $S_{w c}$ é o valor de saturação de água conata. O termo $S_{w c}$ é acrescentado devido a diminuição da porosidade na presença de água presa nos poros.

Deve-se observar que a hipótese de compressibilidade constante para o fluido e formação, impõe a forma de variação dessas propriedades, que são dadas pelas equações 4.20 e 4.21 .

$$
\begin{gathered}
\rho=\rho^{s t d} \exp \left[c_{\rho}^{s t d}\left(p-p^{s t d}\right)\right] \\
\phi=\phi^{r e f} \exp \left[c_{\phi}^{r e f}\left(p-p^{r e f}\right)\right]
\end{gathered}
$$


onde $\rho^{\text {std }}$ e $\phi^{r e f}$ são a densidade do fluido e porosidade da formação às pressões $p^{s t d}$ e $p^{r e f}$, respectivamente.

As equações 4.20 e 4.21 podem ser linearizadas, com boa aproximação para valores pequenos de $c_{\rho}^{\text {std }}$ e $c_{\phi}^{\text {ref }}$, de acordo com as equações 4.22 e 4.23 .

$$
\begin{gathered}
\rho=\rho^{s t d}\left[1+c_{\rho}^{s t d}\left(p-p^{s t d}\right)\right] \\
\phi=\phi^{r e f}\left[1+c_{\phi}^{r e f}\left(p-p^{r e f}\right)\right]
\end{gathered}
$$

\subsection{2}

\section{Gases e Rocha Levemente Compressível}

A equação de estado para gases reais é

$$
\rho=\frac{p}{z R T}
$$

onde $z$ é o fator de compressibilidade do gás, $R$ é a constante do gás e $T$ é a temperatura de referência, no qual o escoamento ocorre.

Neste caso, o produto da massa específica pelo coeficiente de compressibilidade do gás é

$$
\rho c_{\rho}=\frac{\partial \rho}{\partial p}=\frac{1}{z R T}-\frac{p}{z^{2} R T} \frac{\partial z}{\partial p}=\frac{\rho^{s t d}}{p^{s t d}}\left[1-\frac{p}{z} \frac{\partial z}{\partial p}\right]
$$

Portanto, considerando o modelo à compressibilidade constante para a formação, a função $\Gamma$ é dada pela equação 4.26.

$$
\Gamma(p)=\rho^{s t d} \phi S_{w c}\left[\frac{p}{p^{s t d}} c_{\phi}^{r e f}+\frac{1}{p}-\frac{1}{p^{s t d}} \frac{p}{z} \frac{\partial z}{\partial p}\right]
$$

No caso particular de gases ideais $(z=1)$, e a função $\Gamma$ simplifica para:

$$
\Gamma(p)=\rho^{s t d} \phi S_{w c}\left[\frac{p}{p^{s t d}} c_{\phi}^{r e f}+\frac{1}{p}\right]
$$

O cálculo do fator de compressibilidade e sua derivada com a pressão é feito de acordo com a equação de estado escolhida para representar o estado 
do gás, como por exemplo, o modelo de Peng Robinson, que corresponde a uma equação de estado cúbica adequada para predição do estado do gás em elevadas pressões.

\subsection{3}

\section{Modelo Black-Oil para o Fluido e Rocha Levemente Compressível}

O modelo Black-Oil é geralmente utilizado para escoamento isotérmico em reservatórios contendo óleos pesados ou de baixa volatilidade.

No presente trabalho, considerou-se em todos os casos analisados que a pressão encontra-se acima da pressão de bolha. Dessa forma, de acordo com o modelo Black-Oil foi possivel considerar o gás dissolvido no óleo, sendo o escoamento monofáscico.

No caso do modelo Black-Oil, a densidade do fluido é dada pela seguinte equação

$$
\rho=\frac{\rho_{o}^{s t d}+R_{s} \rho_{g}^{s t d}}{B_{o}(p)}
$$

onde $\rho_{o}^{s t d}$ e $\rho_{g}^{s t d}$ são as densidades do óleo e do gás na pressão $p^{\text {std }}, R_{s}$ é o volume de gás dissolvido na fase óleo, dividido pelo volume de óleo, ambos medidos nas condições padrão e $B_{o}$ pode ser definido como o volume da fase óleo (óleo + gás dissolvido) nas condições $(P, T)$ dividido pelo volume de óleo nas condições padrão.

$$
R_{s}=\frac{\forall_{g d}^{s t d}}{\forall_{o}^{s t d}} \quad ; \quad B_{o}(p)=\frac{\forall_{o+g d}^{p, T}}{\forall_{o}^{s t d}}
$$

A variação da massa específica com a pressão, neste caso é

$$
\rho c_{\rho}=\frac{\partial \rho}{\partial p}=\left(\rho_{o}^{s t d}+R_{s} \rho_{g}^{s t d}\right)\left[-\frac{1}{B_{o}^{2}} \frac{\partial B_{o}}{\partial p}\right]=-\frac{\rho}{B_{o}} \frac{\partial B_{o}}{\partial p}
$$

Portanto, considerando novamente o modelo à compressibilidade constante para a formação, a função $\Gamma$ é dada pela equação 4.31 .

$$
\Gamma(p)=\rho \phi S_{w c}\left[c_{\phi}^{r e f}-\frac{1}{B_{o}} \frac{\partial B_{o}}{\partial p}\right]
$$

Considerando uma dependência linear da função $B_{o}$ com a pressão de acordo com função $B_{o}$ dada pela equação 4.32 


$$
B_{o}(p)=B_{o b}\left[1-c_{B_{o}}\left(p-p_{b}\right)\right]
$$

onde $B_{o b}$ corresponde ao valor de $B_{o}$ avaliado na pressão de bolha $p_{b}$, sendo $c_{B_{o}}$ uma constante, podemos obter a seguinte equação para a função $\Gamma$ :

$$
\Gamma(p)=\rho_{o} \phi S_{w c}\left[c_{f}+\frac{B_{o b}}{B_{o}} c_{o}\right]
$$

A viscosidade do fluido depende da pressão e pode ser calculada através da equação 4.34 .

$$
\mu(p)=\mu_{o b}+C_{v i s c}\left(p-p_{b}\right)
$$

onde $\mu_{o b}$ corresponde ao valor de $\mu$ avaliado na pressão de bolha $p_{b}$, sendo $C_{v i s c}$ uma constante. 


\section{5 \\ Escoamento no Poço}

Como mencionado na introdução, visando prever a produtividade de um poço de forma acurada, é necessário determinar o escoamento no interior do poço de forma acoplada ao escoamento no reservatório, pois as condições de fluxo no poço são as condições de contorno impostas para obter o campo de pressão e velocidade no reservatório. Em outras palavras, o escoamento do reservatório para o poço, depende das resistências hidrodinâmicas encontradas no poço. $\mathrm{O}$ escoamento, desta forma, depende do binômio poço-reservatório, evidenciandose a necessidade de resolver o problema de forma acoplada.

Para os casos de poços horizontais e inclinados com grandes comprimentos, ou seja, quando há uma grande área de contato entre poço e reservatório, a perda de carga se torna relevante na produção do poço e a não contabilização da mesma pode levar a estimativas erradas de produtividade. Também é importante que o poço seja representado de forma realista, para que se possa estimar melhor a viabilidade técnica e econômica do desenvolvimento da produção naquele reservatório.

Dessa forma, este capítulo tem como objetivo apresentar a modelagem do poço, ou seja, determinar a vazão que entra no poço proveniente do reservatório, em função da pressão do reservatório e da pressão no interior do poço calculada a partir das perdas de cargas encontradas dentro do poço.

A maioria dos simuladores utilizados na engenharia do petróleo calculam o escoamento do reservatório para o poço utilizando modelos de poço simplificados, como modelo de Peaceman (1978, 1982, 1983, 1987, 1990, 1995, 2003), o qual será descrito brevemente neste capítulo. No presente trabalho, optou-se pela não utilização de modelos simplificados, e sim pela utilização de uma malha computacional que descreve detalhes da interface entre o poço e o reservatório. A diferença entre a escala espacial do reservatório, da ordem de quilômetros, e do diâmetro do poço, da ordem de centímetros, é muito grande. Esta diferença é um desafio numérico que deve ser tratado cuidadosamente na simulação acoplada de poços e reservatórios de petróleo.

É importante ressaltar que o escoamento do reservatório para o poço depende do tipo de completação empregada. No presente trabalho, dois tipos 
de completação foram selecionadas para serem investigadas e serão brevemente descritas neste capítulo.

\section{1}

\section{Modelos Simplificados de Poço}

Para descrever o escoamento no reservatório, é necessário avaliar a vazão através do poço, a qual depende do campo de pressão no poço e reservatório. Outro fator que influencia na determinação deste escoamento é a permeabilidade na região ao redor do poço, a qual é bastante influenciada pelas interações entre a rocha e os fluidos empregados nas operações de perfuração, completação e de estimulação do poço.

Para determinar a capacidade produtiva de um poço para um determinado reservatório é comum a utilização do índice do poço $W I$ apresentado pela equação 1.1, repetida aqui para facilitar a apresentação.

$$
Q=\frac{W I}{\mu}\left(p_{i}-p_{w}\right)
$$

onde $p_{i}$ é a pressão em um ponto do reservatório na proximidade do poço, $p_{w}$ é a pressão conhecida do poço e $\mu$ é a viscosidade molecular do fluido. O índice do poço depende dos detalhes da configuração poço e do reservatório, podendo ser estimado com modelos simplificados.

\subsection{1}

\section{Modelo Simplificado para o Índice do Poço}

Os simuladores comerciais de escoamentos em reservatórios, em sua grande maioria, utilizam o modelo de Peaceman (1978, 1982, 1983, 1987, 1990, 1995, 2003), para considerar a influência da existência do poço na determinação do escoamento no reservatório. O modelo de Peaceman se baseia na solução analítica de um escoamento em regime permanente, monofásico, incompressível, unidimensional na direção radial ao redor de um poço vertical, imerso em um meio poroso isotrópico e homogêneo. A solução analítica deste problema é uma função logarítmica dada pela equação (5.2).

$$
p(r)=p_{w}+\frac{Q \mu}{2 \pi K h}\left[\ln \left(\frac{r}{r_{w}}\right)\right]
$$

onde $p(r)$ é a pressão no reservatório na coordenada $r, r_{w}$ é o raio do poço, $p_{w}$ é a pressão no poco, $h$ é a espessura do reservatório e $K$ a permeabilidade absoluta do meio. 
Uma vez conhecida como a pressão varia no reservatório, pode-se estimar a vazão do reservatório para o poço, a partir do conhecimento da pressão $p_{i}$ em uma determinada posição, $r_{i}$, assim com o índice do poço.

$$
Q=\frac{1}{\mu}\left[\frac{2 \pi K h}{\ln \left(\frac{r_{i}}{r_{w}}\right)}\right]\left(p_{i}-p_{w}\right) \quad \Rightarrow \quad W I=\frac{2 \pi K h}{\ln \left(\frac{r_{i}}{r_{w}}\right)}
$$

O procedimento numérico utilizado para acoplar o poço com o reservatório através da vazão, consiste em aplicar a equação acima, no bloco resultante da discretização do reservatório, que contenha o poço. Nesse tipo de modelagem, o poço é considerado como um termo fonte na equação existente em um determinado bloco da malha. Neste caso, $p_{i}=p_{o}$ é a pressão no bloco, e $r_{i}=r_{o}$ é denominado de raio equivalente, o qual depende das dimensões $x$ e $y$ do bloco $(\Delta x$ e $\Delta y)$, assim como da permeabilidade. Para poços verticais, $r_{o}$ é dado por Peaceman como:

$$
r_{0}=0,28 \frac{\left[\left(\frac{K_{y}}{K_{x}}\right)^{1 / 2} \Delta x^{1 / 2}+\left(\frac{K_{y}}{K_{x}}\right)^{1 / 2} \Delta y^{1 / 2}\right]^{1 / 2}}{\left(\frac{K_{y}}{K_{x}}\right)^{1 / 4}+\left(\frac{K_{x}}{K_{y}}\right)^{1 / 4}}
$$

onde $K_{x}$ e $K_{y}$ correspondem as permeabilidades nas direções $x$ e $y$.

Para casos onde o poço corta o reservatório com trajetória arbitrária, utiliza-se projeções do poço nos eixos (x , y , z). Nesses casos, utiliza-se o modelo de Peaceman projetado, que consiste em uma generalização do modelo tradicional para o cálculo do WI (Peaceman, 1987, 1990). A ideia principal é que quando um segmento de poço com inclinação qualquer corta um volume de controle qualquer, este é projetado em cada um dos eixos coordenados e assim o modelo tradicional de Peaceman é aplicado a cada projeção.

Essas aproximações de modelo do poço, principalmente em caso de poços inclinados e horizontais simplificam a obtenção da solução do escoamento e determinação da produtividade. Essas hipóteses são vantajosas quando utilizadas na simulação de reservatórios em um campo onde existem diversos poços, mas não deve ser considerada quando o problema em questão é o projeto de um poço, por exemplo, onde a escolha do tipo de completação afetará a produtividade do mesmo.

Simulações mais modernas de CFD, utilizam malhas irregulares e não estruturadas, e apresentam vantagens em relação aos simuladores tradicionais, quando aplicadas para casos de avaliação da produtividade de poços. A ger- 
ação de malha é flexível permitindo a descrição em detalhes das geometrias do poço e da completação. Estes detalhes ocorrem em escalas que são muito pequenas em comparação com os elementos de malha dos simuladores de reservatórios típicos. Essas variáveis têm um grande impacto sobre a produtividade dos poços (Karimi, 2011; Chandra, 2011; Huang, 2010a; Byrne, 2009, 2010, 2011a,b; Zeboudj, 2010; Sun, 2011).

\section{2}

\section{Fator Skin}

Como mencionado, a permeabilidade na região próxima ao poço pode sofrer variações e a permeabilidade a ser utilizada para avaliar o campo de pressão deveria levar isto em consideração. Visando ajustar a permeabilidade dominante na região próxima ao poço, é comum a utilização de um fator de correção chamado de skin factor, $s$, traduzido como "fator de película". Caso as alterações na permeabilidade tenham sido causadas por operações de perfuração e completação de poços, geralmente tem-se diminuição da permeabilidade absoluta do reservatório até uma determinada distância do poço, o que gera um skin positivo. Já quando as alterações são causadas por técnicas de estimulação, o efeito sobre a permeabilidade é oposto, levando a um skin negativo e contribuindo para o aumento da relação entre a vazão do poço e seu diferencial de pressão com o reservatório, ou seja, seu índice de injetividade ou produtividade.

Para se determinar o fator skin de correção de permeabilidade, considerase que a zona alterada é restrita a uma região ao redor do poço, conforme ilustrado na figura 5.1.

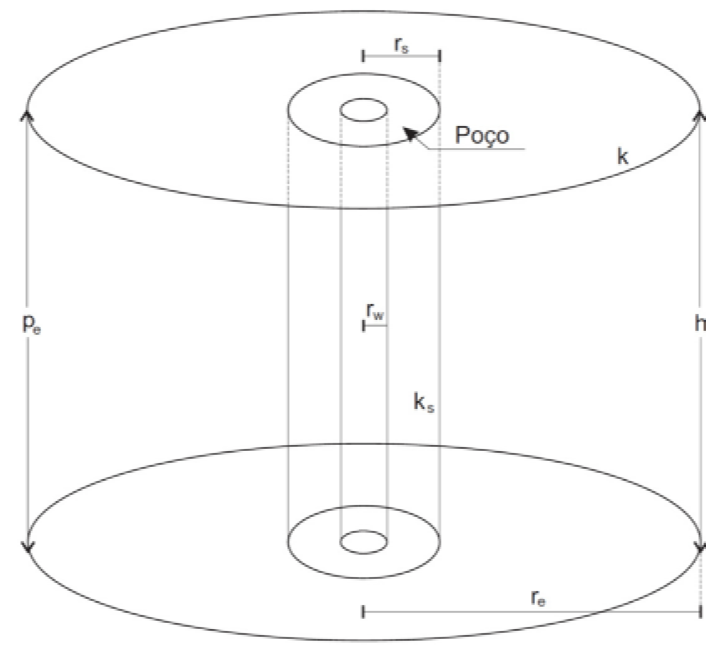

Figura 5.1: Geometria da região modelada pelo fator skin.

O fator skin é um número adimensional que pode ser avaliado a partir 
de testes de pressão em poços. As características da zona de alteração de permeabilidade podem ser equacionadas de forma que se possa encontrar um valor equivalente para a permeabilidade $K_{s}$

$$
\frac{K}{K_{s}}=1+\frac{s}{\ln \frac{r_{s}}{r_{w}}}
$$

O presente desenvolvimento não utiliza a equação do fator de película. A versatilidade do desenho de geometria e da geração de malhas na área de fluido dinâmica computacional pode ser utilizada para desenhar a geometria do dano ao redor do poço de forma generalizada. Pode-se considerar diferentes profundidades e também níveis de heterogeneidade dentro do dano. Qualquer tipo de geometria também pode ser utilizada ao redor do poço para considerar a região do dano. A modelagem proposta aqui pode ser vista em Sun (2011).

\section{3}

\section{Tipos de Completação}

As completações podem ser realizadas de acordo com o revestimento de produção. Tais métodos se referem às configurações básicas poço-formação, aplicáveis a cada situação específica e podem apresentar variações que os tornam bem mais sofisticados. De forma geral quanto ao revestimento de produção, uma completação pode ser:

1. a poço aberto

2. com revestimento canhoneado

3. com liner canhoneado ou rasgado

\subsection{1}

\section{Poço Aberto}

Ese método é aplicável somente a formações totalmente competentes: os embasamentos fraturados, os calcários, dolomitas e os arenitos muito bem consolidados. Também o intervalo produtor não pode ser muito espesso, a menos que a formação produtora tenha características permo-porosas homogêneas e contenha um único fluido.

As principais vantagens do método são: maior área aberta ao fluxo; economia de revestimento e canhoneio; minimiza o dano de formação causado pelo filtrado do fluido de perfuração e da pasta de cimento, já que se pode usar um fluido de perfuração adequado para perfurar a zona produtora, após o assentamento do revestimento de produção. 
A desvantagem mais importante é a impossibilidade de se colocar em produção somente parte do intervalo aberto, visto que não são poucas as vezes em que estão presentes simultaneamente óleo, água e gás, sendo que normalmente o único interesse está na produção do óleo (Garcia, 2010). A figura 5.2 apresenta o esquema de completação a poço aberto.

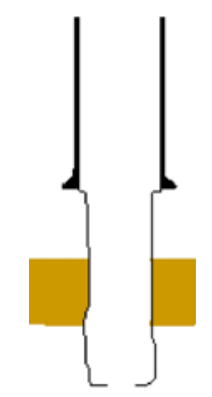

Figura 5.2: Geometria de completação a poço aberto (Garcia, 2010).

\subsection{2}

\section{Poço com Liner}

Quando utiliza-se liner, a coluna de revestimento de produção é assentada e cimentada acima do topo da zona de interesse, prosseguindo-se posteriormente a perfuração até a profundidade final prevista. Avaliada a zona e decidido completar, é descida uma coluna de tubos, os quais podem ser rasgados ou lisos, denominada liner, a qual ficará assentada no fundo do poço e suspensa pela extremidade inferior do revestimento de produção.

As principais vantagens e desvantagens da completação com liner rasgado são similares às do poço aberto. Pode ser acrescida nas vantagens o fato de que sustenta as paredes do poço em frente a zona produtora e nas desvantagens o fato de resultar numa redução do diâmetro do poço frente à zona produtora. Embora em desuso nos poços convencionais, pode encontrar uma boa aplicação em poços horizontais.

No caso de liner com tubos lisos, o qual é cimentado, diferente portanto do liner rasgado, as vantagens e desvantagens são similares ao do revestimento canhoneado. Pode ser acrescida nas vantagens o menor custo com revestimento e nas desvantagens a mudança de diâmetros dentro do poço, gerando dificuldades para passagem de equipamentos (Garcia, 2010). A figura 5.3 apresenta o esquema de completação com liner no poço. 


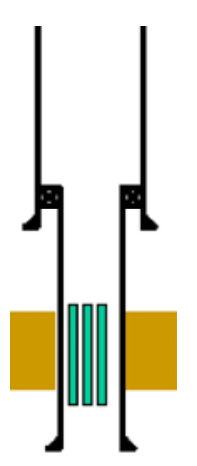

Figura 5.3: Geometria de completação de poço com liner (Garcia, 2010).

\subsection{3}

\section{Poço Revestido Canhoneado}

Perfurado o poço até a profundidade final e avaliada a zona como produtora comercial de óleo e/ou gás, é descido o revestimento de produção até o fundo do poço, sendo em seguida cimentado. Posteriormente é canhoneado o revestimento defronte aos intervalos de interesse mediante a utilização de cargas explosivas, colocando assim o reservatório produtor em comunicação com o interior do poço.

Como grandes vantagens desse método tem-se: permite seletividade, tanto na produção quanto na injeção de fluidos na formação; favorece o êxito das operações de restauração; diâmetro único em todo o poço; permite controlar formações desmoronáveis.

As principais desvantagens do método são: custo do canhoneio; tem sua eficiência dependente de uma adequada operação de cimentação e canhoneio (Garcia, 2010). A figura 5.4 apresenta o esquema de completação de poço revestido canhoneado.

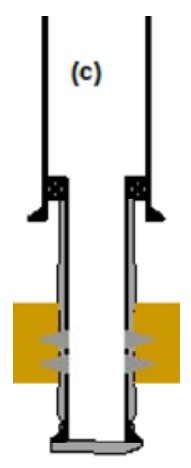

Figura 5.4: Geometria de completação de poço revestido canhoneado (Garcia, 2010). 


\subsection{4}

\section{Modelos de Completação Implementados}

A rotina de perda de carga implementada para o escoamento do poço no presente trabalho leva em consideração dois tipos de completação do poço: poço aberto e revestido-cimentado-canhoneado. A completação a poço aberto pode ser dividida em três tipos: stand-alone não-revestido, stand-alone e gravelpack. A implementação permite que a furação da tela possa ser convencional ou diversiva.

\section{Completação Poço Aberto Não Revestido}

A completação a poço aberto stand-alone não-revestido é simples porque o poço se resume a um furo dentro do reservatório. O fluido escoa para o interior do poço através de toda a área de contato com o reservatório. A única resistência que o fluido encontra é o próprio contato da parede do poço com o reservatório.

Este tipo de completação é utilizada em reservatórios altamente consolidados e quando a base do poço se encontra distante do contato óleo-água, uma vez que não há nenhum tipo de isolamento hidráulico na parede do poço.

A vantagem deste tipo de completação é o seu baixo custo e uma grande área de contato entre poço e reservatório aberta ao fluxo, o que pode promover uma melhor produtividade do poço.

Obviamente, a completação a poço aberto não-revestido não é utilizada em formações inconsolidadas, devido à alta instabilidade mecânica do poço.

\section{Completação Poço Aberto Stand Alone}

Nesse tipo de completação, existe um revestimento ou liner perfurado nãocimentado, em frente ao reservatório, com a única função de manter a estabilidade mecânica do poço. O poço pode, ainda, ao invés do revestimento ou liner, ser equipado com telas de contenção de areia, no caso de formações inconsolidadas.

A furação das telas, revestimento ou liner pode ser convencional, onde os furos para passagem de fluxo são distribuidos uniformemente ao longo da tela, ou diversiva, na qual os furos são dispostos de maneira não-uniforme, de modo a promover uma correção na distribuição de fluxo ao longo do poço. Normalmente, a furação diversiva é utilizada em poços horizontais de longa extensão, onde as perdas de carga ao longo do poço, normalmente, provocam uma distribuição de fluxo concentrada no calcanhar do poço (região próxima ao início do trecho horizontal). 


\section{Completação Poço Aberto com Gravel-Pack}

A completação com gravel-pack, utilizada em formações altamente inconsolidadas, consiste na instalação de telas ou liner ranhurados em frente à zona de interesse, sendo o anular entre tela e parede de poço preenchido com um material granular de alta permeabilidade, que funciona como um filtro para impedir a produção de areia, empacotando o conjunto de telas ou liner ranhurado.

Esse tipo de configuração de poço, para fins de simulação near well, consiste num meio de dupla porosidade, onde, longe do poço o escoamento é regido pelas propriedades permo-porosas do reservatório e, numa pequena região, no espaço anular entre a parede do poço e as telas ou liner, o escoamento sofre a influência da permeabilidade do gravel.

\section{Completação Revestido Cimentado Canhoneado}

Na completação a poço revestido, cimentado e canhoneado, o fluido entra no poço através dos canhoneados, que são pequenos túneis, de comprimentos da ordem de 0,5 metros e diâmetros de 0,5 polegadas, que promovem o contato entre o reservatório e o poço.

Os canhoneados modificam o padrão de fluxo nas proximidades do poço, causando um efeito de linearização do fluxo, apesar de apresentarem uma menor área de contato poço-reservatório em relação à completação a poço aberto.

Alguns modelos matemáticos disponíveis na literatura (Furui, 2005; Karakas, 1991, 1990) propõem a representação do efeito do canhoneio por meio de um fator skin de canhoneio, que pode ser positivo, zero ou negativo, a depender dos parâmetros do canhoneio, tais como, penetração, diâmetro, densidade de jatos e defasagem, além da relação entre as permeabilidades horizontal e vertical do reservatório.

No escopo deste trabalho, os efeitos de canhoneio não são considerados dentro da rotina do escoamento do poço. Considera-se os canhoneios dentro da geometria de CFD. A figura 5.5 apresenta um refino de malha na região próxima do poço detalhando a geometria dos canhoneios.

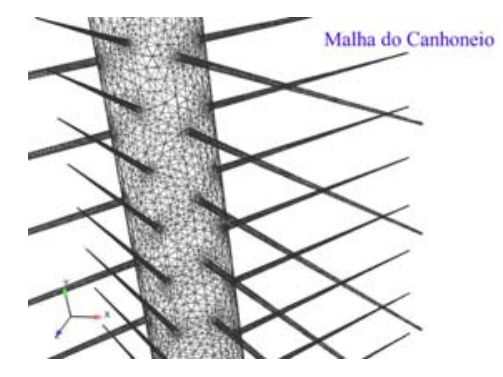

Figura 5.5: Malha detalhando a geometria dos canhoneios em CFD. 


\section{4}

\section{Escoamento no Interior do Poço}

No modelo desenvolvido para determinar o escoamento no interior do poço, considera-se o fluido dentro do poço como compressível, sendo que a viscosidade molecular e massa específica variam com a pressão, da mesma forma que no modelo desenvolvido para prever o escoamento no reservatório.

A equação de conservação da massa unidimensional para o poço é dada por

$$
\frac{\partial \rho}{\partial t}+\frac{\partial(\rho v)}{\partial x}=0
$$

A modelagem implementada considera regime permanente no poço para cada passo de tempo desenvolvido no reservatório, ou seja, o termo transiente pode ser desprezado na equação de continuidade do poço

$$
\frac{\partial(\rho v)}{\partial x}=0
$$

A equação básica para o cálculo do escoamento do fluido é a equação da conservação da quantidade de movimento linear unidimensional, dada por

$$
\rho \frac{D v}{D t}=-\frac{\partial p}{\partial x}-\frac{\tau_{s} S_{s}}{A}-\rho g \sin \theta
$$

onde $v$ é a velocidade ao longo do eixo do poço, direção $x$, com a origem na base do poço, $\rho$ é a massa espécifica que pode ser variável com a pressão $p \mathrm{e}$ $D v / D t$ é aceleração, definida com a derivada material como

$$
\frac{D v}{D t}=\frac{\partial v}{\partial t}+v \frac{\partial v}{\partial t}
$$

$\tau_{s}$ é a tensão viscosa na parede do poço, que possui perímetro $S_{s}, A$ é a área de sua seção transveral, $g$ é a aceleração da gravidade e $\theta$ a inclinação do poço com a horizontal.

Para estimar o atrito viscoso, considera-se o escoamento como localmente desenvolvido e utiliza-se o fator de atrito $f$. A força viscosa por unidade de volume pode então ser escrita como

$$
\frac{\tau_{s} S_{s}}{A}=\rho \frac{f}{2 D} v|v|
$$


onde $D$ é o diâmetro do poço. Note, que o módulo da velocidade é utilizado na equação (5.10) de forma que o atrito viscoso sempre se oponha a direção do escoamento. A equação resultante é

$$
\rho \frac{D v}{D t}=-\frac{\partial p}{\partial x}-\rho \frac{f}{2 D} v|v|-\rho g \sin \theta
$$

Outra forma de avaliar a equação 5.11 é avaliando cada termo como um tipo de perda de carga diferente

$$
\left(\frac{\partial p}{\partial x}\right)_{\text {total }}=\left(\frac{\partial p}{\partial x}\right)_{\text {aceleracao }}+\left(\frac{\partial p}{\partial x}\right)_{\text {friccao }}+\left(\frac{\partial p}{\partial x}\right)_{\text {gravidade }}
$$

No presente trabalho consideu-se escoamento permanente para cada passo de tempo e desprezou-se a aceleração, o que permite estimar a queda de pressão ao longo do poço em função da contribuição viscosa (fricção) e gravitacicional, de acordo com a equação 5.13.

$$
\left(\frac{\partial p}{\partial x}\right)_{\text {total }}=\left(\frac{\partial p}{\partial x}\right)_{\text {friccao }}+\left(\frac{\partial p}{\partial x}\right)_{\text {gravidade }}
$$

Um modelo simplificado para o poço, utilizado pela maioria dos simuladores comerciais, independente de sua configuração, é chamado de Poço de condutividade infinita. Neste casos, considera-se apenas a variação de pressão com relação à profundidade, portanto assume-se que não existe perda de carga dentro do poço. Essa hipótese pode ser aplicada quando a perda de carga do poço é desprezivel em relação a diferença de pressão entre reservatório e poço.

Para avaliar a perda de carga devido a fricção é necesssario definir o fator de atrito $f$, o qual é função do escoamento.

\subsection{1}

\section{Fator de Atrito no Interior do Poço}

O fator de atrito $f$ no interior do poço é estimado considerando escoamento localmente hidrodinamicamante desenvolvido em um duto circular com diâmetro $D$. O fator de atrito depende do número de Reynolds

$$
R e=\frac{\rho|v| D}{\mu} \quad ; \quad|v|=\frac{Q}{\pi D^{2} / 4}
$$


No regime laminar, Re é aproximadamente inferior a 2000, e o fator de atrito pode ser determinado analiticamente sendo igual a

$$
f_{\text {laminar }}=\frac{64}{R e}
$$

Se o número de Reynolds for superior a 4000, o escoamento é considerado turbulento e o fator de atrito é influenciado pela rugosidade do tubo (do poço). Porém, no presente trabalho este efeito foi desprezado e o fator de atrito foi obtido utilizando fórmula de Blasius

$$
f_{\text {turbulento }}=\frac{0,3164}{R e^{1 / 4}}
$$

Para números de Reynolds entre 2000 e 4000 o escoamento é uma transição entre laminar e turbulento completamente desenvolvido. Para facilitar a implementação do fator de atrito, e evitar variações abruptas do mesmo, utilizou-se a expressão para regime laminar até $R e=1187$, e a correlação para regime turbulento para $R e \geq 1187$, onde foi imposto que $f_{\text {laminar }}=f_{\text {turbulento }}$.

\section{4 .2}

\section{Modelagem das Completações do Poço}

Como foi visto, considera-se o escoamento no poço como unidimensional, escoando em regime permanente, porém, ao longo de seu comprimento, ocorre injeção de massa proveniente do reservatório, a qual depende do tipo de completação. A figura 5.6 apresenta a ideia da presente metodologia, utilizando uma analogia com circuito elétrico. O escoamento no interior do poço recebe massa através de sua superfície lateral, a qual é proveniente do reservatório e da região anular que envolve o poço e o separa do reservatório. Para acoplar o reservatório ao poço, impõe-se conservação de massa (ver figura 5.7), tal que

$$
\dot{m}_{p 1}=\dot{m}_{p 2}+\dot{m}_{p e r p}
$$

onde $\dot{m}_{p 1}$ e $\dot{m}_{p 2}$ correspondem as vazões em massa ao longo do comprimento do poço através dos trechos discretizados e $\dot{m}_{\text {perp }}$ a vazão em massa adicionada devido ao fluxo perpendicular ao poço. 


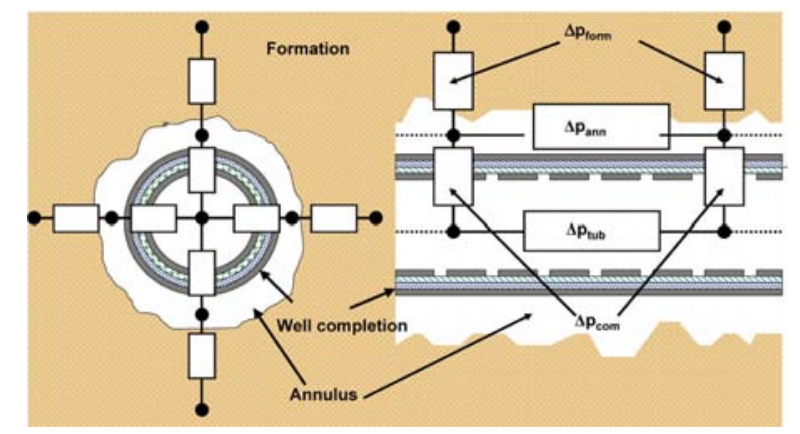

Figura 5.6: Modelos de resistência devido a perda de carga na seção do poço. Figura retirada de Johansen (2007).

No entanto, a vazão $\dot{m}_{\text {perp }}$ depende do tipo de completação empregada, pois o fluido encontrará tipos diferentes de resistência ao seu escoamento. A vazão $\dot{m}_{\text {perp }}$ também deve ser obtida utilizando conservação de massa, sendo igual a

$$
\dot{m}_{\text {perp }}=\dot{m}_{C F D}+\dot{m}_{\text {furos }}+\dot{m}_{\text {anular }}
$$

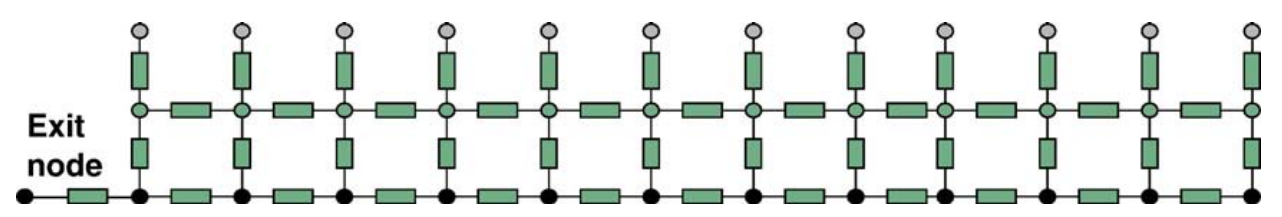

Figura 5.7: Modelos de resistência devido a perda de carga no poço. Figura retirada de Johansen (2007).

A vazão $\dot{m}_{C F D}$, proveniente do reservatório, é obtida diretamente a partir da solução das equações apresentadas no capítulo anterior para obtenção do escoamento no reservatório. Dependendo do tipo de completação, pode haver ou não uma região anular ao redor do poço contendo a presença de furos, o que influenciará na determinação da vazão $\dot{m}_{\text {anular }}$ e $\dot{m}_{\text {furos }}$. A seguir, uma descrição da modelagem do escoamento considerando as completações desenvolvidas no presente trabalho são apresentadas.

\section{Modelagem Poço Aberto Não Revestido}

Considerando que o poço aberto stand-alone não-revestido se resume a um furo dentro do reservatório, a equação de conservação da massa dentro do poço é

$$
\dot{m}_{p 1}-\dot{m}_{p 2}+\dot{m}_{C F D}=0
$$


onde $\dot{m}_{p 1}$ e $\dot{m}_{p 2}$ correspondem as vazões em massa ao longo do comprimento do poço através dos trechos discretizados e $\dot{m}_{C F D}$ a vazão em massa adicionada devido ao fluxo vindo do reservatório através do CFD. A equação de conservação da quantidade de movimento

$$
\frac{d p}{d x}=\frac{1}{2} \frac{f_{p}}{D_{p}}\left(\frac{Q_{p}}{A_{p}}\right)^{2} \quad, \quad A_{p}=\frac{\pi}{4} D_{p}^{2}
$$

onde $A_{d}$ é a área transversal ao escoamento e $D_{p}$ é diâmetro do poço, $Q_{p}$ é a vazão dentro do poço e $f_{p}$ é o fator de atrido dentro do poço.

\section{Modelagem para Poço Aberto Stand Alone}

Para o caso de poço aberto stand-alone, duas regiões de escoamento podem ser identificadas: a região dentro do liner e a região do anular. A equação de continuidade para o liner

$$
\dot{m}_{l 1}-\dot{m}_{l 2}+\dot{m}_{\text {furos }}=0
$$

onde $\dot{m}_{l 1}$ e $\dot{m}_{l 2}$ correspondem as vazões em massa ao longo do comprimento do liner através dos trechos discretizados, $\dot{m}_{\text {furos }}$ a vazão em massa adicionada devido ao fluxo vindo do anular através dos furos. A equação de conservação da quantidade de movimento

$$
\frac{d p}{d x}=\frac{1}{2} \frac{f_{l}}{D_{l}}\left(\frac{Q_{l}}{A_{l}}\right)^{2} \quad, \quad A_{l}=\frac{\pi}{4} D_{l}^{2}
$$

onde $A_{l}$ é a área transversal ao escoamento e $D_{l}$ é diâmetro do liner, $Q_{l}$ é a vazão dentro do liner e $f_{l}$ é o fator de atrido dentro do do liner. A equação de continuidade para a região do anular

$$
\dot{m}_{a 1}-\dot{m}_{a 2}-\dot{m}_{f u r o s}+\dot{m}_{C F D}=0
$$

onde $\dot{m}_{a 1}$ e $\dot{m}_{a 2}$ correspondem as vazões em massa ao longo do comprimento do anular através dos trechos discretizados, $\dot{m}_{\text {furos }}$ a vazão em massa retirada devido ao fluxo saindo do anular através dos furos e $\dot{m}_{C F D}$ a vazão em massa adicionada devido ao fluxo vindo do reservatório calculada através de CFD.

A relação entre a queda de pressão na região anular ao longo do comprimento do poço e a vazão volumétrica $Q_{a n}=\dot{m}_{a n} / \rho$ pode ser obtida utilizando 
um fator de atrito $f_{a n}$, e uma área equivalente para a região anular $A_{e q}$

$$
\frac{d p}{d x}=\frac{1}{2} \frac{f_{a n}}{D}\left(\frac{Q_{a n}}{A_{e q}}\right)^{2} \quad, \quad A_{e q}=\frac{\pi}{4} D_{e q}^{2}
$$

Bourgoyne (1991) sugerem quatro equações para o cálculo do diâmetro equivalente do anular. O presente trabalho utiliza a seguinte equação recomendada pela referência

$$
D_{e q}=\frac{1}{2}\left[\left(D_{p}^{4}-D_{e}^{4}-\frac{\left(D_{p}^{2}-D_{e}^{2}\right)^{2}}{\ln \left(D_{p} / D_{e}\right)}\right)^{1 / 4}-\left(D_{p}^{2}-D_{e}^{2}\right)^{1 / 2}\right]
$$

A vazão vinda do anular para dentro do poço através dos furos, $\dot{m}_{\text {furos }}$, também apresenta uma perda de carga, podendo ser estimada de acordo com Fernandes (2006) pela seguinte equação

$$
Q=\frac{\dot{m}_{\text {furos }}}{\rho}=N_{f} C_{d} d_{f}^{2}\left(\frac{p_{a n}-p}{0,81 \rho}\right)^{1 / 2}
$$

onde $N_{f}$ é o número de furos, $d_{f}$ é o diâmetro dos furos, $C_{d}$ é o coeficiente de descarga e $p_{a n}$ e $p$ são as pressões no espaço anular e no interior do poço.

O coeficiente de descarga é dado pela expressão adimensional (Fernandes, 2006):

$$
C_{d}=\left[1-\exp \left(-2.2 \frac{\left.0.039370079 d_{f}\right)}{\mu^{0.1}}\right)\right]^{2 / 5}
$$

\section{Modelagem para Poço Aberto com Gravel-Pack}

Para o caso de poço aberto com gravel-pack, também temos duas regiões para o escoamento que podem ser identificadas como: a região dentro do liner e a região do anular. No presente caso as equações da região anular diferentem das equações na seção anterior. A equação de continuidade para o liner

$$
\dot{m}_{l 1}-\dot{m}_{l 2}+\dot{m}_{\text {furos }}=0
$$

onde $\dot{m}_{l 1}$ e $\dot{m}_{l 2}$ correspondem as vazões em massa ao longo do comprimento 
do liner através dos trechos discretizados, $\dot{m}_{\text {furos }}$ a vazão em massa adicionada devido ao fluxo vindo do anular através dos furos. A equação de conservação da quantidade de movimento

$$
\frac{d p}{d x}=\frac{1}{2} \frac{f_{l}}{D_{l}}\left(\frac{Q_{l}}{A_{l}}\right)^{2} \quad, \quad A_{l}=\frac{\pi}{4} D_{l}^{2}
$$

onde $A_{l}$ é a área transversal ao escoamento e $D_{l}$ é diâmetro do liner, $Q_{l}$ é a vazão dentro do liner e $f_{l}$ é o fator de atrido dentro do do liner. A equação de continuidade para a região do anular

$$
\dot{m}_{a 1}-\dot{m}_{a 2}-\dot{m}_{\text {furos }}-\dot{m}_{\text {anular }}+\dot{m}_{C F D}=0
$$

onde $\dot{m}_{a 1}$ e $\dot{m}_{a 2}$ correspondem as vazões em massa ao longo do comprimento do anular através dos trechos discretizados, $\dot{m}_{\text {furos }}$ a vazão em massa retirada devido ao fluxo saindo do anular através dos furos, $\dot{m}_{\text {anular }}$ é a vazão na direção radial do anular e $\dot{m}_{C F D}$ a vazão em massa adicionada devido ao fluxo vindo do reservatório calculada através de CFD.

Para a modelagem do escoamento na região anular com gravel, considerou-se o meio como poroso homogêneo e isotrópico, e adotou-se a equação de Darcy para o cálculo da perda de carga. Duas perdas de carga são consideradas: devido ao escoamento longitudinal e radial no gravel. Para o cálculo da vazão devido ao escoamento longitudinal no gravel

$$
Q_{a n}=\frac{\dot{m}_{a n}}{\rho}=-\frac{K_{a n} A_{a n}}{\mu} \frac{\partial p}{\partial x}
$$

onde $K_{a n}$ é a permeabilidade do gravel.

Na equação da vazão do poço horizontal com gravel é necessário considerar a perda de carga entre o gravel e o liner considerando-se o fluxo no gravel radial, tem-se que a equação do fluxo é dada por:

$$
Q_{c}=\frac{2 \pi K L}{\mu\left(\ln \frac{r_{p}}{r_{l}}\right)}\left(p_{a}-p_{f}\right)
$$

A vazão vinda do anular para dentro do poço através dos furos, $\dot{m}_{\text {furos }}$, também apresenta uma perda de carga, podendo ser estimada de acordo com Fernandes (2006) pela seguinte equação 


$$
Q=\frac{\dot{m}_{\text {furos }}}{\rho}=N_{f} C_{d} d_{f}^{2}\left(\frac{p_{a n}-p}{0,81 \rho}\right)^{1 / 2}
$$

onde $N_{f}$ é o número de furos, $d_{f}$ é o diâmetro dos furos, $C_{d}$ é o coeficiente de descarga e $p_{a n}$ e $p$ são as pressões no espaço anular e no interior do poço.

O coeficiente de descarga é dado pela expressão adimensional (Fernandes, 2006):

$$
C_{d}=\left[1-\exp \left(-2.2 \frac{\left.0.039370079 d_{f}\right)}{\mu^{0.1}}\right)\right]^{2 / 5}
$$

\section{Modelagem para Poço Revestido Cimentado Canhoneado}

A modelagem de poço revestido, cimentado e canhoneado, a contabilização da entrada do fluido ocorre através da geometria do modelo de CFD. Os canhoneados são desenhados na malha e promovem o contato entre o reservatório e o poço conforme ilustrado na figura 5.5.

Os canhoneos modificam o padrão de fluxo nas proximidades do poço, causando um efeito de linearização do fluxo. Considerando que o poço aberto stand-alone não-revestido se resume a um furo dentro do reservatório, a equação de conservação da massa dentro do poço é

$$
\dot{m}_{r p 1}=\dot{m}_{r p 2}+\dot{m}_{C F D}
$$

onde $\dot{m}_{r p 1}$ e $\dot{m}_{r p 2}$ correspondem as vazões em massa ao longo do comprimento do revestimento de produção através dos trechos discretizados e $\dot{m}_{C F D}$ a vazão em massa adicionada devido ao fluxo vindo dos canhoneios através do CFD.

A equação de conservação da quantidade de movimento é apresentada da forma

$$
\frac{d p}{d x}=\frac{1}{2} \frac{f_{p}}{D_{r} p}\left(\frac{Q_{r p}}{A_{r p}}\right)^{2} \quad, \quad A_{r p}=\frac{\pi}{4} D_{r p}^{2}
$$

onde $A_{r} p$ é a área transversal ao escoamento e $D_{r p}, Q_{r p}$ e $f_{r p}$ é diâmetro, a vazão e o fator de atrido dentro do revestimento de produção. 


\section{6 \\ Metodologia Numérica}

O presente capítulo apresenta a discretização das equações dos modelos para a contabilização do escoamento no reservatório, ou seja, a equação de difusividade hidráulica e de teoria de média serão apresentadas em sua forma discreta. As metodologias de solução dessas equações também serão apresentadas. A discretização e metodologia de solução para o escoamento no poço também será desenvolvida no presente capítulo. Com o objetivo de mostrar como esses novos modelos podem ser utilizados, uma breve apresentação do software OpenFOAM $\cap$ será feita.

\section{1}

\section{OpenFOAM}

O OpenFOAM® é um software livre, i.e. sem custo de licenças, além de ser um código aberto, ou seja, sem limitações para a implementação de modelos físicos representados por equações diferenciais parciais. O software é versátil, visando a obtenção de soluções de uma grande gama de problemas de fluidodinâmica computacional de forma precisa e eficiente.

O OpenFOAM $\AA$ é baseado no método dos volumes finitos clássico com arranjo co-localizado das variáveis em malhas não-estruturadas, permitindo o uso de malhas poliédricas, malhas móveis e refinamento adaptativo. Permite ainda a utilização de computação paralela massiva para soluções empregando número elevado de volumes de controle. Discretizações de primeira e segunda ordem tanto no tempo como no espaço podem ser utilizadas no software.

Outros fatores relevantes para a escolha do OpenFOAM $\AA$ foi a facilidade para re-utilização de código (library-based implemented) e a linguagem customizada facilitando a implementação de novos modelos (equation mimicking).

A figura 6.1 apresenta a estrutura de pastas do software. O OpenFOAM® não possui uma janela para escolha do setup. Ele é organizado através de pastas e arquivos de texto onde o usuário tem a possibilidade de escolher as equações de transporte adequadas a física simulada, os parâmetros numéricos para o cálculo da solução e as propriedades físicas do problema. 


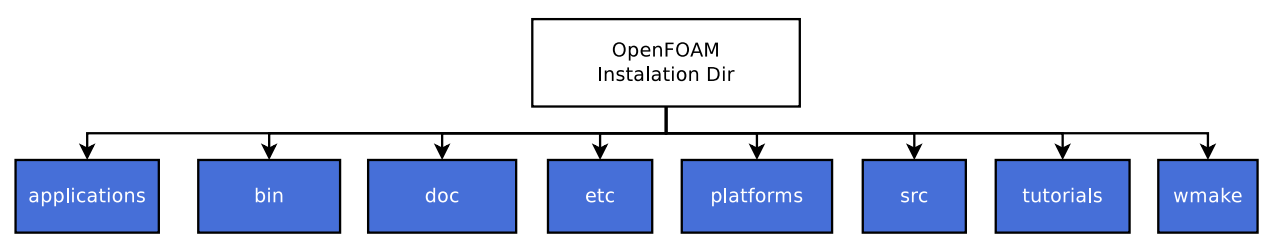

Figura 6.1: Estrutura de diretórios do OpenFOAM@.

O código é implementado em $C^{++}$, utilizando programação orientada à objeto, permitindo facilmente aos usuários implementar suas próprias aplicações e integrá-las facilmente ao conjunto de aplicativos do OpenFOAM@. Novos solvers são organizados em conjunto com os disponíveis na versão utilizada. Todos os solvers desenvolvidos no presente trabalho foram organizados de maneira que qualquer usuário do OpenFOAM $®$ possa utilizá-los.

A figura 6.2 apresenta a estrutura de pastas referente a organização dos solvers do software OpenFOAMß. Observa-se um conjunto de pastas utilitárias (Utilities) referentes a funções de geração de malha, de pré e pósprocessamento, e um segundo conjunto de pastas denominadas de solvers, referentes a implementação das equações de conservação para solução de escoamento incompressíveis, ou escoamentos com troca de calor, ou multifásico, ou na presença de combustão, entre outros.

As rotinas desenvolvidas no presente trabalho foram implementadas utilizando como base os solvers compressíveis do OpenFOAM@. Essas podem estar organizadas em uma nova classe de escoamentos ao lado das físicas descritas na figura 6.2, por exemplo em uma classe chamada porous media.

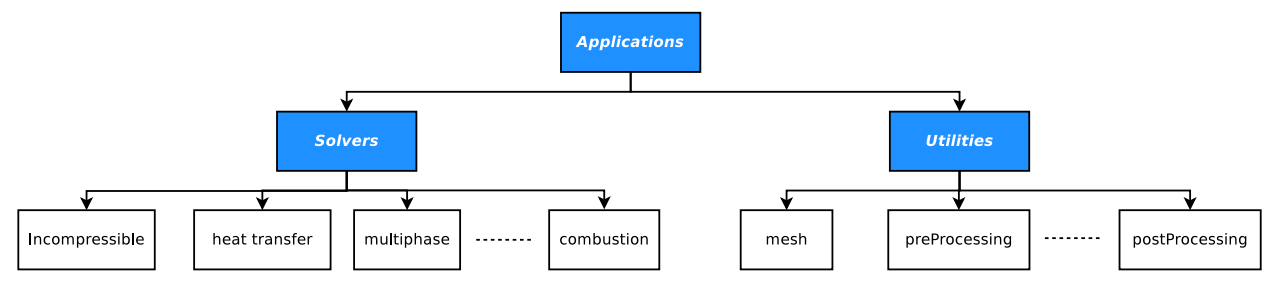

Figura 6.2: Estrutura de diretórios dos solvers do OpenFOAM@.

A figura 6.3 apresenta a organização de pastas e arquivos de um caso específico de simulação. Dentro da pasta system, no arquivo controlDict, o usuário pode escolher os parâmetros numéricos como passo de tempo, tempo inicial e final, frequência de salvamento de resultados, passo de tempo adaptativo, etc. Os esquemas de discretização dos termos das equações são escolhidos no arquivo fvSchemes, como por exemplo, o termo transiente, o esquema de interpolação, o divergente, laplaciano, gradiente, etc. O arquivo fvSolution contém a forma como o sistema linear será resolvido, o valor de residuo das equações, o número de iterações, fatores de relaxação, etc. 
Na pasta constant o usuário seleciona os parâmetros físicos do problema, como os valores de viscosidade, massa específica, permeabilidade, porosidade, gravidade, compressibilidade, etc. As condições iniciais e de contorno das variáveis transportadas são impostas nas pasta 0 . Nas demais pastas em time directories serão encontradas os valores das propriedades físicas e das variáveis calculadas ao longo do tempo.

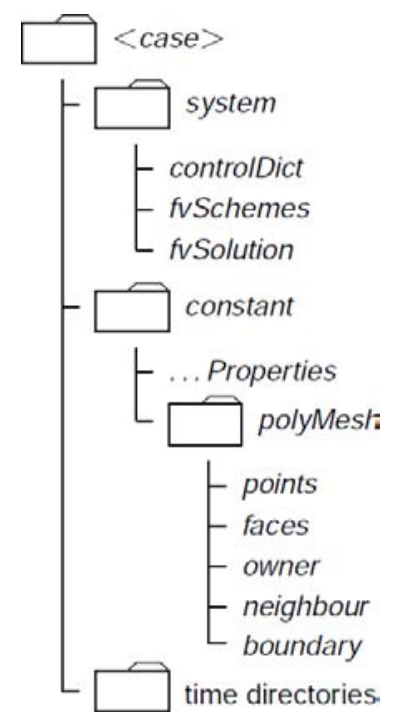

Figura 6.3: Estrutura de diretórios para um caso de simulação no OpenFOAM®.

O método de volumes finitos consiste em discretizar o domínio de solução em volumes de controle, onde cada volume possui um ponto nodal em seu centroide referenciado por $P$, representando o volume elementar, conforme ilustrado na figura 6.4. O volume de controle vizinho é referenciado pelo símbolo $N$. O volume possui faces, referenciadas por $f$. O vetor normal a face $f$ é $\mathbf{n}$, a qual possui área $S_{f}$. As equações de conservação são integradas no tempo e em cada volume, resultando em um sistema de equações discretizadas que representam balanço de cada grandeza de interesse em cada volume.

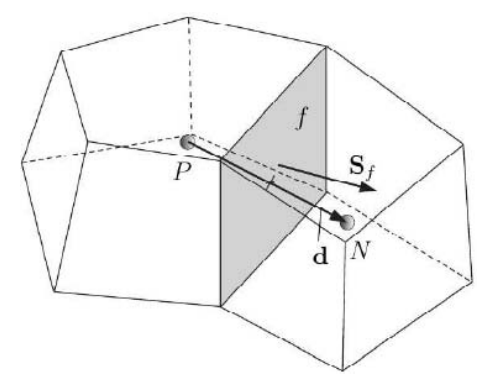

Figura 6.4: Ilustração de duas células poliédricas, $P$ e $N$ compartilhando uma face poligonal $f$, para discretização por volumes finitos. Adaptada de Rushe $(2002)$. 
No método dos volumes finitos com arranjo co-localizado, todos os componentes do vetor velocidade e a pressão são armazenadas no centroide das células. Nas fronteiras do domínio, as variáveis são alocadas no centro das faces. Na avaliação do balanço da grandeza de interesse, é necessário avaliar os fluxos líquidos (que podem ser convectivos e/ou difusivos) nas faces internas da malha, tornando necessário a determinação das variáveis nas faces dos volumes.

Os centróides das células $\left(\mathbf{x}_{P}\right)$ e das faces $\left(\mathbf{x}_{f}\right)$ são definidos de modo a satisfazer

$$
\int_{\forall_{p}}\left(\mathbf{x}-\mathbf{x}_{P}\right) d \forall=0
$$

O vetor área $\mathbf{S}_{f}=S_{f} \mathbf{n}$ aponta da célula $P$ para sua vizinha $N$. O vetor d liga os centróides das células $P$ e $N$, i.e. $\mathbf{d}=\mathbf{x}_{N}-\mathbf{x}_{P}$.

\section{2}

\section{Discretização das Equações para o Reservatório}

Nesta seção será apresentada a discretização de todos os termos das equações de conservação, ou seja, a equação da difusividade hidráulica, a equação média de continuidade e a equação média de quantidade de movimento. O objetivo é solucionar numericamente essas equações para determinar os campos de velocidade e pressão em meios porosos. Conforme apresentado nos capítulos anteriores a equação de difusividade hidráulica é

$$
\Gamma(p) \frac{\partial p}{\partial t}=\nabla \cdot[\gamma \nabla p]+\nabla \cdot[\mathbf{D} \cdot \nabla p-\rho \tilde{\mathbf{K}} \cdot \mathbf{g}]
$$

e as equações obtidas utilizando a teoria da média volumétrica são

$$
\begin{array}{r}
\frac{\partial\left(\phi\left\langle\rho_{\beta}\right\rangle^{\beta}\right)}{\partial t}+\nabla \cdot\left[\phi\left\langle\rho_{\beta}\right\rangle^{\beta}\left\langle\mathbf{v}_{\beta}\right\rangle^{\beta}\right]=0 \\
\frac{\partial\left(\phi\left\langle\rho_{\beta}\right\rangle^{\beta}\left\langle\mathbf{v}_{\beta}\right\rangle^{\beta}\right)}{\partial t}+\nabla \cdot\left[\phi\left\langle\rho_{\beta}\right\rangle^{\beta}\left\langle\mathbf{v}_{\beta}\right\rangle^{\beta}\left\langle\mathbf{v}_{\beta}\right\rangle^{\beta}\right]=-\phi \nabla\langle p\rangle^{\beta} \\
+\phi \nabla \cdot\left[\left\langle\mu_{\beta}\right\rangle^{\beta} \nabla\left\langle\mathbf{v}_{\beta}\right\rangle^{\beta}\right]+\phi \nabla \cdot\left[\left\langle\mu_{\beta}\right\rangle^{\beta}\left(\nabla\left\langle\mathbf{v}_{\beta}\right\rangle^{\beta}\right)^{T}\right] \\
+\phi \nabla\left[\left\langle\lambda_{\beta}\right\rangle^{\beta} \nabla \cdot\left\langle\mathbf{v}_{\beta}\right\rangle^{\beta}\right]+\phi\left\langle\rho_{\beta}\right\rangle^{\beta} \mathbf{g} \\
-\left\langle\mu_{\beta}\right\rangle^{\beta} \phi^{2} \mathbf{K}_{\beta}^{-\mathbf{1}} \cdot\left\langle\mathbf{v}_{\beta}\right\rangle^{\beta}
\end{array}
$$


Estas equações podem ser escritas numa forma geral como

$$
\zeta \frac{\partial \varrho \varphi}{\partial t}+\omega \nabla \cdot \mathbf{J}_{\mathbf{c}}+\varsigma \nabla \cdot \mathbf{J}_{\mathbf{d}}=S, \quad \mathbf{J}_{\mathbf{c}}=\text { Flow } \varphi, \quad \mathbf{J}_{\mathbf{d}}=-\Lambda \nabla \varphi
$$

A equação 6.5 representa a equação da difusividade hidráulica, a equação da continuidade de média e a equação da quantidade de movimento linear média. As tabelas 6.1 e 6.2 apresentam os parâmetros referentes a cada equação especificamente. Essa forma de apresentar as três equações ajudará na explicação da discretização de cada termo das equações desenvolvidas no presente trabalho.

Tabela 6.1: Parâmetros globais para difusividade hidráulica e equação de média de continuidade.

\begin{tabular}{|c|c|c|}
\hline \multicolumn{3}{|c|}{ Parâmetros } \\
\hline Parâmetro & HDF & Média Continuidade \\
\hline$\zeta$ & $\Gamma$ & 1 \\
$\varrho$ & 1 & $\phi\left\langle\rho_{\beta}\right\rangle^{\beta}$ \\
$\varphi$ & $p$ & 1 \\
$\omega$ & 1 & 1 \\
$\varsigma$ & 1 & 1 \\
Flow & 0 & $\phi\left\langle\rho_{\beta}\right\rangle^{\beta}\left\langle\mathbf{v}_{\beta}\right\rangle^{\beta}$ \\
$\Lambda$ & $\gamma$ & 0 \\
$S$ & $\nabla \cdot[\mathbf{D} \cdot \nabla p-\rho \tilde{\mathbf{K}} \cdot \mathbf{g}]$ & 0 \\
\hline
\end{tabular}

Tabela 6.2: Parâmetros globais equação de média de momento.

\begin{tabular}{|c|c|}
\hline \multicolumn{2}{|c|}{ Parâmetros } \\
\hline Parâmetro & Média Momento \\
\hline$\zeta$ & 1 \\
$\varrho$ & $\phi\left\langle\rho_{\beta}\right\rangle^{\beta}$ \\
$\varphi$ & $\left\langle\mathbf{v}_{\beta}\right\rangle^{\beta}$ \\
$\omega$ & 1 \\
$\varsigma$ & $\phi$ \\
Flow & $\phi\left\langle\rho_{\beta}\right\rangle^{\beta}\left\langle\mathbf{v}_{\beta}\right\rangle^{\beta}$ \\
$\Lambda$ & $\left\langle\mu_{\beta}\right\rangle^{\beta}$ \\
$S$ & $-\phi \nabla\langle p\rangle^{\beta}++\phi \nabla \cdot\left[\left\langle\mu_{\beta}\right\rangle^{\beta}\left(\nabla\left\langle\mathbf{v}_{\beta}\right\rangle^{\beta}\right)^{T}\right]+\phi \nabla\left[\left\langle\lambda_{\beta}\right\rangle^{\beta} \nabla \cdot\left\langle\mathbf{v}_{\beta}\right\rangle^{\beta}\right]$ \\
Scont. & $\phi\left\langle\rho_{\beta}\right\rangle^{\beta} \mathbf{g}-\left\langle\mu_{\beta}\right\rangle^{\beta} \phi^{\mathbf{2}} \mathbf{K}_{\beta}^{-\mathbf{1}} \cdot\left\langle\mathbf{v}_{\beta}\right\rangle^{\beta}$ \\
\hline
\end{tabular}

Apresenta-se a discretização no espaço e no tempo de cada termo das equações de conservação, assim como o algoritmo de solução. Como mencionado, a metodologia foi implementada no código aberto OpenFOAM@. Nos códigos, denominados HydraulicDiffusivityFoam e RhoPorousPimpleFoam foram implementadas as equações de difusividade hidráulica e da teoria de média para a determinação de escoamentos em meios porosos, respectivamente. 
Ambos os solvers permitem a determinação de escoamentos em reservatórios homogêneos e heterogêneos, com propriedades termo-físicas constantes ou variáveis.

\subsection{1}

\section{Discretização do Termo Transiente}

O termo transiente das equações de conservação pode ser representado por

$$
\zeta \frac{\partial \varrho \varphi}{\partial t}
$$

Deseja-se realizar a integral no volume e no tempo, porém, primeiramente realiza-se a integral no tempo,

$$
\int_{\forall_{p}} \int_{\Delta t} \zeta \frac{\partial \varrho \varphi}{\partial t} d t d \forall \cong \int_{\forall_{p}} \zeta^{n}\left[\left(\varrho^{n} \varphi^{n}\right)-\left(\varrho^{n-1} \varphi^{n-1}\right)\right] d \forall
$$

onde $n$ representa o instante de tempo atual, para o qual a solução será obtida e $n-1$ corresponde a valores do instante de tempo anterior. Para avaliar a integral de volume, considera-se que as grandezas armazenadas no centroide $P$ do volume de controle prevalecem em todo o volume, resultando na seguinte expressão, após dividir pelo intervalo de tempo $\Delta t$.

$$
\frac{1}{\Delta t} \int_{\forall_{p}} \int_{\Delta t} \zeta \frac{\partial \varrho \varphi}{\partial t} d t d \forall \cong \zeta^{n} \frac{\left[\left(\varrho^{n} \varphi^{n}\right)_{P}-\left(\varrho^{n-1} \varphi^{n-1}\right)_{P}\right]}{\Delta t} \forall_{P}
$$

O termo transiente para a equação de difusividade hidraulica é

$$
\Gamma_{P}^{n} \frac{\forall_{P}}{\Delta t}\left[p_{P}^{n}-p_{P}^{n-1}\right]
$$

Já para o modelo completo, temos para a equação da continuidade

$$
\frac{\forall_{P}}{\Delta t}\left[\left.\phi_{P}^{n}\left\langle\rho_{\beta}\right\rangle^{\beta}\right|_{P} ^{n}-\left.\phi_{P}^{n-1}\left\langle\rho_{\beta}\right\rangle^{\beta}\right|_{P} ^{n-1}\right]
$$

Definindo

$$
a_{P}^{o}=\left.\phi_{P}^{n-1}\left\langle\rho_{\beta}\right\rangle^{\beta}\right|_{P} ^{n-1} \frac{\forall_{P}}{\Delta t} \quad, \quad a_{P}=\left.\phi_{P}^{n}\left\langle\rho_{\beta}\right\rangle^{\beta}\right|_{P} ^{n} \frac{\forall_{P}}{\Delta t}
$$


podemos escrever o termo transiente da equação de conservação de quantidade de movimento como

$$
\left.a_{P}\left\langle\mathbf{v}_{\beta}\right\rangle^{\beta}\right|_{P} ^{n}-\left.a_{P}^{o}\left\langle\mathbf{v}_{\beta}\right\rangle^{\beta}\right|_{P} ^{n-1}
$$

Os solvers desenvolvidos no presente trabalho são implícitos, ou seja, os valores das propriedades são obtidos no próprio passo de tempo. Vale ressaltar que o software OpenFOAM@ resolve as equações de forma segregada, cada variável é resolvida considerando as demais constantes, portanto as propriedades são atualizadas a cada iteração dentro do passo de tempo.

\subsection{2}

\section{Discretização do Fluxo Convectivo}

O operador divergente representa o fluxo líquido por unidade de volume de grandezas de interesse. O fluxo $\mathbf{J}_{\mathbf{c}}$ como apresentado na equação 6.5 representa a parcela convectiva do fluxo líquido

$$
\mathbf{J}_{\mathbf{c}}=\text { Flow } \varphi
$$

A equação da difusividade hidráulica 6.2 não possui fluxo convectivo, i.e. $F L O W=0$ como apresentado na tabela 6.1. Já nas equações macroscópicas de média o fluxo convectivo está presente e precisa ser discretizado. Para equação da continuidade, sendo $\varphi=1$

$$
\mathbf{J}_{\mathbf{c}}=\phi\left\langle\rho_{\beta}\right\rangle^{\beta}\left\langle\mathbf{v}_{\beta}\right\rangle^{\beta}=\text { Flow }
$$

enquanto que a equação de conservação de quantidade de movimento macroscópica média, sendo $\varphi=\left\langle\mathbf{v}_{\beta}\right\rangle^{\beta}$

$$
\mathbf{J}_{\mathbf{c}}=\text { Flow }\left\langle\mathbf{v}_{\beta}\right\rangle^{\beta}
$$

Para avaliar o termo de fluxo convectivo, precisa-se integrar no tempo e no volume. Neste caso, primeiro realiza-se a integral no volume e depois no tempo. 


$$
\int_{\Delta t} \int_{\forall_{P}} \nabla \cdot \mathbf{J}_{\mathbf{c}} d \forall d t
$$

Para avaliar a integral no volume, pode-se utilizar o teorema da divergência de Gauss

$$
\int_{\forall_{P}} \nabla \cdot \mathbf{J}_{\mathbf{c}} d \forall=\oint_{\partial \forall_{P}} \mathbf{n} \cdot \mathbf{J}_{\mathbf{c}} d S \cong \sum_{f} \mathbf{n}_{f} \cdot \mathbf{J}_{\mathbf{c} f} S_{f}
$$

A integração no tempo foi realizada utilizando a aproximação de Euler, totalmente implícita de primeira ordem, isto é

$$
\int_{\Delta t} \mathbf{n}_{f} \cdot \mathbf{J}_{\mathbf{c} f} S_{f} d t=\mathbf{n}_{f} \cdot \mathbf{J}_{\mathbf{c} f}^{n} S_{f} \Delta t
$$

Dessa forma, a integral no tempo e no volume, dividada pelo intervalo de tempo $\Delta t$ é

$$
\frac{1}{\Delta t} \int_{\Delta t} \int_{\forall_{P}} \nabla \cdot \mathbf{J}_{\mathbf{c}} d \forall d t \cong \sum_{f} \mathbf{n}_{f} \cdot \mathbf{J}_{\mathbf{c} f}^{n} S_{f}
$$

\section{Discretização do Termo Advectivo}

Para a avaliação do fluxo líquido convectivo, encontrado nas equações de continuidade e quantidade de movimento para meios porosos, derivado neste trabalho, tem-se

$$
\sum_{f} \mathbf{n}_{f} \cdot \mathbf{J}_{\mathbf{c} f}^{n} S_{f}=\sum_{f} \mathbf{n}_{f} \cdot \text { Flow }^{n} \varphi_{f}^{n} S_{f}=\sum_{f} F_{f} \varphi_{f}
$$

onde $F_{f}$ para a continuidade e equação de movimento macroscópica média é calculado através

$$
F_{f}=\mathbf{s}_{f} \cdot \text { Flow }_{f}=\phi_{f}\left\langle\rho_{\beta}\right\rangle_{f}^{\beta}\left[\left\langle\mathbf{v}_{\beta}\right\rangle_{f}^{\beta} \cdot \mathbf{s}_{f}\right]
$$

onde o vetor $\mathbf{s}_{f}=\mathbf{n}_{f} S_{f}$. 
Para avaliar as grandezas desejadas nas faces, $\varphi_{f}$, como todas as variáveis são armazenadas no centroide do volume de controle, é necessario utilizar algum tipo de interpolação. Para o termo convectivo e para o cálculo as propriedades como porosidade e massa específica, um esquema linear foi utilizado (Patankar, 1981).

$$
\varphi_{f}=f_{x} \varphi_{P}+\left(1-f_{x}\right) \varphi_{N}, \quad f_{x}=\frac{\overline{f N}}{\overline{P N}}
$$

onde $\overline{f N}$ é a distância entre entre o centróide da face $f$ e o centróide do elemento $N$ e $\overline{P N}$ é a distância entre os centróides dos elementos $P$ e $N$, como ilustrado na figura 6.4 .

\subsection{3}

\section{Discretização do Fluxo Difusivo}

Como foi apresentado na seção anterior, o operador divergente representa o fluxo líquido por unidade de volume de grandezas de interesse. Outra parcela importante de fluxo da equação 6.5 é a parte difusiva do fluxo representada por $\mathbf{J}_{\mathbf{d}}$

$$
\mathbf{J}_{\mathbf{d}}=-\Lambda \nabla \varphi
$$

No caso da equação de difusividade hidráulica, o fluxo difusivo é

$$
\mathbf{J}_{\mathbf{d}}=-\gamma \nabla p
$$

e conforme já definido $\varphi=p$ como apresentado na tabela 6.1.

Já no caso das equações de média, a equação da continuidade não possui termo difusivo, sendo $\varphi=1$ e $\Lambda=0$. Enquanto que a equação de conservação de quantidade de movimento média, possui uma parcela difusiva, $\operatorname{com} \varphi=\left\langle\mathbf{v}_{\beta}\right\rangle^{\beta}$ e $\Lambda=\left\langle\mu_{\beta}\right\rangle^{\beta}$

$$
\mathbf{J}_{\mathbf{d}}=-\left\langle\mu_{\beta}\right\rangle^{\beta} \nabla\left\langle\mathbf{v}_{\beta}\right\rangle^{\beta}
$$

Para avaliar o termo de fluxo difusivo, aplica-se um processo análogo através da integral no tempo e no volume do termo. Neste caso, primeiro realiza-se a integral no volume e depois no tempo. 


$$
\int_{\Delta t} \int_{\forall_{P}} \nabla \cdot \mathbf{J}_{\mathbf{d}} d \forall d t
$$

Para avaliar a integral no volume, pode-se utilizar o teorema da divergência de Gauss

$$
\int_{\forall_{P}} \nabla \cdot \mathbf{J}_{\mathbf{d}} d \forall=\oint_{\partial \forall_{P}} \mathbf{n} \cdot \mathbf{J}_{\mathbf{d}} d S \cong \sum_{f} \mathbf{n}_{f} \cdot \mathbf{J}_{\mathbf{d} f} S_{f}
$$

A integração no tempo foi realizada utilizando a aproximação de Euler, totalmente implícita de primeira ordem, isto é

$$
\int_{\Delta t} \mathbf{n}_{f} \cdot \mathbf{J}_{\mathbf{d} f} S_{f} d t=\mathbf{n}_{f} \cdot \mathbf{J}_{\mathbf{d} f}^{n} S_{f} \Delta t
$$

Dessa forma, a integral no tempo e no volume, dividada pelo intervalo de tempo $\Delta t$ é

$$
\frac{1}{\Delta t} \int_{\Delta t} \int_{\forall_{P}} \nabla \cdot \mathbf{J}_{\mathbf{d}} d \forall d t \cong \sum_{f} \mathbf{n}_{f} \cdot \mathbf{J}_{\mathbf{d} f}^{n} S_{f}
$$

\section{Discretização do Termo Difusivo}

Para avaliar o fluxo difusivo é necessario determinar o gradiente da grandeza de interesse nas faces do volume de controle, pois

$$
\sum_{f} \mathbf{n}_{f} \cdot \mathbf{J}_{\mathbf{d} f} S_{f}=\sum_{f} \Lambda_{f} \mathbf{s}_{f} \cdot(\nabla \varphi)_{f}
$$

onde $\mathbf{s}_{f}=\mathbf{n}_{f} S_{f}$.

A avaliação do gradiente de $\varphi$ na face do volume de controle deve ser levada em consideração de forma a resolver a equação 6.30. Analisando a figura 6.4 , se $\mathbf{s}_{f}$ e $\mathbf{d}_{\mathbf{f}}=\overline{P N}$ estão alinhados

$$
\mathbf{s}_{f} \cdot(\nabla \phi)_{f}=\left|\mathbf{s}_{f}\right| \frac{\phi_{N}-\phi_{P}}{\left|\mathbf{d}_{\mathbf{f}}\right|}
$$


onde a propriedade $\Lambda_{f}$ é discretizada através do esquema de diferenças centrais, mantendo $2^{a}$ ordem.

Para malhas não-ortogonais, uma correção $\mathbf{k}$ é adicionada para compensar o ângulo entre o vetor $\mathbf{s}_{f}$ e o vetor $\mathbf{d}_{f}$. Fundamentalmente, o processo consiste na separação da projeção escalar do vetor $\mathbf{s}_{f}=\mathbf{n}_{f} S_{f}$ sobre o vetor $\nabla \varphi$ em uma parcela ortogonal $\boldsymbol{\Delta}$, que é implicitamente avaliada e uma parcela de correção k, que é calculada explicitamente em um processo de correção atrasada. A equação 6.32 mostra a separação da projeção na parte ortogonal e na parcela de correção.

$$
\mathbf{s}_{f} \cdot(\nabla \varphi)_{f} \cong \boldsymbol{\Delta} \cdot(\nabla \varphi)_{f}+\left[\mathbf{k} \cdot(\nabla \varphi)_{f}\right]^{*}
$$

A figura 6.5 ilustra geometricamente o processo de avaliação da não ortogonalidade.

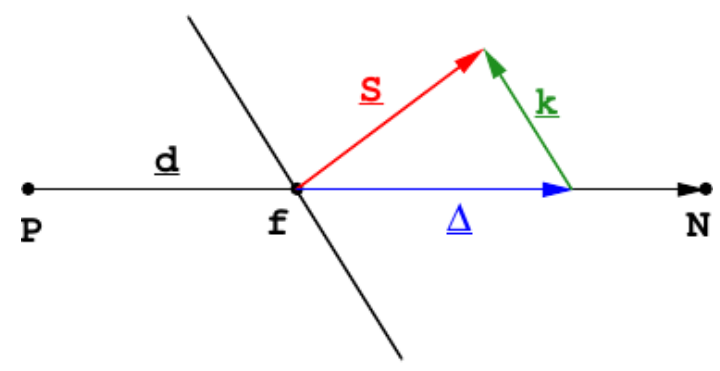

Figura 6.5: Não ortogonalidade entre os vetores que liga os centróides dos elementos e o vetor normal de área. Figura extraída de Jasak (1996).

$\mathrm{O}$ vetor $\mathbf{d}$ une os centroides $P$ e $N$, e o vetor $\mathbf{k}$ corresponde a diferença entre os vetores $\mathbf{S}_{f}$ e $\boldsymbol{\Delta}$ e é definido de acordo com a equação 6.33 (Jasak, 1996).

$$
\Delta=\frac{\mathbf{d} S_{f}}{\mathbf{d} \cdot \mathbf{n}_{f}}
$$

A parcela ortogonal da equação, ou seja, o primeiro termo ao lado direito da equação 6.32 é avaliado implicitamente usando as células vizinhas à face $f$

$$
\Delta \cdot(\nabla \varphi)_{f}=\frac{|\Delta|}{|\mathbf{d}|}\left(\varphi_{N}-\varphi_{P}\right)
$$

Já a parcela não ortogonal, segundo termo ao lado direito da equação 6.32, é tratado explicitamente, sendo denominado pelo OpenFOAMß, de 
termo de correção de não-ortogonalidade da malha. O asteristico na equação 6.32 indica que o termo deve ser tratado explicitamente.

O cálculo do gradiente da variável transportada nas faces pode ser calculado atraves de interpolação linear

$$
\nabla \varphi_{f}=f_{x} \nabla \varphi_{P}+\left(1-f_{x}\right) \nabla \varphi_{N}
$$

onde o gradiente da variável transportada e o valor da variável na face pode ser calculado

$$
\nabla \varphi_{P}=\frac{1}{\forall_{P}} \sum_{f} \varphi_{f} \mathbf{s}_{f} \quad, \quad \varphi_{f}=f_{x} \varphi_{P}+\left(1-f_{x}\right) \varphi_{N}
$$

\subsection{4}

\section{Discretização do Termo Fonte}

O termo de fonte de cada equação de conservação será avaliado aqui, separadamente. Em todos os casos, empregou-se integração de Euler implícita de 1a ordem.

Para avaliar o termo de fonte da equação de difusividade hidraulica, equação 6.2, o teorema de divergencia de Gauss é novamente empregado, resultando em

$$
\begin{array}{r}
\int_{\forall_{P}} \nabla \cdot[\mathbf{D} \cdot \nabla p-\rho \tilde{\mathbf{K}} \cdot \mathbf{g}] d \forall \\
\oint_{\partial} \mathbf{n} \cdot[\mathbf{D} \cdot \nabla p-\rho \tilde{\mathbf{K}} \cdot \mathbf{g}] d S \cong \\
\sum_{\partial} \mathbf{n}_{f} \cdot\left[(\mathbf{D} \cdot \nabla p)_{f}-(\rho \tilde{\mathbf{K}} \cdot \mathbf{g})_{f}\right]^{*} S_{f}
\end{array}
$$

onde o índice sobrescrito * indica uma avaliação explícita do termo usando valores conhecidos da iteração anterior dentro do passo de tempo.

O tensor D e $\tilde{\mathbf{K}}$ são propriedades do reservatório e estão localizados nos centróides dos volumes. Da mesma forma, a propriedade $\rho$ e a variável transportada nessa equação, a pressão $p$, são variáveis alocadas nos centróides das celulas. Para a discretização desses valores foi utilizado um esquema de interpolação linear. Para os valores de $\mathbf{D}, \tilde{\mathbf{K}}$ e $\rho$ 


$$
\varphi_{f}=f_{x} \varphi_{P}+\left(1-f_{x}\right) \varphi_{N}
$$

Para o cálculo do gradiente de pressão nas faces

$$
\nabla p_{f}=f_{x} \nabla p_{P}+\left(1-f_{x}\right) \nabla p_{N}
$$

onde

$$
\nabla p_{P}=\frac{1}{\forall_{P}} \sum_{f} p_{f} \mathbf{s}_{f} \quad, \quad p_{f}=f_{x} p_{P}+\left(1-f_{x}\right) p_{N}
$$

A equação de conservação de massa não possui termo de fonte, mas a equação de conservação de quantidade de movimento linear, equação 6.4, possui três tipos de termos:

(i) termo de fluxo líquido de parcela viscosa, o qual é obtido utilizando o teorema de divergência de Gauss

$$
\begin{array}{r}
\int_{\forall_{P}} \phi \nabla \cdot\left[\left\langle\mu_{\beta}\right\rangle^{\beta}\left(\nabla\left\langle\mathbf{v}_{\beta}\right\rangle^{\beta}\right)^{T}\right] d \forall=\phi_{P} \oint_{\partial \forall_{P}} \mathbf{n} \cdot\left[\left\langle\mu_{\beta}\right\rangle^{\beta}\left(\nabla\left\langle\mathbf{v}_{\beta}\right\rangle^{\beta}\right)^{T}\right] d S \cong \\
\phi_{P} \sum_{f} \mathbf{n}_{f} \cdot\left[\left\langle\mu_{\beta}\right\rangle_{f}^{\beta}\left(\nabla\left\langle\mathbf{v}_{\beta}\right\rangle^{\beta}\right)_{f}^{T}\right] S_{f}
\end{array}
$$

Para a discretização desses valores foi utilizado um esquema de interpolação linear. Para a viscosidade $\left\langle\mu_{\beta}\right\rangle_{f}^{\beta}$

$$
\left\langle\mu_{\beta}\right\rangle_{f}^{\beta}=f_{x}\left\langle\mu_{\beta}\right\rangle_{P}^{\beta}+\left(1-f_{x}\right)\left\langle\mu_{\beta}\right\rangle_{N}^{\beta}
$$

Para o cálculo do gradiente transposto de velocidade nas faces

$$
\left(\nabla\left\langle\mathbf{v}_{\beta}\right\rangle^{\beta}\right)_{f}^{T}=f_{x}\left(\nabla\left\langle\mathbf{v}_{\beta}\right\rangle^{\beta}\right)_{P}^{T}+\left(1-f_{x}\right)\left(\nabla\left\langle\mathbf{v}_{\beta}\right\rangle^{\beta}\right)_{N}^{T}
$$

onde o gradiente transposto de velocidade é calculado a partir da transposta 
do gradiente de velocidade

$$
\left(\nabla\left\langle\mathbf{v}_{\beta}\right\rangle^{\beta}\right)_{P}=\frac{1}{\forall_{P}} \sum_{f}\left\langle\mathbf{v}_{\beta}\right\rangle_{f}^{\beta} \mathbf{s}_{f}, \quad\left\langle\mathbf{v}_{\beta}\right\rangle_{f}^{\beta}=f_{x}\left\langle\mathbf{v}_{\beta}\right\rangle_{P}^{\beta}+\left(1-f_{x}\right)\left\langle\mathbf{v}_{\beta}\right\rangle_{N}^{\beta}
$$

(ii) parcelas volumétricas, as quais são avaliadas no centroide e consideradas constantes no interior do volume de controle

$$
\begin{gathered}
\int_{\forall_{P}} \phi\left\langle\rho_{\beta}\right\rangle^{\beta} \mathbf{g}-\left\langle\mu_{\beta}\right\rangle^{\beta} \phi^{2} \mathbf{K}_{\beta}^{-\mathbf{1}}\left\langle\mathbf{v}_{\beta}\right\rangle^{\beta} \mathbf{d} \forall= \\
{\left[\phi_{P}\left\langle\rho_{\beta}\right\rangle_{P}^{\beta} \mathbf{g}-\left\langle\mu_{\beta}\right\rangle_{P}^{\beta} \phi_{P}^{2} \mathbf{K}_{\beta_{\mathbf{P}}}^{-\mathbf{1}}\left\langle\mathbf{v}_{\beta}\right\rangle_{\mathbf{P}}^{\beta}\right] \forall_{P}}
\end{gathered}
$$

(iii) parcela que envolve gradiente da pressão. A equação 6.4 possui dois termos que envolvem gradiente. Um deles é associado a contribuição viscosa devido a dilatação do elemento de fluido e o segundo é a força de pressão, a qual é muito importante pois é a parcela responsável por forçar o escoamento e acopla os três componentes da equação de conservação de quantidade de movimento.

A integração do gradiente de pressão no volume pode ser realizada utilizando o teorema de Gauss

$$
\int_{\forall_{P}} \phi \nabla p d \forall \approx \phi_{P} \oint_{\partial \forall_{P}} \mathbf{n} p d S \cong \phi_{P} \sum_{f} p_{f} \mathbf{n}_{f} S_{f}
$$

A pressão em cada face da superfície de controle deve ser obtida por interpolação a partir do valor nos centróides das células adjacentes.

$$
p_{f}=f_{x} p_{P}+\left(1-f_{x}\right) p_{N}
$$

O termo associado a contribuição viscosa devido a dilatação do elemento de fluido 


$$
\begin{array}{r}
\left.\int_{\forall_{P}} \phi \nabla\left[\left\langle\lambda_{\beta}\right\rangle^{\beta} \nabla \cdot\left\langle\mathbf{v}_{\beta}\right\rangle^{\beta}\right] d \forall=\phi_{P} \oint_{\partial \forall_{P}} \mathbf{n}\left[\left\langle\lambda_{\beta}\right\rangle^{\beta} \nabla \cdot\left\langle\mathbf{v}_{\beta}\right\rangle^{\beta}\right]\right) d S \cong \\
\phi_{P} \sum_{f}\left[\left\langle\lambda_{\beta}\right\rangle_{f}^{\beta} \nabla \cdot\left\langle\mathbf{v}_{\beta}\right\rangle_{f}^{\beta}\right] \mathbf{n}_{f} S_{f}
\end{array}
$$

Para a discretização do parâmetro $\left\langle\lambda_{\beta}\right\rangle_{f}^{\beta}$

$$
\left\langle\lambda_{\beta}\right\rangle_{f}^{\beta}=f_{x}\left\langle\lambda_{\beta}\right\rangle_{P}^{\beta}+\left(1-f_{x}\right)\left\langle\lambda_{\beta}\right\rangle_{N}^{\beta}
$$

Para o cálculo do divergente de velocidade nas faces

$$
\nabla \cdot\left\langle\mathbf{v}_{\beta}\right\rangle_{f}^{\beta}=f_{x} \nabla \cdot\left\langle\mathbf{v}_{\beta}\right\rangle_{P}^{\beta}+\left(1-f_{x}\right) \nabla \cdot\left\langle\mathbf{v}_{\beta}\right\rangle_{N}^{\beta}
$$

onde o divergente de velocidade é calculado

$$
\nabla \cdot\left\langle\mathbf{v}_{\beta}\right\rangle_{P}^{\beta}=\frac{1}{\forall_{P}} \sum_{f}\left\langle\mathbf{v}_{\beta}\right\rangle_{f}^{\beta} \cdot \mathbf{s}_{f}, \quad\left\langle\mathbf{v}_{\beta}\right\rangle_{f}^{\beta}=f_{x}\left\langle\mathbf{v}_{\beta}\right\rangle_{P}^{\beta}+\left(1-f_{x}\right)\left\langle\mathbf{v}_{\beta}\right\rangle_{N}^{\beta}
$$

É importante ressaltar que grande parte dos termos foram discretizados utilizando um esquema linear de interpolação. A figura 6.4 mostra um caso em que a linha que liga as centróides de duas células adjacentes à face $f$ não passa exatamente pelo centróide desta face. Para os casos em que a linha que liga os centróides de duas células coincide com o centróide da face, o método escolhido de interpolação linear preserva acurácia de $2^{a}$ ordem. Em todos os casos, a interpolação é dada da forma da equação 6.52 .

$$
\varphi_{f}=f_{x} \varphi_{P}+\left(1-f_{x}\right) \varphi_{N} \quad, \quad f_{x}=\frac{\overline{f N}}{\overline{P N}}
$$

onde $\overline{f N}$ é a distância entre o centróide da face $f$ e o centróide do elemento $N$ e $\overline{P N}$ é a distância entre os centróides dos elementos $P$ e $N$, como ilustrado na Figura 6.4.

Em geral, para malhas com elevada anisotropia (i.e. skewness), a linha que liga os centróides dos elementos adjacentes à face $f$ não passa pelo centróide da face. Neste caso, a interpolação linear não preserva $2^{a}$ ordem de acurácia e, 
consequente, a integração de Gauss para o cálculo do gradiente é prejudicada. Para manter a ordem usando esse esquema para o cálculo do gradiente, uma correção explícita deve ser inserida na interpolação das variáveis para a face, denominada skewness correction, conforme procedimento descrito em Moraes (2013).

\section{3}

\section{Metodologia de Solução - Difusividade Hidráulica}

O solver implementado para a solução da equação de difusividade hidráulica foi denominado hydraulicDiffusivityFoam. O algorítimo é capaz de resolver escoamentos em reservatórios de substâncias puras sob condições isotérmicas. Contudo, ele é genérico em relação aos modelos para densidade e viscosidade do fluido como funções de sua pressão, temperatura e composição. A extensão para escoamentos não-isotérmicos de misturas é possível, mas requer a implementação, a nível de programa principal, das equações de energia e espécies químicas da mistura, aproveitando completamente a biblioteca termo-física do OpenFOAM $囚$.

A metodologia de solução da equação de difusividade hidráulica empregada no solver é sintetizada no programa principal dado pela figura 6.6. Os três primeiros arquivos incluídos no escopo global do arquivo (arquivos fvCFD.H, pimpleControl.H e psiThermo.H) contém os protótipos das classes e funções responsáveis, respectivamente, pelo método de volumes finitos, controles do esquema de solução e modelos termo-físicos do OpenFOAM@).

Já os três primeiros arquivos incluídos no escopo local da função (i.e. setRootCase.H, createTime.H e createMesh.H), contém, respectivamente, a declaração do objeto para entrada de dados no OpenFOAMß via linha de comando, a prototipagem das classes e funções para a construção e manipulação da malha temporal e a prototipagem das classes e funções para a construção e manipulação da malha espacial da simulação CFD.

$\mathrm{O}$ arquivo createFields.H contém a declaração dos objetos, variáveis e parâmetros utilizados na simulação. Particularmente, nele são declaradas e construídas as variáveis que fazem parte do processo de solução do modelo, como a densidade, a velocidade, viscosidade, porosidade e pressão. Neste arquivo é também definido o dicionário para entrada de dados relativos às propriedades da formação (meio poroso). O arquivo createPhi.H declara e constrói a variável fluxo $F_{f}=\mathbf{n}_{f} \cdot$ Flow $S_{f}$, a qual é alocada no centróide das faces de cada elemento da malha.

O primeiro loop while controla o avanço temporal da solução. Os dois loops mais internos controlam dois níveis de iterações no passo de tempo. Usual- 


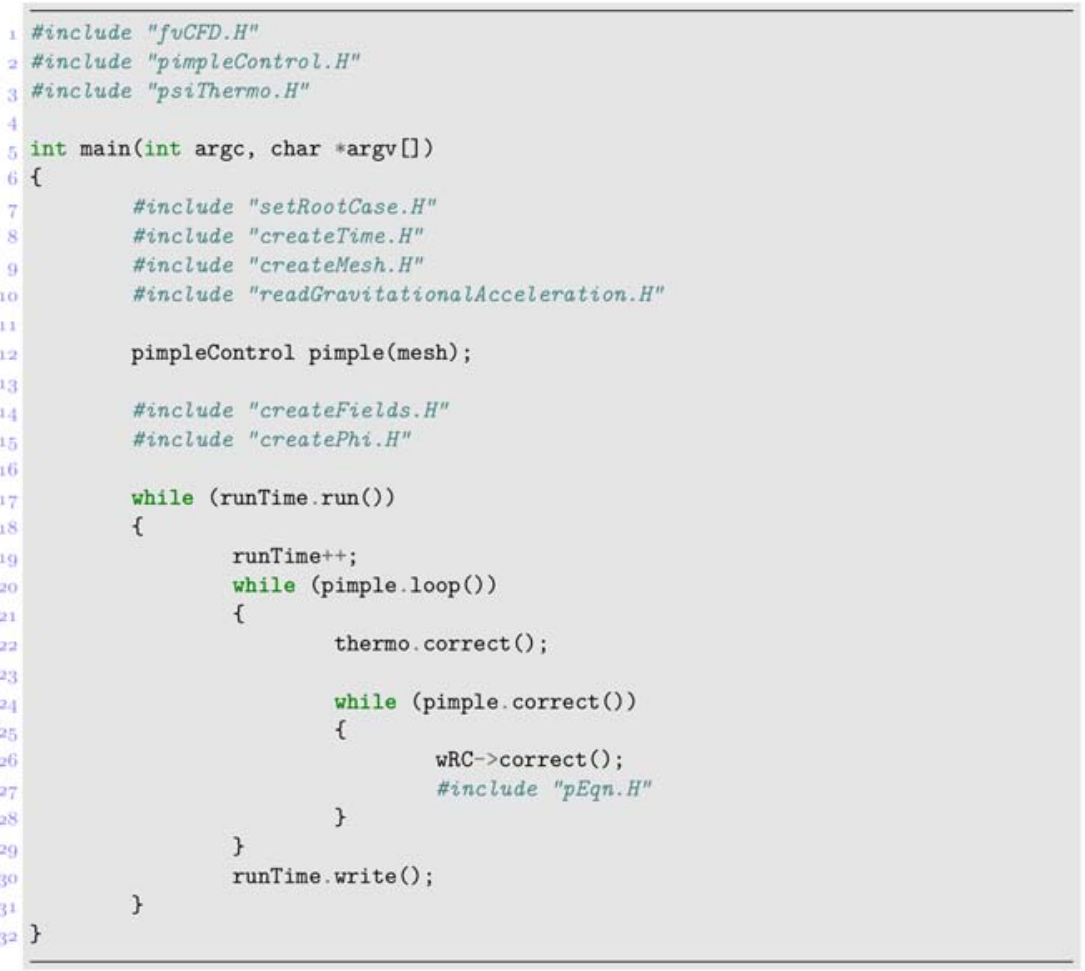

Figura 6.6: Trecho de código do programa principal para solução da equação de difusividade hidráulica.

mente, o loop de iterações mais interno (i.e. pimple.correct()) está presente na solução das equações de Navier-Stokes quando esquemas de acoplamento pressão-velocidade do tipo PISO são utilizados. Já as iterações do loop mais externo (i.e. pimple.loop () ) são utilizadas para convergência do sistema nãolinear de equações dentro do passo de tempo, sendo usualmente denominadas de iterações do algoritmo PIMPLE. No caso do hydraulicDiffusivityFoam, particularmente nas situações em que o acoplamento com o poço não é resolvido, o loop mais interno de correção não é necessário e o usuário pode especificar apenas uma iteração.

A chamada da função thermo.correct() atualiza a biblioteca termodinâmica com os campos de pressão, temperatura e composição, o que é necessário para o cálculo das propriedades termofísicas do fluido. Essa chamada é fundamental, pois a classe thermo (declarada e construída no arquivo createFields.H) é base para as classes de cálculo das propriedades termofísicas do fluido.

Antes da construção e resolução do sistema linear da pressão, a função wRC-correct() é chamada para atualização da condição de contorno de pressão no poço. A sigla wRC foi definida para wellReservoirCoupling. Essa função especifica uma condição de $1^{o}$ tipo não-uniforme para a pressão nas faces de contorno baseado no modelo selecionado pelo usuário para o acoplamento 
poço-reservatório. Três modelos de correção estão atualmente implementados conforme ilustra a figura 6.7.

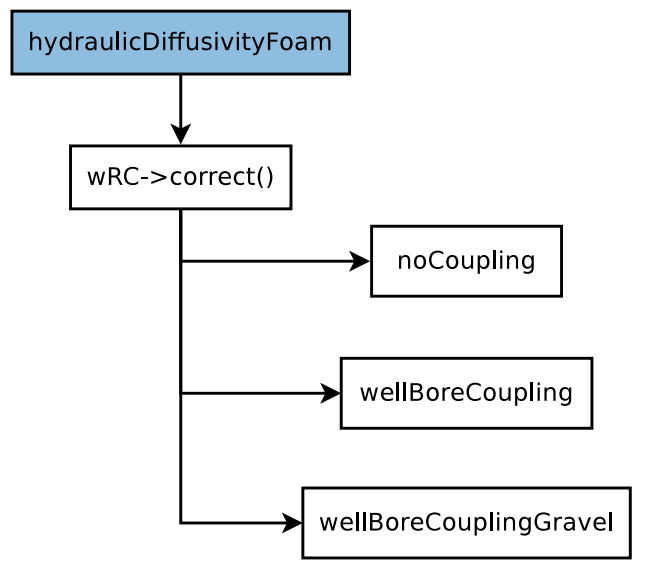

Figura 6.7: Modelos de acoplamento poço-reservatório implementados e disponíveis para uso com o hydraulicDiffusivityFoam.

Para a implementação desses modelos, a classe wellReservoirCoupling foi desenvolvida com o objetivo de fornecer flexibilidade à implementação no nível de programação do solver hydraulicDiffusivityFoam. A wellReservoirCoupling é a classe base para as classes noCoupling, wellBoreCoupling e wellBoreGravelCoupling, cujos nomes representam os modelos que implementam. Especificamente, o modelo noCoupling apenas retorna a pressão já conhecida nas faces do contorno, correspondendo portanto, a situação em que não há acoplamento entre poço e reservatório ou, em outras palavras, poço com condutividade infinita. O modelo wellBoreCoupling calcula a pressão nas faces do poço, o qual é baseado em um balanço de vazões volumétricas em segmentações do poço chamadas anular e liner. Já o modelo wellBoreGravelCoupling faz fundamentalmente a mesma função da wellBoreCoupling, considerando, contudo, uma perda de carga adicional causada pela presença do gravel na região anular do poço.

O conteúdo do arquivo pEqn.H é dado no trecho de código representado na figura 6.8. Os três primeiros termos atualizam os campos de porosidade, densidade e viscosidade. No caso da porosidade, como apenas o modelo à compressibilidade constante foi utilizado, essa atualização foi feita diretamente no programa principal. Por outro lado, a densidade e viscosidade, como já mencionado anteriormente, foram implementadas na biblioteca de modelos termofísicos do OpenFOAM $®$ de modo a conferir generalidade e extensibilidade ao solver. Os modelos para essas propriedades são, portanto, escolhidos pelo usuário no momento de execução do código.

A função thermo.zeta() depende da escolha da equação de estado usada para representar o fluido. Ela foi implementada na biblioteca termodinâmica 
do OpenFOAM $®$ para conferir generalidade ao cálculo da função $\Gamma$ em relação à equação de estado do fluido, além de flexibilidade para desenvolvimento de novas metodologias de solução a nível da programação principal do hydraulicDiffusivityFoam. A figura 6.9 ilustra alguns dos modelos disponíveis para cálculo da viscosidade, densidade e função zeta.

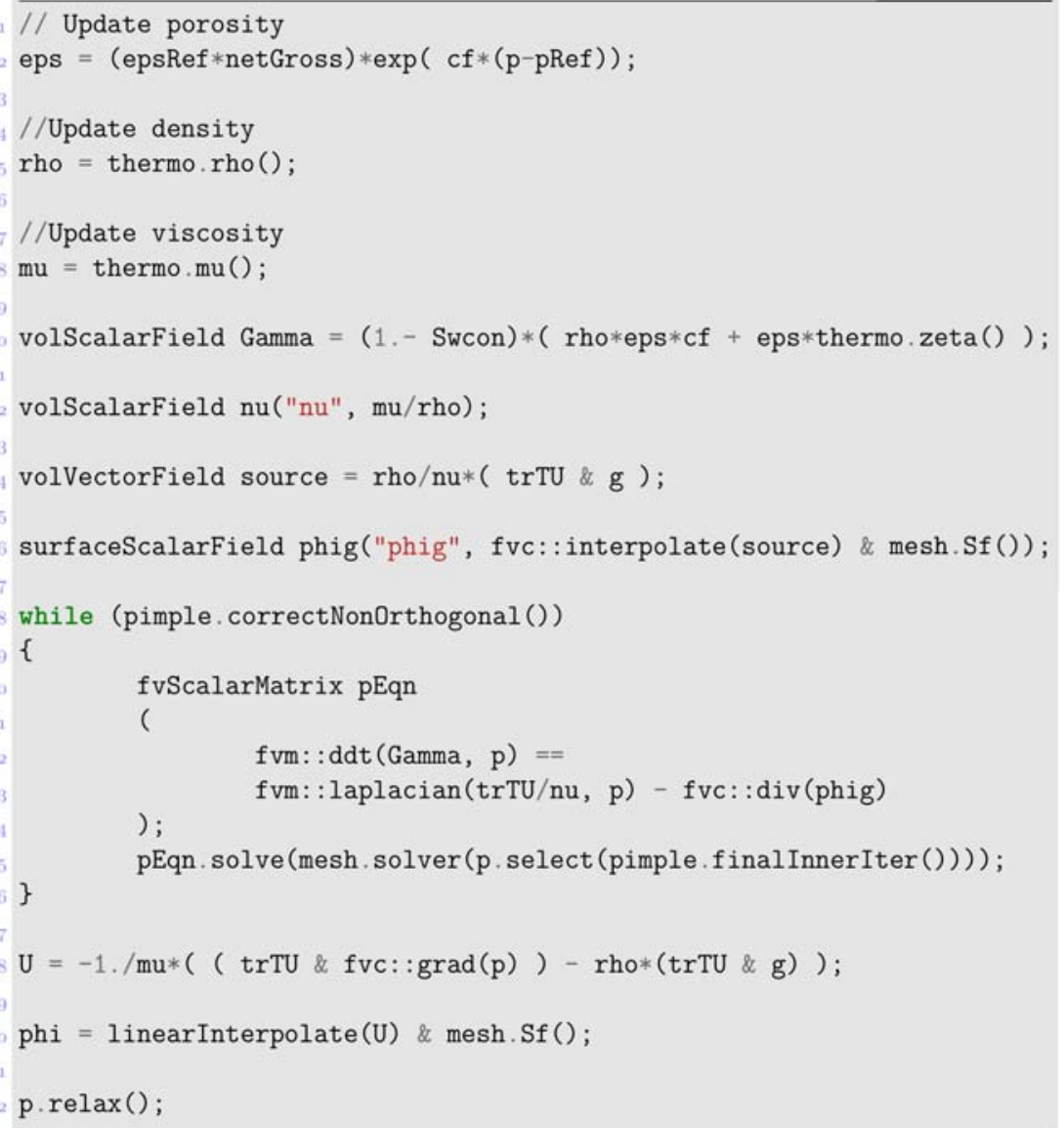

Figura 6.8: Trecho de código do programa principal contendo solução da equação da pressão e avanço do campo de velocidades.

A montagem da matriz de solução da equação da pressão é feita dentro de um loop para correção de não ortogonalidade da malha. O número de iterações desse loop é também controlado pelo usuário devendo ser usado quando a malha numérica do reservatório for constituída por elementos não ortogonais. Essas correções explícitas de não-ortogonalidade são calculadas conforme descrição das seções anteriores (Jasak, 1996; Ferziger, 1995; Moraes, 2013). A escolha dos métodos de discretização do termo transiente (fvm::ddt) e difusivo (fvm::laplacian) pode ser feita em tempo de execução pelo usuário através dos arquivos de configuração do caso de simulação do OpenFOAM@.

Após resolução do sistema linear da pressão, a velocidade e fluxo são atualizados, sendo o cálculo da velocidade feito de acordo com a equação 


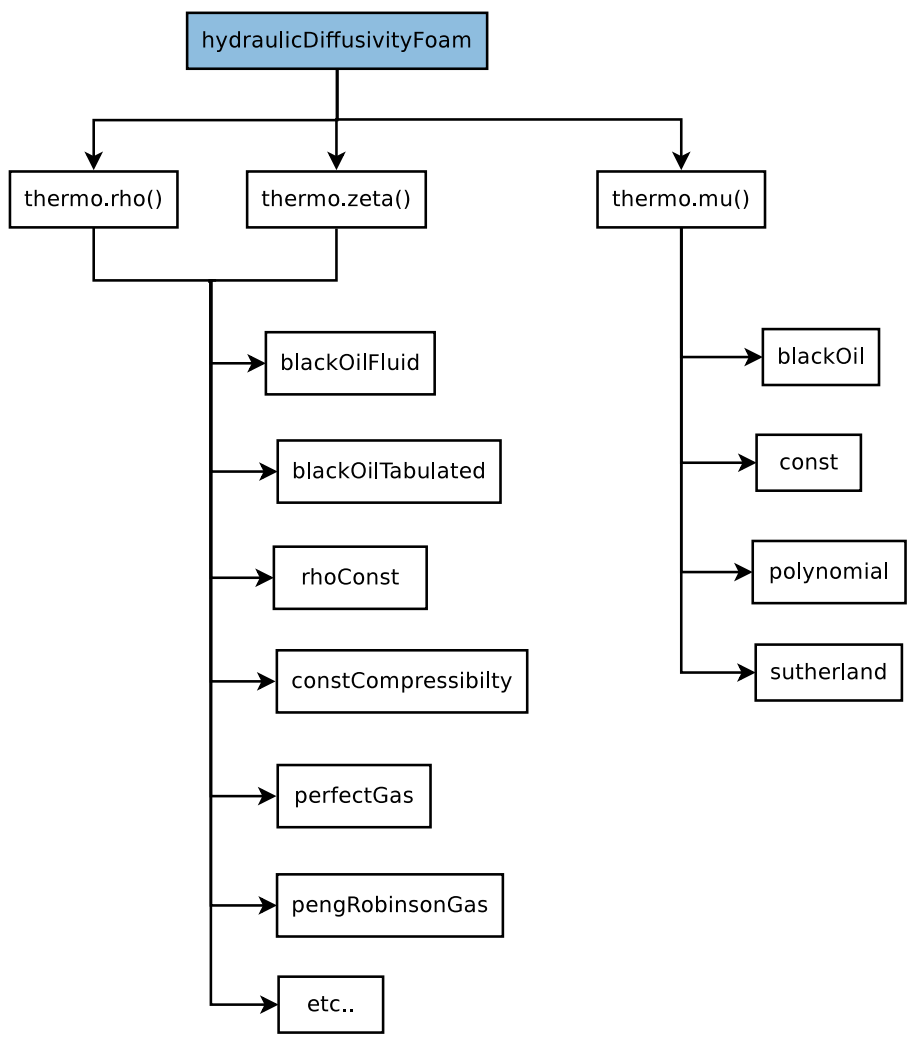

Figura 6.9: Modelos termofísicos disponíveis para uso com o hydraulicDiffusivityFoam.

de Darcy. O esquema para o cálculo do gradiente de pressão é, da mesma maneira, selecionado em tempo de execução pelo usuário através dos arquivos de configuração do caso de simulação.

Por fim, a implementação permite relaxações explícitas no campo de pressão, que podem ser utilizadas para conferir maior estabilidade à simulação em situações de elevadas não-linearidades nas equações. Essas relaxações podem ser realizadas de maneira diferenciada dentro das iterações internas de solução no passo de tempo, possibilitando o usuário variar o fator entre as $n-1$ primeiras iterações e a última iteração do loop pimple.loop(). Essa atribuição diferenciada fornece flexibilidade ao usuário para estabilizar a solução transiente em passos de tempo elevados.

\section{4}

\section{Metodologia de Solução - Teoria de Média para Meios Porosos}

As equações 6.3 e 6.4 apresentam a média volumétrica das equações de conservação de massa e de conservação de quantidade de movimento no meio poroso. É importante ressaltar que foi considerada a formulação baseada na velocidade média intrínseca do fluido no solver, ou seja, a velocidade transportada é a média da velocidade do fluido no espaço ou volume equivalente 
a região fluida do meio poroso.

A equação de média foi desenvolvida de forma a contabilizar modelos para escoamentos compressíveis, não isotérmicos e possibilitando a variação da viscosidade com a pressão e temperatura. O algoritmo de solução do sistema de equações foi adaptado a partir do solver rhoPimpleFoam, o qual é baseado no algoritmo PIMPLE (Merged SIMPLE-PISO) do OpenFOAM@ (Holzmann, 2016). O algoritmo para o cálculo do escoamento é baseado na solução de uma equação para a pressão, a qual é obtida pela imposição da equação de continuidade sobre a equação semi-discretizada da quantidade de movimento.

É importante ressaltar que as equações de média de conservação para meios porosos não podem ser contabilizadas apenas com o acréscimo de um termo fonte na equação de quantidade de movimento linear. As equações médias de continuidade e de quantidade de movimento linear possuim seus termos alterados quando comparados com a equação de Navier-Stokes mais um termo fonte de Darcy. Ou seja, o fato da porosidade aparecer nos termos de fluxo (convectivo e difusivo) das equações de conservação de média, além de alterar a discretização dos termos também altera a metodologia de solução já que a equação de pressão não é mais a mesma.

Logo a equação de pressão do solver PIMPLE no OpenFOAM $囚$, precisou ser aterada no código. No solver rhoPorousPimpleFoam a equação de pressão contabiliza as porosidades de forma adequada.

A forma semi-discretizada da quantidade de movimento é dada pela equação 6.53 .

$$
a_{P} \mathbf{v}_{P}=H-\phi \nabla p
$$

onde $a_{P}$ representa os coeficientes da diagonal principal da matriz de quantidade de movimento, $H$ é o vetor que contém os termos tratados explicitamente na discretização e os termos implícitos associados a parte não diagonal da matriz de quantidade de movimento, como mostra a equação 6.54

$$
H=\sum_{N} a_{N} \mathbf{v}_{N}+\frac{(\rho \phi \mathbf{v})_{P}^{0} V_{P}}{\Delta t}+B^{0}
$$

onde o termo $B^{0}$ agrupa os termos de discretização da quantidade de movimento que são tratados explicitamente no processo de solução, i.e. contribuem no vetor independente do sistema linear de equações da quantidade de movimento. O índice sobre-escrito "0" indica a avaliação dos termos usando valores 
conhecidos da variável na iteração e/ou passo de tempo atual.

Como mencionado, a equação da pressão precisou ser modificada no software devido a presença das porosidades adicionais em relação à equação de Navier Stokes. A equação 6.54 foi multiplicada por $\rho \phi$ e aplicando o operador divergente sobre a equação resultante, obtém-se:

$$
\nabla \cdot\left[\left(\rho \phi \mathbf{v}_{P}\right)\right]=\nabla \cdot\left[\frac{\rho \phi H}{a_{P}}\right]-\nabla \cdot\left[\frac{\rho \phi^{2}}{a_{P}} \nabla p\right]
$$

Substituindo a equação 6.3 ao lado esquerdo da equação 6.55 , obtemos a equação 6.56 .

$$
\Gamma(p) \frac{\partial p}{\partial t}=\nabla \cdot\left[\frac{\rho \phi H}{a_{P}}\right]-\nabla \cdot\left[\frac{\rho \phi^{2}}{a_{P}} \nabla p\right]
$$

onde,

$$
\Gamma(p)=p \frac{\partial \psi}{\partial p}+\psi \quad, \quad \rho=\psi p
$$

A função $\psi$ é uma função de estado genérica que relaciona a densidade e a pressão do fluido. Na equação 6.56 não foi considerado a variação da porosidade com o tempo ou como uma função explícita da pressão, mas ela é tratada neste trabalho como uma distribuição no espaço cartesiano. Uma vez que a equação da pressão foi deduzida pela imposição da equação da continuidade, a solução obtida desta equação permite calcular um fluxo conservativo, dado pela equação 6.58

$$
(\rho \mathbf{v})_{f} \cdot \mathbf{s}_{f}=\left(\frac{\rho H}{a_{P}}-\frac{\rho \phi}{a_{P}} \nabla p\right)_{f} \cdot \mathbf{s}_{f}
$$

onde $\mathbf{s}_{f}$ são os vetores normais às faces dos volumes de controle, com magnitude igual à área da face.

A figura 6.10 apresenta um trecho simplificado do código para a solução do escoamento descrito pela modelagem desta seção. O primeiro loop while controla o avanço temporal da solução. Os dois loops mais internos controlam dois níveis de iterações no passo de tempo. O loop de iterações mais interno (i.e. pimple.correct()) está presente na solução das equações de Navier-Stokes quando esquemas de acoplamento pressão-velocidade do tipo PISO são utilizados. Já as iterações do loop mais externo (i.e. pimple.loop()) são utilizadas para convergência do sistema não-linear de equações dentro do passo de tempo, 
sendo usualmente denominadas de iterações do algoritmo PIMPLE (Holzmann, 2016).

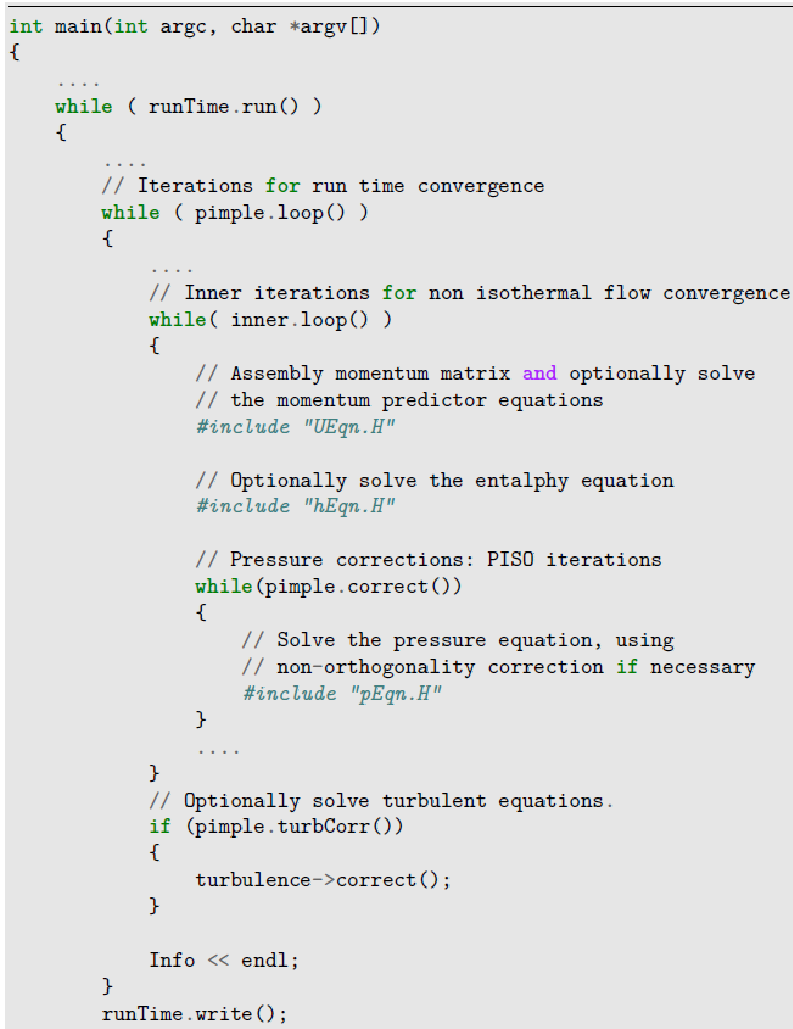

Figura 6.10: Trecho de código do programa principal para solução das equações de conservação de média em meios porosos.

\section{5}

\section{Discretização e Metodologia de Solução da Equação no Poço}

A figura 6.11, ilustra um esquema da região do poço. O poço corresponde a região perfurada da rocha do reservatório. Como foi visto no capítulo 5 , dependendo do tipo de completação o furo no reservatório pode conter uma tubulação em seu interior, denominada liner. Este tubo é perfurado de forma a permitir o fluxo do reservatório para o seu interior. Como este tubo (liner) possui diâmetro menor do que o orifício aberto na rocha, uma região anular é formada entre o liner e o reservatório propriamente dito. A extremidade final do poço é conhecida como dedão e a extremidade inicial da região horizontal é conhecida como calcanhar. O liner pode possuir trechos sem furos, os quais são denominados de "segmentos cegos". A região anular pode estar preenchida ou não por material permeável, material conhecido como gravel.

A figura 6.11 apresenta a malha unidimensional do poço, ou seja, como o poço é discretizado em pequenos segmentos ao longo de seu comprimento 
para o cálculo do escoamento. Na formulação utilizada no presente trabalho admiti-se que as faces referentes ao dedão e as faces do anular no calcanhar são impermeáveis.

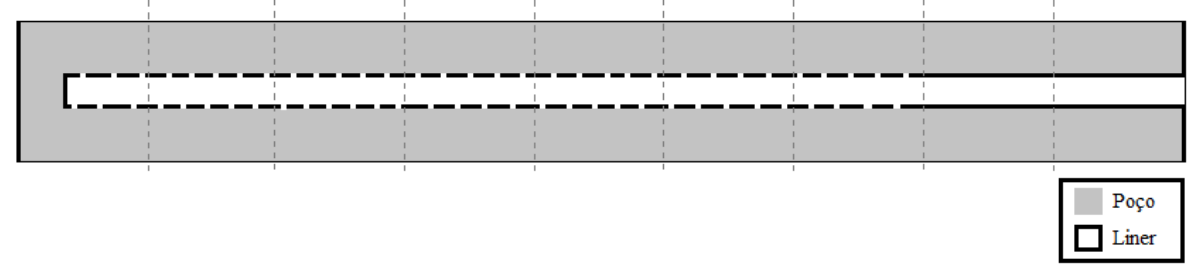

Figura 6.11: Modelo de segmentos do poço.

Os detalhes da construção da rotina, bem como o método numérico utilizado para o escoamento no poço é apresentado na presente seção. O cálculo da distribuição de pressão no liner é importante, pois esta afeta a distribuição da pressão na região do anular e, consequentemente, na parede do poço que está em contato com o reservatório.

O acoplamento entre o poço e reservatório é realizado através da condição de contorno de pressão na parede do poço, necessária para a determinação do escoamento no reservatório. A partir do campo calculado no reservatório, calcula-se a vazão que chega no poço. Com o valor dessa vazão, a perda de carga necessária para transportar esse fluxo pelo poço é avaliada, resultando em um novo perfil de pressão para parede do poço. Esse novo perfil de pressão é imposto como nova condição de contorno para o reservatório. Este é o procedimento para cada iteração até atingir-se a convergência dentro de um passo de tempo.

\subsection{1}

\section{Discretização do Poço Aberto com Liner sem Gravel}

O poço aberto com liner sem gravel será subdividido em duas regiões: interior do liner e região anular (ver figura 6.12), onde a região em cinza compreende a região do anular e a região em branco a região do liner. Assume-se que por trecho, pode-se escrever o balanço de vazão com apenas os valores para as pressões dentro do liner e dentro do anular. As figuras também ilustram a metodologia utilizada para numerar os nós corespondentes a cada segmento do poço. No caso sem gravel a numeração é inicializada no interior duto (liner), passando para a região anular. 


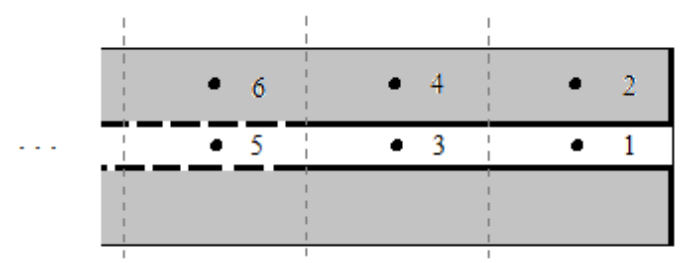

Figura 6.12: Numeração para poço aberto com liner sem Gravel.

Para descrever a perda de carga dentro do poço com liner sem gravel, ou seja, descrever o escoamento dentro do liner e anular, utilizou-se um balanço de vazão mais a equação de perda de carga em duto. Para um trecho genérico, o balanço de vazão pode ser expresso pela equação 6.59.

$$
\Sigma_{i} Q_{i}=0
$$

Para um trecho genérico, a equação que relaciona a vazão com a pressão para o escoamento dentro do liner

$$
Q_{l}=A_{l}\left[\frac{\left(p_{i+1}-p_{i}\right)}{\left(x_{i+1}-x_{i}\right)} \frac{2 D_{l}}{f \rho}\right]^{1 / 2}
$$

Já a equação que relaciona a vazão com a pressão para o escoamento dentro do anular é

$$
Q_{a}=A_{e q}\left[\frac{\left(p_{i+1}-p_{i}\right)}{\left(x_{i+1}-x_{i}\right)} \frac{2 D_{e q}}{f \rho}\right]^{1 / 2}
$$

A equação que relaciona a vazão dos furos que conecta as regiões do anular ao liner

$$
Q_{i}=N_{f} C_{d} d_{f}^{2}\left(\frac{p_{a n}-p_{l}}{0,81 \rho}\right)^{1 / 2}
$$

Em um trecho genérico, as vazões podem ser obtidas em função das pressões, as quais encontram-se ilustradas na figura 6.13, onde a seta verde na figura indica o sentido arbitrário assumido para o fluxo. Para um trecho $\mathrm{n}$ a variável de pressão dentro do liner é indexada por 2n-1 e a do anular por 2n. Na figura 6.13 indexaram-se as variáveis por i e i+1, respectivamente. 


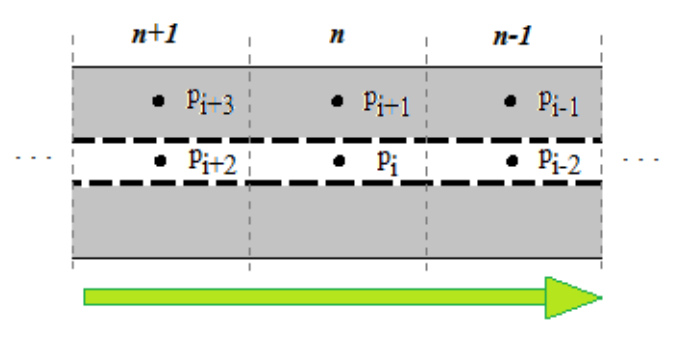

Figura 6.13: Trecho genérico de poço aberto com liner sem Gravel.

Portanto, para o escoamento dentro do liner, a equação de balanço que equilibra a vazão é a equação 6.63

$$
\begin{aligned}
& A_{l}\left[\frac{\left(p_{i+2}-p_{i}\right)}{\overline{\Delta x}_{i}^{i+2}} \frac{2 D_{l}}{\bar{f} \bar{\rho}}\right]^{1 / 2}+N_{f} C_{d} d_{f}^{2}\left(\frac{p_{i+1}-p_{i}}{0,81 \rho}\right)^{1 / 2} \\
&-A_{l}\left[\frac{\left(p_{i}-p_{i-2}\right)}{\overline{\Delta x}_{i-2}^{i}} \frac{2 D_{l}}{\bar{f} \bar{\rho}}\right]^{1 / 2}=0
\end{aligned}
$$

Portanto, para o escoamento dentro do anular, considerando a vazão que entra no poço pelo reservatório como $q_{i}$, a equação de balanço que equilibra a vazão é a equação 6.64

$$
\begin{aligned}
A_{e q}\left[\frac{\left(p_{i+3}-p_{i+1}\right)}{\overline{\Delta x}_{i+1}^{i+3}} \frac{2 D_{e q}}{\bar{f} \bar{\rho}}\right]^{1 / 2} & +q_{i}-N_{f} C_{d} d_{f}^{2}\left(\frac{p_{i+1}-p_{i}}{0,81 \rho}\right)^{1 / 2} \\
& -A_{e q}\left[\frac{\left(p_{i+1}-p_{i-1}\right)}{\overline{\Delta x}_{i-1}^{i+1}} \frac{2 D_{e q}}{\bar{f} \bar{\rho}}\right]^{1 / 2}=0
\end{aligned}
$$

É importante ressaltar que a perda de carga no anular ao longo da direção radial é desprezada nesse caso, portanto os valores de $p_{i+3}, p_{i+1}$ e $p_{i-1}$ são os valores da pressão retornadas ao reservatório através das faces do poço. Vale ressaltar que caso o segmento de poço seja cego, ou seja, sem furos, o valor de $N_{f}$ é igual a zero para aquele segmento.

Os símbolos sinalizados com barra referem-se a médias. Por exemplo, o termo referente ao comprimento do trecho $\overline{\Delta x}$, é tido na verdade como a média entre os trechos adjacentes. Por exemplo, no caso de $i$ e $i+2$, toma-se na verdade o comprimento $\overline{\Delta x}_{i}^{i+2}=1 / 2\left(\Delta x_{i+2}+\Delta x_{i}\right)$ para calcular a perda de carga no liner. De forma semelhante é feito para $f$ e $\rho$ no mesmo trecho, porém usando os valores $p_{i+2}$ e $p_{i}$. 
A essa altura vale ressaltar o problema intrínseco das equações 6.63 e 6.64 . Da forma que estão formuladas, estas simplesmente preferenciam um sentido para o escoamento, que seria do dedão do poço para o calcanhar do mesmo. Contudo, sabe-se que pode haver trechos em que a vazão de óleo não ocorrerá necessariamente assim. Se as equações acima fossem implementadas dessa forma, encontrar-se-ia, para alguns trechos, diferenças de pressão negativas e vazões imaginárias. Logo, as equações precisam ser implementadas de forma geral, independente do sentido do escoamento. Para corrigir esse empecilho, define-se o modulo da diferença de pressão e usa-se a função sinal (sign function), conforme apresentado na equação 6.65 .

$$
\Delta \bar{p}_{i j}=\left|p_{i}-p_{j}\right| \quad, \quad \operatorname{Sign}\left[\Delta \bar{p}_{i j}\right]=\frac{\Delta \bar{p}_{i j}}{p_{i}-p_{j}}
$$

Dessa forma pode-se reescrever as equações para escoamento dentro do liner e anular para o poço aberto com liner sem gravel

$$
\begin{array}{r}
\operatorname{Sign}\left[\Delta \bar{p}_{i+1}^{i+3}\right] A_{e q}\left[\frac{\left(p_{i+3}-p_{i+1}\right)}{\overline{\Delta x}_{i+1}^{i+3}} \frac{2 D_{e q}}{\bar{f} \bar{\rho}}\right]^{1 / 2}+q_{i} \\
-\operatorname{Sign}\left[\Delta \bar{p}_{i}^{i+1}\right] N_{f} C_{d} d_{f}^{2}\left(\frac{p_{i+1}-p_{i}}{0,81 \rho}\right)^{1 / 2} \\
-\operatorname{Sign}\left[\Delta \bar{p}_{i-1}^{i+1}\right] A_{e q}\left[\frac{\left(p_{i+1}-p_{i-1}\right)}{\overline{\Delta x}_{i-1}^{i+1}} \frac{2 D_{e q}}{\bar{f} \bar{\rho}}\right]^{1 / 2}=0
\end{array}
$$




\section{5 .2}

\section{Discretização do Poço Aberto com Liner com Gravel}

Da mesma forma que na seção anterior em relação a divisão de regiões, o poço aberto com liner com gravel será subdividido em duas regiões: interior do liner e região anular (ver figura 6.14). A diferença é que agora, três pressões por trecho são utilizadas para escrever o balanço de vazão: as pressões dentro do liner, na superfície do liner, ou seja, em seus furos, e na superfície externa do anular. Isso ocorre porque a perda de carga na direção radial no anular não é mais desprezível. A figura 6.14 também ilustra a metodologia utilizada para numerar os nós correspondentes a cada segmento do poço para o caso com gravel. A numeração é iniciada no interior do liner, passando pela superfície do liner e chega na na superfície externa da região do anular.

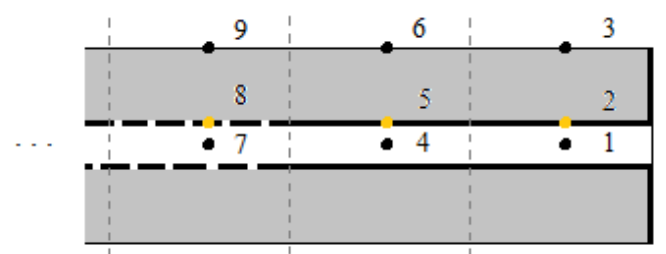

Figura 6.14: Numeração para poço aberto com liner com gravel.

Para descrever a perda de carga dentro do poço com liner com gravel, ou seja, descrever o escoamento dentro do liner e anular, utiliza-se um balanço de vazão mais a equação de perda de carga em duto (liner) e perda de carga pela equação de Darcy (gravel). Para um trecho genérico, o balanço de vazão pode ser expresso pela equação 6.68 .

$$
\Sigma_{i} Q_{i}=0
$$

Para um trecho genérico, a equação que relaciona a vazão com a pressão para o escoamento dentro do liner

$$
Q_{l}=A_{l}\left[\frac{\left(p_{i+1}-p_{i}\right)}{\left(x_{i+1}-x_{i}\right)} \frac{2 D_{l}}{f \rho}\right]^{1 / 2}
$$

A equação que relaciona a vazão com a pressão para o escoamento dentro do anular para fluxo longitudinal é a equação de Darcy

$$
Q_{a l}=\frac{K A_{e q}}{\mu} \frac{\left(p_{i+1}-p_{i}\right)}{\left(x_{i+1}-x_{i}\right)}
$$


A equação que relaciona a vazão com a pressão para o escoamento dentro do anular para fluxo radial é a equação de Darcy

$$
Q_{a r}=\frac{2 \pi K}{\mu} \frac{\left(p_{a}-p_{l}\right)}{\ln \frac{r_{p}}{r_{l}}}
$$

onde $r_{p}$ e $p_{p}$ é o raio do poço e a pressão nas paredes do poço e $r_{l}$ e $p_{l}$ é o raio do liner e a pressão na superfície do liner.

Já a equação que relaciona a vazão dos furos que conecta as regiões do anular ao liner

$$
Q_{i}=N_{f} C_{d} d_{f}^{2}\left(\frac{p_{a n}-p_{l}}{0,81 \rho}\right)^{1 / 2}
$$

Semelhante ao caso anterior, pode-se admitir, em um trecho genérico, que as vazões que compõem o balanço podem ser obtidas utilizando a distribuição de pontos de pressão conforme ilustrado na figura 6.15 , onde a seta verde na figura indica o sentido arbitrário assumido para o fluxo. Ressalva-se que caso anterior necessitava de apenas duas variáveis por trecho, agora são necessárias três, ou seja, valores para as pressões dentro do liner, nos furos e na parede externa do anular.

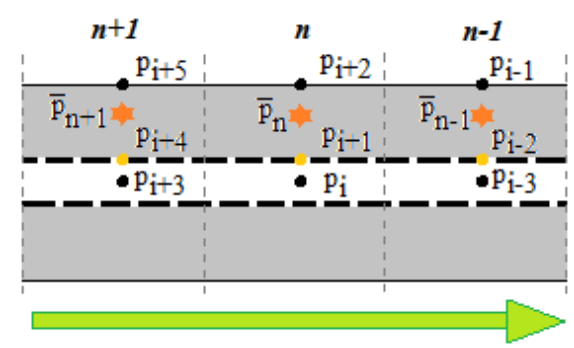

Figura 6.15: Trecho genérico para poço aberto com liner com gravel.

Portanto, para o escoamento dentro do liner, a equação de balanço que equilibra a vazão é a equação 6.73 


$$
\begin{gathered}
\operatorname{Sign}\left[\Delta \bar{p}_{i}^{i+3}\right] A_{l}\left[\frac{\left(p_{i+3}-p_{i}\right)}{\overline{\Delta x}_{i}^{i+3}} \frac{2 D_{l}}{\bar{f} \bar{\rho}}\right]^{1 / 2} \\
+\operatorname{Sign}\left[\Delta \bar{p}_{i}^{i+1}\right] N_{f} C_{d} d_{f}^{2}\left(\frac{p_{i+1}-p_{i}}{0,81 \rho}\right)^{1 / 2} \\
-\operatorname{Sign}\left[\Delta \overline{p_{i-3}^{i}}\right] A_{l}\left[\frac{\left(p_{i}-p_{i-3}\right)}{\overline{\Delta x}_{i-3}^{i}} \frac{2 D_{l}}{\bar{f} \bar{\rho}}\right]^{1 / 2}=0
\end{gathered}
$$

Para o caso com gravel, criar-se-á o índice $n$ que representa as variáveis alocadas no meio do anular. Portanto, para o escoamento dentro do anular, a equação de balanço que equilibra a vazão é a equação 6.74

$$
\begin{array}{r}
\operatorname{Sign}\left[\Delta \bar{p}_{n}^{n+1}\right] \frac{K A_{e q}}{\mu} \frac{\left(p_{n+1}-p_{n}\right)}{\overline{\Delta x}_{n}^{n+1}}+q_{i} \\
-\operatorname{Sign}\left[\Delta \bar{p}_{i+1}^{i+2}\right] \frac{2 \pi K}{\mu} \frac{\left(p_{i+2}-p_{i+1}\right)}{\ln \left(r_{p} / r_{l}\right)} \\
-\operatorname{Sign}\left[\Delta \bar{p}_{i}^{i+1}\right] N_{f} C_{d} d_{f}^{2}\left(\frac{p_{i+1}-p_{i}}{0,81 \rho}\right)^{1 / 2} \\
-\operatorname{Sign}\left[\Delta \bar{p}_{n-1}^{n}\right] \frac{K A_{e q}}{\mu} \frac{\left(p_{n}-p_{n-1}\right)}{\overline{\Delta x}_{n-1}^{n}}=0
\end{array}
$$

Os valores da pressão e posição dentro da região do anular são facilmente encontrados através

$$
\begin{gathered}
p_{n-1}=\frac{p_{i-2}+p_{i-1}}{2}, \quad p_{n}=\frac{p_{i+1}+p_{i+2}}{2}, \quad p_{n+1}=\frac{p_{i+4}+p_{i+5}}{2} \\
\overline{\Delta x}_{n}^{n+1}=\overline{\Delta x}_{i}^{i+3} \quad \text { e } \quad \overline{\Delta x}_{n-1}^{n}=\overline{\Delta x}_{i-3}^{i}
\end{gathered}
$$

A perda de carga radial foi considerada na região anular, ou seja, o escoamento do fluido atravessando o gravel, da parede externa do poço até logo após os furos do liner foi contabilizado. Considerando-se a saída de fluido na direção radial, temos que a vazão entre $p_{i+2}$ e $p_{i+1}$ considerada pela equação de Darcy precisa ser igual a vazão pelos furos entre $p_{i+1}$ e $p_{i}$ considerada pela perda de carga do furos. Logo a equação que está faltando para esse caso é 


$$
\frac{2 \pi K}{\mu} \frac{\left(p_{i+2}-p_{i+1}\right)}{\ln \left(r_{p} / r_{l}\right)}-N_{f} C_{d} d_{f}^{2}\left(\frac{p_{i+1}-p_{i}}{0,81 \rho}\right)^{1 / 2}=0
$$

\subsection{3}

\section{Metodologia de solução}

As equações descritas no presente capítulo compõem essencialmente um sistema de equações não lineares. A depender de cada caso, ou seja, se há ou não gravel no anular, o número de variáveis está diretamente relacionado com o número de trechos em que o poço foi divido. Quando não existir gravel, teremos $2 n$ variáveis e quando existir, serão $3 n$ variáveis, onde $n$ é o número de divisões do poço. No entanto, tal sistema estaria indeterminado e não passível de ser solucionado numericamente. A vista desta última consideração, fixa-se então a pressão do calcanhar a fim de determinar o sistema de equações, por exemplo atribuindo $p_{1}=p_{w}$, onde $p_{w}$ é a pressão no calcanhar do poço.

O método de Newton-Raphson foi utilizado para encontrar a solução do sistema de equação para múltiplas variáveis. Para tal, escreveu as equações do presente capítulo de forma vetorial como descreve a equação 6.78.

$$
\mathbf{F}\left(p_{i}\right)=0
$$

onde $p_{i}$ é o vetor solução $\left(p_{1}, p_{2}, p_{3}, p_{4}, p_{5}, \ldots\right)$ e as componentes da matriz $\mathbf{F}$ podem ser encontradas no lado esquerdo das equações 6.66, 6.67, 6.73, 6.74 e 6.77. O método é iterativo e descrito pela equação 6.79 precisando de um chute inicial $p_{0}$

$$
p_{k+1}=p_{k}-\left[J^{-1}(p) \cdot F(p)\right] \mid p=p_{k}
$$

onde

$$
J=\frac{\partial F(p)^{T}}{\partial t}=\nabla^{T} F(x) \quad e \quad J \cdot J^{-1}=1
$$

A equação 6.80 apresenta a definição do Jacobiano de $F(p)$ e de sua inversa, respectivamente. $\mathrm{O}$ algoritmo implementado na rotina não utiliza 6.78 diretamente, mas sim uma alternativa mais barata computacionalmente do que a inversa da matriz Jocabiana. Inverter uma matriz já representa um custo 
elevado para um método numérico, mais severo ainda é quando este é iterativo. Visando otimizar o código, propôs-se na verdade as equações 6.81, 6.82 e 6.83 .

$$
p_{k+1}=p_{k}+y_{k}
$$

$$
J\left(p_{k}\right) \cdot y_{k}=-F\left(p_{k}\right)
$$

$$
r e s_{k}=\left\langle y_{k} \mid y_{k}\right\rangle \leq \text { tol }
$$

As equações acima convertem o sistema de equações não lineares $F(p)=0$ em diversos sistemas lineares para $y_{k}$. Tal incremento é então adicionado ao $p_{k}$ e constrói-se portanto o próximo vetor para a iteração seguinte. Enquanto a norma ao quadrado do incremento $y_{k}$ for maior que uma tolerância estipulada, o algoritmo procede. Caso contrário, decreta-se que a convergência foi atingida. Este método iterativo vem apresentando boa convergência e resultados bastante coerentes.

Outro aspecto importante do método é como as equações foram montadas. A matrix Jacobiana assume a forma de matriz em banda. Isso facilita muito a resolução do sistema linear, pois a maior parte dos componentes da matriz são nulos e não há necessidade de se computar todos os elementos no método utilizado. 


\section{7 \\ Testes de Verificação e Validação}

O objetivo do presente capítulo é apresentar a verificação e validação da implementação das metodologias descritas nos capítulos anteriores.

O modelo de difusividade hidráulica foi implementado no presente trabalho em dois softwares de CFD: no software aberto OpenFOAM $\cap$ onde um novo solver foi criado, o hidraulicDiffusivityFoam, e no software comercial Ansys Fluent (Ansys, 2014), onde a equação foi implementada através de programação de usuário (UDF). Nos estágios inicias deste trabalho de tese, havia-se selecionado o software comercial Fluent como código básico de trabalho. No entanto, posteriormente, optou-se por utilizar o software livre OpenFOAM@. A

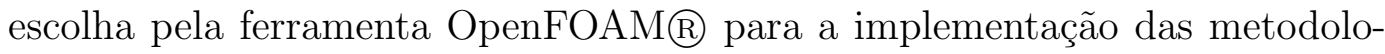
gias desenvolvidas neste trabalho ocorreu pela facilidade na re-utilização de código e na linguagem customizada facilitando a implementação de novos modelos. O modelo geral baseado na teoria das médias em meio poroso foi implementado no software OpenFOAM $\AA$ apenas, recebendo o nome de rhoPorousPimpleFoam.

Na primeira parte deste capítulo, apresenta-se testes de verificação dos algorítimos implementados. Isto é, realiza-se testes para demonstrar que as equações de conservação, assim como o algorítimo de solução do sistema algébrico encontram-se implementados corretamente, respeitando a ordem de precisão dos modelos de interpolação implementados. Uma vez que o código foi verificado de forma satisfatória, diversos testes de validação da metodologia são realizados.

Para validar as implementações, primeiramente, o desempenho do modelo de difusividade hidráulica e do modelo de teoria de média são avaliados em casos simplificados. Os casos consistem de situações uni-dimensionais, e contemplam exemplos em regime permanente e transiente.

Após essa primeira etapa de validação, o modelo de difusividade hidráulica implementado em CFD é comparado com o software comercial IMEX (CMG, 2016), muito utilizado pela indústria de petróleo. O software IMEX também utiliza a equação de Darcy para a contabilização do escoamento no reservatório. Logo, a ideia principal dessa etapa é validar o solver implemen- 
tado, considerando poços verticais e horizontais em reservatórios homogêneos e heterogêneos. Para o caso de poços horizontais também considerou-se o escoamento do reservatório acoplado ao escoamento do poço.

A terceira etapa de validação consiste em comparar o modelo de teoria de média também em casos reais. Para isso, compara-se o modelo de média com o modelo já validado de difusividade hidráulica em casos de poços verticais fraturados e poços horizontais em reservatórios homogêneos e heterogêneos. Nessa etapa, os dois solvers desenvolvidos no OpenFOAM@ são comparados.

Antes de iniciar a apresentação dos testes de validação, é conveneiente mencionar que os solvers implementados são tri-dimensionais. Situações 2D são facilmente definidas (procedimento comum do OpenFOAM $囚$ ), como possuindo uma terceira dimensão unitária, com gradiente nulos em ambas as fronteiras. Também é preciso mencionar, que como a técnica numérica de solução é transiente, mesmo para problemas em regime permamente, uma condição inicial precisa ser definida, a qual não deve influenciar a solução de regime permanente obtida.

\section{1}

\section{Verificação do Código}

Esta seção tem como objetivo a verificação dos códigos implementados no presente trabalho. O objetivo da verificação de código é analisar se a implementação desenvolvida está coerente, independe da física do modelo, respeitando a ordem de precisão. A metodologia escolhida para a verificação do código foi o método de soluções manufaturadas (Roache, 2002).

Primeiramente, é selecionada uma solução contínua analítica a que possua a capacidade de avaliar todos os processos matemáticos contidos no modelo: diferenciações, termos cruzados, etc. Essa solução deve ser inserida na equação (ou sistema de equações) diferencial parcial (PDE) que deseja avaliar para fornecer o termo de produção $S=S(x, y, z, t)$, tal que:

$$
\operatorname{PDE}(\mathbf{a})=\mathrm{S}(\mathrm{x}, \mathrm{y}, \mathrm{z}, \mathrm{t})
$$

Deseja-se então determinar numericamente $\mathbf{b}$, através da solução de

$$
\operatorname{PDE}(\mathbf{b})-\mathrm{S}(\mathrm{x}, \mathrm{y}, \mathrm{z}, \mathrm{t})=0
$$

Pode-se determinar o erro absoluto da seguinte forma: 


$$
\varepsilon=|\mathbf{b}-\mathbf{a}|
$$

O próximo passo é monitorar esse erro numérico em função do refinamento sistemático da malha.

A solução analítica adequada (solução manufaturada) selecionada para avaliar a ordem de precisão dos termos da PDE (Roache, 2002) é

$$
\mathrm{F}_{\mathrm{m}}=\mathrm{x}_{1}^{\mathrm{m}+1} \mathrm{x}_{2}^{\mathrm{m}+2} \mathrm{x}_{3}^{\mathrm{m}+3}
$$

onde

$$
\mathrm{m}=\mathrm{nl}+\mathrm{na}-1
$$

nl é a ordem da operação ( $\mathrm{nl}=2$, para Laplaciano) na é a ordem de precisão da discretização, (na $=2$ para os esquemas de interpolação utilizanos no OpenFOAM)

\subsection{1}

\section{Verificação do Código HDF}

Aplicando a metodologia acima, temos o seguinte procedimento:

- Definir o domínio do problema: Quadrado de lado unitário. Note que poderia ser usado qualquer domínio sem perda de generalidade.

- Definir a solução contínua analítica. Para esse problema, $n l=2, n a=$ $2 \Rightarrow m=3$. Logo:

$$
p=x^{4} y^{5}
$$

onde $\mathrm{x}$, y são as coordenadas do centro de cada célula do domínio.

O termo fonte encontrado ao substituir a solução manufaturada na equação de difusividade hidráulica é

$$
S(x, y)=12 x^{2} y^{5}+20 x^{4} y^{3}
$$


O problema escolhido é bidimensional cujo domínio varia de 0 a 1 em $\mathrm{x}$ e de 0 a 1 em $\mathrm{y}$. As condições de contorno são $p(0, y)=0, p(x, 0)=0$, $p(1, y)=y^{5}$ e $p(x, 1)=x^{4}$. A figura 7.3 apresenta o campo de erro associado a solução numérica com termo fonte e a solução manufaturada para uma malha de 20x20 elementos e outra de 100x100 elementos.
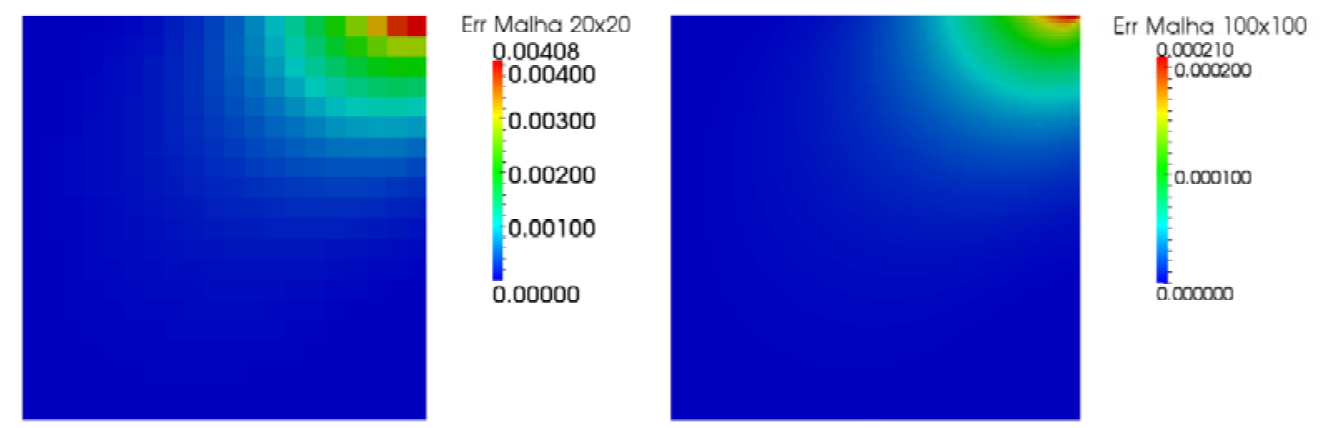

Figura 7.1: Campo do erro para diferentes malhas - HDF.

A figura 7.4 apresenta o índice de convergência $I=\varepsilon / \Delta x^{2}$ em função do número de elementos da malha. Para um esquema difusivo de segunda ordem, este índice deve tender para um valor constante, a medida que a malha é refinada (Roache, 2002). Analisando a figura 7.4, observa-se que um índice constante foi obtido, o que garante que o código HDF foi implementado corretamente.

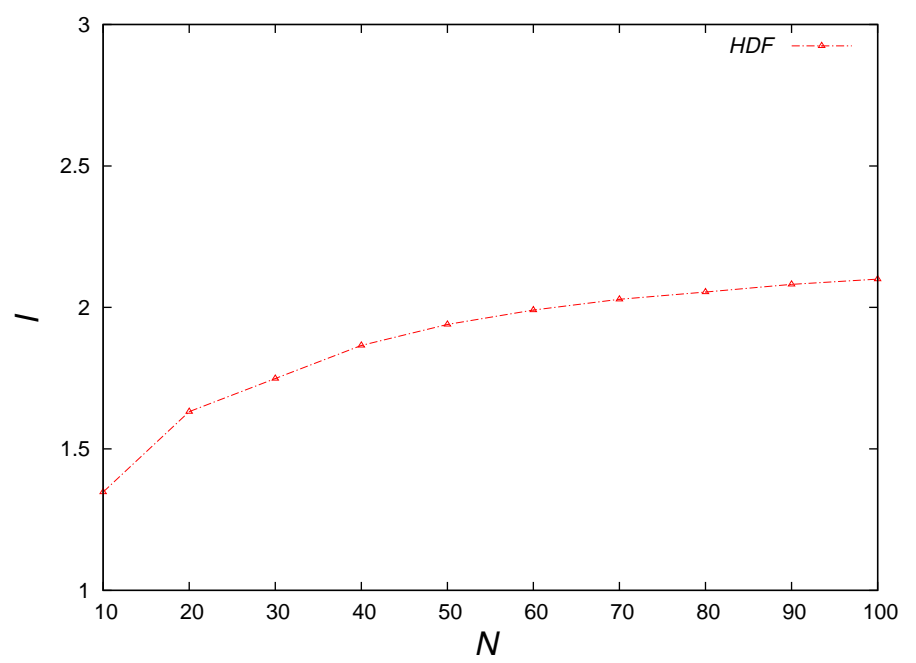

Figura 7.2: Índice de convergência em função do número de elementos de malha - HDF. 


\subsection{2}

\section{Verificação do Código RPPF}

O mesmo processo de verificação de código será aplicado para o solver RPPF. O mesmo domínio será utilizado e a mesma solução contínua analítica para a pressão será utilizada $p=x^{4} y^{5}$.

Neste caso, para testar o modelo, precisa-se de um campo analítico de pressão e de velocidade. Dessa forma, para o campo de velocidade, vamos usar a equação de Darcy, assumindo que o tensor permeabilidade é isotrópico com $k_{11}=k_{22}=k_{33}=K$, onde a permeabilidade é suficientemente alta para que o erro relativo entre os modelos de média e Darcy seja desprezível.

$$
\begin{aligned}
& v_{x}=-\frac{K}{\phi \mu} \nabla P=-\frac{K}{\phi \mu} 4 x^{3} y^{5} \\
& v_{y}=-\frac{K}{\phi \mu} \nabla P=-\frac{K}{\phi \mu} 5 x^{4} y^{4}
\end{aligned}
$$

O próximo passo da metodologia é obter um termo fonte baseado na solução analítica, de modo a forçar o programa a obtê-las, com um erro a ser medido. Primeiramente, assumi-se que as propriedades são constantes, gravidade nula e que o regime é permanente. Ficamos com o seguinte sistema:

$$
\begin{gathered}
\frac{\partial \phi v_{x}}{\partial x}+\frac{\partial \phi v_{y}}{\partial y}=S_{1} \\
\rho \phi\left(\frac{\partial v_{x} v_{x}}{\partial x}+\frac{\partial v_{y} v_{x}}{\partial y}\right)=-\phi \frac{\partial p}{\partial x}-\mu \phi^{2} K^{-1} v_{x}+\phi \mu\left(\frac{\partial^{2} v_{x}}{\partial^{2} x}+\frac{\partial^{2} v_{x}}{\partial^{2} y}\right) \\
\rho \phi\left(\frac{\partial v_{y} v_{x}}{\partial x}+\frac{\partial v_{y} v_{y}}{\partial y}\right)=-\phi \frac{\partial p}{\partial y}-\mu \phi^{2} K^{-1} v_{y}+\phi \mu\left(\frac{\partial^{2} v_{y}}{\partial^{2} x}+\frac{\partial^{2} v_{y}}{\partial^{2} y}\right)
\end{gathered}
$$

Fazendo $\rho=1$ e $\mu=1$, substituindo $p$ e $U$ pelas suas respectivas expressões analíticas e fazendo as devidas simplificações, obtemos os termos fonte em função de x e y:

$$
\begin{array}{r}
S_{1}=-12 K x^{2} y^{5}-20 K x^{4} y^{3} \\
S_{2 A}=\frac{K^{2}}{\phi}\left(48 x^{5} y^{10}+100 x^{7} y^{8}\right)+K\left(80 x^{3} y^{3}+24 x^{5} y\right) \\
S_{2 B}=\frac{K^{2}}{\phi}\left(80 x^{6} y^{9}+100 x^{8} y^{7}\right)+K\left(60 x^{2} y^{4}+60 x^{4} y^{2}\right)
\end{array}
$$


Conforme apresentado no capítulo seis, na metodologia RPPF, as equações de conservação de quantidade de movimento são combinadas com a equação de conservação da massa, para obter uma equação para a pressão. O mesmo procedimento foi utilizado aqui, acrescentando $S_{1}, S_{2 A}$ e $S_{2 B}$. As condições de contorno são $p(0, y)=0, p(x, 0)=0, p(1, y)=y^{5}$ e $p(x, 1)=x^{4}$. A figura 7.3 apresenta o campo de erro de pressão associado a solução numérica com termo fonte e a solução manufaturada para uma malha de 20x20 elementos e outra de 100x100 elementos, onde observa-se redução substancial do erro com o refino da malha.
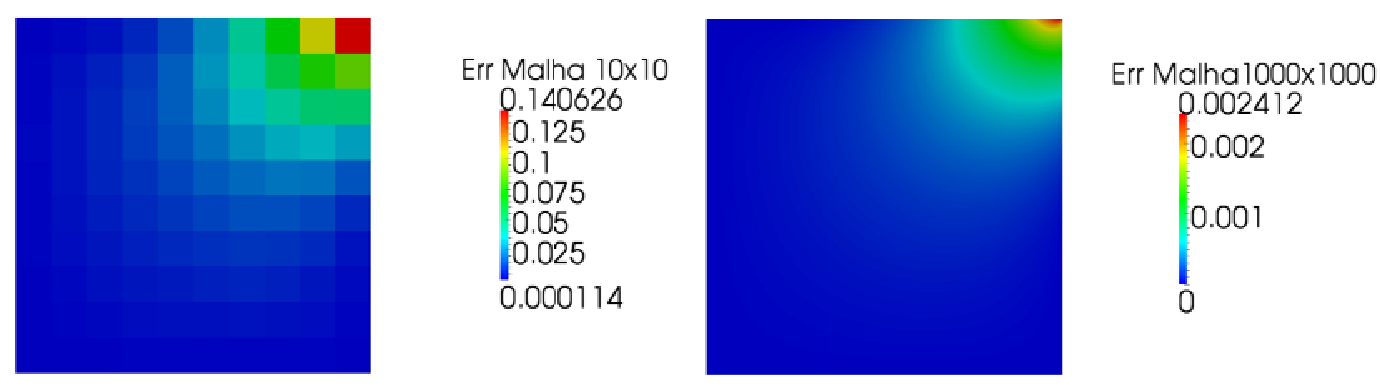

Figura 7.3: Campo do erro para diferentes malhas - RPPF

Neste caso, devido a presença dos termos convectivos, comprova-se que o código encontra-se corretamente implementado quando o índice de convergência definido como $I=$ erro/ $\Delta x$ é constante (Roache, 2002). Analisando a figura 7.4 observa-se que o um índice constante foi obtido com o refino de malha permitindo afirmar que o código foi adequadamente verificado.

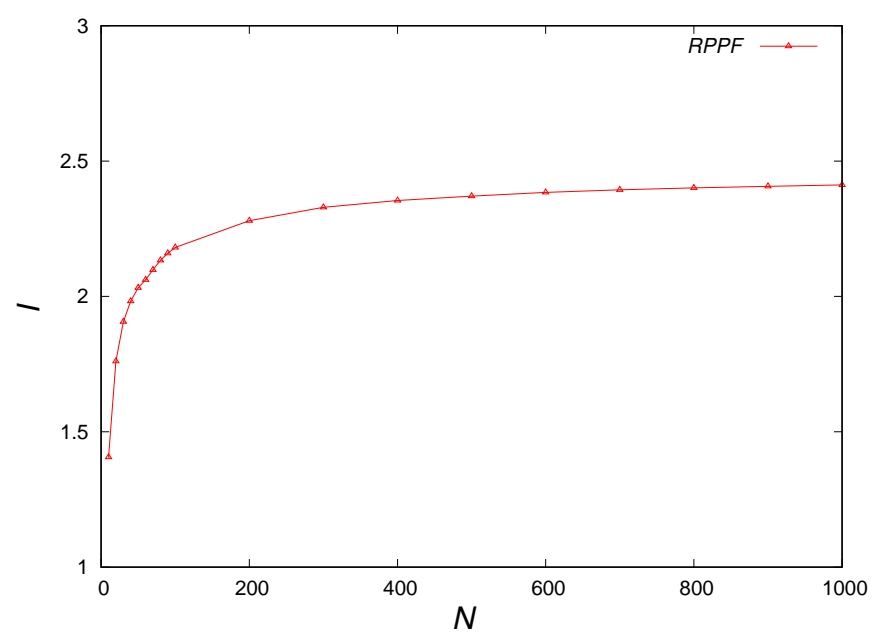

Figura 7.4: Índice de convergência em função do número de elementos de malha - RPPF. 


\section{2}

\section{Validação do Código}

O objetivo dessa seção é validar os solvers hidraulicDifusivityFoam (HDF) e rhoPorousPimpleFoam (RPPF) através da solução de situações simples, para as quais modelos analíticos encontram-se disponíveis.

\subsection{1}

\section{Teste 1.1: Escoamento 1D em Regime Permanente}

O primeiro teste consiste em um plug homogêneo, como porosidade e permeabilidade constantes. Deseja-se determinar a vazão através do plug em regime permanente, considerando que só existe escoamento na direção axial $x$, devido a um diferencial de pressão imposto nas fronteiras do plug de comprimento $L=7 \mathrm{~cm}$. A pressão na entrada $(x=0)$ é $p_{i n}=790,8 \mathrm{kPa}$ e na saída $(x=L)$ é igual a pressão atmosférica, $p_{\text {out }}=p_{\text {atm }}=101,3250 \mathrm{kPa}$. A malha é $1 \mathrm{D}$ e tem 100 elementos.

As propriedades do fluido também são constantes. A tabela 7.1 apresenta as propriedades do reservatório e fluido utilizados neste teste.

Tabela 7.1: Propriedades do fluido e reservatório. Teste 1.1: 1D permanente.

\begin{tabular}{|c|c|c|c|c|c|}
\hline \multicolumn{3}{|c|}{ Propriedades do fluido } & \multicolumn{3}{c|}{ Propriedades da formação } \\
\hline Propriedade & Unidade & Valor & Propriedade & Unidade & Valor \\
\hline$\mu$ & $P a s$ & 0,001 & $K_{x x}$ & Darcy & 0,001 \\
$C_{\text {visc }}$ & $s$ & 0 & $K_{y y}$ & Darcy & 0,001 \\
$p_{b}$ & $k P a$ & $1,0 \times 10^{5}$ & $K_{z z}$ & Darcy & 0,001 \\
$\rho$ & $K g / m^{3}$ & 998,2 & $\phi_{\text {ref }}$ & {[]} & 0,2 \\
$B_{o}$ & {[]} & 1,0 & $p_{\text {ref }}$ & $k P a$ & 101,325 \\
$R_{s}$ & {[]} & 0 & $S_{w c o n}$ & {[]} & 0 \\
$c_{o}$ & $1 / P a$ & 0 & $c_{f}$ & $1 / P a$ & 0 \\
\hline
\end{tabular}

A vazão através do plug pode ser determinada analiticamente pela equação de Darcy com

$$
Q=\frac{K A}{\mu} \frac{\Delta p}{L}
$$

Para simular este caso, é necessario especificar um domínio 2D. Criou-se um domínio com comprimento igual a $L=7 \mathrm{~cm}$, e com altura igual a $2,8 \mathrm{~cm}$. Para reproduzir uma situação 1D, é necessário prescrever gradiente nulo nas fronteiras superior e inferior. Para iniciar a metodologia numérica, um campo uniforme de pressão igual a pressão atmosférica foi imposto. 
A tabela 7.2 apresenta os valores de vazão em massa através do plug encontrados para o presente caso, para o modelo de difusividade hidráulica (HDF) e para o modelo baseado na teoria de média (RPPF) e compara com a vazão analítica. Pode-se observar boa concordância entre os resultados e a solução exata.

Tabela 7.2: Produção: vazão mássica. Teste 1.1: 1D Regime permanente.

\begin{tabular}{|c|c|c|}
\hline \multicolumn{3}{|c|}{ Vazão mássica $10^{-4}(\mathrm{~kg} / \mathbf{s})$} \\
\hline HDF & RPPF & Analítico \\
\hline 2,7529 & 2,7529 & 2,7529 \\
\hline
\end{tabular}

A figura 7.6 apresenta o perfil de pressão ao longo do comprimento calculado pelos modelos HDF e RPPF. Compara-se os resultados com a solução analítica e pode-se observar que a solução uni-dimensional é validada pelos dois métodos.

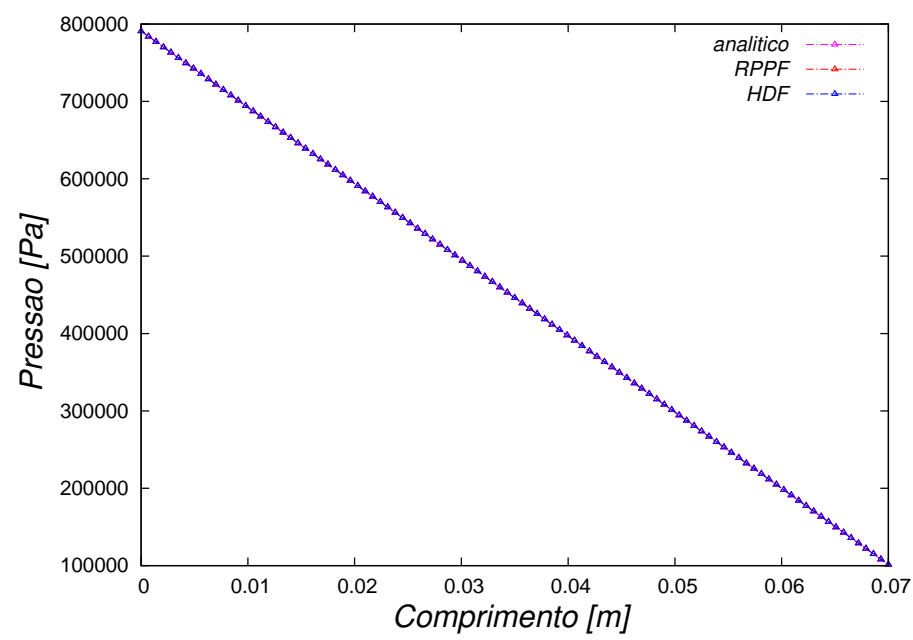

Figura 7.5: Perfil de pressão. Teste 1.1: 1D regime permanente.

\subsection{2}

\section{Teste 1.2: Escoamento 1D em Regime Transiente}

O segundo teste consiste em uma comparação do modelo de difusividade hidráulica (HDF) com o modelo baseado na teoria de média (RPPF) com relação a previsão da variação do perfil de pressão ao longo do tempo para uma situação de um meio poroso unidimensional. Considera-se que o escoamento ocorre de $x=L$ para $x=0$. Considera-se um meio poroso homogêneo, sendo as propriedades do fluido constantes (indicadas na tabela 7.3).

Neste caso, o meio poroso possui comprimento $L=100 \mathrm{~m}$. A condição inicial do problema transiente corresponde a um campo de velocidade nulo, 
com pressão uniforme e igual a $p_{\text {inicial }}=39,226 \mathrm{MPa}$. O início do escoamento ocorre quando a pressão em $(x=L)$ é alterada para $p_{\text {out }}=47,467 \mathrm{MPa}$. A condição de contorno ao longe $(x=0)$ foi prescrita como $p_{i n l}=39,226$ MPa. Para simular o reservatório 1D, especificou-se domínio com altura igual a $1 \mathrm{~m}$, sendo a condição de contorno na parte superior e inferior do domínio computacional definida com gradiente nulo. Para esse caso, foi gerada uma malha 1D com 1000 elementos. O passo de tempo utilizado na simulação foi de 10 segundos.

Tabela 7.3: Propriedades do fluido e reservatório. Teste 1.2: 1D regime transiente.

\begin{tabular}{|c|c|c|c|c|c|}
\hline \multicolumn{3}{|c|}{ Propriedades do fluido } & \multicolumn{2}{c|}{ Propriedades da formação } \\
\hline Propriedade & Unidade & Valor & Propriedade & Unidade & Valor \\
\hline$\mu$ & $K g /(m s)$ & 0,001 & $K_{x x}$ & Darcy & 1 \\
$C_{v i s c}$ & $s$ & 0 & $K_{y y}$ & Darcy & 1 \\
$p_{b}$ & $M P a$ & 100 & $K_{z z}$ & Darcy & 1 \\
$\rho$ & $K g / m^{3}$ & 675 & $\phi_{r e f}$ & {[]} & 0,2 \\
$B_{o}$ & {[]} & 1,0 & $p_{r e f}$ & $M P a$ & 47,467 \\
$R_{s}$ & {[]} & 0 & $S_{w c}$ & {[]} & 0 \\
$c_{o}$ & $1 / P a$ & $1,12 \times 10^{-9}$ & $c_{f}$ & $1 / P a$ & $1,12 \times 10^{-9}$ \\
\hline
\end{tabular}

A figura 7.6 apresenta a comparação da variação temporal da vazão volumétrica obtida com os modelos HDF e RPPF, onde pode-se observar resultados coincidentes, não sendo possível identificar diferenças entre as curvas. Para a validação dos solvers em regime transiente, para a situação 1D com propriedades constantes, listadas na tabela 7.3, a equação da difusividade hidráulica pode ser simplificada, tornando-se a equação diferencial 7.13.

$$
\frac{\phi \mu\left(c_{f}+c_{o}\right)}{K} \frac{\partial p}{\partial t}=\nabla^{2} p
$$

A solução da equação 7.13 é encontrada pelo método de separação de variáveis e tem a forma da equação 7.14.

$$
p(x, t)=p_{1}+\frac{\Delta p}{L}+\sum_{n=1}^{\infty}\left[\frac{2 \Delta p(-1)^{n}}{n \pi} \sin \left(\frac{n \pi x}{L}\right) e^{-\frac{n^{2} \pi^{2} a^{2}}{L^{2}} t}\right]
$$

onde $p_{1}=p(x=0), a^{2}=\frac{K}{\phi \mu\left(c_{f}+c_{o}\right)}$. 


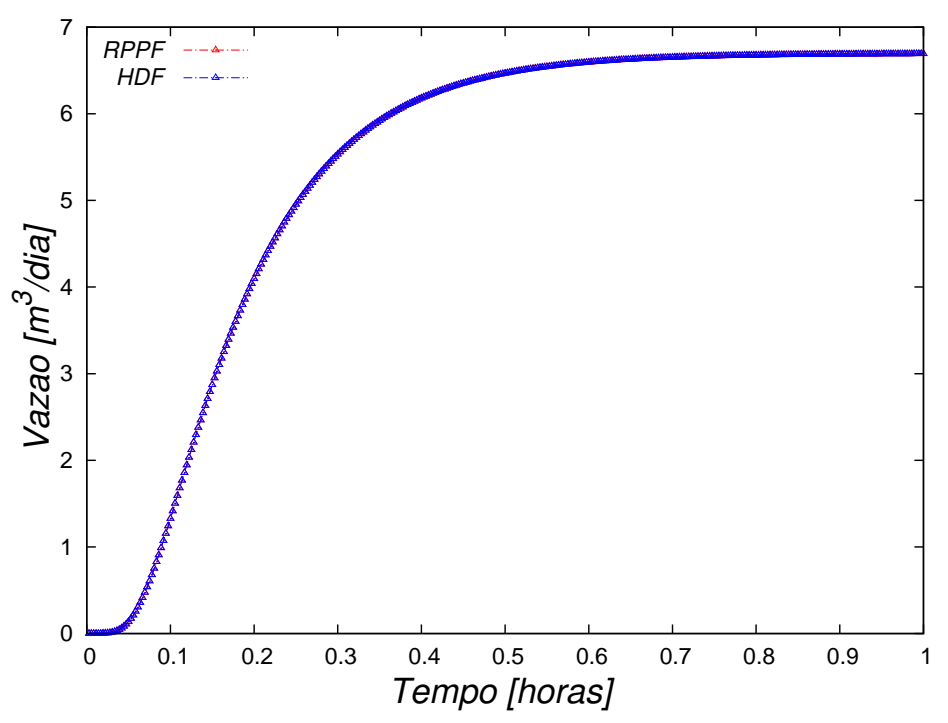

Figura 7.6: Comparação da variação temporal da vazão volumétrica de HDF com RPPF. Teste 1.2: 1D regime transiente.

A figura 7.7 apresenta a comparação do perfil de pressão ao longo do domínio para o tempo de $50 \mathrm{~s}$ obtido com os modelos HDF e RPPF com a solução analítica. Observa-se perfeita concordância entre a solução analítica e o modelos numéricos para prever o escoamento transiente.

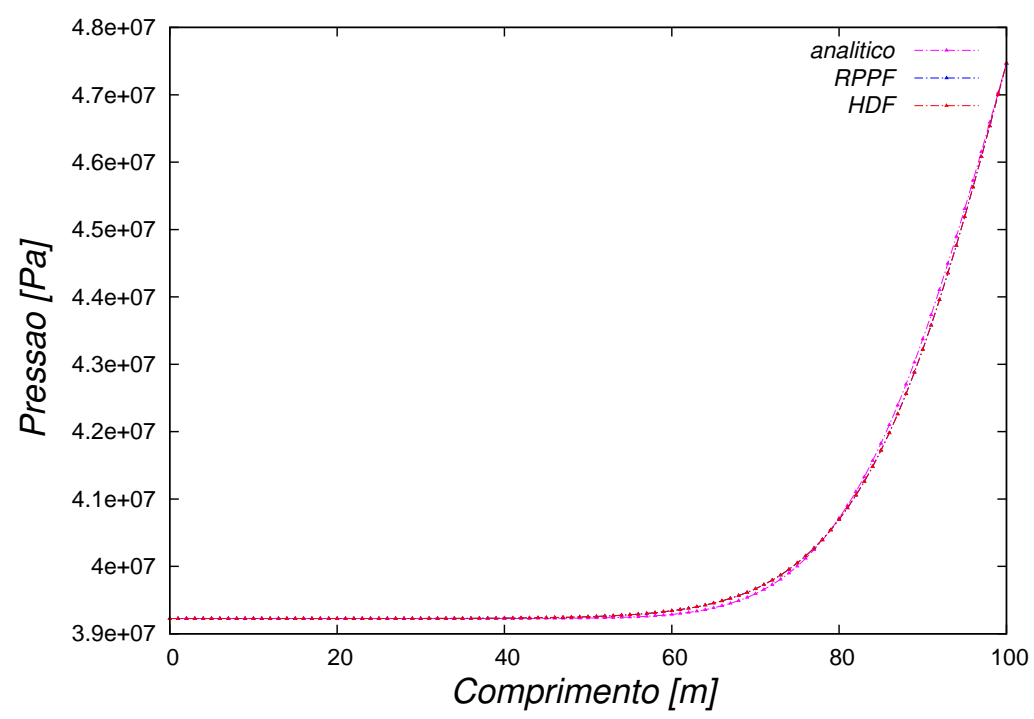

Figura 7.7: Perfil axial de pressão para o tempo de 50 s. Teste 1.2: 1D regime transiente. 


\section{3}

\section{Comparação do Modelo de Difusidade Hidráulica com o Software IMEX - Escala de Poço.}

O objetivo da presente seção é validar a implementação do modelo de difusividade hidráulica realizada no presente trabalho, através de comparações com o software comercial IMEX, amplamente utilizado pela indústria de petróleo. Investigou-se a produção de poços verticais e horizontais em reservatórios homogêneos e heterogêneos. A presente validação contempla não somente a implementação da modelagem do escoamento de acordo com a equação de Darcy, mas também, para o caso de poço horizontal, o acoplamento entre reservatóriopoço. É importante ressaltar que todos os testes consideram a hipótese de condutividade infinita para o escoamento dentro do poço, exceto o teste 2.6.

A modelagem da equação da difusividade hidráulica foi implementada em dois softwares diferentes de CFD: Ansys Fluent e OpenFOAM®.Os dois primeiros testes foram realizados utilizando a rotina desenvolvidada no Fluent. É importante ressaltar que o software Fluent não possui a modelagem da difusividade hidráulica em suas versões. Este modelo precisou ser implementado dentro do programa através de UDF (user defined functions). Para os testes restantes, os dois novos solvers, implementados no Fluent e OpenFOAM@, são comparados com o IMEX.

Para os casos de comparação entre os softwres IMEX e de CFD, o mesmo tamanho de malha foi utilizada nas regiões longe do poço. A diferença entre as malhas é encontrada na região ao redor do poço. A metodologia de CFD utiliza um refino local na região do poço e o software IMEX utiliza um termo fonte para contabilizar o poço. Para ilustrar o refino utilizado na região do poço, apresenta-se as figuras 7.8 e 7.9 como um caso representativo de refino ao redor do poço e da região próxima ao poço para os softwres de CFD.
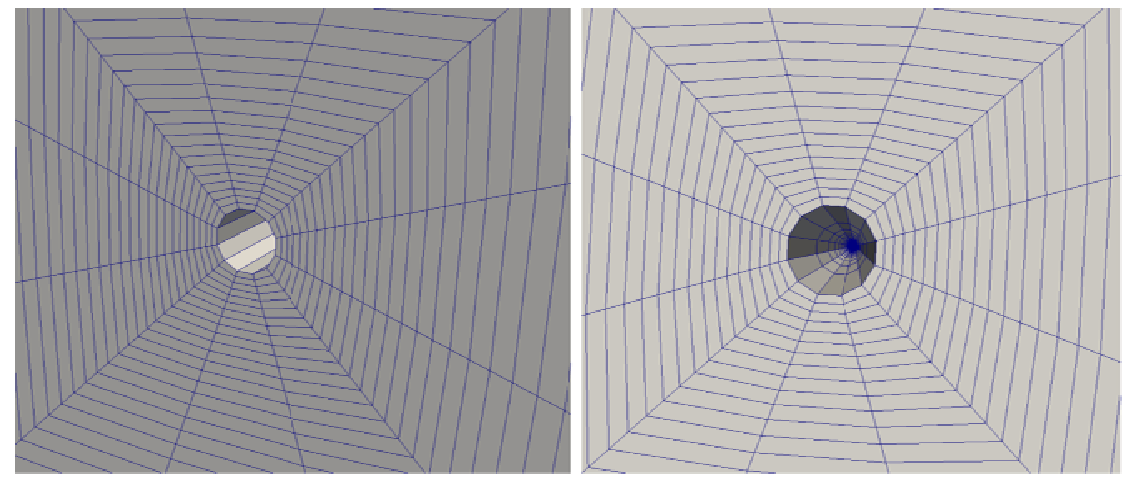

Figura 7.8: Dois ângulos de visão com amplificação do refino da malha no poço para metodologia de CFD. 

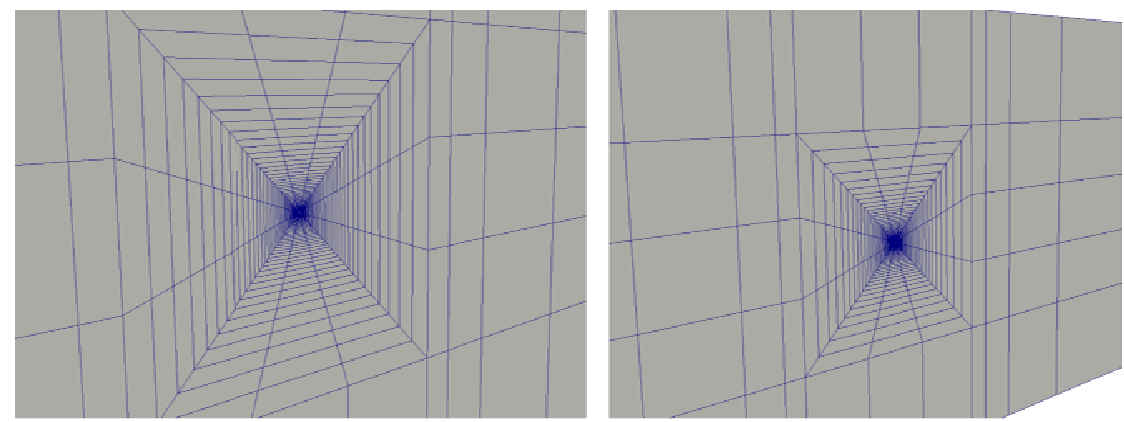

Figura 7.9: Dois ângulos de visão da malha em uma região mais afastada do poço. Refino da malha no poço para metodologia de CFD.

\subsection{1}

\section{Teste 2.1: Poço Vertical em um Reservatório Homogêneo Circular}

A simulação apresentada nesta seção refere-se a produção de um poço vertical em um reservatório circular homogêneo. Esse tipo de exemplo é o mais comum em simulação de reservatórios. A tabela 7.4 apresenta as informações da geometria do poço e reservatório, que apresentam simetria angular.

Tabela 7.4: Dimensões do poço vertical em reservatório circular. Teste 2.1.

\begin{tabular}{|c|c|c|}
\hline Nome & Valor & Unidade \\
\hline Raio do reservatório & 1000 & $m$ \\
Espessura do reservatório & 100 & $m$ \\
Diâmetro do poço & 12 & $i n$ \\
\hline
\end{tabular}

No início do processo, considera-se vazão (velocidade) nula no reservatório e poço, ambos com distribuição de pressão hidrostática. Como o reservatório encontra-se em uma cota significativamente abaixo do nível do mar, a pressão no topo da área de drenagem é igual a $640 \mathrm{kgf} / \mathrm{cm}^{2}$. Já a pressão no topo da área de drenagem na geometria do poço é $400 \mathrm{kgf} / \mathrm{cm}^{2}$. Inicialmente, o poço e o reservatório estão pressurizados considerando a pressão hidrostática. Como o reservatório está pressurizado a uma pressão superior à pressão do poço, um gradiente de pressão é estabelecido fazendo com que o fluido escoe. O presente caso não considera a manutenção de pressão nas bordas do reservatório, dessa forma, gradientes de pressão nulos são prescritos em todas as fronteiras do reservatório.

A tabela 7.5 apresenta as propriedades do fluido e do reservatório para a simulação. É importante ressaltar que o presente exemplo considera as propriedades do fluido, como massa específica e viscosidade, variando com a pressão. Outra contabilização importante no exemplo é a consideração da compressibilidade da rocha. 
Apesar do modelo implementado considerar apenas escoamentos monofásicos, a presença de água conata nos poros dificulta o escoamento do fluido. Visando levar em consideração este efeito, considera-se $S_{w c}=0,1$ como mostrado na tabela

Tabela 7.5: Propriedades do fluido e reservatório para o Teste 2.1.

\begin{tabular}{|c|c|c|c|c|c|}
\hline \multicolumn{3}{|c|}{ Propriedades do fluido } & \multicolumn{3}{c|}{ Propriedades da formação } \\
\hline Propriedade & Dimensão & Valor & Propriedade & Dimensão & Valor \\
\hline$\mu @ p_{b}$ & $c p$ & 0,6253 & $K_{x x}$ & mDarcy & 100 \\
$C_{v i s c}$ & $s$ & $1,2 \times 10^{-4}$ & $K_{y y}$ & mDarcy & 10 \\
$p_{b}$ & $k g f / \mathrm{cm}^{2}$ & 400,1 & $K_{z z}$ & mDarcy & 1 \\
$\rho$ & $K g / \mathrm{m}^{3}$ & 882,31 & $\phi_{r e f}$ & {[]} & 0,2 \\
$B_{o} @ p_{b}$ & {[]} & 1,62 & $p_{r e f}$ & $\mathrm{kgf} / \mathrm{cm}^{2}$ & 560 \\
$R_{s}$ & {[]} & 275,13 & $S_{w c}$ & {[]} & 0,1 \\
$c_{o}$ & $c m^{2} / \mathrm{kgf}$ & $1,12 \times 10^{-4}$ & $c_{f}$ & $\mathrm{~cm}^{2} / \mathrm{kgf}$ & $5 \times 10^{-5}$ \\
$\rho_{g} @ S C$ & $K g / \mathrm{m}^{3}$ & 1,2631 & & & \\
\hline
\end{tabular}

As figuras 7.10 e 7.11 apresentam a malha utilizada para a presente simulação de CFD. Um refino local na região do poço é definido para que a geometria do poço possa ser contabilizada. A malha contém 942.328 elementos e o passo de tempo utilizado foi de 2 dias. A malha utizada no IMEX tem o mesmo tamanho de elemento na região longe do poço.
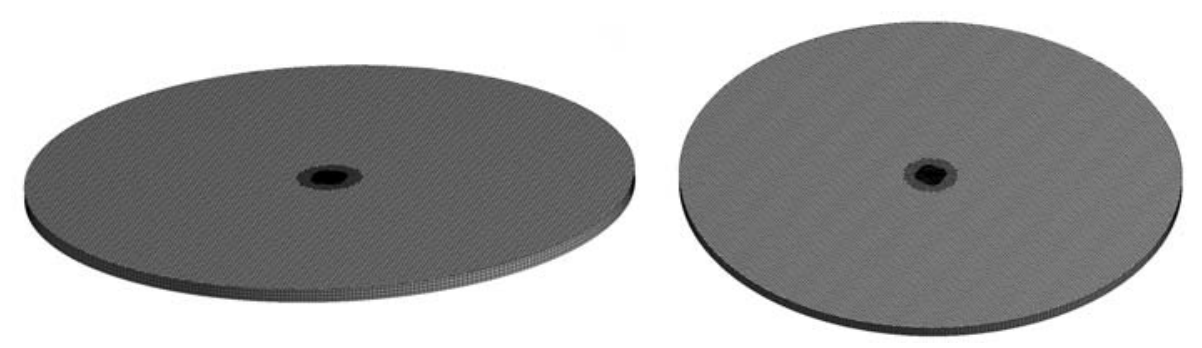

Figura 7.10: Dois âgulos de visão diferentes da mesma malha - Teste 2.1.
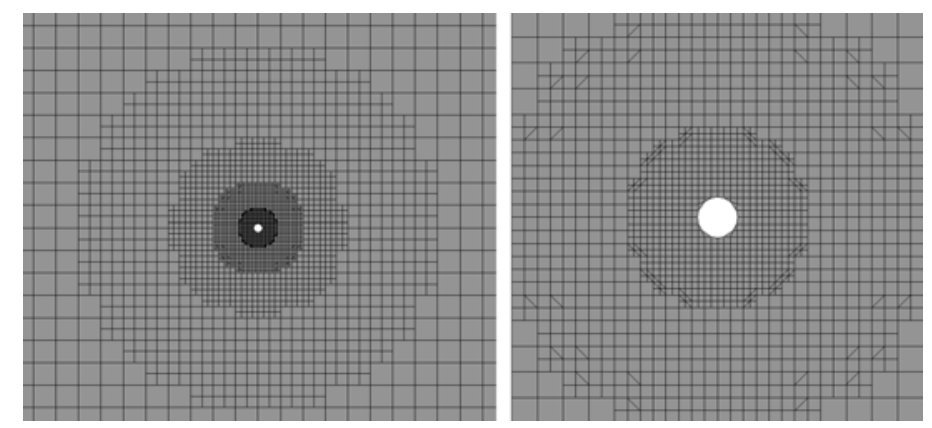

Figura 7.11: Dois níveis de amplificação daregião de refino da malha na região do poço - Teste 2.1 . 
Inicialmente uma comparação qualitativa entre os resultados obtidos, com a rotina implementada no Fluent e o software comercial IMEX é realizada. Para avaliar o campo de pressão dentro do reservatório, a figura 7.12 apresenta em um corte no meio do reservatório, as previsões de pressão obtidas com os dois softwares. Observa-se que os dois softwares prevêem o mesmo comportamento de propagação da pressão pelo reservatório. A forma como os gradientes de pressão se estabelecem pelo reservatório está diretamente relacionada à produção do poço. Analisando a figura 7.12, a qual apresenta escala de pressão semelhante entre os dois casos, observa-se qualitativamente boa concordância entre os resultados obtidos com o modelo de difusidade hidráulica, HDF, em relação ao software comercial IMEX.

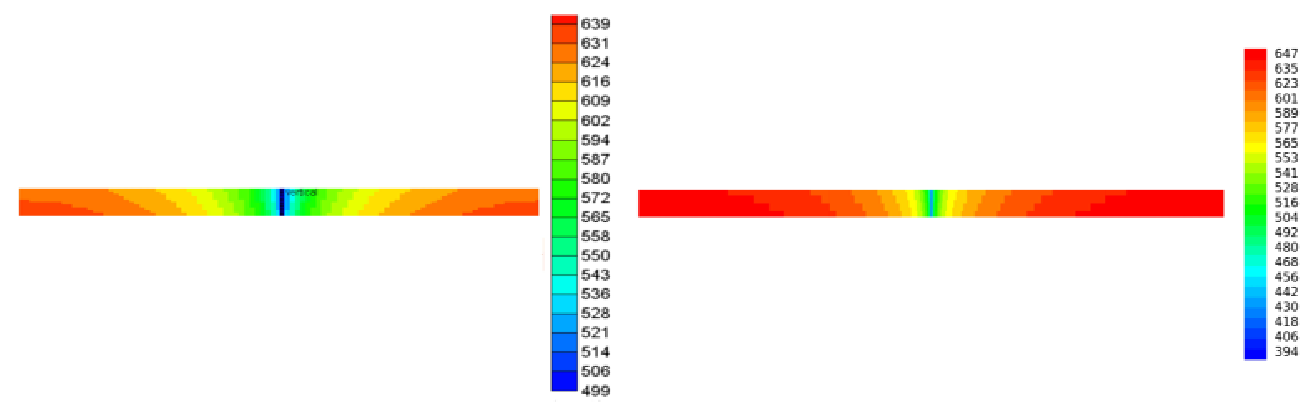

Figura 7.12: Plano central - pressão após dez dias de produção para Teste 2.1. (a) IMEX a esquerda (b) HDF Fluent a direita.

Avalia-se na figura 7.13 o campo de pressão nas faces externas do reservatório, após 10 dias de produção. Percebe-se como a condição de pressão do poço afetou o reservatório. Comparando-se os resultados observa-se que a propagação da pressão pelo reservatório obtida nas duas simulações são bem próximas.
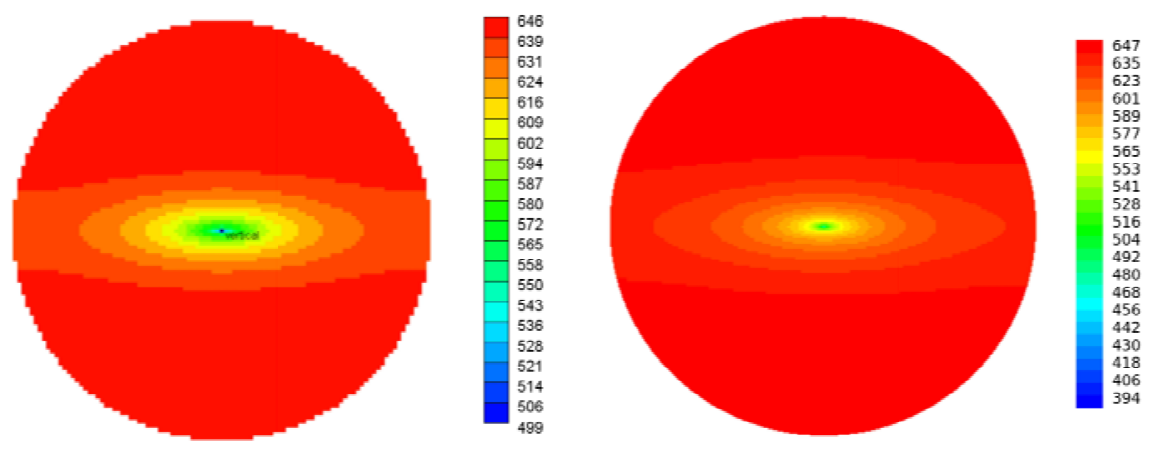

Figura 7.13: Campo de pressão após dez dias de produção para Teste 2.1. (a) IMEX a esquerda (b) HDF Fluent a direita. 
A comparação quantitativa é ilustrada na figura 7.14, que apresenta a produção do poço em $\mathrm{m}^{3} /$ dia em função do tempo, calculada pela rotina desenvolvida no software Fluent e pelo software IMEX. Esta comparação mostra que a implementação no software Fluent concorda com o resultado previsto pelo IMEX. A figura 7.14 apresenta a produtividade do poço vertical para os primeiros dias de produção.

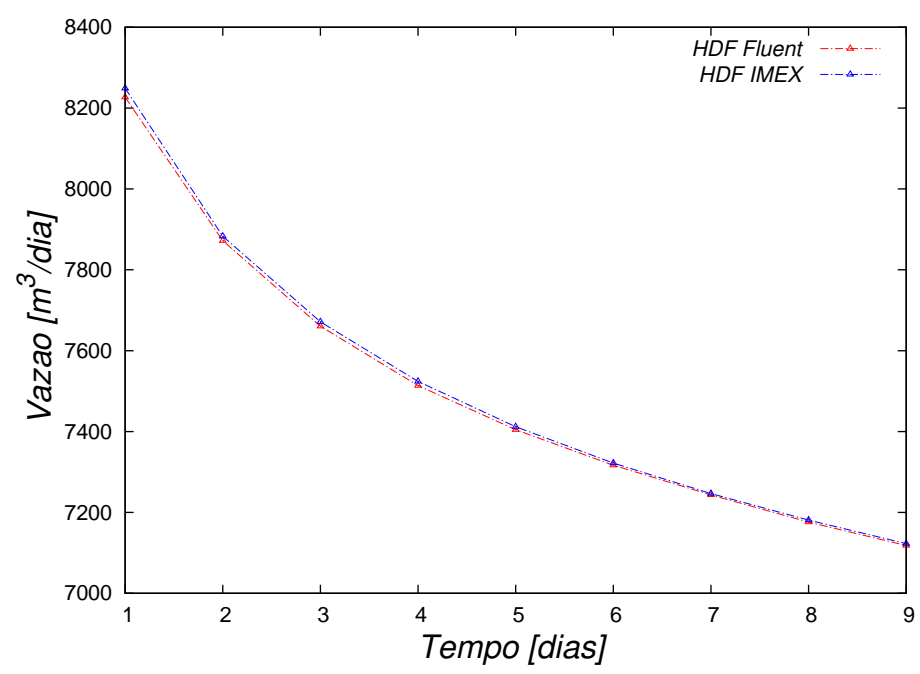

Figura 7.14: Comparação da variação temporal da vazão volumétrica obtida com Fluent e IMEX, para um poço vertical em um reservatório circular. Teste 2.1 .

\subsection{2}

\section{Teste 2.2: Poço Vertical em um Reservatório Homogêneo Quadrado}

Neste teste, o reservatório é considerado através de uma geometria quadrada. As dimensões do reservatório podem ser vistas na tabela 7.6 e as propriedade do fluido e do reservatório encontram-se na tabela 7.7.

Tabela 7.6: Dimensões do poço vertical em reservatório circular. Teste 2.2.

\begin{tabular}{|c|c|c|}
\hline Nome & Valor & Unidade \\
\hline Lado do reservatório & 1776,6 & $m$ \\
Espessura do reservatório & 100 & $m$ \\
Diâmetro do poço & 12,28 & in \\
\hline
\end{tabular}


Tabela 7.7: Propriedades do fluido e reservatório para o Teste 2.2.

\begin{tabular}{|c|c|c|c|c|c|}
\hline \multicolumn{2}{|c|}{ Propriedades do fluido } & \multicolumn{2}{c|}{ Propriedades da formação } \\
\hline Propriedade & Unidade & Valor & Propriedade & Unidade & Valor \\
\hline$\mu @ p_{b}$ & $c p$ & 0,6253 & $K_{x x}$ & $m$ Darcy & 50 \\
$C_{v i s c}$ & $s$ & $1,2 \times 10^{-4}$ & $K_{y y}$ & $m$ Darcy & 10 \\
$p_{b}$ & $k g f / \mathrm{cm}^{2}$ & 400,1 & $K_{z z}$ & $m$ Darcy & 1 \\
$\rho$ & $K g / \mathrm{m}^{3}$ & 882,31 & $\phi_{\text {ref }}$ & {[]} & 0,2 \\
$B_{o} @ p_{b}$ & {[]} & 1,62 & $p_{r e f}$ & $\mathrm{kgf} / \mathrm{cm}^{2}$ & 560 \\
$R_{s}$ & {[]} & 275,13 & $S_{w c}$ & {[]} & 0 \\
$c_{o}$ & $c m^{2} / \mathrm{kgf}$ & $1,12 \times 10^{-4}$ & $c_{f}$ & $\mathrm{~cm}^{2} / \mathrm{kgf}$ & $5 \times 10^{-5}$ \\
$\rho_{g} @ S C$ & $K g / \mathrm{m}^{3}$ & 1,2631 & $S_{w}$ & {[]} & 0,5 \\
\hline
\end{tabular}

Nesse teste, o poço não está mais no centro do reservatório, está posicionado a 82,25 $\mathrm{m}$ das bordas laterais da área de drenagem do reservatório. Os tamanhos dos lados do reservatório são escolhidos de forma que a área de drenagem do reservatório tenha um de raio de $1000 \mathrm{~m}$.

A figura 7.15 apresenta duas vistas da malha utilizada para a presente simulação de CFD, utilizando o Fluent. Um refino local na região do poço é definido para que a geometria do poço possa ser contabilizada. A malha contém 954.620 elementos e o passo de tempo utilizado foi de 2 dias.

Um detalhe da região do poço, para ilustrar o refino empregado pode ser vista na figura 7.16, a qual apresenta duas amplificações e ângulos diferentes, para melhor visualizar os detalhes da malha.
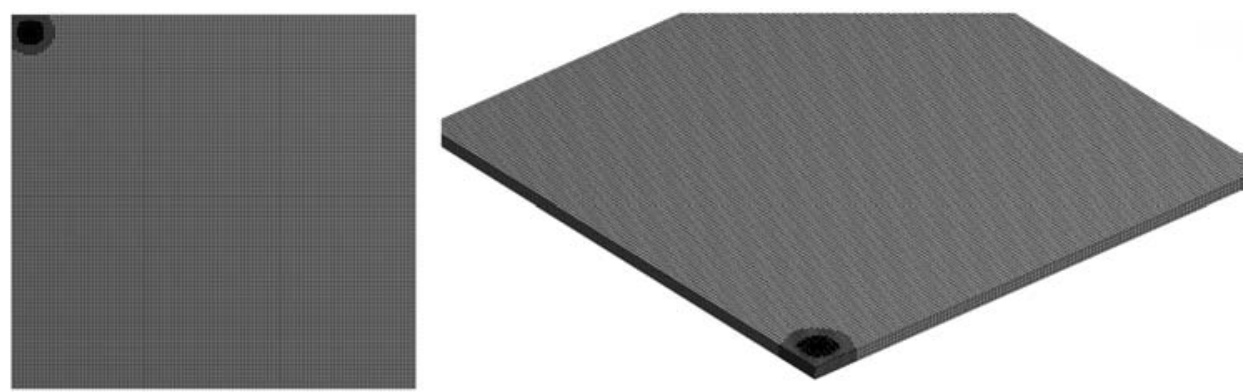

Figura 7.15: Malha do Teste 2.2.
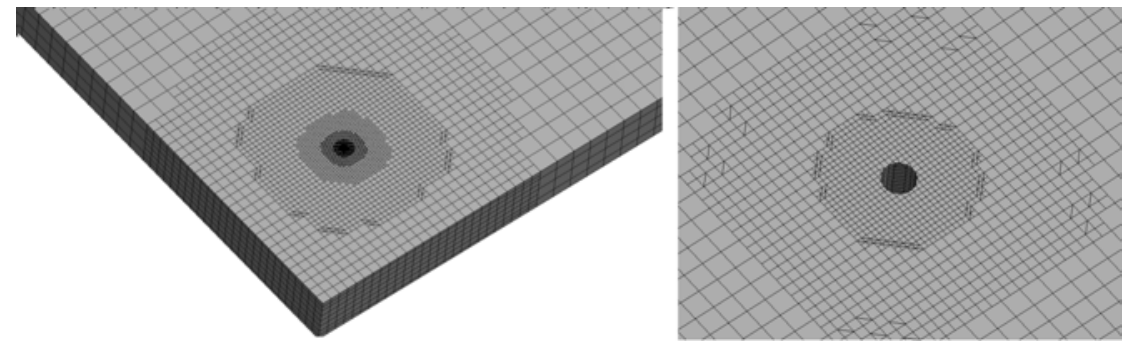

Figura 7.16: Refino da malha na região do poço. Teste 2.2. 
As mesmas condições de contorno e inicial do caso anterior são impostas aqui. Ou seja, vazão nula, sendo a pressão inicial hidrostática. Esta é igual a $640 \mathrm{kgf} / \mathrm{cm}^{2}$ no topo do reservatório e igual a $400 \mathrm{kgf} / \mathrm{cm}^{2}$ no topo do poço. Inicialmente, o poço e o reservatório estão pressurizados considerando a pressão hidrostática. Um gradiente nulo de pressão é imposto em todas as fronteiras do reservatório.

A figura 7.17 apresenta uma vista em perspectiva do campo de pressão após dez dias de produção, previsto com os dois softwares, IMEX e Fluent. Para melhor avaliar o campo de pressão, uma comparação dos dois solvers também é apresentada na figura 7.18, a qual mostra o campo de pressão utilizando uma vista superior do reservatório.

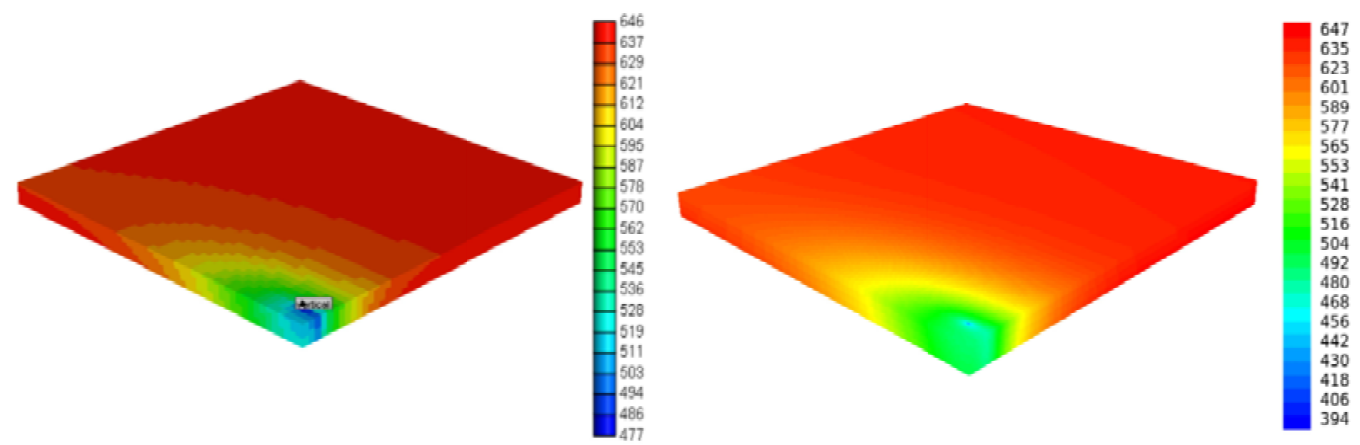

Figura 7.17: Campo de pressão após dez dias de produção para Teste 2.2. (a) IMEX a esquerda (b) HDF Fluent a direita.
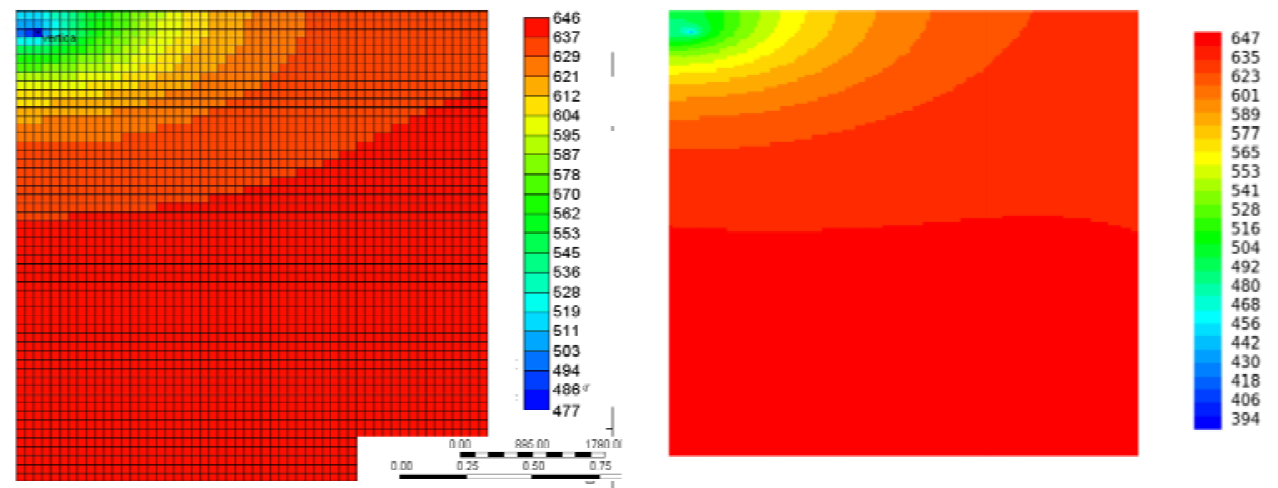

Figura 7.18: Vista de topo - Campo de pressão após dez dias de produção para Teste 2.2. (a) IMEX a esquerda (b) HDF Fluent a direita.

Observa-se através das figuras 7.17 e 7.18 a influência do poço na região do reservatório ao seu redor. Os resultados para a propagação de pressão continuam coerentes. No caso do software Fluent, a interpolação entre os volumes de controle na etapa de pós processamento leva a um campo de pressão 
mais suave, ou seja, sem uma alta diferença entre mudança de cores. Apesar do software IMEX não possuir tal funcionalidade, os campos de pressão obtidos são bastante próximos.

Finalmente, uma comparação quantitativa é ilustrada na figura 7.19, que apresenta a produção do poço em $\mathrm{m}^{3} /$ dia em função do tempo, calculada pela rotina desenvolvida no software Fluent e pelo software IMEX. Esta comparação mostra que a implementação no software Fluent concorda com o resultado previsto pelo IMEX. A pequena diferença entre os resultados pode ser atribuida ao modelo de poço utilizada pelo software IMEX perto da região de contorno.

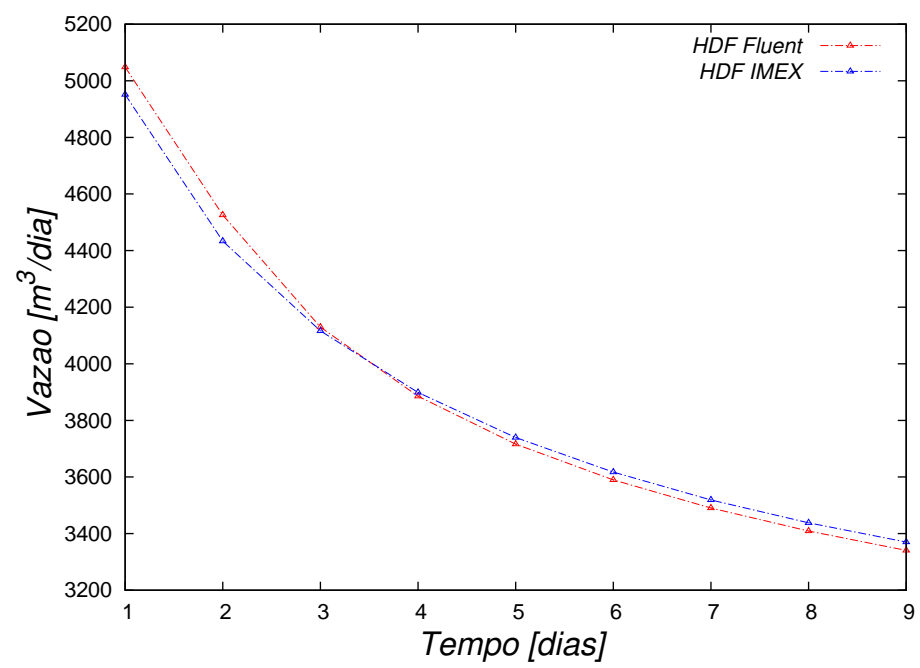

Figura 7.19: Comparação da variação da vazão volumétrica obtida com Fluent e IMEX, para poço vertical em um reservatório quadrado. Teste 2.2.

\subsection{3}

\section{Teste 2.3: Poço Vertical em um Reservatório Homogêneo Circular}

Este teste também considera um poço vertical em um reservatório circular homogêneo, sendo bem semelhante ao Teste 2.1. O objetivo deste teste foi comparar os resultados obtidos com o modelo de difusividade hidráulica implementado no OpenFOAM $₫$, com o modelo implementado no Fluent e com o software comercial IMEX.

A tabela 7.8 apresenta as informações da geometria do poço e reservatório. Já as propriedades do fluido e do reservatório encontram-se na tabela 7.9. Como no exemplo anterior, a velocidade é nula no instante inicial e o reservatório encontra-se com distribuição de pressão hidrostática, sendo a pressão no topo do reservatório igual a $640 \mathrm{kgf} / \mathrm{cm}^{2}$, e no topo do poço igual a 400 $\mathrm{kgf} / \mathrm{cm}^{2}$. Inicialmente, o poço e o reservatório estão pressurizados considerando a pressão hidrostática. Considera-se gradiente de pressão nulo em todas as fronteiras do reservatório. 
Tabela 7.8: Dimensões do caso de poço vertical em reservatório circular. Teste 2.3

\begin{tabular}{|c|c|c|}
\hline Nome & Valor & Unidade \\
\hline Raio do reservatório & 1000 & $m$ \\
Espessura do reservatório & 40 & $m$ \\
Diâmetro do poço & 12 & in \\
\hline
\end{tabular}

Tabela 7.9: Propriedades do fluido e reservatório para o Teste 2.3.

\begin{tabular}{|c|c|c|c|c|c|}
\hline \multicolumn{3}{|c|}{ Propriedades do fluido } & \multicolumn{3}{|c|}{ Propriedades da formação } \\
\hline Propriedade & Dimensão & Valor & Propriedade & Dimensão & Valor \\
\hline$\mu @ p_{b}$ & $c p$ & 1,076 & $K_{x x}$ & mDarcy & 100 \\
\hline$C_{v i s c}$ & $\mu s$ & $5,45 \times 10^{-6}$ & $K_{y y}$ & mDarcy & 100 \\
\hline$p_{b}$ & $M P a$ & 30,8 & $K_{z z}$ & mDarcy & 100 \\
\hline$\rho$ & $K g / m^{3}$ & 897 & $\phi_{\text {ref }}$ & [ ] & 0,1 \\
\hline$B_{o} @ p_{b}$ & {$[$ ] } & 1,43 & $p_{\text {ref }}$ & $M P a$ & 54,92 \\
\hline$R_{s}$ & [ ] & 0 & $S_{w c}$ & [ ] & 0 \\
\hline$c_{o}$ & $1 / M P a$ & $7,25 \times 10^{-4}$ & $c_{f}$ & $1 / M P a$ & $7,25 \times 10^{-4}$ \\
\hline$\rho_{g} @ S C$ & $K g / m^{3}$ & 0 & $S_{w}$ & [ ] & 0 \\
\hline
\end{tabular}

A figura 7.20 ilustra a malha do reservatório e detalhe na região do poço para o cálculo de CFD no software OpenFOAM@. A mesma malha foi utilizada nos dois softwares e contem 942.328 elementos. O mesmo passo de tempo foi utilizados nos dois softwares cujo valor foi de 2 dias.
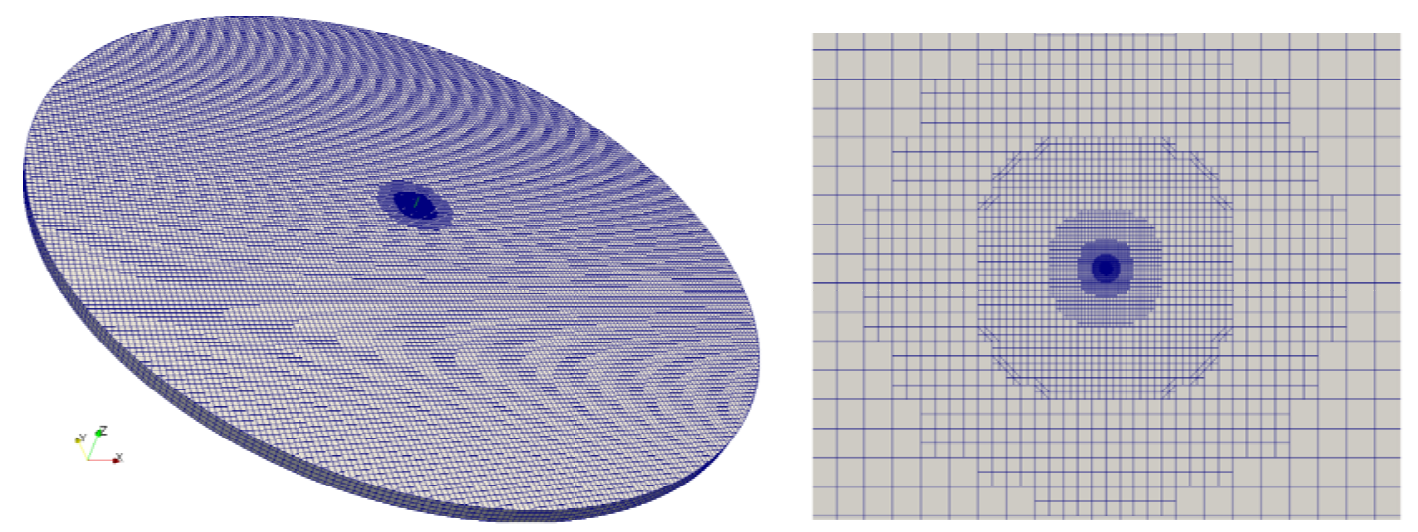

Figura 7.20: Malha de CFD para Teste 2.3. (a) reservatório circular (b) detalhe do poço

A Figura 7.21 ilustra o campo de pressões no reservatório após quatro dias de produção calculado pelo OpenFOAM $®$. 


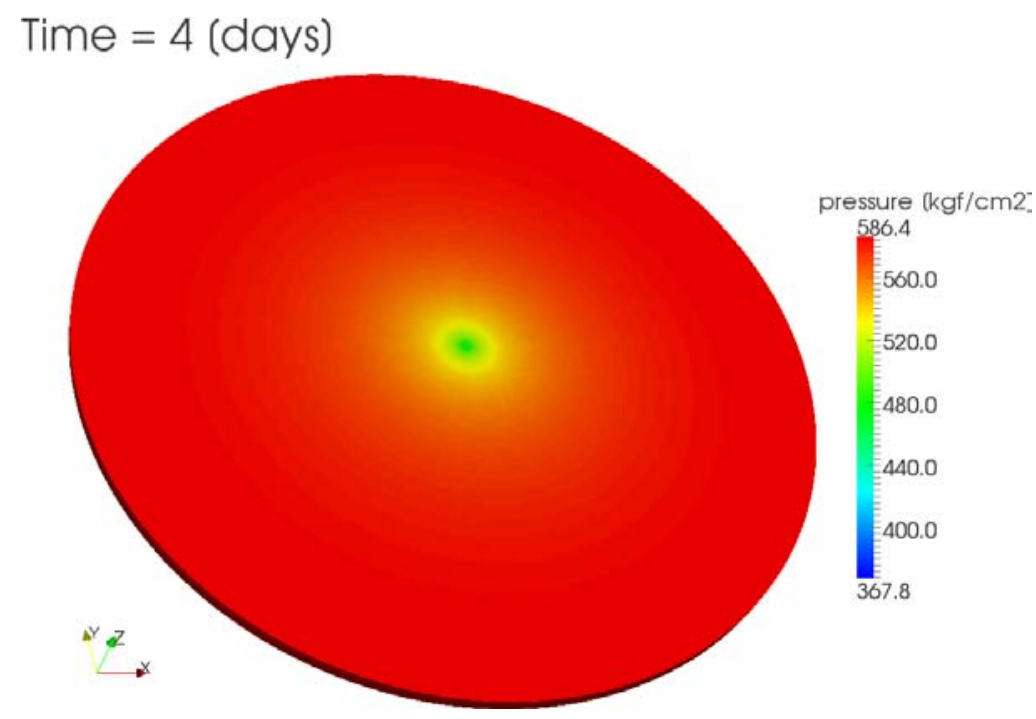

Figura 7.21: Campo de pressão após quatro dias de produção para Teste 2.3. HDF OpenFOAMR.

Observa-se o mesmo tipo de resultado para o campo de pressão ilustrado anteriormente. Quantitativamente, o comportamento da propagação da pressão no reservatório ao redor do poço é coerente.

A comparação da variação da produtividade do poço ao longo do tempo, obtidos por cada software é ilustrada na figura 7.22. Os resultados apresentados mostram que as três ferramentas numéricas fornecem fundamentalmente o mesmo resultado para o modelo de difusividade hidráulica, validando também o solver hydraulicDiffusivityFoam.

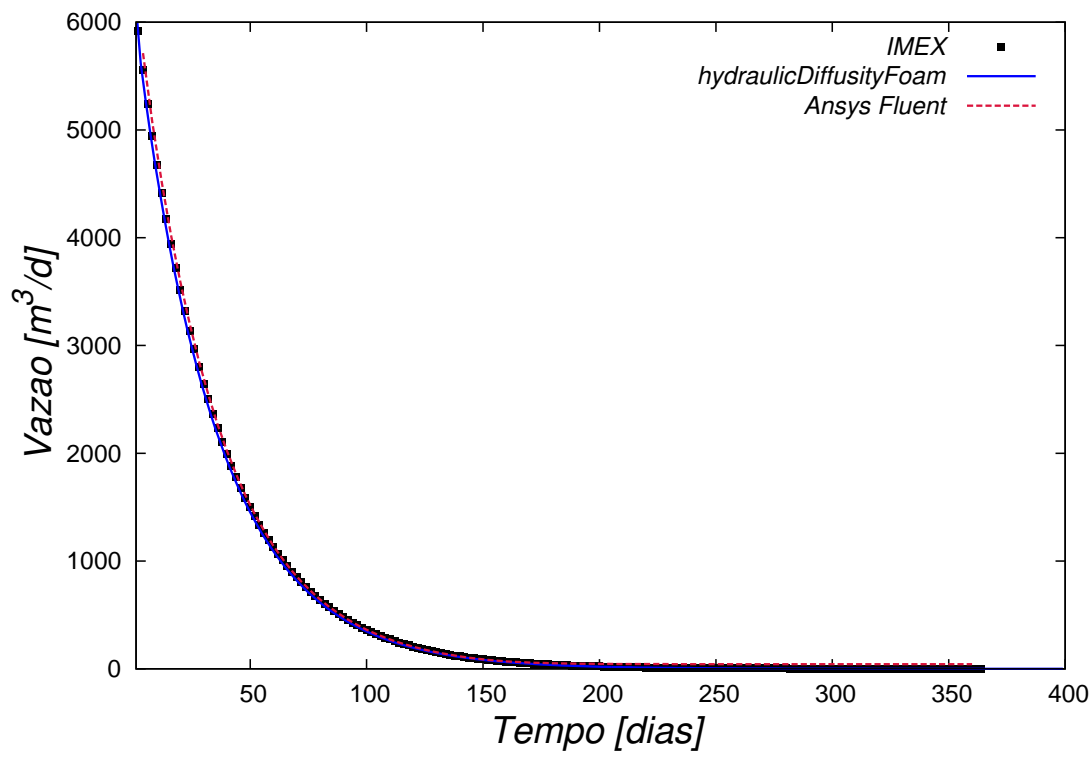

Figura 7.22: Produtividade do poço ao longo do tempo calculada pelos softwares HDF OpenFOAM@, HDF Fluent e IMEX. Teste 2.3. 


\subsection{4}

\section{Teste 2.4: Poço vertical em um Reservatório Heterogêneo Quadrado}

Este teste foi projetado para avaliar o desempenho das ferramentas numéricas implementadas para tratar reservatórios heterogêneos. A heterogeneidade do meio nesta simulação foi importada do software IMEX. Ou seja, a permeabilidade foi mapeada a partir de dados da malha do software IMEX. Para que o campo de permeabilidade do software IMEX pudesse ser transferido para um software de CFD, um programa de mapeamento de propriedades entre diferentes malhas precisou ser desenvolvido. As rotinas de mapeamento foram integradas ao OpenFOAM pelo desenvolvimento de três programas:

1. writeMeshCentroids: programa que escreve em arquivo o centróide dos volumes da malha CFD que será lido pelo programa de mapeamento.

2. mappingImexData: programa que escreve em arquivo as properidades mapeadas do software IMEX para a malha CFD.

3. imexDataToFoam: programa que escreve as variáveis de campo mapeadas para a simulação CFD: permeabilidade, porosidade, netGross e Swcon.

Para ter um modelo de CFD fiel ao modelo IMEX foram desenvolvidas rotinas para a leitura estruturada de um arquivo de entrada de IMEX. Criou-se um executável para exportar a geometria de um arquivo de entrada de IMEX para um arquivo possível de ser lido dentro de um gerador de malha de CFD. Um segundo executável foi criado para fazer o mapeamento de propriedades de reservatório entre os elementos da malha IMEX e os elementos da malha de um software CFD.

O esquema da transferência de propriedades entre as malhas é exemplificado na figura 7.23. Inicialmente, as propriedades da "Malha 1" (malha com 4 retângulos) são transferidas para a "Malha 2" (malha de triângulos), estando ambas sobrepostas no espaço. A seguir, ainda com malhas superpostas, ajusta-se as propriedades para a "Malha 2", comparandoos centros geométricos mais próximos entre elementos das duas malhas. Finalmente, obtém-se a distribuição de propriedades para a "Malha 2". Na representação da transferência de informação entre as malhas, um código de cores foi utilizado para auxiliar a interpretação do processo. 


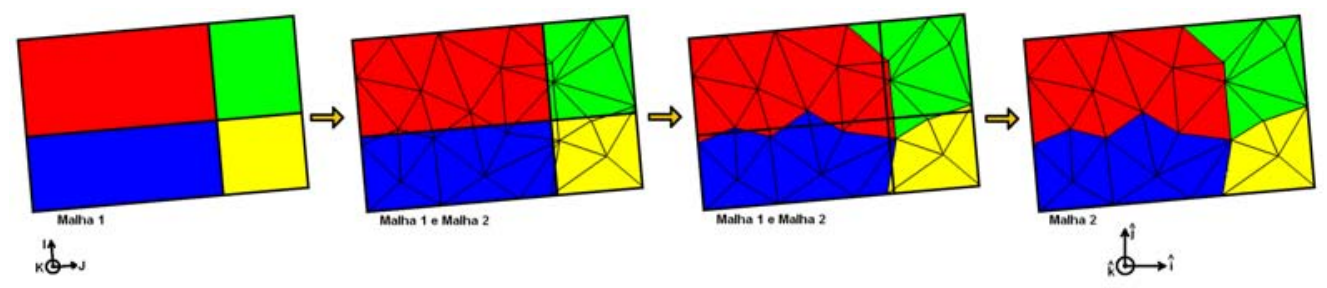

Figura 7.23: Mapeamento de uma propriedade qualquer do software IMEX para software CFD.

As dimensões do poço e do reservatório são apresentadas na tabela 7.10. A tabela 7.11 mostra os parâmetros e propriedades do fluido e formação utilizados neste teste. Os campos iniciais e as condições de contorno para o caso de poço vertical em um reservatório heterogêneo são: vazão nula e pressão inicial hidrostática. A pressão no topo do reservatório é $640 \mathrm{kgf} / \mathrm{cm}^{2}$, e no topo do poço é $400 \mathrm{kgf} / \mathrm{cm}^{2}$. Inicialmente, o poço e o reservatório estão pressurizados considerando a pressão hidrostática. Mais uma vez, considera-se gradiente nulo de pressão nas bordas do reservatório.

Tabela 7.10: Dimensões do caso de poço vertical em reservatório heterogêneo circular. Teste 2.4 .

\begin{tabular}{|c|c|c|}
\hline Nome & Valor & Unidade \\
\hline Lados do reservatório & 1772,45 & $m$ \\
Espessura do reservatório & 40 & $m$ \\
Diâmetro do poço & 0,312 & $m$ \\
\hline
\end{tabular}

Tabela 7.11: Propriedades do fluido e reservatório para o Teste 2.4

\begin{tabular}{|c|c|c|c|c|c|}
\hline \multicolumn{3}{|c|}{ Propriedades do fluido } & \multicolumn{3}{c|}{ Propriedades da formação } \\
\hline Propriedade & Unidade & Valor & Propriedade & Unidade & Valor \\
\hline$\mu @ p_{b}$ & $c p$ & 1,076 & $K_{x x}$ & mDarcy & 100 \\
$C_{v i s c}$ & $s$ & $5,447 \times 10^{-6}$ & $K_{y y}$ & mDarcy & 100 \\
$p_{b}$ & $M P a$ & 30,8 & $K_{z z}$ & $m$ Darcy & 100 \\
$\rho$ & $K g / m^{3}$ & 897 & $\phi_{r e f}$ & {[]} & 0,1 \\
$B_{o} @ p_{b}$ & {[]} & 1,43 & $p_{r e f}$ & $M P a$ & 54,92 \\
$R_{s}$ & {[]} & 0 & $S_{w c}$ & {[]} & 0 \\
$c_{o}$ & $1 / M P a$ & $7,252 \times 10^{-4}$ & $c_{f}$ & $1 / M P a$ & $5,099 \times 10^{-4}$ \\
$\rho_{g} @ S C$ & $K g / m^{3}$ & 0 & $S_{w}$ & {[]} & 0 \\
\hline
\end{tabular}

A figura 7.24 ilustra o campo de permeabilidade visualizado na malha do IMEX e HDF OpenFOAM@. Percebe-se que os campos de permeabilidade dos dois softwares são idênticos. 

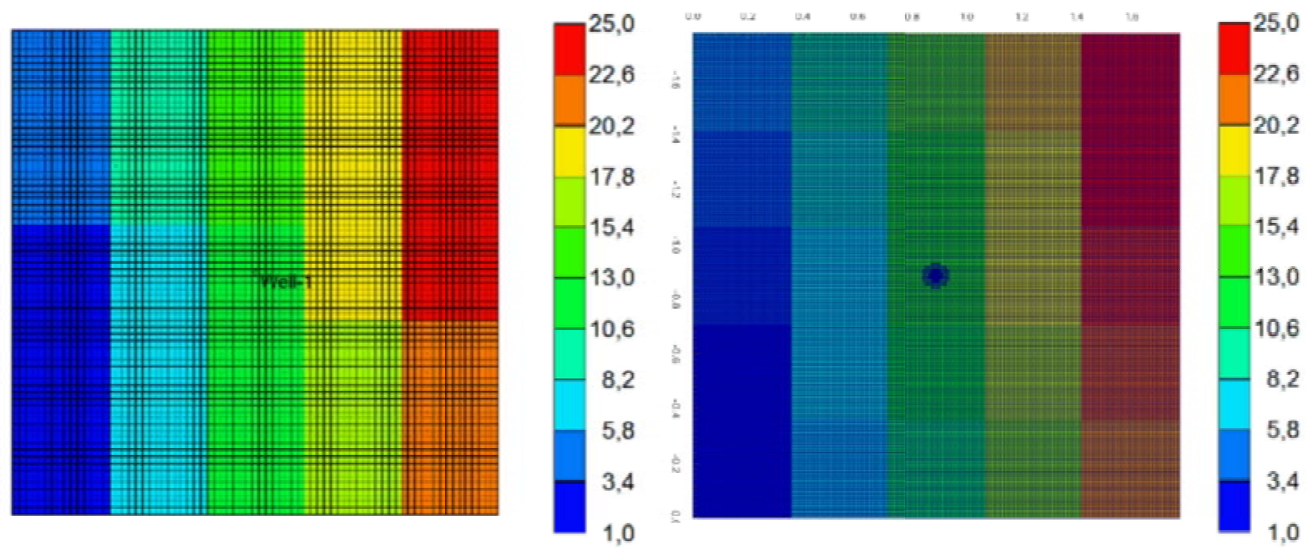

Figura 7.24: Componente $K_{x x}$ do tensor de permeabilidade. (a) IMEX à esquerda (b) HDF OpenFOAM@ à direita.

As figuras 7.25 apresentam a malha utilizada para a presente simulação de CFD, do OpenFOAM® (reservatório e detalhe do poço). Um refino local na região do poço é definido para que a geometria do poço possa ser contabilizada. A malha contem 940.504 elementos e o passo de tempo utilizado foi de 2 dias. Mais uma vez, longe do poço (distâncias superiores a dez diâmetros do poço) os elementos dos dois solvers são equivalentes.
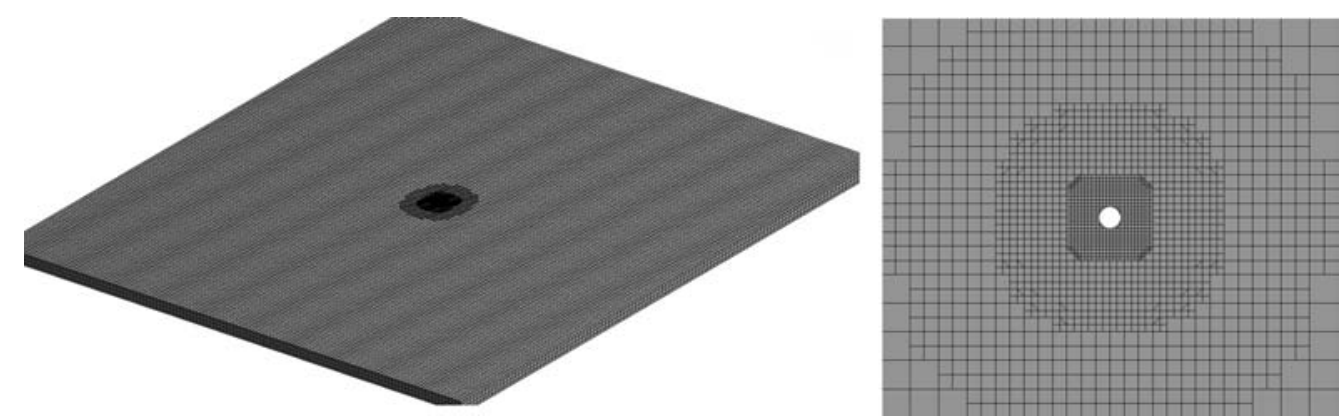

Figura 7.25: Malha do Teste 2.4.

A figura 7.26 mostra o campo de pressões no reservatório após 400 dias, ilustrando a assimetria no campo de pressão devido a heterogeneidade do tensor permeabilidade, conforme esperado. A figura 7.26 apresenta o resultado obtido pelo OpenFOAM@. Este caso é validado comparando os resultados encontrados no OpenFOAM@ com os resultados obtidos com o solftware comercial IMEX. Apresenta-se a variação temporal da vazão produzida no poço na figura 7.27. Observa-se mais uma vez que boa concordância entre os resultados. 


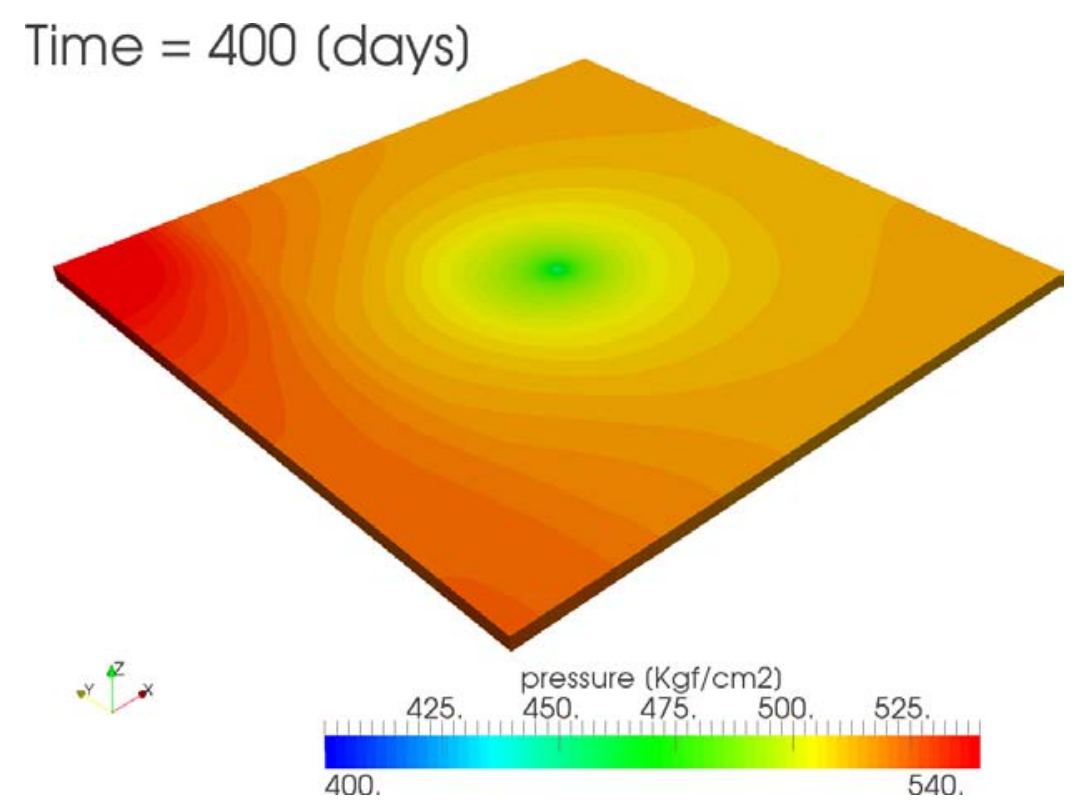

Figura 7.26: Campo de pressões no reservatório após 400 (quatrocentos) dias de simulação. HDF OpenFOAM@. Teste 2.4.

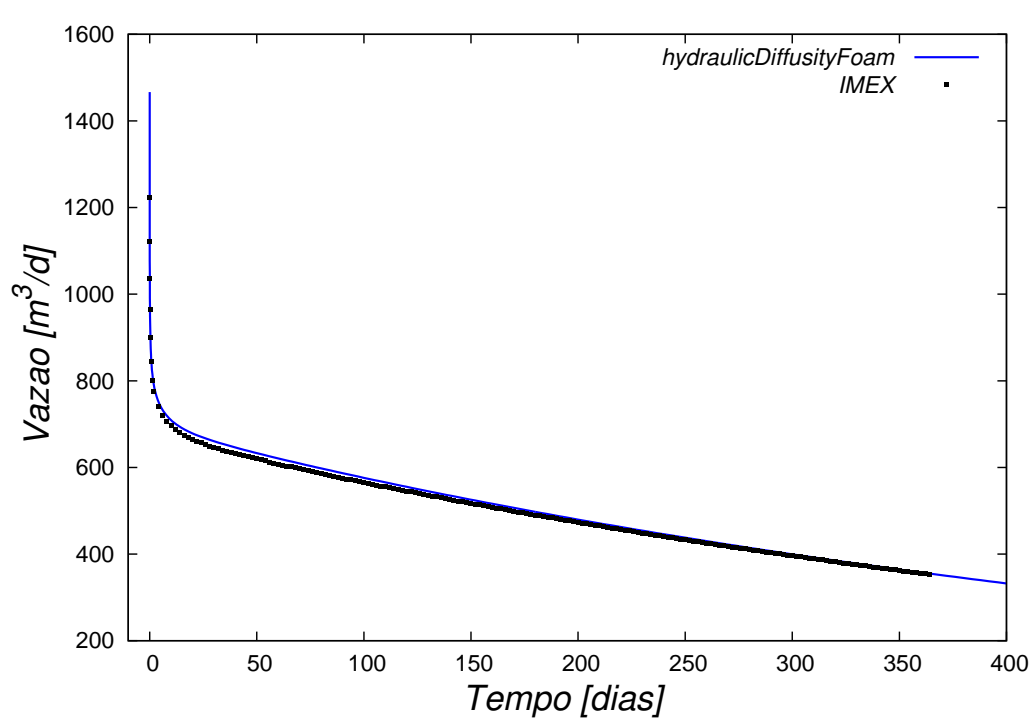

Figura 7.27: Variação temporal da vazão obtida com os softwares hydraulicDiffusivityFoam e IMEX, para um poço vertical em um reservatório circular heterogêneo. Teste 2.4.

\subsection{5}

Teste 2.5: Poço Horizontal em um Reservatório Heterôgeneo Retangular

A simulação apresentada nesta seção representa mais uma validação do modelo de difusividade hidráulica em CFD, agora para um poço horizontal em um reservatório heterogêneo considerando o fluido pela modelagem blackOil. 
Este teste consiste de um reservatório com um poço horizontal posicionado a $11 \mathrm{~m}$ abaixo do topo do reservatório e centralizado quando visto de cima. A área de drenagem do reservatório tem geometria retangular. As dimensões do poço e do reservatório podem ser vistas na tabela 7.12. A hetereogeneidade do reservatório é configurada por uma permeabilidade variando de forma abrupta na direção ao longo do poço (direção $y$ ) e diferente da permeabilidade na direção transversal $x$ e vertical $z$. A tabela 7.13 apresenta as propriedades do fluido e do reservatório para este teste.

Tabela 7.12: Dimensões do caso de poço horizontal em reservatório retangular. Teste 2.5

\begin{tabular}{|c|c|c|}
\hline Nome & Valor & Unidade \\
\hline Lado 1 do reservatório & 2500 & $m$ \\
Lado 2 do reservatório & 1700 & $m$ \\
Espessura do reservatório & 22 & $m$ \\
Comprimento do poço & 800 & $m$ \\
Diâmetro do poço & 6 & $i n$ \\
\hline
\end{tabular}

Tabela 7.13: Propriedades do fluido e reservatório para o caso de poço horizontal em reservatório retangular. Teste 2.5.

\begin{tabular}{|c|c|c|c|c|c|}
\hline \multicolumn{3}{|c|}{ Propriedades do fluido } & \multicolumn{3}{c|}{ Propriedades da formação } \\
\hline Propriedade & Unidade & Valor & Propriedade & Unidade & Valor \\
\hline$\mu @ p_{b}$ & $c p$ & 0,6253 & $K_{x x}$ & $m$ Darcy & 100 \\
$C_{v i s c}$ & $s$ & $1,2 \times 10^{-4}$ & $K_{y y}$ & $m$ Darcy & 25 e 250 \\
$p_{b}$ & $k g f / \mathrm{cm}^{2}$ & 400,1 & $K_{z z}$ & $m$ Darcy & 10 \\
$\rho$ & $K g / \mathrm{m}^{3}$ & 882,31 & $\phi_{r e f}$ & {[]} & 0,12 \\
$B_{o} @ p_{b}$ & {[]} & 1,62 & $p_{r e f}$ & $\mathrm{kgf} / \mathrm{cm}^{2}$ & 560 \\
$R_{s}$ & {[]} & 275,13 & $S_{w c}$ & {[]} & 0 \\
$c_{O}$ & $c m^{2} / \mathrm{kgf}$ & $1,12 \times 10^{-4}$ & $c_{f}$ & $\mathrm{~cm}^{2} / \mathrm{kgf}$ & $5 \times 10^{-5}$ \\
$\rho_{g} @ S C$ & $K g / \mathrm{m}^{3}$ & 1,2631 & $S_{w}$ & {[]} & 0,25 \\
\hline
\end{tabular}

A figura 7.28 apresenta a vista de topo do reservatório com o campo de permeabilidade $K_{y y}$ considerado. A figura foi retirada do software IMEX (onde a direção $x$ é a direção $J$, a direção $y$ é denominada de $I$ e a direção $z$ é referenciada como $K$ ). Para os casos de CFD (Fluent e OpenFOAM@), exatamente o mesmo campo de permeabilidade foi imposto, porém, considerouse simetria em relação ao poço, e somente metade do reservatório foi simulado. 


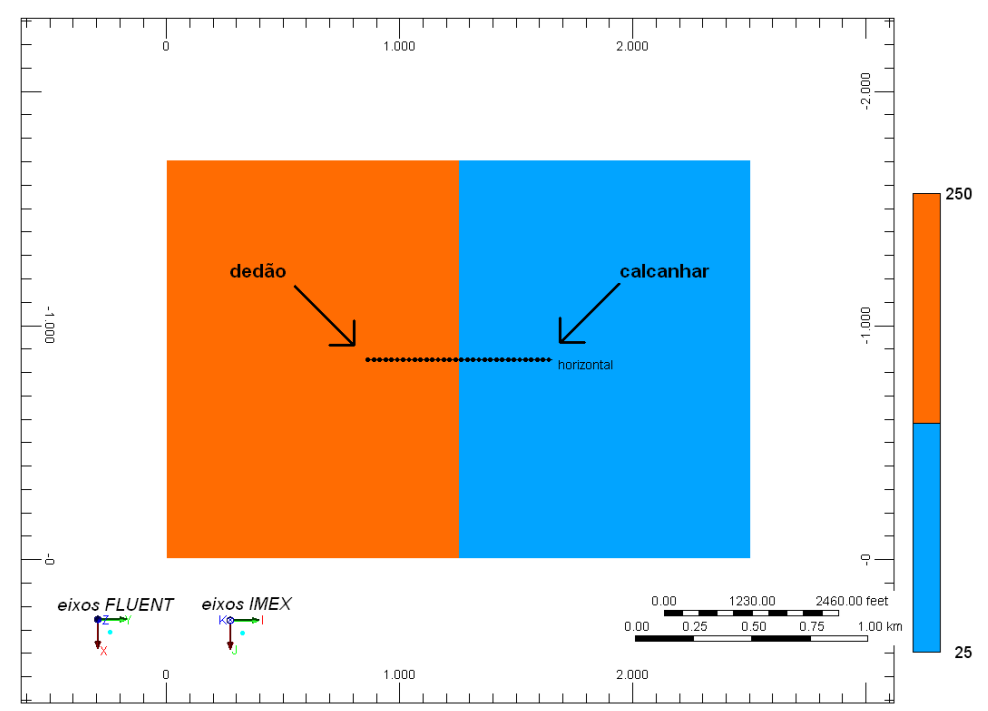

Figura 7.28: Campo de permeabilidade $K_{y y}$ para poço horizontal em reservatório retangular.

Os campos iniciais consistem mais uma vez de velocidade nula e um campo hidrostático de pressão. A pressão no topo do reservatório é igual a 640 $\mathrm{kgf} / \mathrm{cm}^{2}$ e a pressão no topo do poço é $400 \mathrm{kgf} / \mathrm{cm}^{2}$. Mais uma vez, considera-se gradiente nulo de pressão em todas as fronteiras do reservatório.

A figura 7.29 apresenta dois ângulos diferentes da região próxima do poço. A figura 7.29 apresenta a malha na região próxima ao poço para o cálculo de CFD, a qual foi utilizada no Fluent e no OpenFOAMß. A malha contém 5.395.160 de elementos e o passo de tempo utilizado foi de 1 hora.
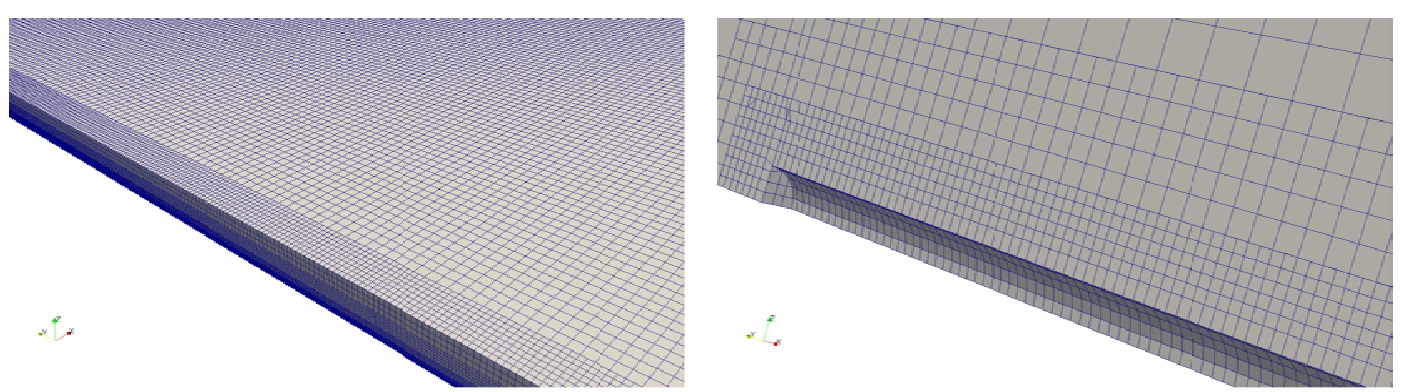

Figura 7.29: Malha para o cálculo de CFD - Teste 2.5.

A figura 7.30 apresenta uma vista superior do campo de pressão, após 1 dia e 3 dias de produção. O lado esquerdo apresenta os resultados da simulação obtida com o Fluent e do lado direito os resultados obtidos com o solver hydraulicDiffusivityFoam implementado no OpenFOAM@. 

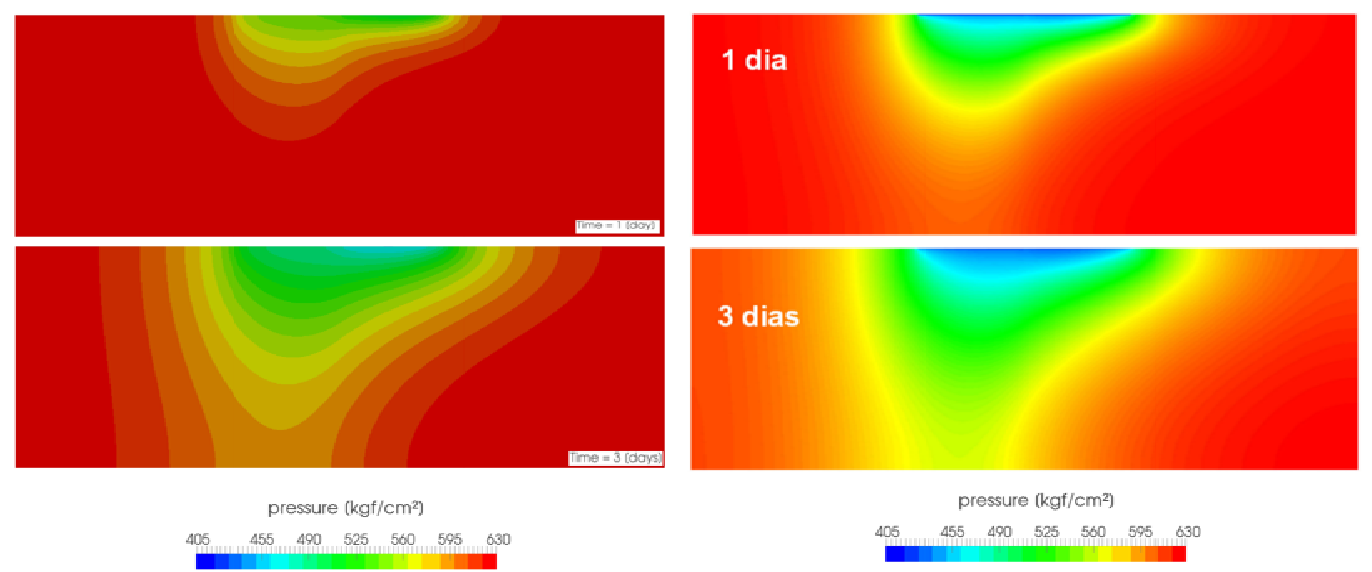

Figura 7.30: Campo de pressão para poço horizontal em reservatório retangular, heterogêoneo, após após 1 e 3 dias de produção. Teste 2.5. (a) HDF OpenFOAM@ à esquerda (b) HDF Fluent à direita.

Observa-se na figura 7.30 como o campo de pressão se propaga durante alguns dias de produção e como o efeito da hetereogenidade do reservatório afeta o campo de pressão. Percebe-se níveis mais baixos de pressão na região com permeabilidade mais alta. Note que os mesmos resultados foram obtidos com as duas ferramentas.

A figura 7.31 apresenta o campo de pressão obtido com o IMEX, após três dias de produção, utilizando a mesma vista utilizada nas figuras anteriores. No IMEX não foi considerada a hipótese de simetria, logo todo reservatório precisou ser simulado. Comparando-se as previsões de ambos os softwares após 3 dias de produção (7.30) com as previsões obtidas com o software IMEX, figura 7.31. Pode-se afirmar mais uma vez que qualitativamente o mesmo resultado foi obtido.

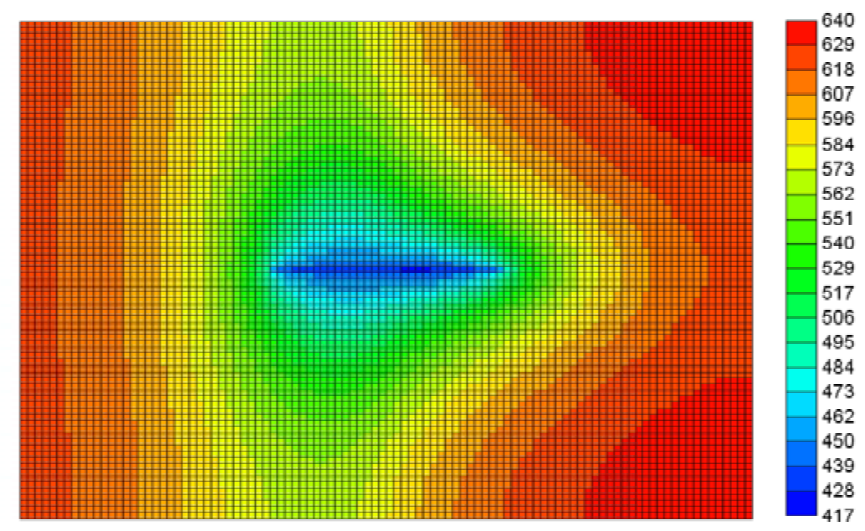

Figura 7.31: Campo de pressão para poço horizontal em reservatório retangular, após 3 dias. Teste 2.5. IMEX. 
A figura 7.32 apresenta o campo de pressão pelo reservatório, obtido com IMEX e Fluent, após dez dias de produção. Pode ser visto excelente concordânica entre as previsões.

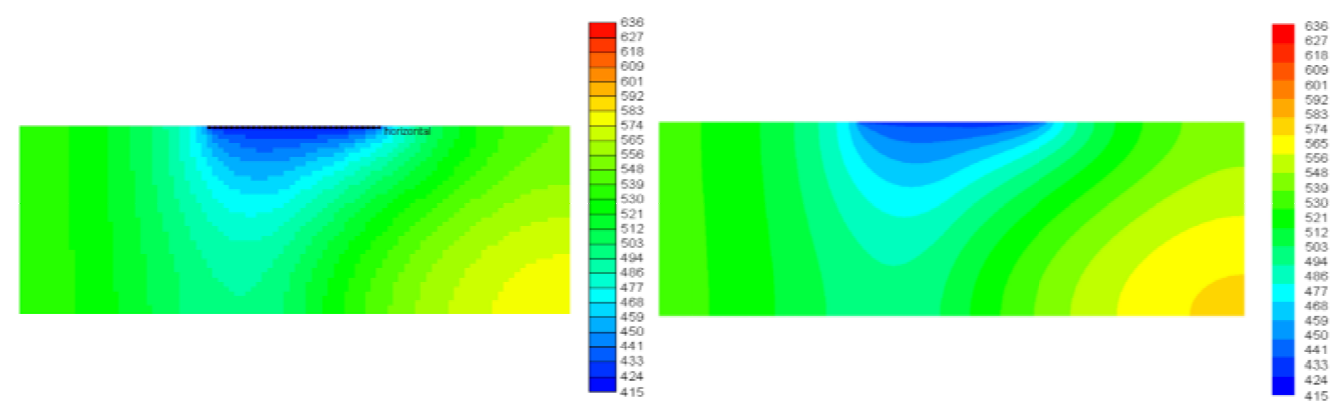

Figura 7.32: Plano central - Pressão para poço horizontal em reservatório retangular heterogêoneo, após 10 dias de produção. Teste 2.5. (a) IMEX à esquerda (b) HDF Fluent à direita.

A produção do poço calculada pelos três softwares é apresentada na figura 7.33. A concordância do resultado quantitativo mostra que a implementação no software Fluent e o novo solver implemetado no OpenFOAM $®$ concordam com o resultado previsto pelo IMEX para o caso de produtividade de um poço horizontal, em reservatório heterogêneo. Os resultados equivalentes obtidos com as diferentes ferramentas, valida o solver hydraulicDiffusivityFoam com relação a previsão de escoamento em reservatórios heterogêneos com propriedades variáveis.

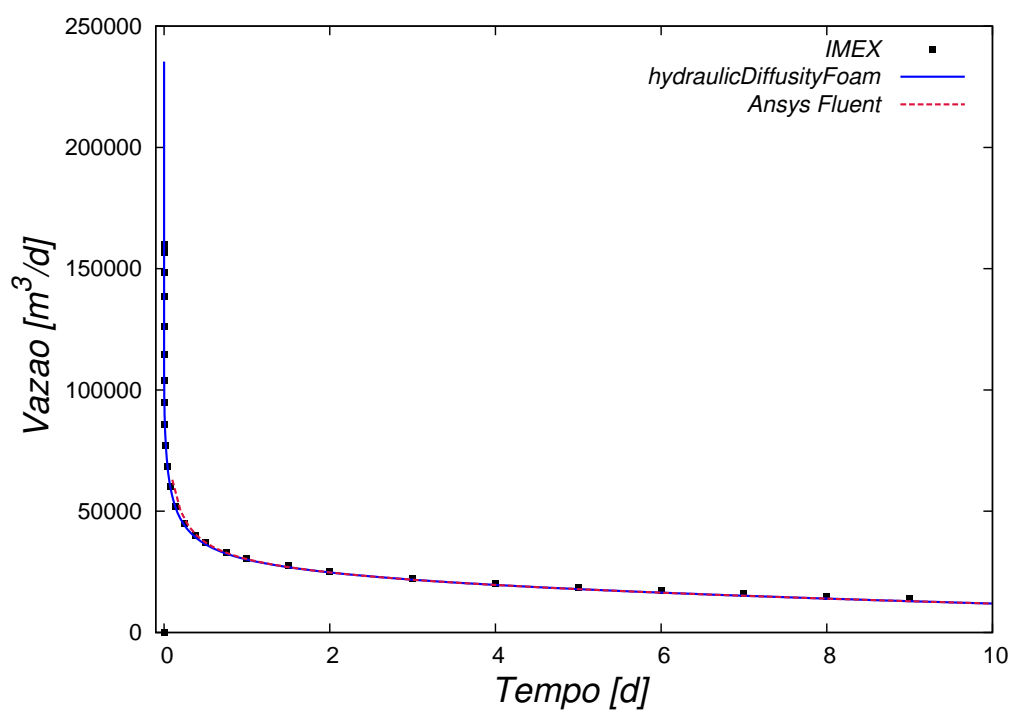

Figura 7.33: Produtividade do poço horizontal ao longo do tempo para a simulação do reservatório heterogêneo com propriedades variáveis. Teste 2.5 


\subsection{6}

\section{Teste 2.6: Poço Horizontal em Reservatório Heterogêneo Retangular com Acoplamento Poço Reservatório}

O objetivo do presente teste é avaliar a influência do acoplamento poçoreservatório, resolvendo o escoamento nas duas regiões, visando melhorar as previsões da produtividade de poços de petróleo. Vale lembrar que por ser um simulador específico de reservatórios, o software IMEX não contabiliza o escoamento dentro do poço. Este teste também ilustra a versatilidade da ferramenta desenvolvida, a qual acopla domínios com escalas completamente diferentes. A metodologia foi implementada nos softwares OpenFOAM $\mathbb{R}$ e Ansys Fluent.

Considera-se o mesmo domínio computacional e propriedades do fluido e formação apresentados na seção 7.3.5. Ou seja, as informações da tabela 7.12 e 7.13 foram utilizadas no presente teste. Os campos iniciais consistem mais uma vez de velocidade nula e um campo hidrostático de pressão. A pressão no topo do reservatório é igual a $640 \mathrm{kgf} / \mathrm{cm}^{2}$ e a pressão no poço agora é contabilizada pelo escoamento dentro do poço através do acoplamento entre poço-reservatório. Mais uma vez, considera-se gradiente nulo de pressão em todas as fronteiras do reservatório.

A completação escolhida para o presente teste considera o liner com a presença de gravel na região anular. A tabela 7.14 apresenta as informações necessárias para a consideração do escoamento dentro do poço.

Tabela 7.14: Dimensões do caso de poço vertical em reservatório circular. Teste 2.6 .

\begin{tabular}{|c|c|c|}
\hline Nome & Valor & Unidade \\
\hline diâmetro interno do liner & 4 & in \\
diâmetro externo do liner & 4,5 & in \\
Permeabilidade do gravel & 50 & Darcy \\
Diâmetro dos furos & 0,25 & in \\
Densidade dos furos & 1 & $1 / m$ \\
\hline
\end{tabular}

As previsões de ambos os softwares são comparadas entre si, validando a metodologia de acoplameno, e são comparados com as previsões do software IMEX para ilustrar a influência da previsão do escoamento através do poço na produtividade do reservatório. A Figura 7.34 apresenta a produtividade no poço obtida com as duas ferramentas de CFD (OpenFOAM® e Fluent), ilustrando perfeita concordância entre as previsões. 


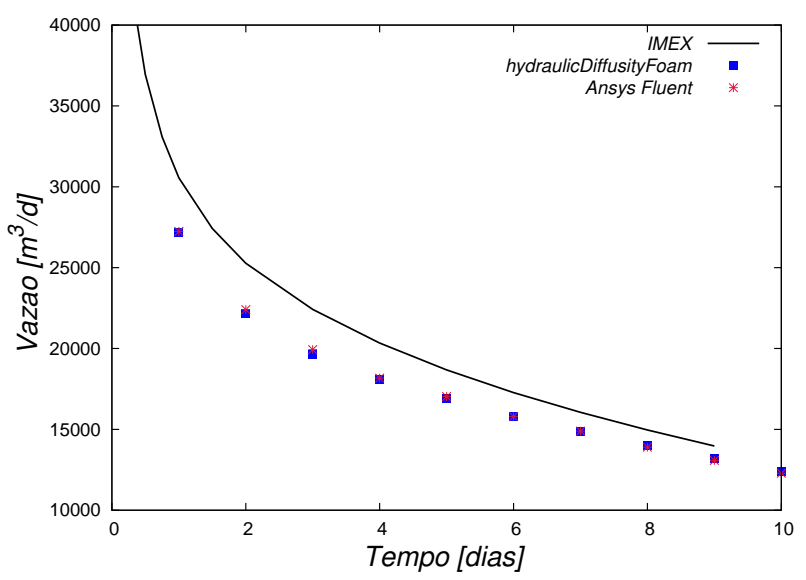

Figura 7.34: Produtividade do poço horizontal em um reservatório heterogêneo. Poço horizontal com liner com a presença de gravel no anular. Teste 2.6.

A figura 7.34 também mostra a produção obtida com o software IMEX, que não considera o escoamento dentro do poço. O resultado ilustra a diferença entre previsões da produção dos poços quando não se leva em consideração o cálculo do escoamento ao longo do poço, mostrando a importância do acoplamento entre poço e reservatório.

Observa-se na figura 7.34 que ao se considerar a perda de carga ao longo do poço, vazões menores são obtidas, representando de forma mais realista o escoamento, e consequentemente melhorando a previsão da produtividade.

A figura 7.35 mostra os perfis de vazão ao longo do poço para o tempo de 10 dias após o início da produção, obtidos com o hydraulicDiffusivityFoam e pelo Ansys Fluent. A coordenada zero do poço representa o calcanhar do poço horizontal e a coordenada 800 representa o dedão.

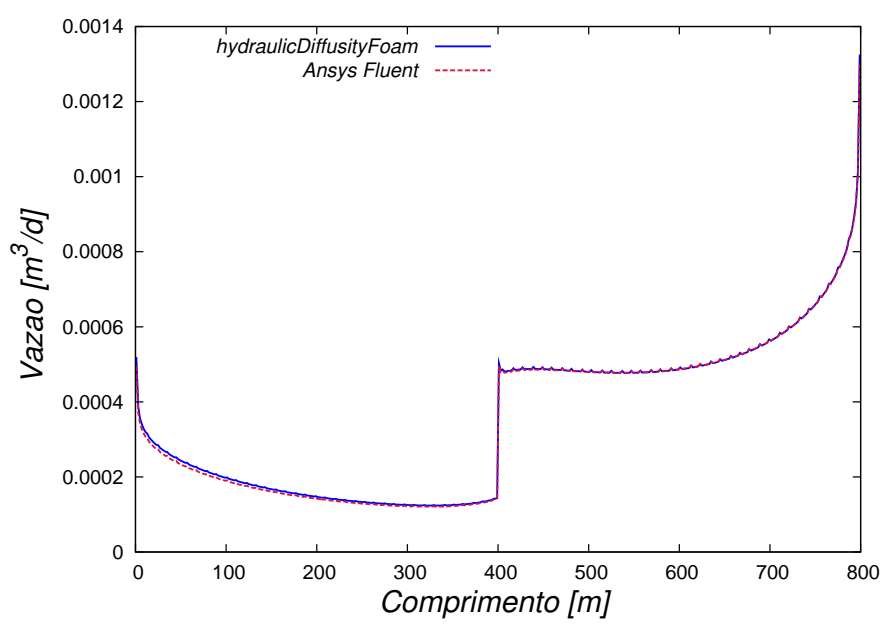

Figura 7.35: Vazão volumétrica ao longo do comprimento do poço para 10 dias. Poço horizontal com liner com gravel no anular.Teste 2.6. 
Como apresentado na figura 7.28 o campo de permeabilidades do reservatório é heterôgeneo tendo sua permeabilidade mais alta na região do dedão do poço. Logo, a vazão que chega na região do dedão $(\mathrm{x}=800)$ deve ser maior. Observa-se uma pequena redução da vazão ao longo do comprimento do poço. Isso ocorre devido ao fluxo esférico vindo das regiões do lado esquerdo e direito do poço horizontal. Note que ambos os softwares apresentam a mesma distribuição espacial de vazão ao longo do poço.

\section{4}

\section{Comparação do Modelo de Média com o Modelo de Darcy.}

O objetivo desta seção é mostrar que os resultados obtidos com uma ferramenta numérica baseada no modelo de Darcy, também podem ser obtidos a partir da ferramenta baseada no modelo mais completo, desenvolvido neste trabalho, a partir da teoria de médias.

Como mencionado no capítulo quatro, o modelo de Darcy pode ser obtido do modelo mais geral se uma série de simplificações forem introduzidas. A presente seção tem como objetivo validar de forma sistemática o novo solver rhoPorousPimleFoam desenvolvido no OpenFOAM@, visto que os modelos são baseados em formulações matemáticas diferentes.

Nas seções anteriores, a ferramenta hydraulicDiffusivityFoam (HDF) baseada no modelo de Darcy foi validada. Nesta seção as previsões obtidas com a ferramenta rhoPorousPimleFoam (RPPF) são comparadas com as previsões de hydraulicDiffusivityFoam, para casos onde os dois modelos são válidos.

Os casos escolhidos precisam estar no âmbito de aplicação da equação de Darcy, vistas no início do capítulo quatro, i.e., todas as hipóteses que permitem a utilização de Darcy foram consideradas nos testes realizados nesta seção. Para os casos dessa seção, o acoplamento poço-reservatório não foi considerado.

\subsection{1}

Teste 3.1: Poço Horizontal em um Reservatório Homogêneo

A primeira simulação refere-se a um poço horizontal cuja área de drenagem do reservatório foi modelada por um paralelepípedo. A tabela 7.15 apresenta as dimensões da geometria do poço e do reservatório. Considera-se que o poço está posicionado no centro do reservatório. 
Tabela 7.15: Dimensões do poço horizontal em um reservatório homogêneo. Teste 3.1 .

\begin{tabular}{|c|c|c|c|c|c|}
\hline \multicolumn{3}{|c|}{ Reservatório } & \multicolumn{3}{c|}{ Poço } \\
\hline Nome & Valor & Unidade & Nome & Valor & Unidade \\
\hline Comprimento & 2340 & $m$ & Comprimento & 500 & $m$ \\
Largura & 2340 & $m$ & Diâmetro & 8,5 & in \\
Espessura & 104,8 & $m$ & Posição & central & {[]} \\
Altura @Topo & 4338 & $m$ & & & \\
\hline
\end{tabular}

Em todos os casos anteriores as pressões do poço e do reservatório se encontravam no topo do domínio. Na presente simulação, a referência da pressão para as condições iniciais e de contorno não estão localizada na zona produtora, ou seja, no domínio computacional. Devido a esse tipo de informação, a cota (posição em termos da altura) do topo do reservatório é necessária para que a diferença de altura seja contabilizada no cálculo da pressão hidrostática.

Na presente simulação, considera-se a porosidade do reservatório e massa específica do fluido como dependentes da pressão. A viscosidade, nesse caso, não varia com a pressão. A tabela 7.16 apresenta as propriedades do fluido e do reservatório para este caso.

Tabela 7.16: Propriedades do fluido e reservatório em poço horizontal em um reservatório homogêneo. Teste 3.1.

\begin{tabular}{|c|c|c|c|c|c|}
\hline \multicolumn{3}{|c|}{ Propriedades do fluido } & \multicolumn{3}{c|}{ Propriedades da formação } \\
\hline Propriedade & Dimensão & Valor & Propriedade & Dimensão & Valor \\
\hline$\mu$ & $K g /(m s)$ & $1,0 \times 10^{-3}$ & $K_{x x}$ & Darcy & 0,1 \\
$C_{v i s c}$ & $s$ & 0 & $K_{y y}$ & Darcy & 0,1 \\
$p_{b}$ & $M P a$ & 100 & $K_{z z}$ & Darcy & 0,1 \\
$\rho$ & $K g / m^{3}$ & 675,0 & $\phi_{r e f}$ & {[]} & 0,2 \\
$B_{o}$ & {[]} & 1,0 & $p_{r e f}$ & $M P a$ & 474,679 \\
$R_{s}$ & {[]} & 0 & $S_{w c}$ & {[]} & 0 \\
$c_{o}$ & $1 / P a$ & $1,11 \times 10^{-9}$ & $c_{f}$ & $1 / P a$ & $1,11 \times 10^{-9}$ \\
\hline
\end{tabular}

Inicialmente, o fluido no reservatório está parado, com a distribuição de pressão hidrostática. Sabe-se que a pressão para o reservatório, é medida na coordenada a $4485 \mathrm{~m}$ é igual a 484,03 kgf $/ \mathrm{cm}^{2}$. Também não há escoamento no poço, pois considera-se que inicialmente toda a extensão do poço encontra-se isolado do reservatório, sendo a pressão constante e igual a 406,15 $\mathrm{kgf} / \mathrm{cm}^{2}$, pois o poço é horizontal. 
Para o solver hydraulicDiffusivityFoam, somente uma equação para obter a distribuição de pressão é resolvida, e neste caso, considera-se gradiente nulo de pressão em todas as fronteiras do reservatório. Já para o solver rhoPorousPimleFoam, as equações de conservação de masssa e quantidade de movimento linear para as três direções coordenadas precisam ser resolvidas, e condições de contorno para a pressão e três componentes de velocidades precisam ser prescritas. O gradiente nulo de todas as variáveis é imposto em todas as fronteiras do reservatório. Com relação ao poço, considera-se que no dedão e no calcanhar do poço, existem paredes, i.e, velocidade nula.

As figuras 7.36 e 7.37 apresentam diferentes amplificações da região próxima ao poço, onde percebe-se o tipo de refino de malha feito aplicado no caso de poço horizontal. A malha tem 2.134.000 de elementos. Foi utilizado um passo de tempo de 2 horas para essa simulação.
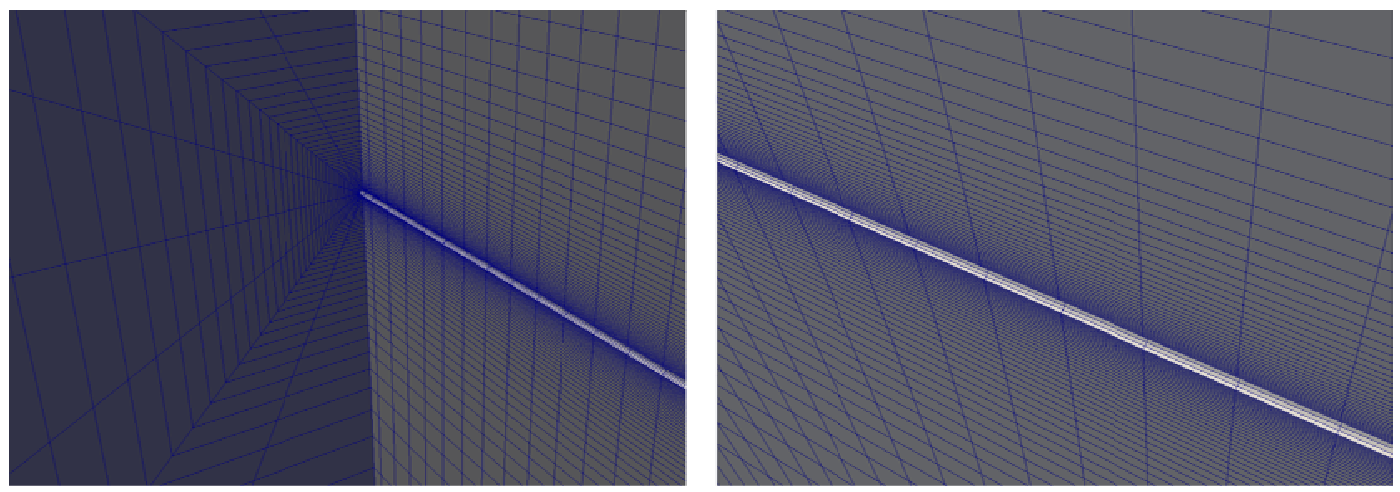

Figura 7.36: Refino da malha na região do poço. Teste 3.1.
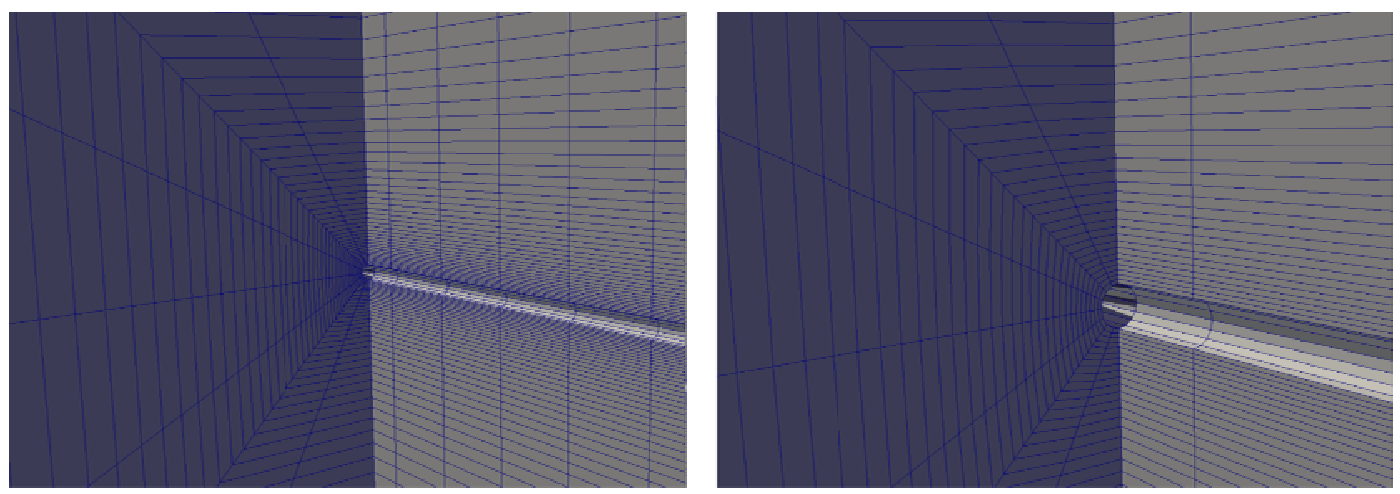

Figura 7.37: Refino ao redor poço. Teste 3.1.

O escoamento se inicia, considerando que instantaneamente todo o poço foi exposto ao reservatório. Uma vez que o fluido e reservatório são levemente compressíveis, uma onda de pressão é dissipada pelo reservatório ao longo do 
tempo. As figuras 7.38 e 7.39 apresentam uma comparação do campo de pressão obtido com os dois solvers, após dois dias do início da produção, com diferentes ângulos de visualização. Observa-se resultados idênticos, como esperado.

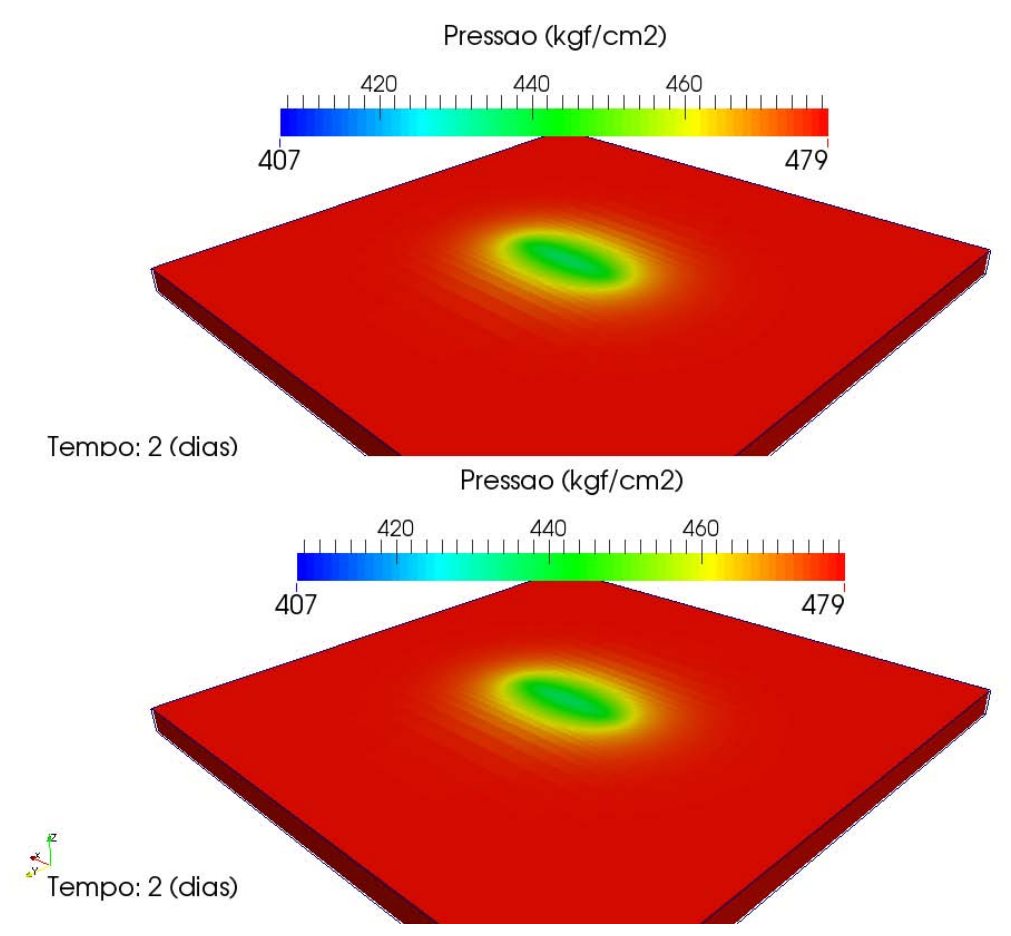

Figura 7.38: Campo de pressão após dois dias de produção. corte horizontal. Teste 3.1. Acima HDF e abaixo RPPF.

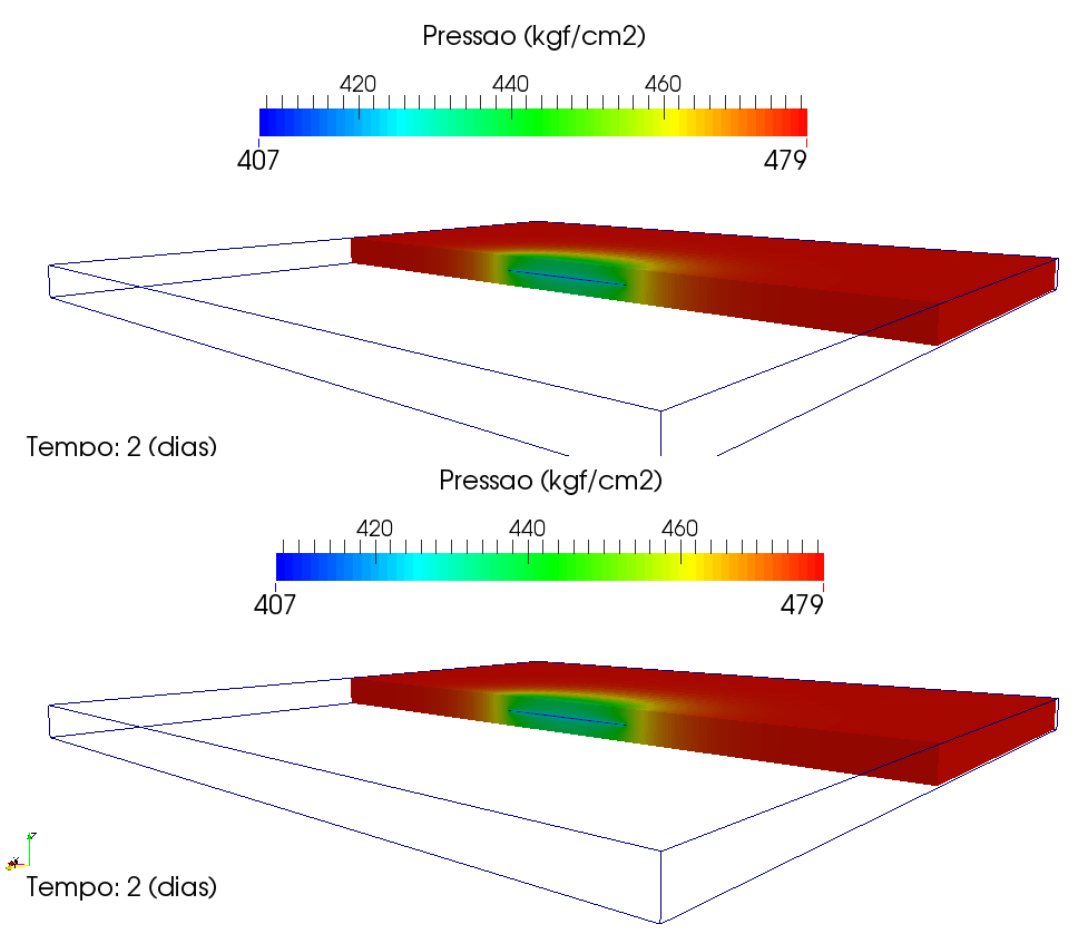

Figura 7.39: Campo de pressão após dois dias de produção - corte transversal. Teste 3.1. Acima HDF e Abaixo RPPF 
Analisando a figura 7.38 é possível observar que ambas as ferramentas foram capazes de captar uma onda de pressão se deslocando ao longo do reservatório, a partir do poço, devido aos efeitos de compressibilidade. Já uma análise da figura 7.39, que agora apresenta um corte na vertical, passando pelo poço, permite notar a diferença de pressão imposta pelo poço e como o gradiente se difunde na três direções.

A figura 7.40 apresenta como o reservatório está depletando. Compara-se a previsão dos dois softwares, as quais são idênticas. Observa-se que a medida que o tempo de produção passa, a onda de pressão se desloca, e após 20 dias atinge as bordas do reservatório. Após 60 dias de produção, a pressão do reservatório começa a se uniformizar em um patamar inferior, proximo à pressão do inicial do poço.

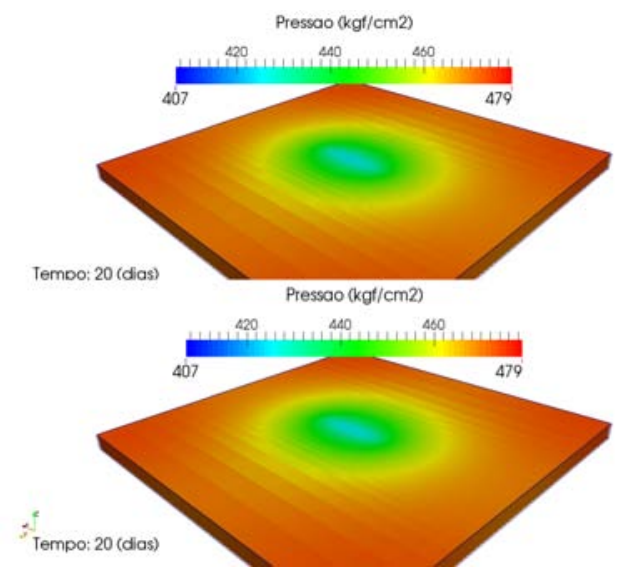

7.40(a): 20 dias

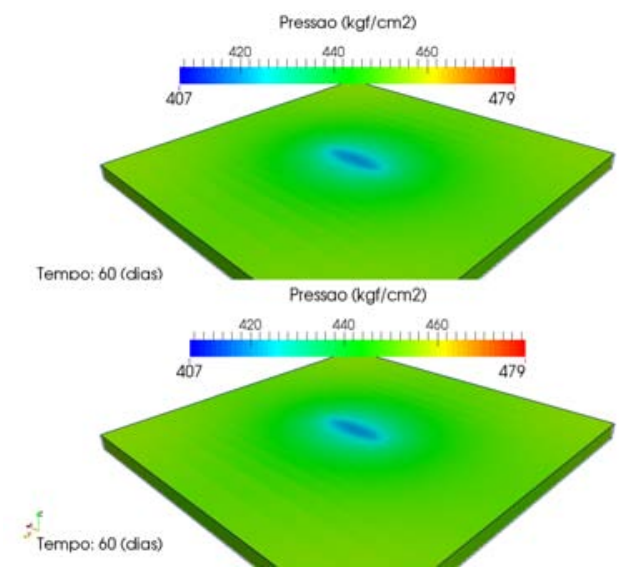

7.40(b): 60 dias

Figura 7.40: Campo de pressão. Teste 3.1. (a) vinte dias de produção (b) 60 dias de produção. Acima HDF e Abaixo RPPF

A figura 7.41 apresenta uma comparação do campo do módulo da velocidade superficial ao longo do reservatório obtida com o solver hydraulicDiffusivityFoam e com o rhoPorousPimleFoam, onde nota-se que resultados idênticos foram obtidos. O lado direiro apresenta um corte horizontal do campo após 2 dias de produção e o lado esquerdo um corte transversal, após 40 dias de produção, ambos os cortes passando pelo poço. Os resultados permitem observar que as maiores velocidades encontram-se na região muito próxima ao poço.

Os resultados apresentados são praticamente os mesmos, porém, para realizar uma real comparação, uma comparação quantitativa deve ser realizada. 


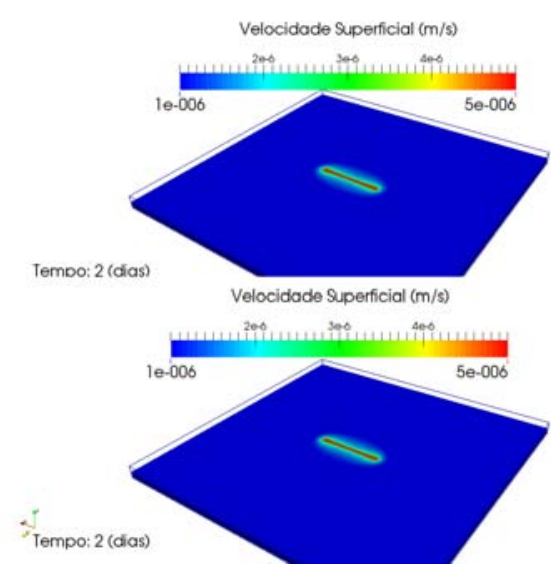

7.41(a): 2 dias de produção

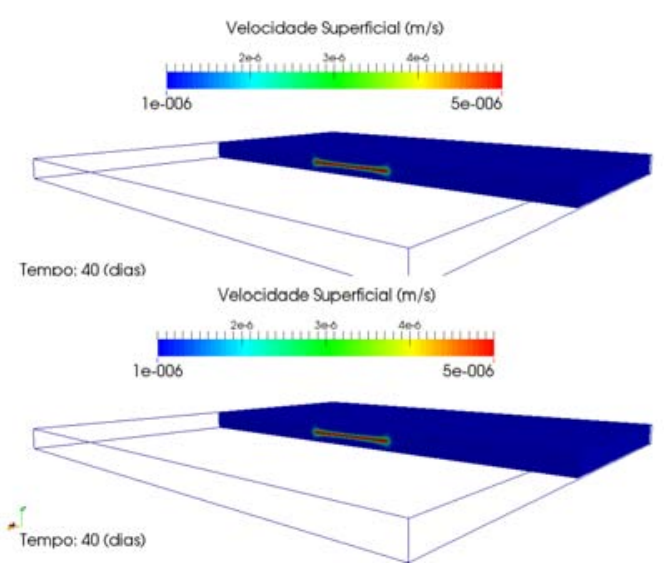

7.41(b): 40 dias de produção

Figura 7.41: Campo de velocidade. Teste 3.1. (a) 2 dias de produção (b) 40 dias de produção. Acima HDF e Abaixo RPPF

Três diferentes malhas foram geradas para confirmar a não dependência das malhas nas soluções encontradas com ambos os solvers HDF e RPPF. Uma malha mais grosseira $(1,5 \mathrm{G})$ com 1.155.664 elementos, e outras duas mais refinadas, uma com 10.305.500 elementos (1,2R) e outra com 15.052.288 elementos (1,5R). Observa-se ue perfeita concordância foi obtida com ambos os solvers, com relaçãoa evolução da produção com o tempo para as três malhas. Este resultadoindica que a solução independe da malha e que mesma a malha mais grosseira já é suficiente para a análise da produção. Pode-se afirmar que para o caso do poço horizontal em um reservatório homogêneo, as modelagens da equação de Darcy e da teoria de média fornecem os mesmos resultados.
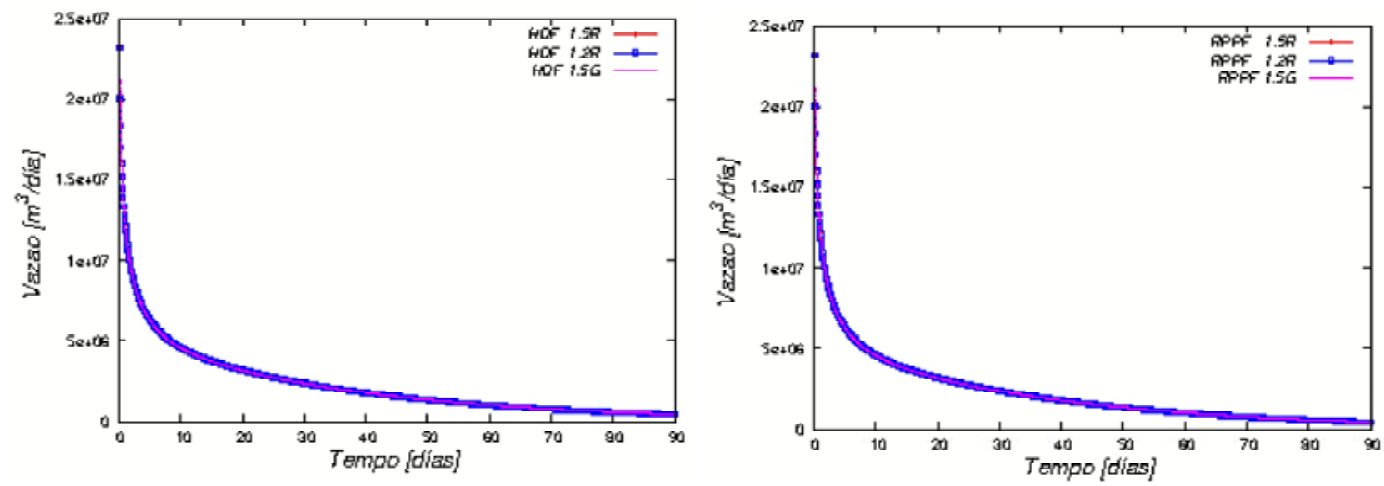

Figura 7.42: Produtividade do poço em reservatório homogêneo. Teste 3.1. Comparação entre malhas - (a) HDF à esquerda (b) à direita.

O tempo de simulação para obter a solução pelo solver RPPF é aproximadamente o dobro do tempo do cálculo do solver HDF. Apesar de mais cus- 
toso computacionalmente devido a um número maior de equações para resolver, o RPPF deve ser utilizado em alguns casos de simulação de produtividade de poços.

\subsection{2}

\section{Teste 3.2: Poço Horizontal em um Reservatório Heterogêneo}

A segunda simulação refere-se a um poço horizontal cuja a área de drenagem do reservatório foi modelada pelo mesma região da seção anterior. A tabela 7.15 apresenta as dimensões da geometria do poço e do reservatório. Emprega-se também as mesmas propriedades do fluido e do reservatório do caso anterior, descritas na tabela 7.16. A única diferença é o campo de permeabilidade do reservatório que será heterôgeneo aleatório como mostrado pela figura 7.43. As mesmas condições iniciais e de contorno do Teste 3.1 também são aplicadas neste caso. A mesma malha do Teste 3.1 é utilizada e o passo de tempo utilizado foi de 1 hora para essa simulação.

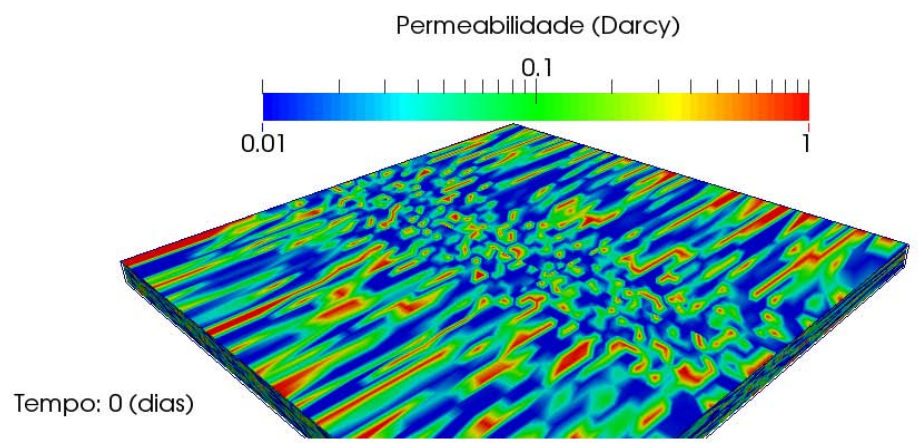

Figura 7.43: Campo de Permeabilidade para poço horizontal com reservatório heterogêneo. Teste 3.2.

As figuras 7.44 e 7.45 mostram o campo de pressão para diferentes instantes de tempo logo após o início da produção, obtidas com os dois solvers. Diferente do caso anterior, o campo de pressão não apresenta mais um comportamente concêntrico observado no caso anterior, mostrando claramente uma direção preferencial do escoamento. A medida que o tempo passa, observase a redução da pressão, indicando que o reservatório esta sendo depletado. Após 16 horas, a distribuição de pressão é quase uniforme e próxima ao valor reinante no poço. Mais uma vez, observa-se que resultados equivalentes foram obtidos com os dois solvers. 


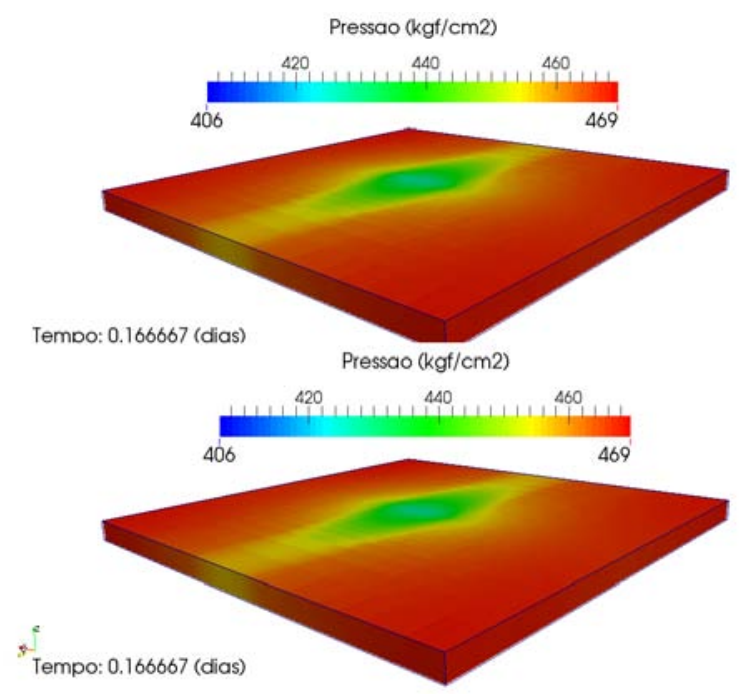

Figura 7.44: Campo de pressão após 4 horas de produção. Teste 3.2. Acima HDF e Abaixo RPPF.

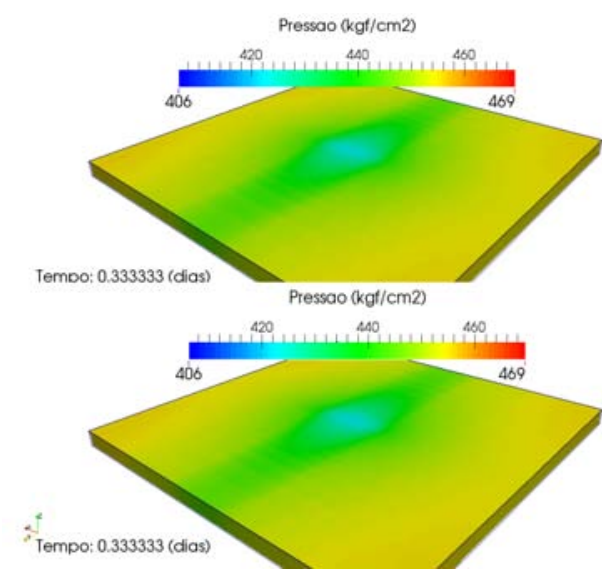

$7.45(\mathrm{a}): 8$ horas

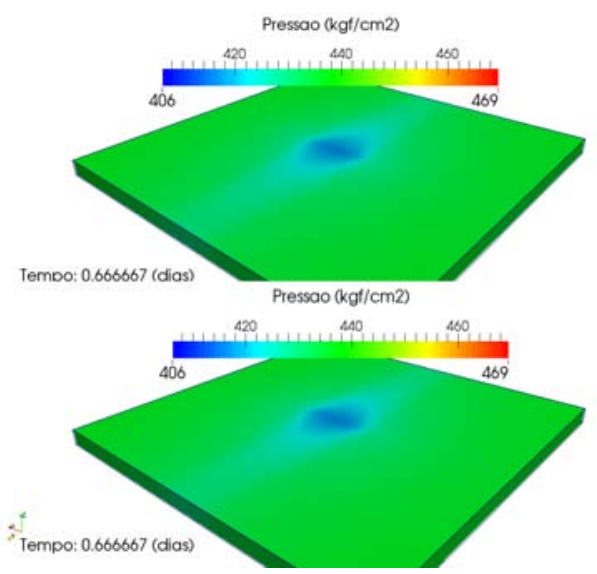

7.45(b): 16 horas

Figura 7.45: Campo de pressão. Teste 3.2. (a) 8 horas de produção. (b) 16 horas de produção. Acima HDF e Abaixo RPPF.

As figuras 7.46 e 7.47 apresentam um corte no meio do reservatório e mostra o módulo do campo de velocidade superficial obtida com o modelo de Darcy HDF, para diferentes instantes de tempo. Observa-se uma aletoriedade do campo de velocidade, a qual é devido a heterogeneidade do campo de permeabilidade. 


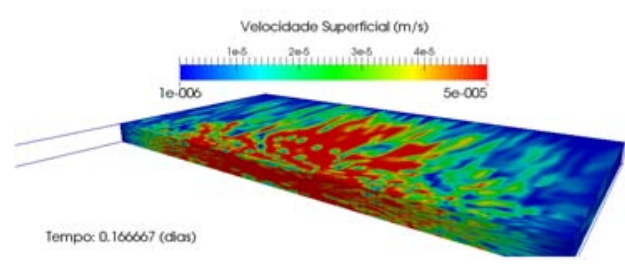

7.46(a): 4 horas $=0,16$ dias

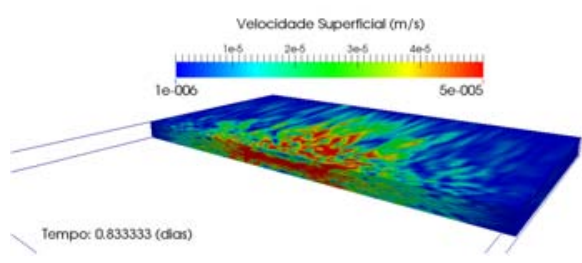

7.46(b): 20 horas $=0,83$ dias

Figura 7.46: Campo de velocidade superficial. Teste 3.2 (a) 4 horas (b) 20 horas (c) 1,6 dias (d) 3,3 dias. HDF

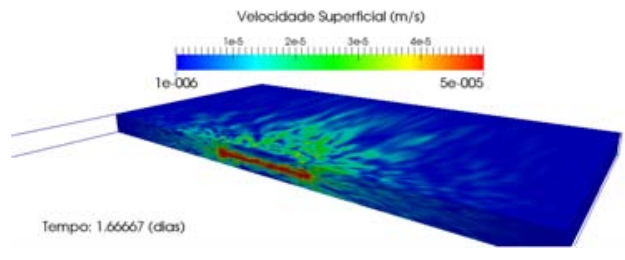

$7.47(\mathrm{a}): 1,6$ dias

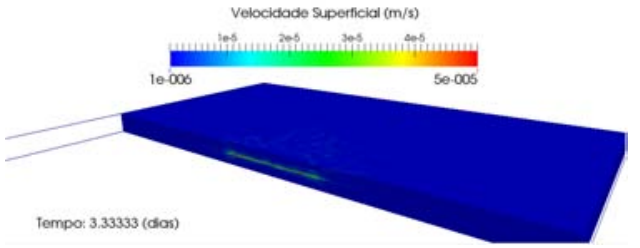

$7.47(\mathrm{~b}): 3,3$ dias

Figura 7.47: Campo de velocidade superficial. Teste 3.2 (a) 4 horas (b) 20 horas

(c) 1,6 dias (d) 3,3 dias. HDF

Observa-se uma redução na intensidade do campo de velocidade a medida que o tempo passa, devido a redução do diferencial de pressão. Para esse caso hipotético, após 3,3 dias o campo de velocidade é quase nulo, indicando que praticamente todo o óleo já teria sido produzido nesse intervalo de tempo.

As figuras 7.46 e 7.47 não apresentam uma comparação entre os campos de velocidade obtidos com os dois solvers. Isso foi feito intencionalmente, visto que ambos apresentaram o mesmo resultado. A intenção da apresentação dessas figuras, visto que ambos solvers deram campos iguais, foi apresentar como o campo de velocidade varia ao longo da produção.

Para apresentar os resultados de forma quantitativa, a produção do poço ao longo do tempo é apresentada na figura 7.48. A produção do poço obtida com as duas modelagens apresentam valores muito próximos, não sendo visível diferenças no gráfico apresentado. 


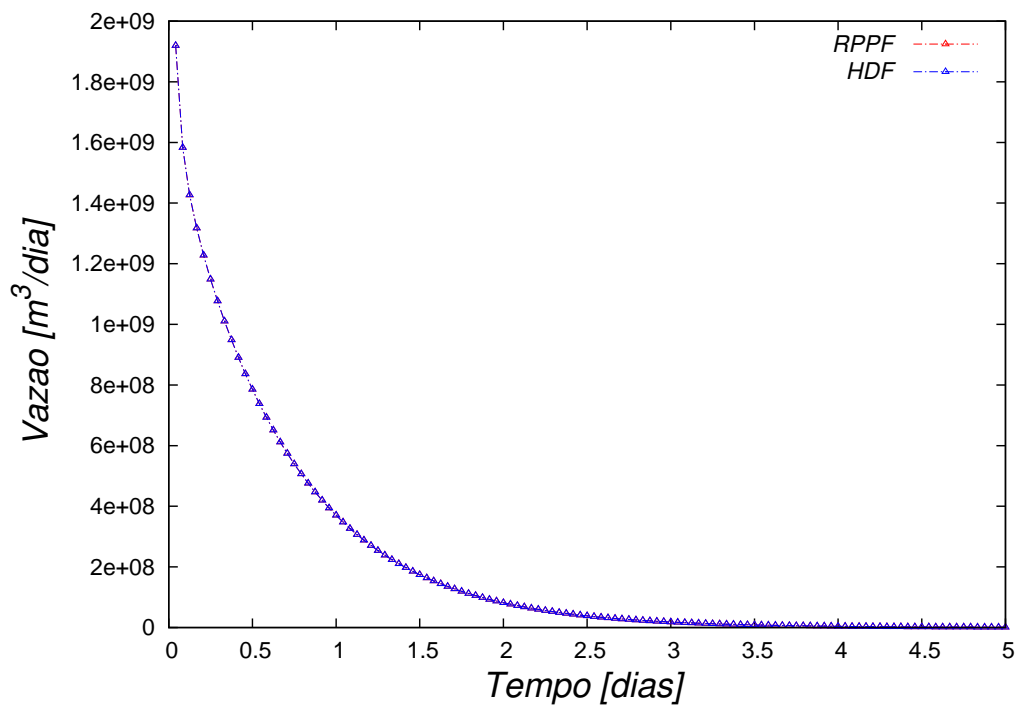

Figura 7.48: Produtividade do poço em reservatório heterogêneo. Teste 3.2. Comparação HDF e RPPF.

\subsection{3}

Teste 3.3: Poço vertical com uma Fratura em um Reservatório Homogêneo

A presente simulação refere-se a um poço vertical com uma fratura hidráulica cuja a área de drenagem do reservatório foi modelada por um paralelepípedo. A tabela 7.17 apresenta as dimensões da geometria do poço, fratura e do reservatório. Considera-se que o poço está posicionado no centro do reservatório.

Assim como as simulações anteriores dessa seção, o presente teste tem a referência da pressão para as condições iniciais e de contorno fora da zona produtora. Devido a esse tipo de informação, a informação da cota do topo do reservatório é necessária para que a diferença de altura seja contabilizada no cálculo da pressão hidrostática.

Tabela 7.17: Dimensões do poço vertical em um reservatório homogêneo. Teste 3.3.

\begin{tabular}{|c|c|c|c|c|c|}
\hline \multicolumn{3}{|c|}{ Reservatório } & \multicolumn{3}{c|}{ Poço/Fratura } \\
\hline Nome & Valor & Unidade & Nome & Valor & Unidade \\
\hline Comprimento & 2340 & $m$ & Comprimento $_{\text {poco }}$ & 104,8 & $m$ \\
Largura & 2340 & $m$ & Diâmetro $_{\text {poco }}$ & 8,5 & in \\
Espessura & 104,8 & $m$ & largura $_{\text {frat }}$ & 10 & $m m$ \\
Altura Topo & 4338 & $m$ & raio $_{\text {frat }}$ & 52,4 & $m$ \\
\hline
\end{tabular}

Todas as propriedades do fluido e do reservatório indicadas na tabela 7.16 se repetem aqui. A única diferença é o campo de permeabilidade do 
reservatório, o qual é alterado na região da fratura como mostrado pela figura 7.49. Apesar da geometria do reservatório ter as mesmas dimensões que dos dois casos anteriores, no presente caso, duas condições de simetria foram impostas. A primeira em relação ao plano perpendicular a fratura e a outra em relação ao próprio plano da fratura. A figura 7.49 apresenta $1 / 4$ de reservatório.

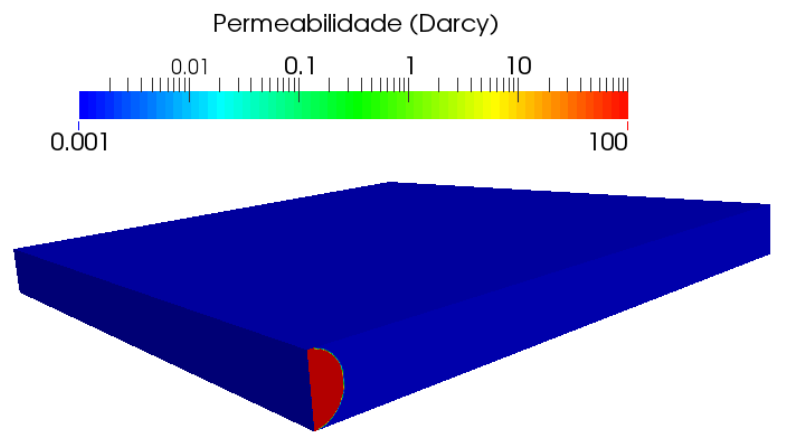

Figura 7.49: Campo de permeabilidade - Poço vertical fraturado. Teste 3.3.

As figuras 7.50 e 7.51 apresentam o refino na região do poço para o caso estudado. Uma malha estruturada foi desenvolvida para a presente simulação. As figuras apresentam como o refino da malha ocorre gradualmente de forma suáve ao aproximar-se do poço. A malha utilizada para essa simulação tem 1.736.386 elementos. O passo de tempo para essa simulação foi de 10 segundos.
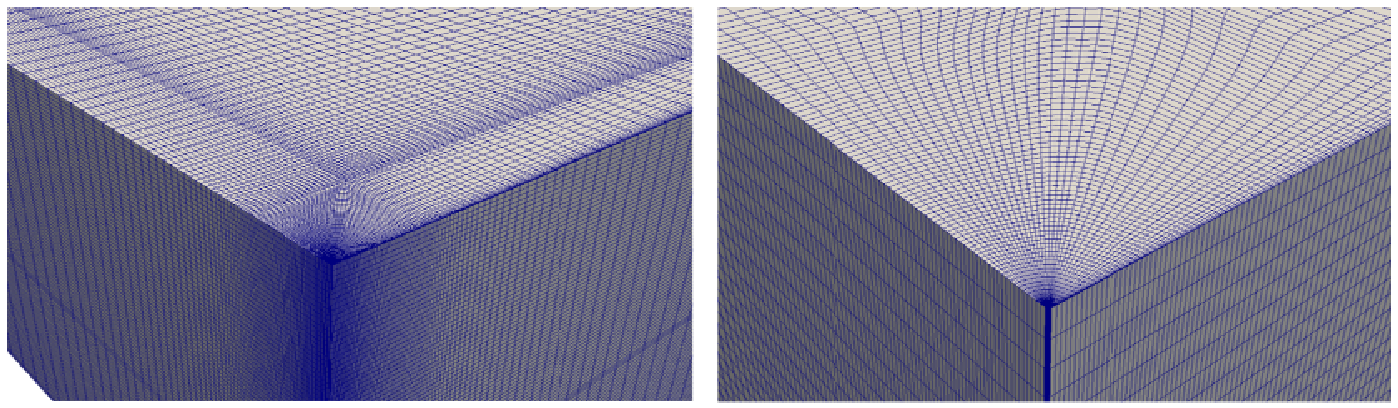

Figura 7.50: Refino da malha na região do poço. Teste 3.3.
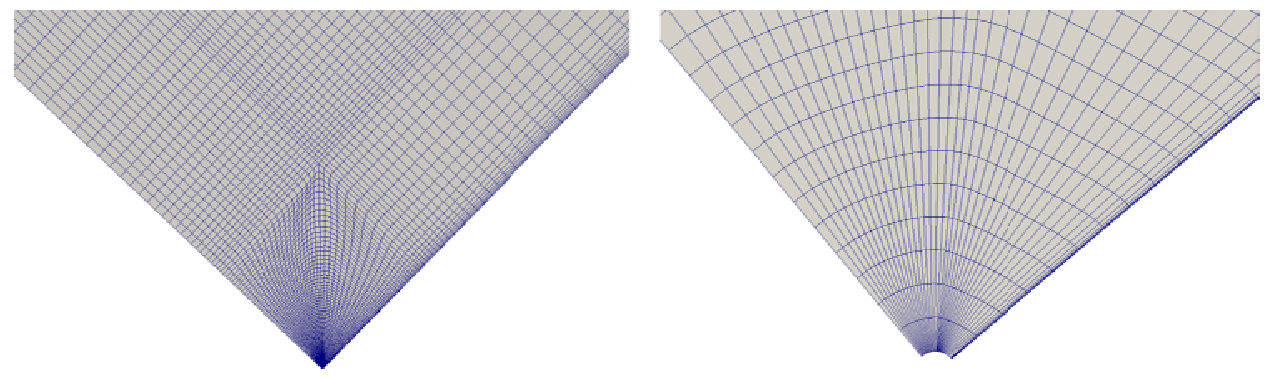

Figura 7.51: Refino da malha ao redor do poço. Teste 3.3. 
O presente teste consiste de um reservatório pressurizado inicialmente e sem manutenção de pressão em seus contornos. Apenas a pressão hidrostática está estabelecida no reservatório e no poço e o fluido encontra-se parado. A pressão no topo do poço é 406,15 kgf $/ \mathrm{cm}^{2}$ e a pressão do reservatório na cota vertical igual a $4485 \mathrm{~m}$ é $484,03 \mathrm{kgf} / \mathrm{cm}^{2}$.

A figura 7.52 apresenta o campo de pressão em dois instantes de tempo, obtidas com os dois solvers, HDF e RPPF. Após 1,6 horas do início da produção, observa-se que a propagação da pressão na fratura não afeta o reservatório. Ou seja, nesse instante, apenas a fratura está produzindo. A medida que o tempo passa, a pressão do poço começa a se estabelecer na fratura, como pode ser visto após 33 horas de produção. Isso pode ser observado pelo valor da pressão do poço, cor azul, começando a tomar conta da fratura.

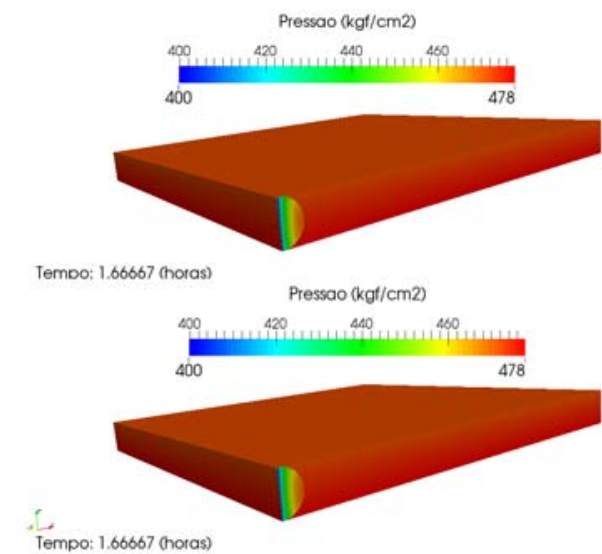

$7.52(\mathrm{a}): 1,6$ horas

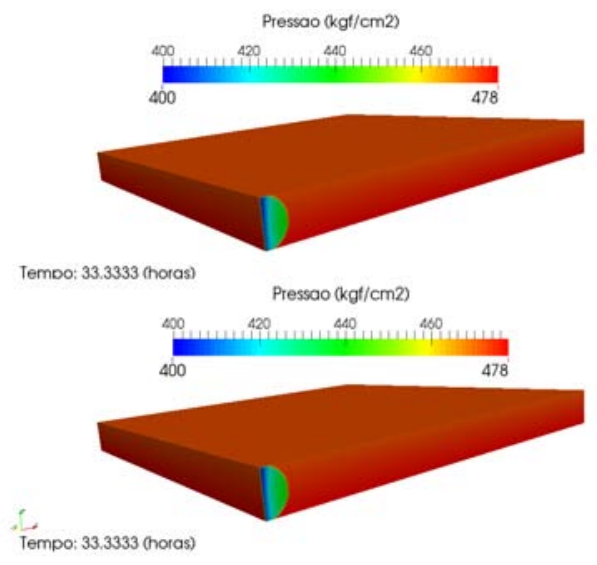

7.52(b): 33 horas

Figura 7.52: Campo de pressão em poço vertical fraturado. Teste 3.3. (a) 1,6 horas de produção (b) 33 horas de produção. Acima HDF e abaixo RPPF.

A figura 7.53 apresenta o campo de velocidade superficial após 1,6 horas e 60 horas do início da produção. Percebe-se que a velocidade dentro da fratura diminue. Analisando as figuras, pode-se afirmar que tanto o campo de pressão como o campo de velocidade obtidos com os dois solvers também foram iguais para o caso de reservatório com fratura. 


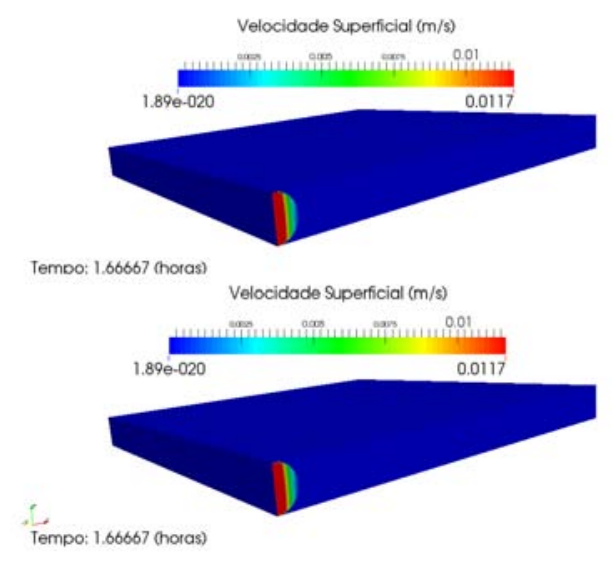

7.53(a): 1,6 horas

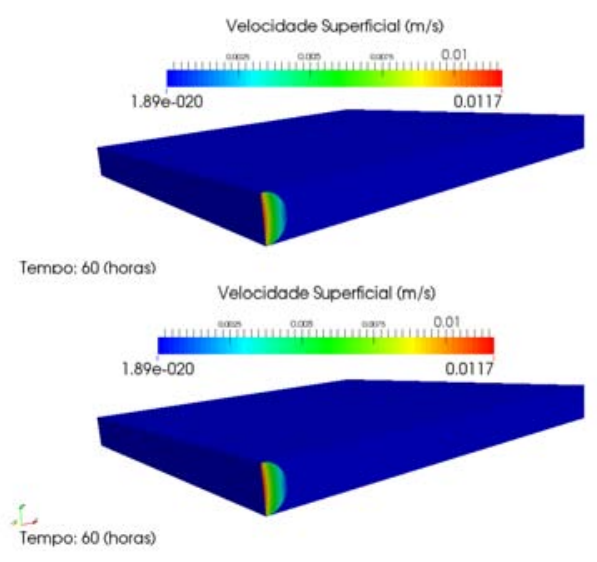

7.53(b): 60 horas

Figura 7.53: Campo de velocidade em poço vertical fraturado. Teste 3.3. (a) 1,6 horas de produção (b) 60 horas de produção. Acima HDF e abaixo RPPF.

Para apresentar os resultados de forma quantitativa, a produção de uma asa de fratura é apresentada ao longo do tempo na figura 7.54. Mais uma vez, mostra-se que a produção do poço através das duas modelagens (HDF e $\mathrm{RPPF}$ ) apresentam valores muito próximos.

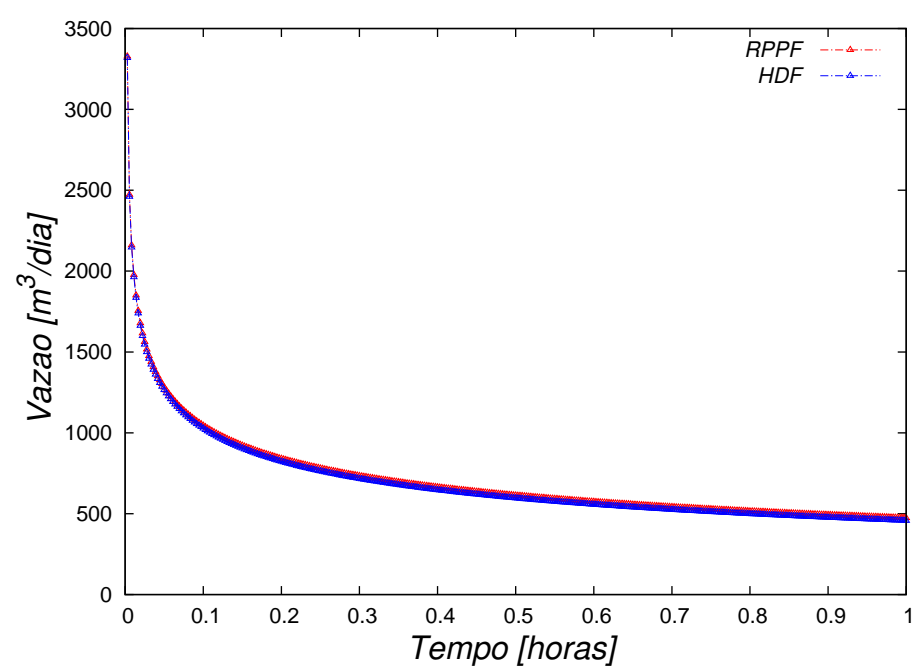

Figura 7.54: Produtividade do poço vertical fraturado - Comparação HDF e RPPF - Teste 3.3.

\subsection{4}

Teste 3.4: Poço Vertical com uma Fratura de Altíssima Permeabilidade em um Reservatório Homogêneo

Um caso mais agressivo de permeabilidade, ou seja, com altíssima permeabilidade é proposto. A tabela 7.17 apresenta as dimensões da geometria do poço, da fratura e do reservatório. Todas as propriedades do fluido e do reservatório 
da tabela 7.16 se repetem aqui. A única diferença é a permeabilidade da fratura que será mostrada pela figura 7.55. As mesmas condições iniciais e de contorno do caso anterior são consideradas.

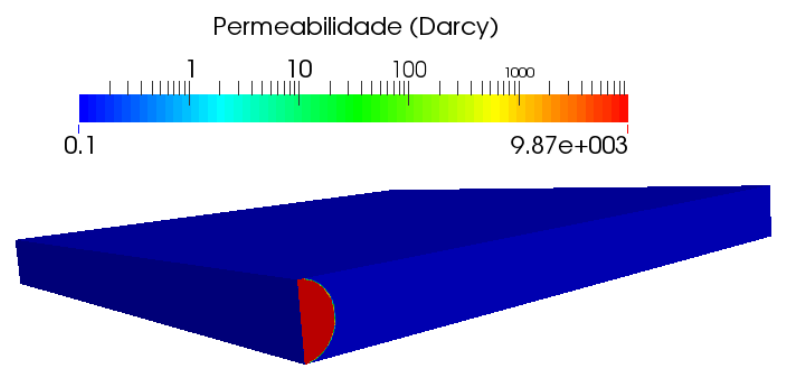

Figura 7.55: Campo de permeabilidade agressivo - Poço vertical fraturado. Teste 3.4

A mesma malha e o mesmo passo de tempo do Teste 3.3 foram utilizados no presente teste. A figura 7.56 apresenta a produção do poço pela fratura e por uma parte pequena do reservatório, para dois instantes de tempo e para as duas ferramentas numéricas. Observa-se que após 33 horas do início da produção, o valor da pressão do poço, cor azul, já compreende a fratura em sua totalidade e resultados idênticos foram obtidos com o HDF e RPPF.

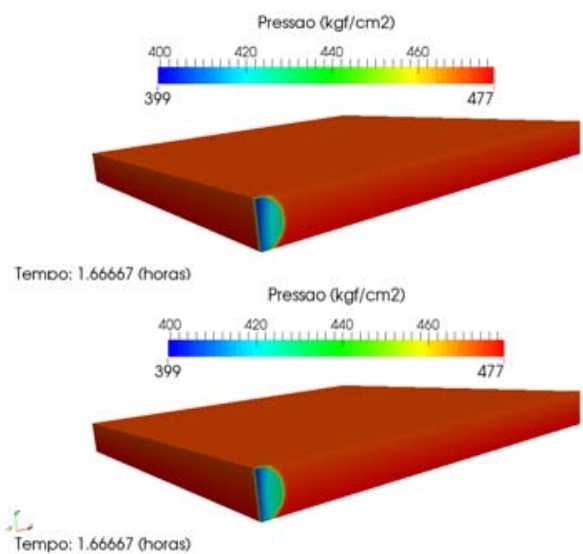

7.56(a): 1,6 horas

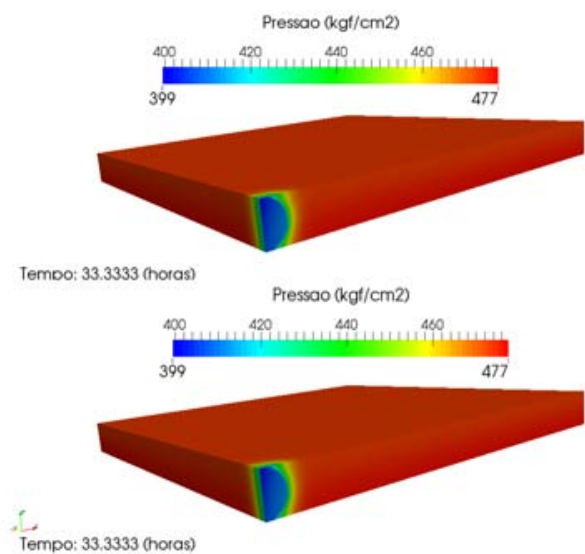

7.56(b): 33 horas

Figura 7.56: Campo de pressão em poço vertical fraturado agressivo. Teste 3.4. (a) 1,6 horas de produção (b) 33 horas de produção. Acima HDF e abaixo RPPF.

A figura 7.57 apresenta o campo de velocidade superficial após 1,6 horas e 33 horas de produção obtidos com o HDF e RPPF. Percebe-se que as velocidades dentro da fratura diminuiram. Novamante campos iguais de velocidade foram obtidos com as duas ferramentas numéricas. 


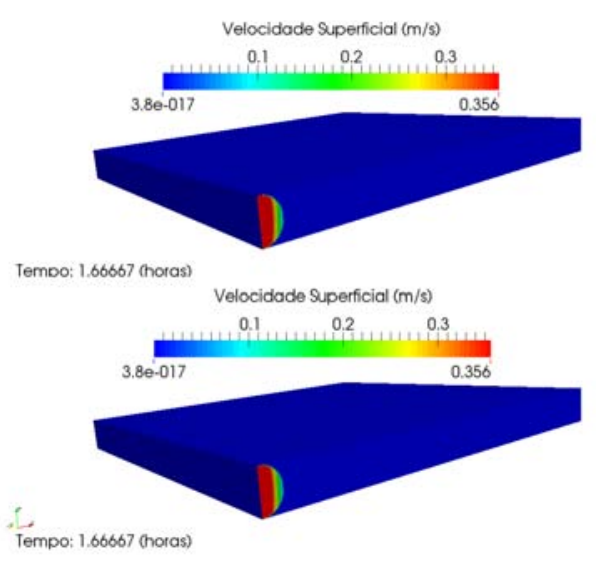

$7.57(\mathrm{a}): 1,6$ horas

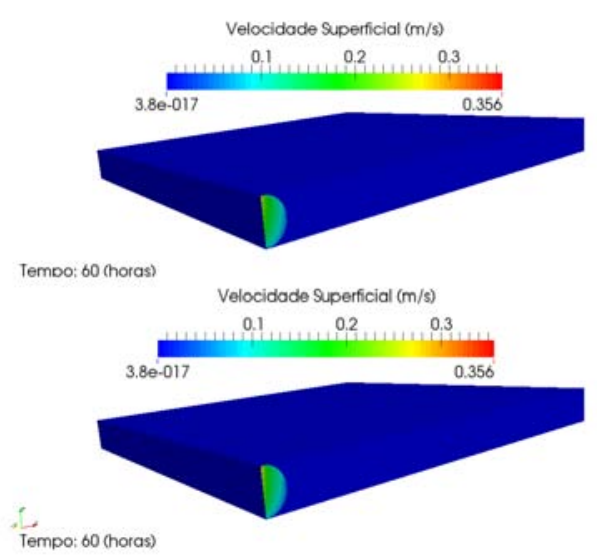

7.57(b): 60 horas

Figura 7.57: Campo de velocidade em poço vertical fraturado agressivo. Teste 3.4. (a) 1,6 horas de produção (b) 33 horas de produção. Acima HDF e abaixo RPPF.

Para apresentar os resultados de forma quantitativa, a produção de uma asa de fratura é apresentada ao longo do tempo na figura 7.58. Mais uma vez, a previsão da produção do poço através das duas modelagens apresentam valores muito próximos, com curvas praticamente coincidentes.

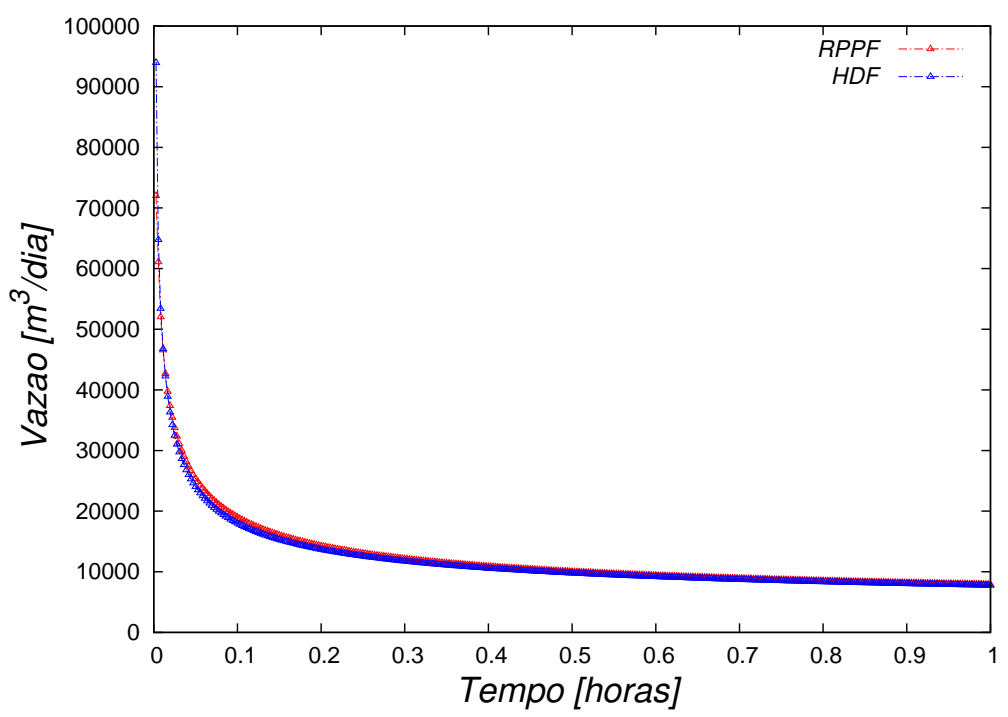

Figura 7.58: Produtividade do poço vertical fraturado agressivo. Teste 3.4. Comparação HDF e RPPF. 


\section{8 \\ Resultados}

O presente capítulo tem como objetivo apresentar os resultados da metodologia sugerida para a contabilização da produtividade de poços através de soluções de fluido dinâmica computacional. Ambos os solvers, hydraulicDiffusivityFoam e rhoPorousPimpleFoam são utilizados em todos os casos com o objetivo de mostrar até onde a equação de Darcy é uma boa hipótese para modelar o escoamento no reservatório. É importante ressaltar que a equação de Darcy, em simulação de reservatórios, é considerada como regra prática de modelagem e não discutida em termos de sua aplicabilidade. O presente trabalho entende que a equação de Darcy é válida para alguns casos em simulação de reservatório, mas ao longo do texto deixa claro suas limitações. Ou seja, apesar da equação de Darcy continuar ocupando um lugar central no estudo de escoamentos através de meios porosos, esta equação só é válida para uma classe especial de escoamentos, sendo necessário o desenvolvimento de outras aproximações que são aplicáveis a outras situações na área de simulação de reservatórios.

Com o objetivo de mostrar algumas limitações da equação de Darcy, simulações são realizadas para prever o escoamento em plugs de rocha altamente heterôgenea. Aplica-se a equação de Darcy e a equação de média e os resultados encontrados mostram que dependendo da permeabilidade e da pressão imposta, diferentes resultados de produtividade são obtidos, indicando que alguns dos parâmetros comumente desprezados, possuem um papel significativo no escoamento. Portanto nessas situações a equação de Darcy não seria uma boa escolha para o cálculo do escoamento em meios porosos. Os resultados mostram a importância de uma avaliação sobre a aplicabilidade da equação de Darcy em simulação de reservatório.

Três tipos de análises são realizadas aqui. A primeira, a solução analítica para um caso particular bidimensional é encontrada para as duas modelagens. Compara-se então a variação da pressão com a vazão para diferentes permeabilidades. A segunda e terceira análise modela a heterogenidade dos plugs de duas formas: (i) simplificada - permeabilidade bem definida e (ii) complexa permeabilidade aleatória. Para todos os meios são impostos um diferencial de pressão para que a vazão seja uma variável determinada. O objetivo de apre- 
sentar primeiramente casos de heterogeneidade simplificada é para que uma sensibilidade possa ser adquirida ao analisar os resultados comparativos entre as modelagens de Darcy e de teoria de média.

Os modelos simplificados de heterogeneidade permitem um entendimento de quais são as condições onde a equação de Darcy e de teoria de média não prevêem o mesmo resultado de vazão. Ou seja, quais são as permeabilidades e pressão impostas onde os termos desprezados da equação completa (média) são significativos, e os resultados obtidos são diferentes dos obtidos com o uso da equação simplificada (Darcy).

Após essa etapa, plugs com heterogeneidade complexa são estudados. Nessa avaliação ilustra-se a importância dos resultados obtidos no presente trabalho e a aplicabilidade do estudo aos reservatórios altamente heterogêneos do pré-sal, pois a utilização da equação de Darcy em reservatórios altamente heterogeneos pode levar a estimativas errôneas de produção.

Apesar da análise ser realizada em regiões de reservatório, ou seja plugs de centímetros ou metros (e não em um reservatório inteiro) mostra-se que a presente análise não perde a aplicabilidade em relação aos casos práticos de produtividade dos poços. Na verdade, esse tipo de análise traz uma noção maior em que tipo de reservatório a equação simplificada de Darcy pode levar a resultados mal estimados. Apresenta-se o impacto na curva de produtividade do poço, da equação escolhida para contabilização do escoamento, dependendo da permeabilidade do meio.

\section{1}

\section{Cálculo Analítico}

O problema a ser resolvido consiste no escoamento em um meio poroso bidimensional, com uma entrada à esquerda, uma saída à direita e paredes nas laterais. Compara-se então dois modelos teóricos: o modelo de Darcy e o modelo de média volumétrica. Hipóteses simplificadoras são utilizadas para possibilitar o desenvolvimento de soluções analíticas.

- Regime Permanente

- Escoamento Completamente Desenvolvido

- Escoamento Incompressível, $\rho$ constante

- Porosidade do meio constante no espaço e tempo, $\phi$ constante

- Viscosidade do fluido constante no espaço e tempo, $\mu$ constante

- Gravidade Nula, $\mathbf{g}=\mathbf{0}$

- Tensor Permeabilidade é isotrópico com $k_{11}=k_{22}=k_{33}=K$ 


\subsection{1}

\section{Modelo de Darcy}

Como apresentado no presente trabalho, o modelo de Darcy é uma simplificação do modelo de média. O cálculo analítico da pressão em relação a vazão é facilmente alcançado

$$
0=\phi \frac{\Delta P}{L}-\mu \phi^{2} K^{-1} v_{x}
$$

Sendo o perfil de velocidade:

$$
v_{x}=\frac{\Delta P K}{\mu L \phi}
$$

Logo, a perda de carga total em função da vazão será:

$$
\Delta p=\frac{\mu L \phi Q}{K A}
$$

onde $A=D * 1$ e $D$ é a altura em $y$ do domínio.

\subsection{2}

\section{Modelo de Média}

A conservação da massa pela teoria de média é

$$
\frac{\partial \phi \rho}{\partial t}+\nabla \cdot[\phi \rho \mathbf{v}]=0
$$

Aplicando as hipóteses de regime permanente, escomento completamente desenvolvido e propriedades constantes:

$$
\frac{\partial v_{y}}{\partial y}=0
$$

Resolvendo a equação chega-se 


$$
v_{y}=\text { Const } \in \Re
$$

Levando em consideração que o escomento é incompressível $(\nabla \cdot \mathbf{v}=\mathbf{0})$, $\mu$ é constante e sabendo que $\nabla \cdot\left[\nabla \mathbf{v}^{\mathbf{T}}\right]=\nabla(\nabla \cdot \mathbf{v})=\mathbf{0}$, o termo laplaciano se torna:

$$
\phi \nabla \cdot[\mu \nabla \mathbf{v}]
$$

A equação de conservação do quantidade de movimento na direção $y$ pode ser simplificada levando em consideração as hipóteses do problema.

$$
\begin{gathered}
\phi \rho \frac{\partial v_{y}}{\partial t}+\rho \phi\left(\frac{\partial v_{y} v_{x}}{\partial x}+\frac{\partial v_{y} v_{y}}{\partial y}\right)=-\phi \frac{\partial P}{\partial y} \\
-\mu \phi^{2} K^{-1} v_{y}+\phi \rho g_{y}+\phi \mu\left(\frac{\partial^{2} v_{y}}{\partial x^{2}}+\frac{\partial^{2} v_{y}}{\partial y^{2}}\right)
\end{gathered}
$$

Considerando a hipótese de regime permanente, gravidade desprezível, $v_{y}$ constante, $\partial x=\frac{\partial v_{y}}{\partial y}=0$, escoamento completamente desenvolvido e $\frac{\partial P}{\partial y}=0$ pela imposição do problema, temos que a equação de conservação de quantidade de movimento da direção $y$ torna-se.

$$
0=-\mu \phi^{2} K^{-1} v_{y}
$$

Portanto $v_{y}=0$. A equação de conservação do quantidade de movimento na direção $x$ pode ser então avaliada.

$$
\begin{gathered}
\phi \rho \frac{\partial v_{x}}{\partial t}+\rho \phi\left(\frac{\partial v_{x} v_{x}}{\partial x}+\frac{\partial v_{y} v_{x}}{\partial y}\right)=-\phi \frac{\partial P}{\partial x} \\
-\mu \phi^{2} K^{-1} v_{x}+\phi \rho g_{x}+\phi \mu\left(\frac{\partial^{2} v_{x}}{\partial^{2} x}+\frac{\partial^{2} v_{x}}{\partial^{2} y}\right)
\end{gathered}
$$

Pelas mesmas hipóteses aplicadas na direção $y$, chega-se na seguinte equação para direção $x$ 


$$
0=-\phi \frac{\partial P}{\partial x}-\mu \phi^{2} K^{-1} v_{x}+\phi \mu \frac{d^{2} v_{x}}{d y^{2}}
$$

Chega-se a uma equação diferencial ordinária de segunda ordem nãohomogênea. Fazendo $\frac{d P}{d x}=\frac{\Delta P}{L}$, obtemos:

$$
\frac{d^{2} v_{x}}{d^{2} y}-\phi K^{-1} v_{x}-\frac{\Delta P}{\mu L}=0
$$

Essa equação possui equação característica $r^{2}-\frac{\phi}{K}=0$ com raízes reais distintas $r_{1}, r_{2}= \pm \sqrt{\frac{\phi}{K}}$. A solução homogênea associada será:

$$
v_{x H}=C_{1} e^{r_{1}}+C_{2} e^{r_{2}}
$$

As condições de contorno para o problema são $y=0 \Rightarrow v_{x}=\frac{Q}{A}$ e $y=D \Rightarrow v_{x}=\frac{Q}{A}$, onde $Q$ é a vazão de entrada e $A$ é a área da secão transversal ao escoamento por unidade de profundidade, ou seja, $A=D * 1 m=D$. Com essa condições, chega-se na solução do problema homogêneo:

$$
v_{x H}=\frac{\frac{Q}{A}\left(e^{-D \sqrt{\frac{\phi}{K}}}\right)}{e^{-D \sqrt{\frac{\phi}{K}}}-e^{D \sqrt{\frac{\phi}{K}}}} e^{\sqrt{\frac{\phi}{K} y}}+\frac{\frac{Q}{A}-\frac{Q}{A} e^{D \sqrt{\frac{\phi}{K}}}}{e^{-D \sqrt{\frac{\phi}{K}}}-e^{D \sqrt{\frac{\phi}{K}}}} e^{-\sqrt{\frac{\phi}{K} y}}
$$

Para encontrar as possíveis soluções particulares $v_{x P}$, supõe-se a solução particular constante $v_{x P}=B$. Substituíndo na equação 8.12:

$$
0=-\phi \frac{\Delta P}{L}-\mu \phi^{2} K^{-1} B+\phi \mu \frac{d^{2} B}{d^{2} y}
$$

Sabendo que a derivada de um valor constante é nulo, então:

$$
B=v_{x P}=\frac{-\Delta P K}{\mu L \phi}
$$

Chega-se então no perfil final de velocidade: 


$$
v_{x}=\frac{\frac{Q}{A}\left(e^{-D \sqrt{\frac{\phi}{K}}}\right)}{e^{-D \sqrt{\frac{\phi}{K}}}-e^{D \sqrt{\frac{\phi}{K}}}} e^{\sqrt{\frac{\phi}{K} y}}+\frac{\frac{Q}{A}-\frac{Q}{A} e^{D \sqrt{\frac{\phi}{K}}}}{e^{-D \sqrt{\frac{\phi}{K}}}-e^{D \sqrt{\frac{\phi}{K}}}} e^{-\sqrt{\frac{\phi}{K} y}}-\frac{\Delta p K}{\mu L \phi}
$$

Para achar a pressão em função da vazão, integra-se $v_{x}$ em $y$ de 0 até $\mathrm{D}$, obtendo:

$$
\begin{array}{r}
\Delta p=\frac{L \phi \mu Q}{K D^{2}}\left[\frac{e^{-D \sqrt{\frac{\phi}{K}}}-1}{e^{-D \sqrt{\frac{\phi}{K}}} e^{D \sqrt{\frac{\phi}{K}}}}\left(\frac{e^{D \sqrt{\frac{\phi}{K}}}}{\sqrt{\frac{\phi}{K}}}-\frac{1}{\sqrt{\frac{\phi}{K}}}\right)\right] \\
+\frac{L \phi \mu Q}{K D^{2}}\left[\frac{1-e^{D \sqrt{\frac{\phi}{K}}}}{e^{-D \sqrt{\frac{\phi}{K}}}-e^{D \sqrt{\frac{\phi}{K}}}}\left(\frac{e^{-D \sqrt{\frac{\phi}{K}}}}{-\sqrt{\frac{\phi}{K}}}-\frac{1}{-\sqrt{\frac{\phi}{K}}}\right)\right] \\
-\frac{L \phi \mu Q}{K D}
\end{array}
$$

A figura 8.1 apresenta a previsão de perda de carga considerando os valores de $\phi=0.2, \mu=1 \mathrm{cp}, D=0.28 \mathrm{~cm}$ e $L=7 \mathrm{~cm}$, variando a permeabilidade de $10^{4} \mathrm{mD}$ a $10^{9} \mathrm{mD}$.
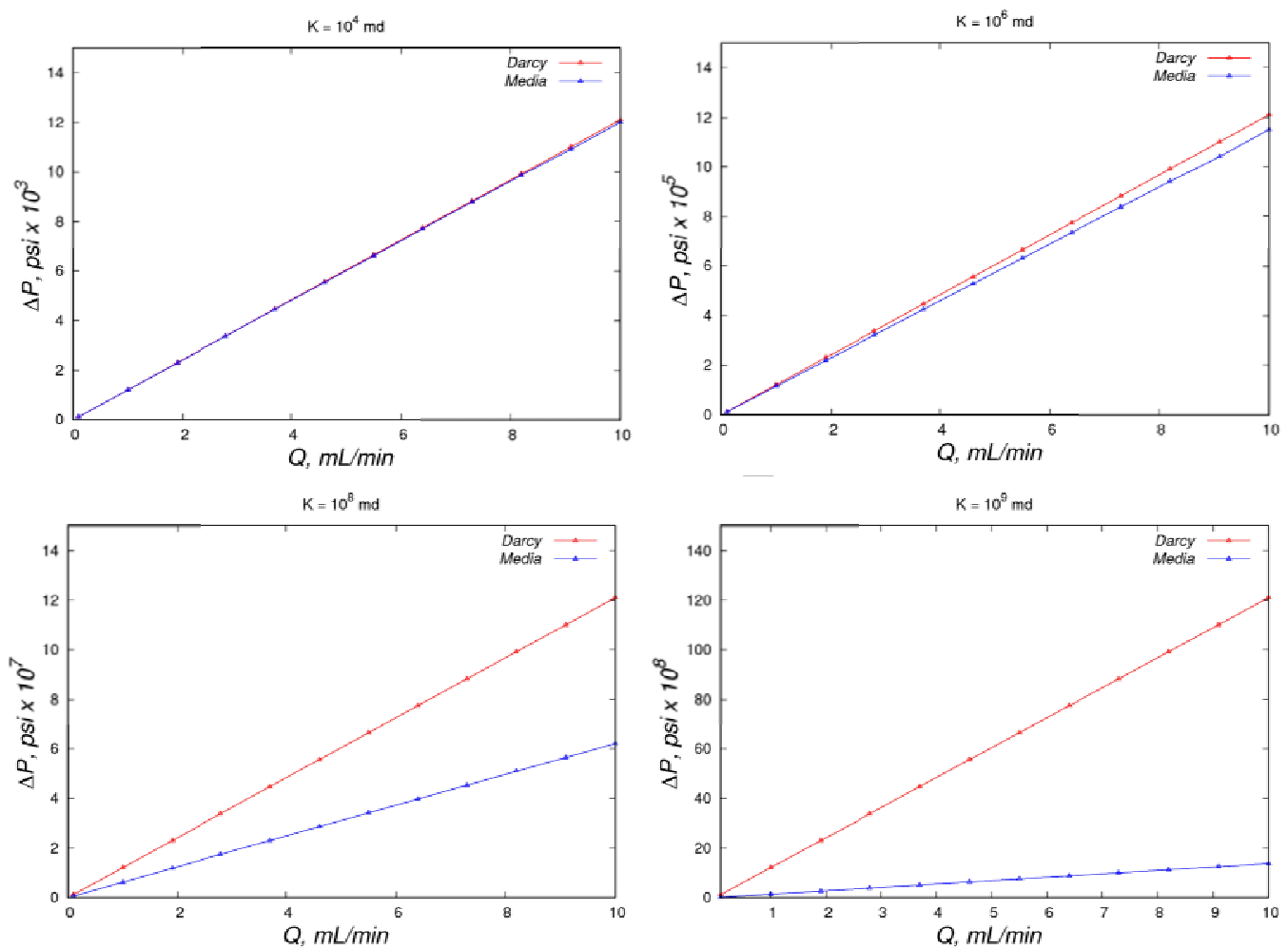

Figura 8.1: Variação da pressão em função da vazão para várias permeabilidades diferentes. 
Pode-se encontrar a diferença significativa entre os dois modelos aplicando as equações 8.3 e 8.18 considerando os valores de $Q=10 \mathrm{~mL} / \mathrm{min}$, $\phi=0.2, \mu=1 \mathrm{cp}, D=0.28 \mathrm{~cm}$ e $L=7 \mathrm{~cm}$. A tabela 8.1 .2 apresenta o erro entre os modelos em função da permeabilidade do meio poroso. Este resultado mostra a grande influência do termo viscoso na previsão de escoamento, em casos de alta permeabilidade. Nestes casos, o modelo de Darcy superestima a queda de pressão, o que tras impacto direto na produção de um poço quando calculado em domínio reais.

Tabela 8.1: Diferença de previsão perda de carga entre Darcy e média para diferentes permeabilidades

\begin{tabular}{|c|c|c|c|}
\hline $\mathrm{K}(\mathrm{md})$ & $\Delta P_{\text {darcy }}($ psi $)$ & $\Delta P_{\text {media }}($ psi $)$ & Erro Relativo \\
\hline $10^{9}$ & $1.2087 \times 10^{-3}$ & $1.3656 \times 10^{-4}$ & $88.7017 \%$ \\
$10^{8}$ & $1.2087 \times 10^{-2}$ & $6.2103 \times 10^{-3}$ & $48.6176 \%$ \\
$10^{7}$ & $1.2087 \times 10^{-1}$ & $1.0156 \times 10^{-1}$ & $15.9718 \%$ \\
$10^{6}$ & 1.2087 & 1.1476 & $5.0508 \%$ \\
$10^{5}$ & $1.2087 \times 10$ & $1.1893 \times 10$ & $1.5972 \%$ \\
$10^{4}$ & $1.2087 \times 10^{2}$ & $1.2025 \times 10^{2}$ & $0.5051 \%$ \\
$10^{3}$ & $1.2087 \times 10^{3}$ & $1.2067 \times 10^{3}$ & $0.1597 \%$ \\
$10^{2}$ & $1.2087 \times 10^{4}$ & $1.2080 \times 10^{4}$ & $0.0505 \%$ \\
10 & $1.2087 \times 10^{5}$ & $1.2085 \times 10^{5}$ & $0.0160 \%$ \\
1 & $1.2087 \times 10^{6}$ & $1.2086 \times 10^{6}$ & $0.0051 \%$ \\
0.1 & $1.2087 \times 10^{7}$ & $1.2086 \times 10^{7}$ & $0.0016 \%$ \\
\hline
\end{tabular}

\section{2}

\section{Plug com Heterogeneidade Simplificada}

O presente teste consiste de um plug bi-dimensional, possuindo formato retangular com $1 \mathrm{~m}$ de comprimento e 0,5 m de altura. No centro do plug existe um círculo de raio igual a $0,16667 \mathrm{~m}$. A permeabilidade no interior do círculo é igual a $1 \mathrm{mD}$, e diferentes valores de permeabilidade fora do círculo são investigados. Este teste é baseado no trabalho de Srinivasan (2016b), que discute os efeitos da heterogenidade na modelagem de meios porosos.

A heterogeneidade de um meio poroso é complexa e aleatória. A modelagem da mesma com o objetivo de representar a realidade é no mínimo desafiador. Ao modelar uma heterogeneidade simplificada seremos capazes de avaliar a importância da escolha mais adequada do modelo de escoamento para um meio poroso.

A escolha de um meio menos permeável no centro é intencional. A diminuição da área de escoamento para o fluido devido a presença da rocha mais resistente ao escoamento fará com que o fluido ganhe velocidade. A intenção 
é avaliar a importância dos termos simplificados pela equação de Darcy e que estão contidos na equação de teoria de média.

Quatro casos são considerados nesta seção. Para todos os casos, considera-se gradiente nulo de pressão nas fronteiras superior e inferior, e uma diferença de pressão é imposta entre a fronteira esquerda (entrada de escoamento) e fronteira direita (saída). Adicionalmente para o modelo RPPF, impôs-se velocidade nulas nas fronteiras superior e inferior, consideradas como paredes. Em todos os casos, a pressão na saída é mantida igual a pressão atmosférica, $p_{a t m}=101,325 \mathrm{k}$ Pa. Nos três primeiros testes, o mesmo diferencial de pressão é imposto e varia-se o valor da permeabilidade fora do círculo, a qual é bem elevada, para ressaltar o efeito da heterogenidade. No quarto caso, aumenta-se o diferencial de pressão. Em todos os casos, utilizou-se como condição inicial velocidade nula e distribuição de pressão uniforme e igual a pressão atmosférica. A tabela 8.2 apresenta um resumo das diferenças dos casos. Emprega-se os dois solvers para avaliar a vazão, dada a imposição de um $\Delta p$ em um meio heterogêneo, e a diferença encontrada nos resultados é discutida.

Tabela 8.2: Plug com Heterogeneidade Simplificada

\begin{tabular}{|c|c|c|}
\hline Caso & $\Delta p$ & $K_{\text {plug }}$ \\
\hline Caso 1.1 & $10 \mathrm{k} \mathrm{Pa}$ & $1 \times 10^{8} \mathrm{D}$ \\
\hline Caso 1.2 & $10 \mathrm{k} \mathrm{Pa}$ & $1 \times 10^{7} \mathrm{D}$ \\
\hline Caso 1.3 & $10 \mathrm{k} \mathrm{Pa}$ & $1 \times 10^{6} \mathrm{D}$ \\
\hline Caso 1.4 & $1000 \mathrm{k} \mathrm{Pa}$ & $1 \times 10^{7} \mathrm{D}$ \\
\hline
\end{tabular}

Considera-se a porosidade do reservatório, a massa específica e viscosidade do fluido como constantes. A tabela 8.3 apresenta as propriedades do fluido e do reservatório para a simulação.

Tabela 8.3: Propriedades do fluido e plug. Caso 1.1 a 1.4

\begin{tabular}{|c|c|c|c|c|c|}
\hline \multicolumn{2}{|c|}{ Propriedades do fluido } & \multicolumn{2}{c|}{ Propriedades da formação } \\
\hline Propriedade & Unidade & Valor & Propriedade & Dimensão & Valor \\
\hline$\mu$ & $K g /(m s)$ & $1,0 \times 10^{-3}$ & $K_{\text {plug }}$ & Darcy & $10^{6}$ a $10^{8}$ \\
$C_{v i s c}$ & $s$ & 0 & $K_{\text {circ }}$ & Darcy & 0,001 \\
$p_{b}$ & $k P a$ & 101,325 & & & \\
$\rho$ & $K g / m^{3}$ & 998,0 & $\phi_{\text {ref }}$ & {[]} & 0,2 \\
$B_{o}$ & {[]} & 1,0 & $p_{\text {ref }}$ & $k P a$ & 101,325 \\
$R_{s}$ & {[]} & 0 & $S_{w c o n}$ & {[]} & 0 \\
$c_{o}$ & $1 / P a$ & 0 & $c_{f}$ & $1 / P a$ & 0 \\
\hline
\end{tabular}


A figura 8.2 apresenta o campo de permeabilidade do plug, para o Caso 1.1. A distribuição de permeabilidade é alta no plug e baixa no interior do círculo $(1 \mathrm{mD})$. A figura ilustra o salto de permeabilidade na fronteira do círculo. Todos os outros casos são análogos.

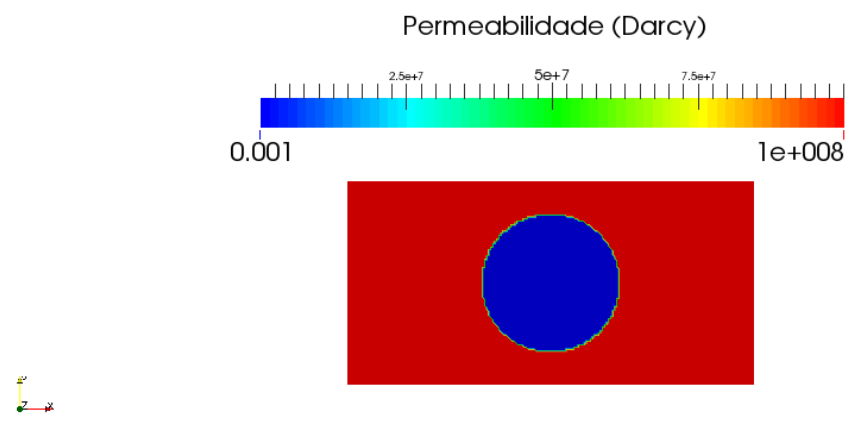

Figura 8.2: Campo de permeabilidade do plug de $10^{8} D$. Caso 1.1

O Caso 1.1 considera um meio poroso muito permeável, cuja permeabilidade é isotrópica e com valor de $1 \times 10^{8} \mathrm{D}$. A figura 8.3 apresenta a comparação entre os campo de pressão e de velocidade superficial obtidos com os modelos HDF e RPPF, onde pode-se observar uma diferença significativa para os dois campos obtidas com os dois modelos, indicando que as hipóteses introduzidas na equação de Darcy não são desprezíveis.

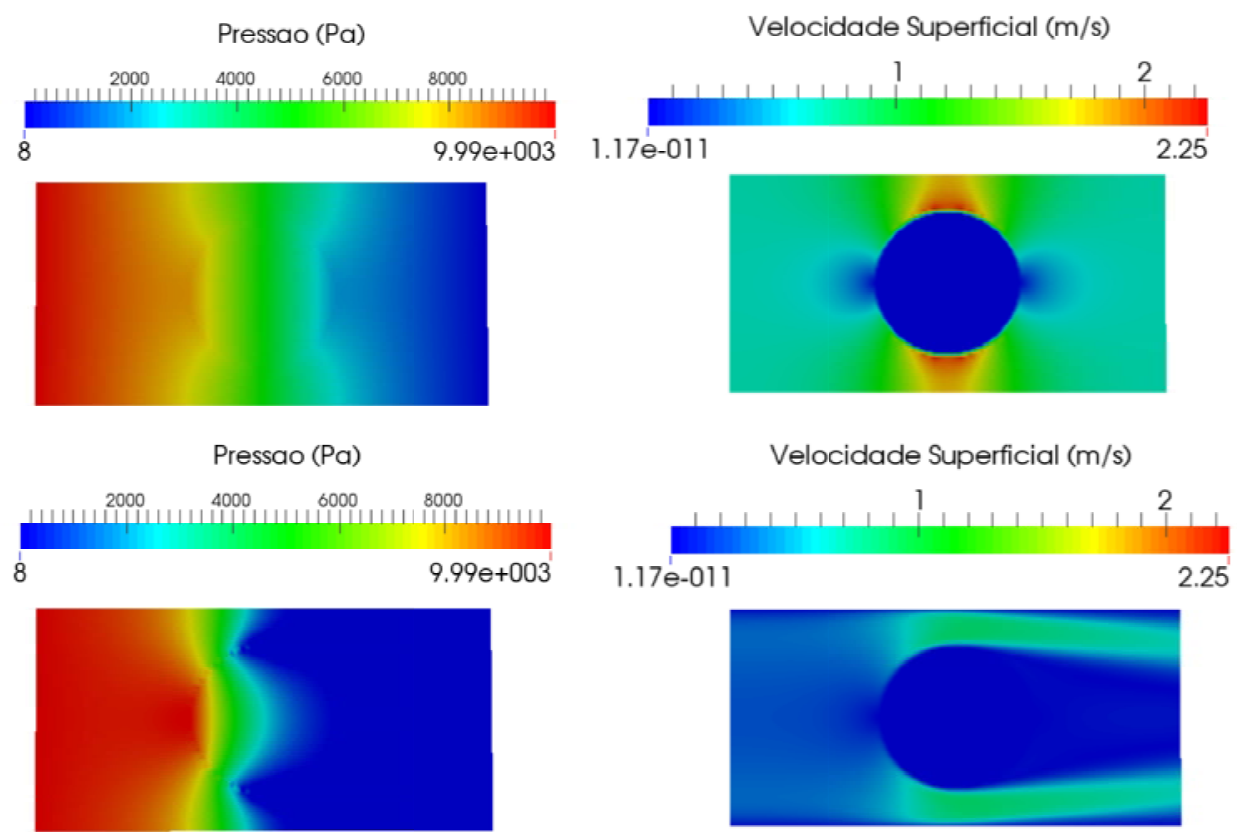

Figura 8.3: Caso 1.1. $\Delta p=10 \mathrm{k} \mathrm{Pa}, K_{p l g}=10^{8} \mathrm{D}$. (a) Campo de pressão (b) Campo de velocidade superfical. Acima HDF e abaixo RPPF. 
A figura 8.3 apresenta uma distribuição da pressão mais difusa no modelo simplificado, e o campo de pressão é simétrico. No caso RPPF, a montante do círculo, devido a efeitos convectivos, o campo de pressão e velocidade é mais uniforme, porém a jusante do círculo, a influência do salto de permeabilidade na borda do círculo é mais visível no campo de pressão, e a velocidade é praticamente nula, pois o escoamento preferencial ocorre através da parte superior e inferior ao círculo. Percebe-se que a equação de Darcy (modelo HDF) prevê valores mais altos de velocidade, com picos de velocidade de $2,25 \mathrm{~m} / \mathrm{s}$ enquanto que o modelo de teoria de média tem a velocidade máxima em torno de $1 \mathrm{~m} / \mathrm{s}$, menos que a metade do resultado encontrado por Darcy.

As figuras 8.4 e 8.5 apresentam o perfil de velocidade ao longo de uma linha vertical passando pelo centro do domínio considerando diferentes malhas. As malhas consideradas contém 20, 80 e 320 mil elementos.

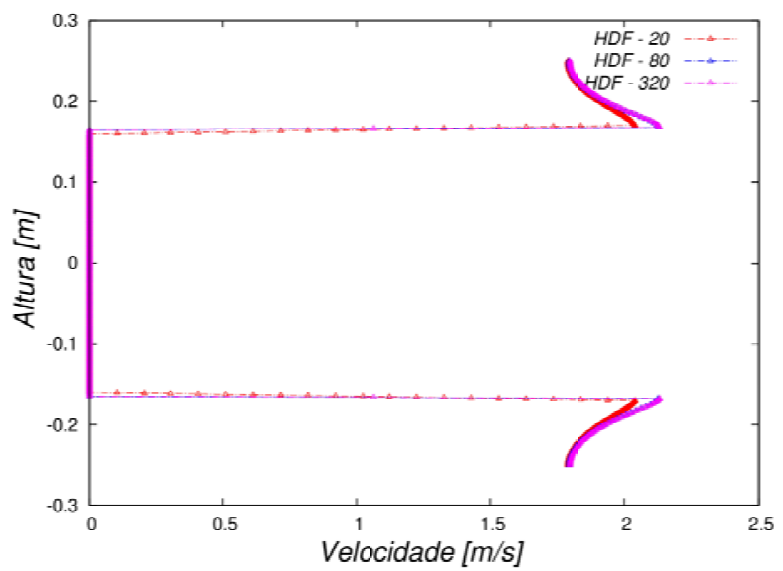

Figura 8.4: Caso 1.1. Perfil de velocidade superficial (HDF) ao longo da vertical no centro do plug. $\Delta p=10 \mathrm{k} \mathrm{Pa}, K_{\text {plug }}=10^{8} \mathrm{D}$.

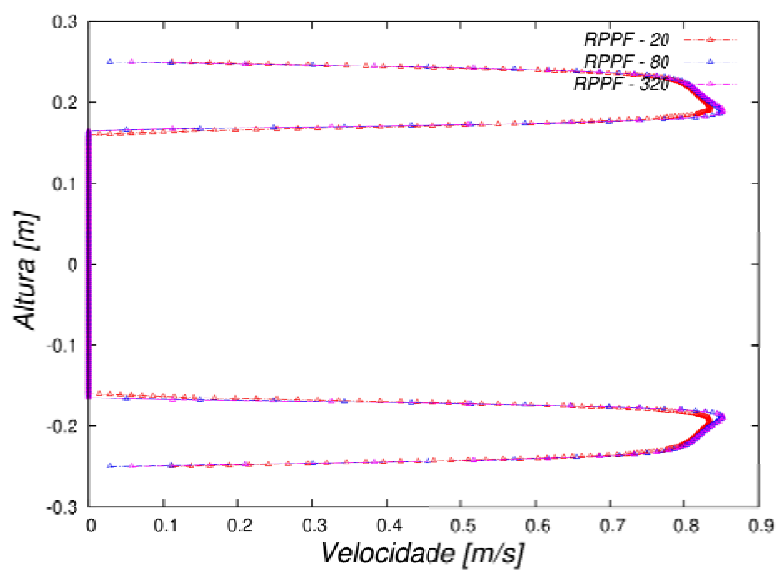

Figura 8.5: Caso 1.1. Perfil de velocidade superficial (RPPF) ao longo da vertical no centro do plug. $\Delta p=10 \mathrm{k} \mathrm{Pa}, K_{\text {plug }}=10^{8} \mathrm{D}$. 
A figura 8.6 compara o perfil de velocidade ao longo de uma linha vertical passando pelo centro do domínio obtido com o HDF (modelo de Darcy) e RPPF (modelo de média). Fica claro que a equação de Darcy prevê velocidades maiores para o caso apresentado. Isso ocorre devido a ausência dos demais termos que impõem outros tipos de perda de carga para o fluido.

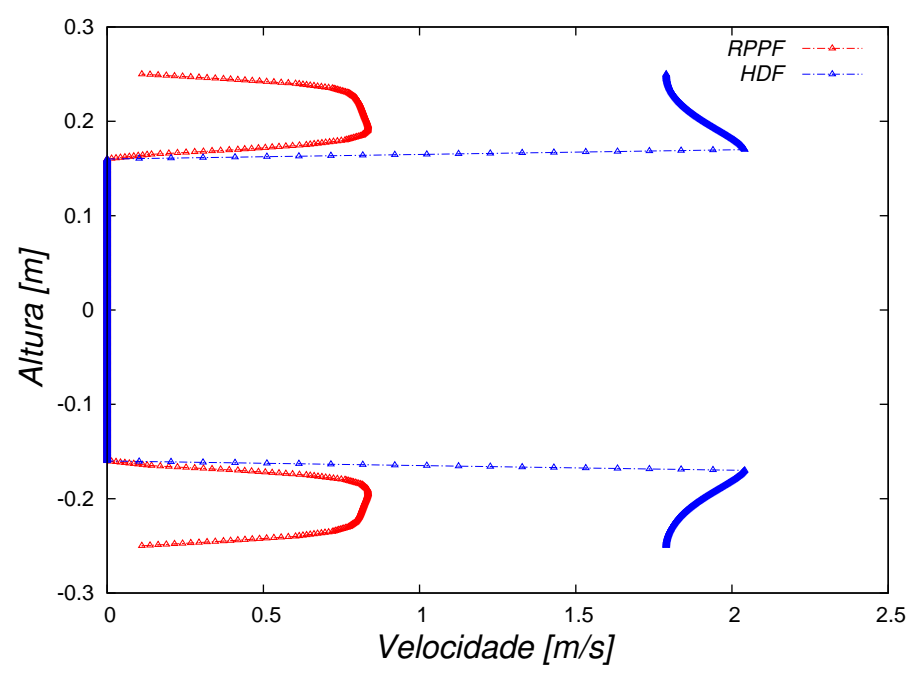

Figura 8.6: Caso 1.1. Perfil de velocidade superficial ao longo da vertical no centro do plug. $\Delta p=10 \mathrm{k} \mathrm{Pa}, K_{\text {plug }}=10^{8} \mathrm{D}$.

No segundo e terceiro testes, Caso 1.2 e Caso 1.3, manteve-se todos os parâmetros iguais ao caso anterior, mas diminuiu-se a permeabilidade do meio para $1 \times 10^{7} \quad \mathrm{D}$ e $1 \times 10^{6} \mathrm{D}$, respectivamente, mantendo a permeabilidade do círculo. O objetivo é avaliar o comportamento das modelagens em um meio poroso ainda altamente heterogêneo, mas reduzindo cada vez mais a heterogêneidade com relação ao caso anterior.

As figuras 8.7 e 8.8 apresentam os campo de pressão e de velocidade superficial obtidos com os modelos HDF e RPPF, para os dois casos. Com relação ao Caso 1.2, observa-se que a distribuição da pressão pelo domínio é praticamente a mesma para os dois modelos. Percebe-se que os campos diferem um pouco na forma da região onde se encontram as maiores velocidades e na parede.

O Caso 1.3 apresenta praticamente o mesmo campo de pressão, e os campos de velocidade também são muito semelhantes. 


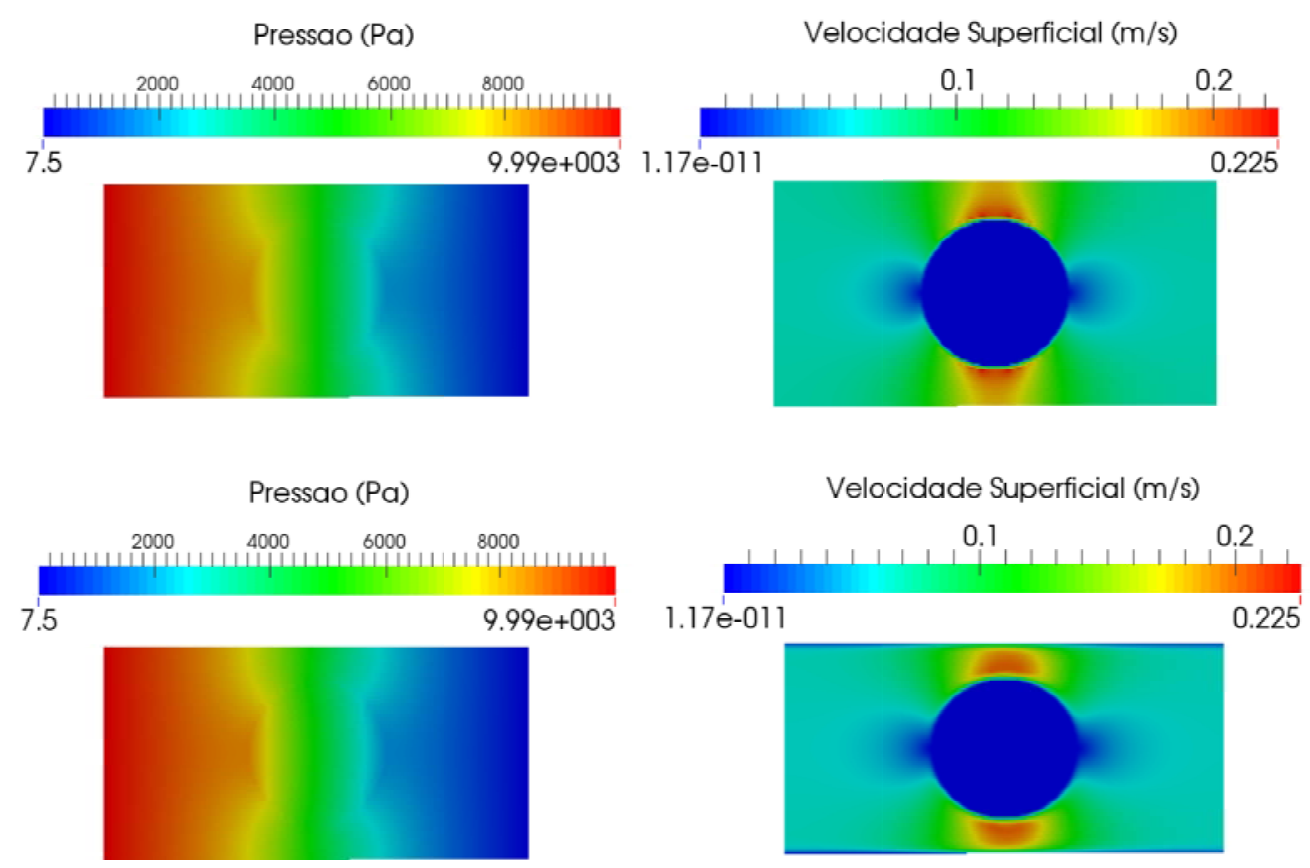

Figura 8.7: Caso 1.2. $\Delta p=10 \mathrm{k} \mathrm{Pa}, K_{\text {plug }}=10^{7}$ D. (a) Campo de pressão (b)

Campo de velocidade superfical. Acima HDF e abaixo RPPF.

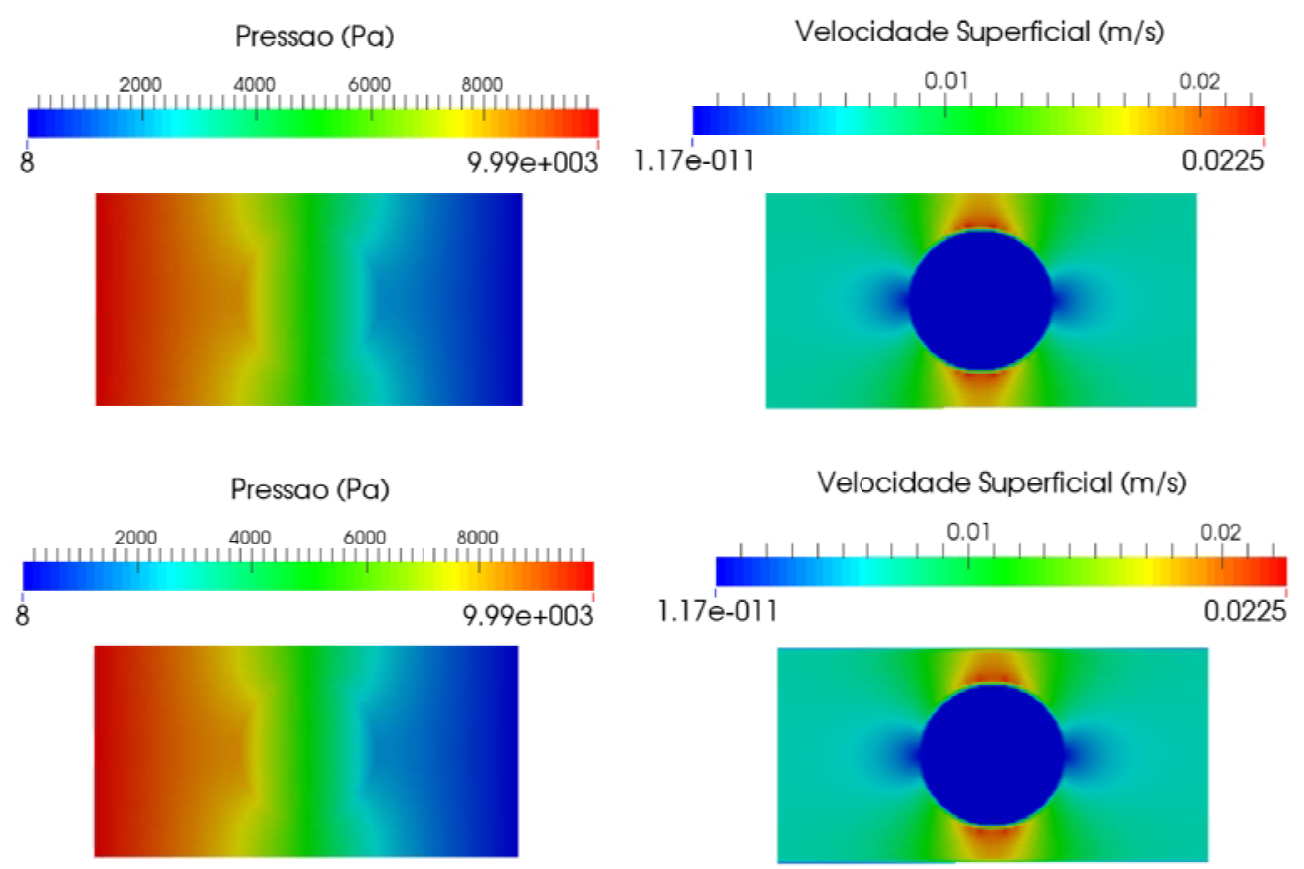

Figura 8.8: Caso 1.3. $\Delta p=10 \mathrm{k} \mathrm{Pa}, K_{\text {plug }}=10^{6}$ D. (a) Campo de pressão (b) Campo de velocidade superfical. Acima HDF e abaixo RPPF.

A figura 8.7 corresponde ao Caso 1.2, mostra o campo de escoamento para um modelo de meio poroso altamente heterogeneo, onde as modelagens de Darcy e de teoria de média encontram resultados muito próximos. A 
questão chave para uma boa previsão de produtividade é saber modelar a permeabilidade do meio.

Outro fator relevante que precisa ser mencionado é que a equação de Darcy é utilizada incondicionalmente para a determinação da permeabilidade do meio. Experimentos em plugs impondo pressão e medindo vazão são muito comuns. Após a medição, a equação de Darcy é utilizada para a determinação da permeabilidade do plug. Quando temos a presença de um vug, ou seja, um espaço vazio ao longo do plug, o uso da equação de Darcy pode levar a valores mal estimados sendo melhor a utilização da equação completa de quantidade de movimento linear média.

Para melhor avaliar a diferença entre os modelos, analisa-se o perfil de velocidade ao longo da coordenada vertical, passando pelo centro do plug. A figura 8.9 corresponde ao Caso 1.2 e a figura 8.10 ao Caso 1.3, com menor heterogenidade. Percebe-se que para o Caso 1.2, o formato dos perfis de velocidade ainda não são idênticos, mas pode-se afirmar que a importância dos demais termos da equação da modelagem de média diminui drasticamente nesse caso. Com relação ao Caso 1.3, percebe-se que o formato dos perfis de velocidade são mais próximos que os dois casos simulados anteriormente. No entanto, o modelo RPPF consegue prever uma região de parede, diferentemente do modelo HDF.

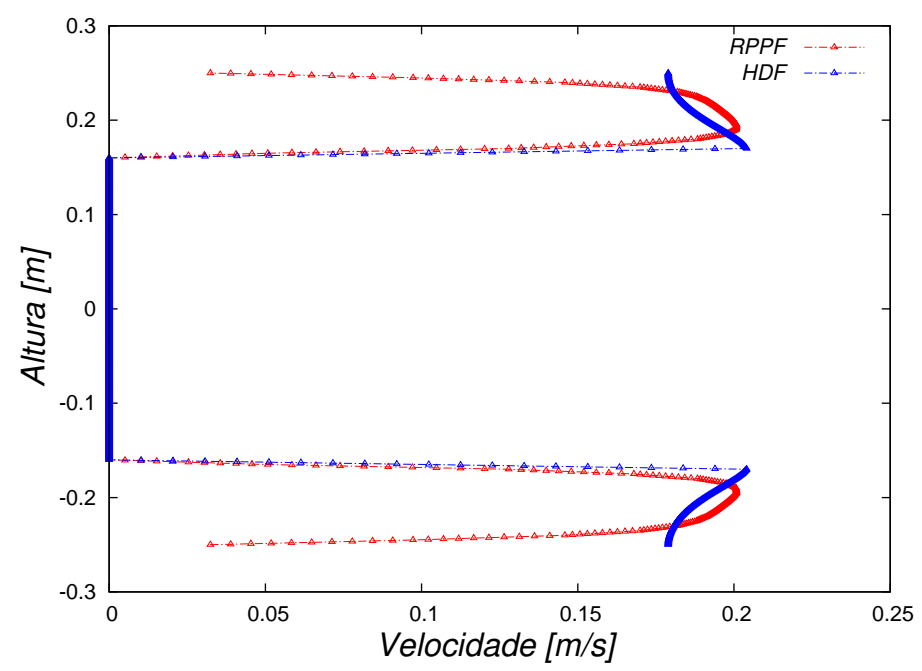

Figura 8.9: Caso 1.2. Perfil de velocidade superficial ao longo da vertical no centro do plug. $\Delta p=10 \mathrm{k} \mathrm{Pa}, K_{\text {plug }}=10^{7} \mathrm{D}$. 


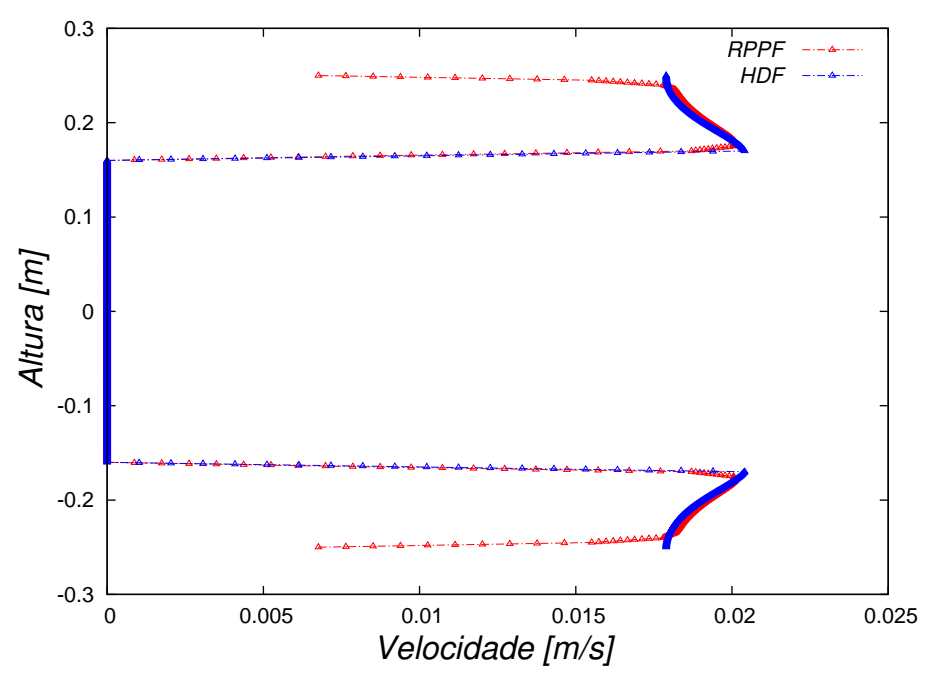

Figura 8.10: Caso 1.3. Perfil de velocidade superficial ao longo da vertical no centro do plug. $\Delta p=10 \mathrm{k} \mathrm{Pa}, K_{\text {plug }}=10^{6} \mathrm{D}$.

A tabela 8.4 apresenta a vazão mássica na saída do plug para todos os casos. Verifica-se que no Caso 1.1, altamente heterogêneo, a equação de Darcy prevê um valor de vazão superior a duas vezes o valor da teoria de média. Com relação aos Casos 1.2 e 1.3, nota-se que apesar dos campos de pressão e velocidade serem muito parecidos e o perfil de velocidade ter picos de velocidades próximos, a vazão na saída do plug, para as duas modelagens, ainda apresenta uma diferença de aproximadamente 10 por cento.

Tabela 8.4: Produção no Plug. Casos 1.1, 1.2 e 1.3

\begin{tabular}{|c|c|c|c|}
\hline & & Vazão mássica $(\mathrm{Kg} / \mathrm{s})$ & \\
\hline Caso & $K_{\text {plug }}$ & $\mathrm{HDF}$ & $\mathrm{RPPF}$ \\
\hline Caso 1.1 & $10^{8} \mathrm{D}$ & $1,608 \times 10^{0}$ & $5,947 \times 10^{-1}$ \\
\hline Caso 1.2 & $10^{7} \mathrm{D}$ & $1,608 \times 10^{-1}$ & $1,461 \times 10^{-1}$ \\
\hline Caso 1.3 & $10^{6} \mathrm{D}$ & $1,608 \times 10^{-2}$ & $1,577 \times 10^{-2}$ \\
\hline
\end{tabular}

Uma comparação dos resultados encontrados na presente seção mostra a dependência da intensidade de heterogeneidade, ou seja, da diferença entre permeabilidades em uma região de meio poroso. As mesmas condições foram impostas em cada caso, apenas a heterogeneidade mudou. Observa-se que o valor da permeabilidade do meio poroso é fundamental para a previsão correta do comportamento do escoamento.

É possivel encontrar cavernas do comprimento de dezenas a centenas de metros com diâmetro de dezenas de centímetros em reservatórios carbonáticos. A imposição da pseudo permeabilidade desses espaços vazios e consequente- 
mente a escolha do modelo adequado para o escoamento é de fundamental importância.

O quarto caso avaliado nesta seção, Caso 1.4 (tabela 8.2), é muito importante para o presente trabalho. Ainda foi utilizado um alto valor de permeabilidade no plug, igual ao Caso 1.2. Nesta simulação, aumentou-se substancialmente o diferença de pressão imposto ao plug. Aqui mostra-se que os resultados de previsão de vazão em plugs não dependem apenas da maior permeabilidade do meio. A imposição de uma pressão maior pode fazer com que a estimativa da vazão entre modelos diferenciem ainda mais.

A figura 8.11 apresenta resultados importantes para a discussão do presente trabalho. Elas apresentam uma diferença clara nos campos de velocidade e de pressão para os modelos HDF e RPPF em um modelo de heterogeneidade igual ao caso 1.2. Devido ao aumento significativo do diferencal de pressão a figura 8.11 mostra uma diferença bastante assentuada entre os modelos, diferentemente da figura 8.7. Lembra-se que o caso 1.4 é idêntico ao caso 1.2, apenas a condição de contorno de pressão foi intensificada.

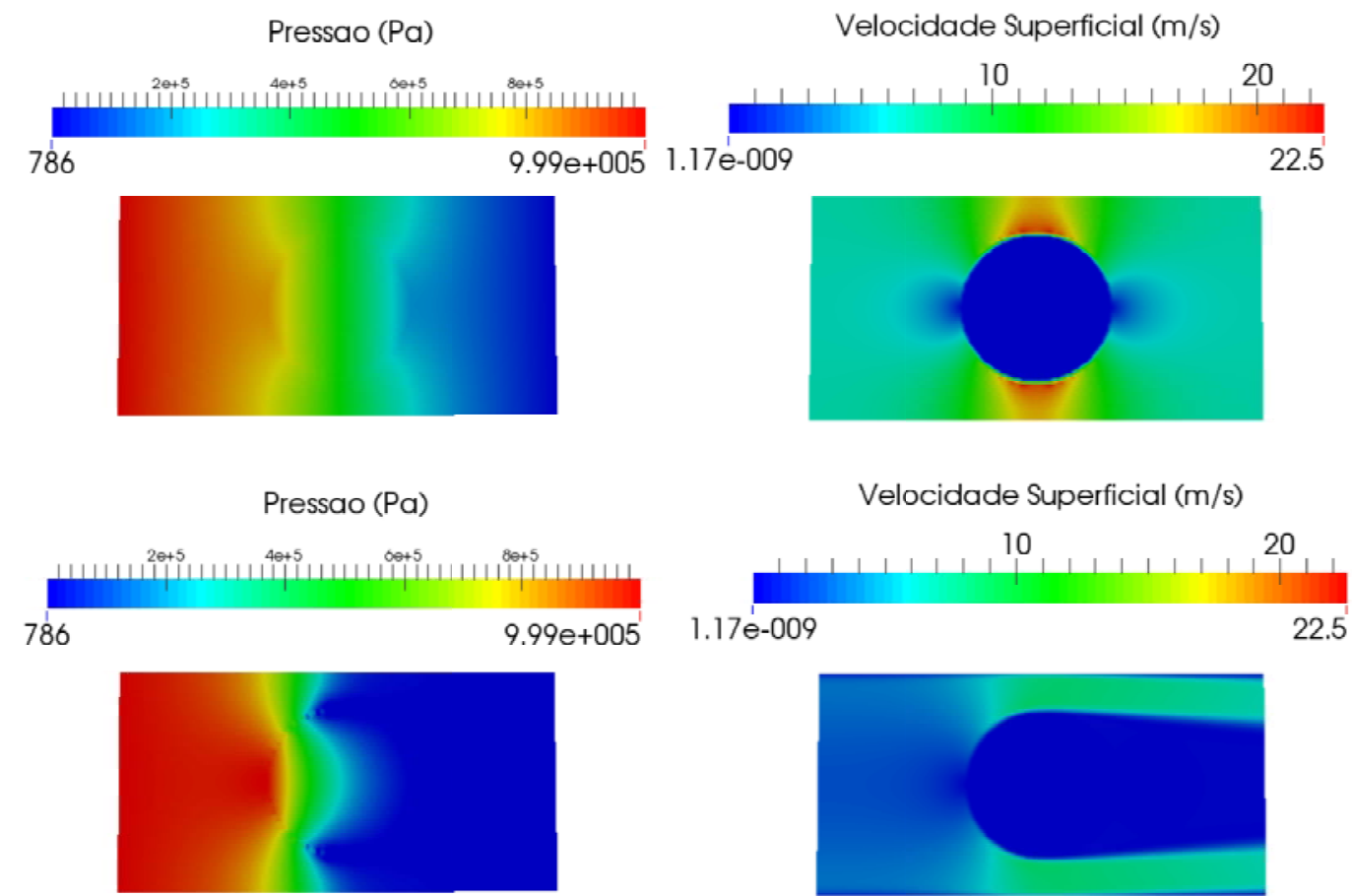

Figura 8.11: Caso 1.4. $\Delta p=1 \mathrm{M} \mathrm{Pa}, K_{p l u g}=10^{7}$ D. (a) Campo de pressão (b) Campo de velocidade superfical.

A imposição de um gradiente de pressão maior induziu a campos de velocidade e pressão para o presente caso (figura 8.11) muito semelhantes aos 
campos obtidos para o Caso 1.1 (altíssimea heterogeneidade), figura 8.3. A figura 8.12 apresenta o perfil de velocidade ao longo da linha vertical pela passa pelo centro do domínio. Percebe-se que o formato dos perfis de velocidade se afastaram ainda mais quando comparado com a figura 8.9.

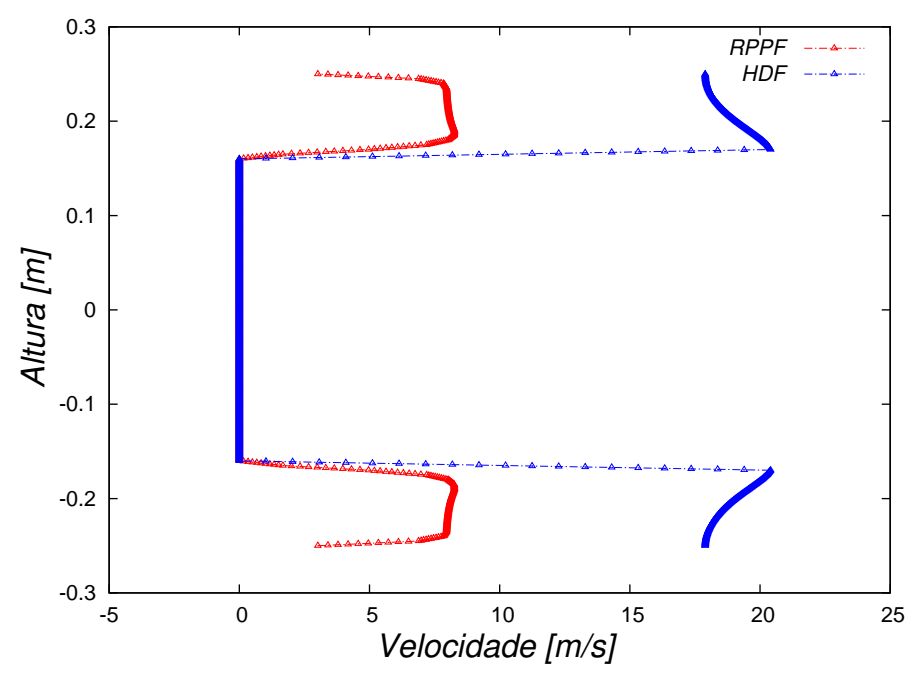

Figura 8.12: Caso 1.4. Perfil de velocidade superficial ao longo da vertical no centro do plug. $\Delta p=1 \mathrm{M} \mathrm{Pa}, K_{\text {plug }}=10^{7} \mathrm{D}$.

A tabela 8.5 apresenta a vazão mássica na saída do plug para o Caso 1.4, onde nota-se uma diferença considerável na estimativa das vazões. Os resultados obtidos no presente teste, mostram que a previsão de vazão de um meio poroso, deve passar pela escolha de qual equação de movimento utilizar. Os Casos 1.2 e 1.4 possuem a mesma heterogenidade, porém, no Caso 1.4, o plug é submetido a um diferencial de pressão 100 vezes maior. Para um $\Delta P=10$ $\mathrm{KPa}$, a diferença entre os modelos para a vazão na saída do meio poroso foi de $10 \%$. Quando esse mesmo meio poroso foi submetido a um diferencial de pressão 100 vezes maior $(\Delta p=1 \mathrm{MPa})$, a diferença entre os modelos para a vazão é igual a $150 \%$.

Tabela 8.5: Produção no Plug. Caso 1.4

\begin{tabular}{|c|c|c|}
\hline \multicolumn{3}{|c|}{ Vazão mássica $(\mathrm{Kg} / \mathrm{s})$} \\
\hline Caso & HDF & RPPF \\
\hline Caso 1.4 & 16,075 & 6,413 \\
\hline
\end{tabular}

A importância de avaliar meios porosos com heterogeneidade bem comportada foi apresentada com o objetivo de criar sensibilidade para o cálculo da estimativa de vazão em meios porosos heterogêneos. Percebe-se a importância da escolha de um modelo matemático mais completo para a previsão da vazão 
em meios porosos haja vista a generalidade do mesmo para diferentes tipos de heterogeneidade. Outra relevante informação é a modelagem da imposta permeabilidade. O modelo de uma pseudo permeabilidade de vugs influenciará demasiadamente na previsão da vazão haja visto que a equação de Darcy prevê valores superiores à equação completa.

É importante ressaltar que a escolha para esse tipo de heterogeneidade e consequente simulação foi inspirada no artigo de Srinivasan (2016b). Os resultados da tese não foram comparados quantitativamente através de perfis de velocidade ou curvas de pressão com os de Srinivasan (2016b), mas apresentaram excelentes resultados qualitativos quando comparados com os campos de velocidade e pressão do artigo.

\section{3}

\section{Plug com Heterogeneidade Complexa}

Um meio poroso é naturalmente heterogêneo e sua heterogeneidade é fundamentalmente aleatória. Com o objetivo de modelar plugs mais reais e prever a vazão em regiões de reservatórios carbonatos onde existem caminhos preferenciais na rocha, testes em plugs que apresentam alta heterogeneidade são avaliados.

A modelagem simplificada de heterogeneidade auxiliou na avaliação da importância da utilização da equação completa para a contabilização do escoamento em meios porosos. Nessa seção, investiga-se a importância de utilizar a equação de teoria de média para reservatórios altamente heterogêneios. Esta heterogeneidade pode ser devido a existência de caminhos preferenciais, i.e., caminhos com permeabilidades mais alta, típico de regiões com fraturas naturais ou vugs.

Quatro casos são analisados nesta seção. Os três primeiros consistem de rochas bi-dimensionais e o quarto caso, visando uma representação mais realista de rocha, é tri-dimensional. A configuração dos casos $2 \mathrm{D}$ possui $7 \mathrm{~cm}$ de comprimento e $2,8 \mathrm{~cm}$ de altura. $\mathrm{O}$ caso 3D tem a intensão de modelar uma amostra de um reservatório real cujo comprimento tem $7 \mathrm{~cm}$ e base quadrada de lado $2,8 \mathrm{~cm}$.

Em todos os casos de plug com heterogeneidade complexa considera-se a porosidade do reservatório, a massa específica e viscosidade do fluido como constantes. A tabela 8.6 apresenta as propriedades do fluido e do reservatório para a simulação. 
Tabela 8.6: Propriedades do fluido e plug. Caso 2.1 a 2.4

\begin{tabular}{|c|c|c|c|c|c|}
\hline \multicolumn{2}{|c|}{ Propriedades do fluido } & \multicolumn{2}{c|}{ Propriedades da formação } \\
\hline Propriedade & Unidade & Valor & Propriedade & Dimensão & Valor \\
\hline$\mu$ & $K g /(m s)$ & 0,01 & $\phi_{\text {ref }}$ & {[]} & 0,2 \\
$C_{v i s c}$ & $s$ & 0 & $p_{\text {ref }}$ & $k P a$ & 101,325 \\
$p_{b}$ & $k P a$ & 101,325 & $c_{f}$ & $1 / P a$ & 0 \\
$\rho$ & $K g / m^{3}$ & 800 & $S_{w c o n}$ & {[]} & 0 \\
$B_{o}$ & {[]} & 1,0 & & & \\
$R_{s}$ & {[]} & 0 & & & \\
$c_{o}$ & $1 / P a$ & 0 & & & \\
\hline
\end{tabular}

Para todos os casos 2D analisados, e para o caso 3D, determinou-se a vazão através do plug devido a um diferencial de pressão, onde a pressão na saída (lado direito do plug) é igual à pressão atmosférica $p_{a t m}=101,325$ kPa e a pressão na entrada (lado esquerdo do plug) é igual a 108,219 kPa. A superfícies superior e inferior do plug são paredes, onde gradiente nulo de pressão e velocidade nula (no caso RPPF) são impostos. No caso 3D, estas condições também são empregadas nas fronteiras anterior e posterior.

Em todos os casos, utilizou-se como condição inicial velocidade nula e distribuição de pressão uniforme e igual a $p_{a t m}=101,325 \mathrm{kPa}$. Como já mencionado, a heterogeneidade de um meio poroso é complexa e aleatória. A modelagem da mesma com o objetivo de representar a realidade é no mínimo desafiador. A intenção é avaliar a previsão da vazão em uma região de rocha com uma representação próxima da real. A escolha de um meio poroso com um caminho preferencial é intencional, tendo por objetivo representar uma rocha carbonática com algum tipo de vug ou fratura natural. Pretende-se ilustrar com uma avaliação dos resultados que os termos desprezados por Darcy podem ser relevantes para casos de reservatórios com alta heterogeneidade.

\subsection{1}

\section{Caso 2.1 - Plug 2D pouco permeável, com fratura natural}

A primeira simulação dessa seção considera um meio poroso muito pouco permeável, mas com um caminho preferencial para o escoamento, como se fosse uma fratura natural. A figura 8.13 apresenta o campo de permeabilidade do plug com heterogeneidade complexa do Caso 2.1. 


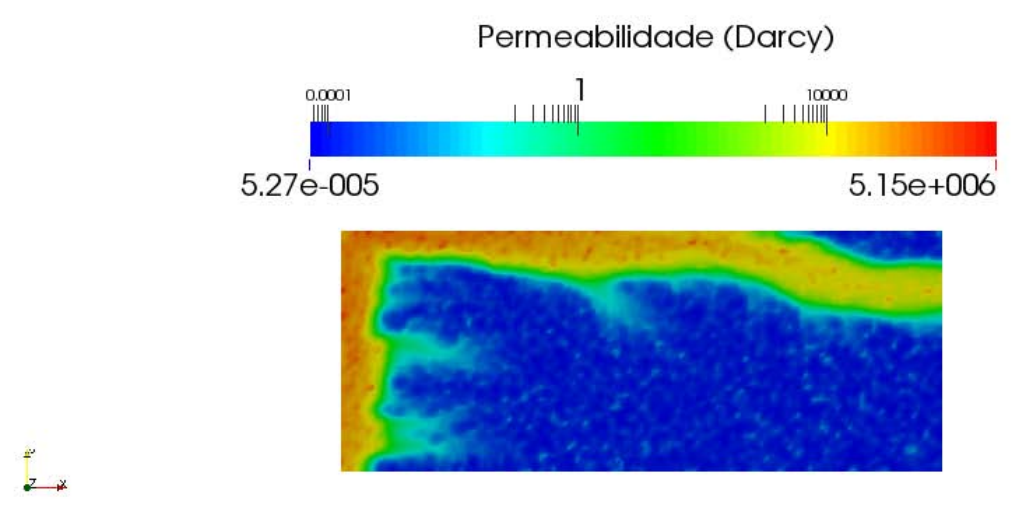

Figura 8.13: Campo de permeabilidade com fratura natural. Caso 2.1.

A figura 8.14 apresenta uma comparação entre os campos de pressão e de velocidade superfical obtidos com os modelos HDF e RPPF para o Caso 2.1. Analisando as figuras, pode-se observar uma diferença significativa entre os campos de pressão obtidos com os dois modelos, para os mesmos parâmetros que governam o escoamento. As diferenças entre os campos de velocidade são menores, porém, nota-se que uma solução mais suavisada foi obtida com o modelo RPPF, provavelmente devido a presença dos termos difusivos, desprezados na modelagem simplificada.

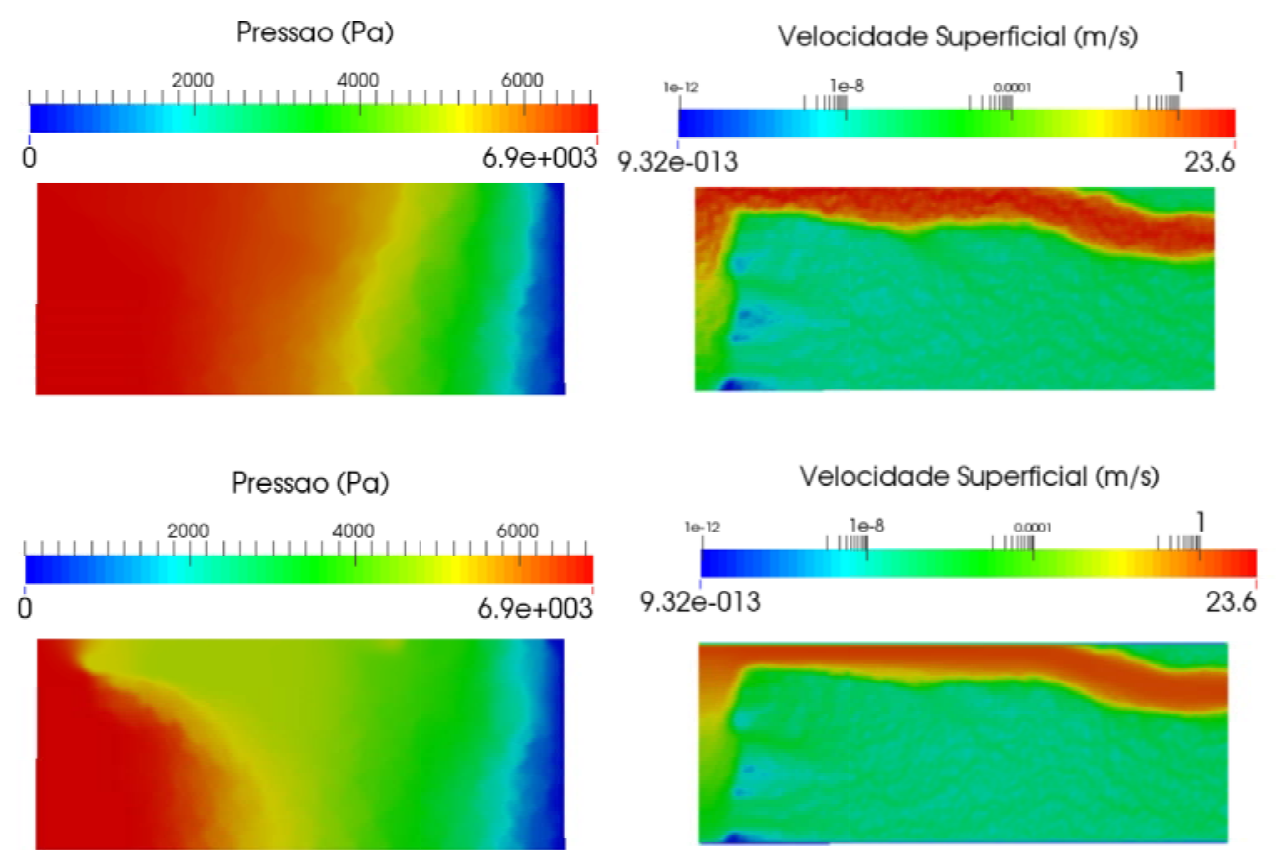

Figura 8.14: Caso 2.1. (a) Campo de pressão (b) Campo de velocidade superficial. Acima HDF e abaixo RPPF. 
A figura 8.15 apresenta o perfil de velocidade superficial ao longo da linha vertical que passa pelo centro do domínio. Observa-se que a solução baseada na equação de Darcy prevê velocidades maiores para o caso apresentado do que o modelo RPPF. Isso ocorre no caminho preferencial, onde a permeabilidade é mais alta. A ausência dos termos que impõem uma perda de carga adicional na equação de Darcy prejudicam a estimativa correta da velocidade.

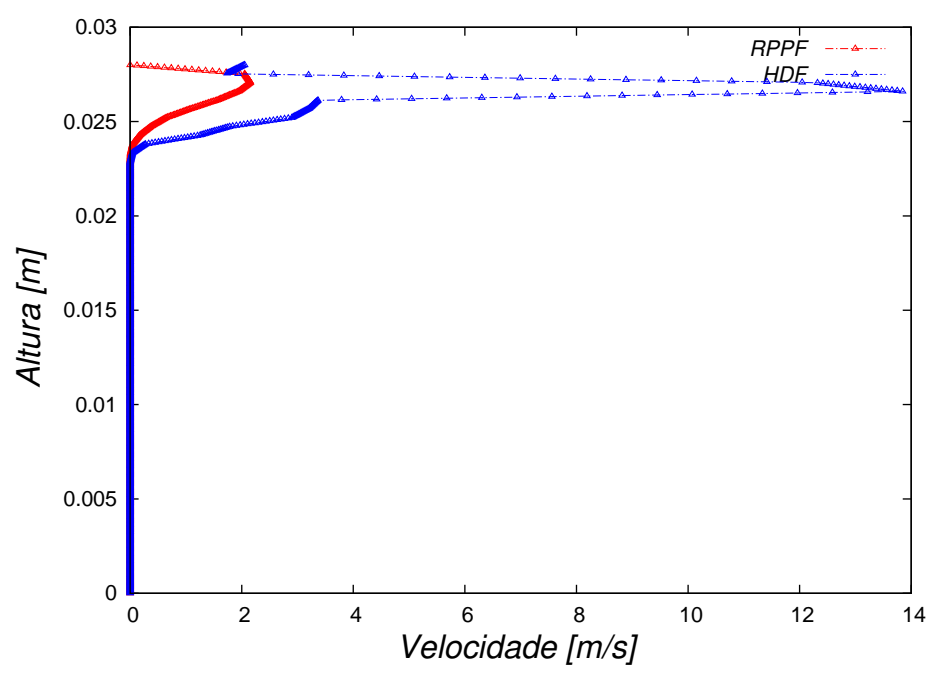

Figura 8.15: Caso 2.1. Perfil de velocidade superficial ao longo da vertical no centro para plug.

\subsection{2}

Caso 2.2 - Plug 2D pouco permeável, com heterogeneidades distintas em série

Neste segundo caso, não existe um caminho preferêncial, conforme ilustra a figura 8.16, que apresenta o campo de permeabilidade do plug com heterogeneidade complexa, utilizada no presente teste. Diferente do caso anterior, não existe um caminho ao longo do plug conectando toda a passagem do fluido. Este plug é formado por duas regiões de heterogeneidade distintas em série. É importante ressaltar que o meio poroso escolhido tem em sua maior região a permeabilidade abaixo de 0,1 $\mathrm{mD}$. Esse tipo de permeabilidade é bem característica de uma rocha de reservatório real.

Este teste visa representar rochas possuindo regiões muito permeáveis (vugs), altamente heterogênas. Pretende-se verificar se as previsões de vazões obtidas com as duas modelagem HDF e RPPF coincidam ou não. 


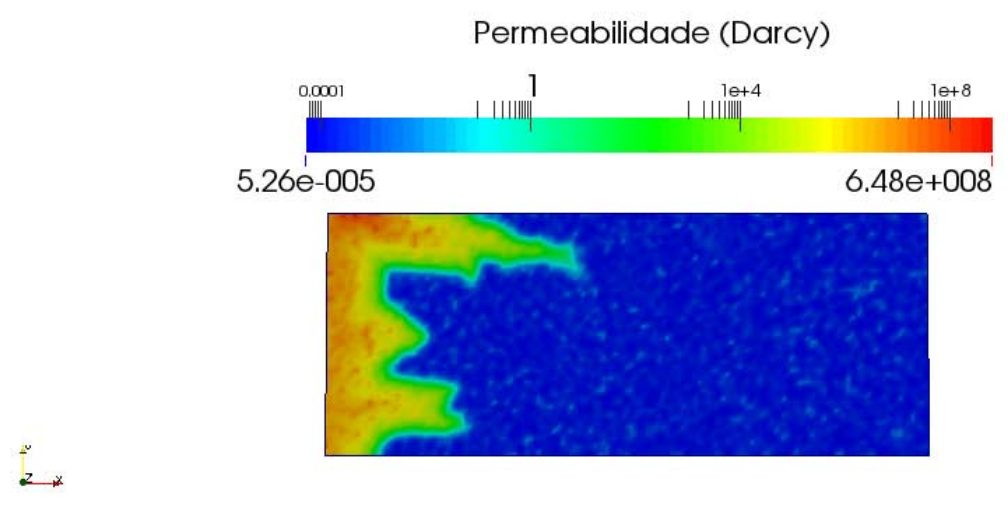

Figura 8.16: Campo de permeabilidade com heterogeneidade distintas em série. Caso 2.2.

A figura 8.17 apresenta uma comparação entre os campos de pressão e de velocidade superficial obtidos com os modelos HDF e RPPF para o caso 2.2. Para as mesmas imposições e condições, nota-se uma grande semelhança no campo de pressão, ambos os modelos prevêem um campo de pressão quase uni-dimensional. Observa-se que a região de alta pressão prevista pelo RPPF é um pouco maior e a de baixa pressão menor.

Para analisar o campo de velocidade, deve-se ressaltar que a escala de cores está em formato logarítimico, visando permitir apreciar as grandes variações de velocidade encontradas no médio. Analisando o campo de velocidade na figura 8.17, nota-se que o modelo baseado na equação de Darcy prevê valores mais altos de velocidade, em especial na região de alta permeabilidade, próximo à entrada e superfície superior. A presença da parede na solução do modelo RPPF também pode ser observada através de uma região de pequena espessura azul ao longo das superfícies superior e inferior. A possibilidade da representação de uma parede com o modelo RPPF, induz a uma desaceleração adicional do escoamento, contribuindo, juntamente com a presença de termos difusivos, desacelerar o escoamento em relação ao caso baseado na equação de Darcy. 


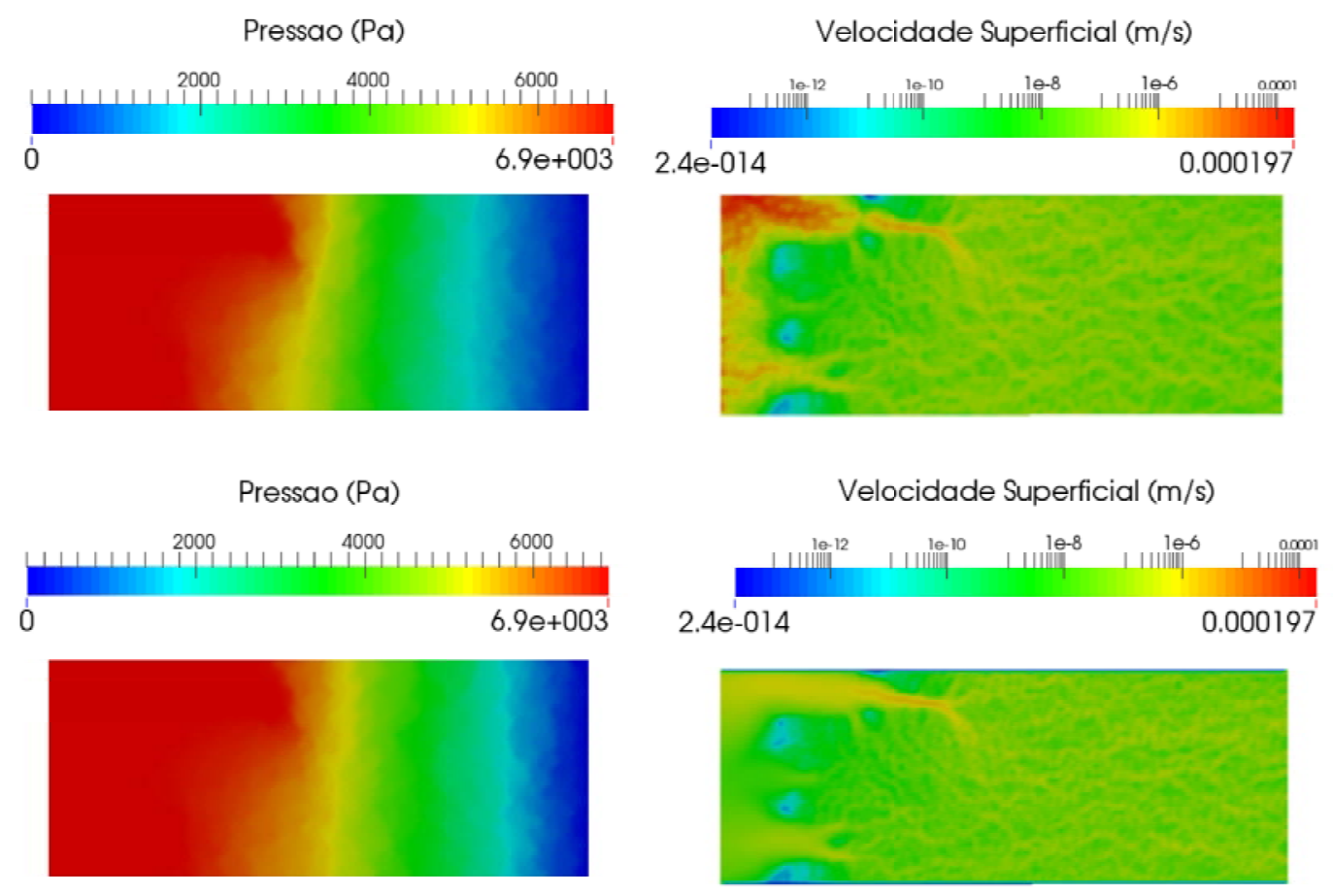

Figura 8.17: Caso 2.2. (a) Campo de pressão (b) Campo de velocidade superficial. Acima HDF e abaixo RPPF.

Uma análise do perfil de velocidade superficial, ao longo de uma linha vertical no centro do domínio, na figura 8.18, mostra que neste caso, baixíssimas velocidades são encontradas com ambos os modelos porém, mais uma vez, o modelo de Darcy também prevê velocidades maiores que o modelo RPPF.

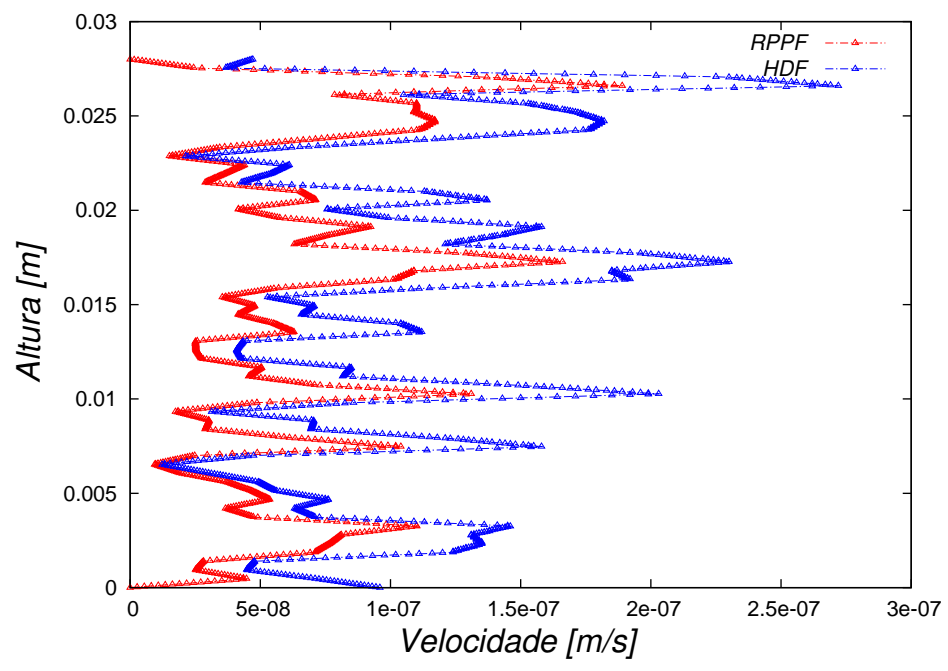

Figura 8.18: Caso 2.2. Perfil de velocidade superficial ao longo da vertical no centro para plug. 


\subsection{3}

\section{Caso 2.3 - Plug 2D pouco permeável, com heterogeneidade distintas em série e fratura}

Para a terceira simulação, o campo de permeabilidade empregado é ilustrado na figura 8.19. Este campo pode ser considerado como possuindo heterogenidade em série e ao mesmo tempo apresenta um caminho preferencial, típico de quando existem fraturas.

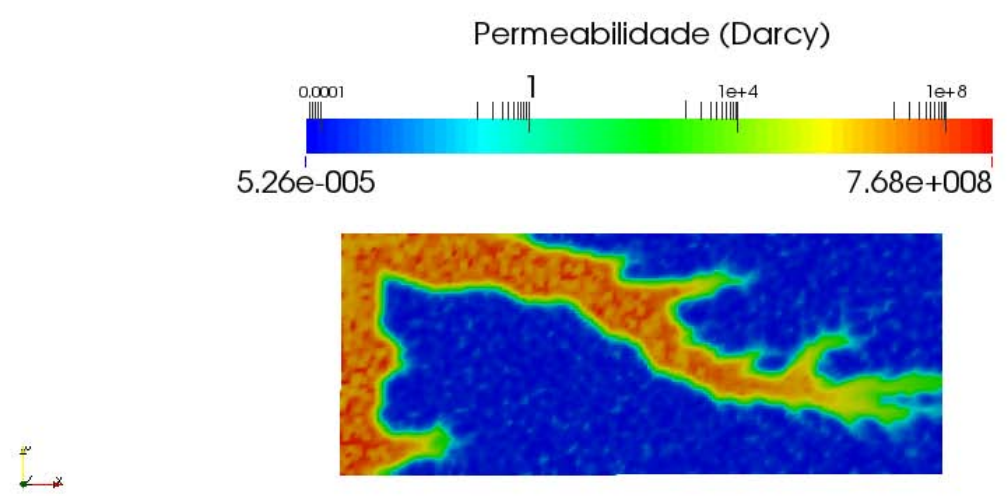

Figura 8.19: Campo de permeabilidade com heterogeneidade distintas em série com fratura. Caso 2.3.

A figura 8.20 apresenta os resultados obtidos com os dois modelos para o campo de pressão e de velocidade superficial. Nesse caso, os campos encontrados de pressão para os dois modelos são bem próximos, com praticamento todo o plug com alto nível de pressão.

Analisando o campo de velocidade, observa-se variações mais acentuadas de velocidade no caso do modelo de Darcy, com velocidade muito baixas atrás da região de alta permeabilidade, pois praticamente todo o fluido escoa pela fratura. Como já mencionado, a presença dos termos difusivos no modelo RPPF induzem um campo com variações mais suavisadas.

Nota-se também, que a presença dos termos convectivos contribui para um aumento da velocidade após a região de alta permeabilidade. É importante ressaltar que as variações de velocidade neste caso, são muito acentuadas, pois a escala de cores está em formato logarítimico. 


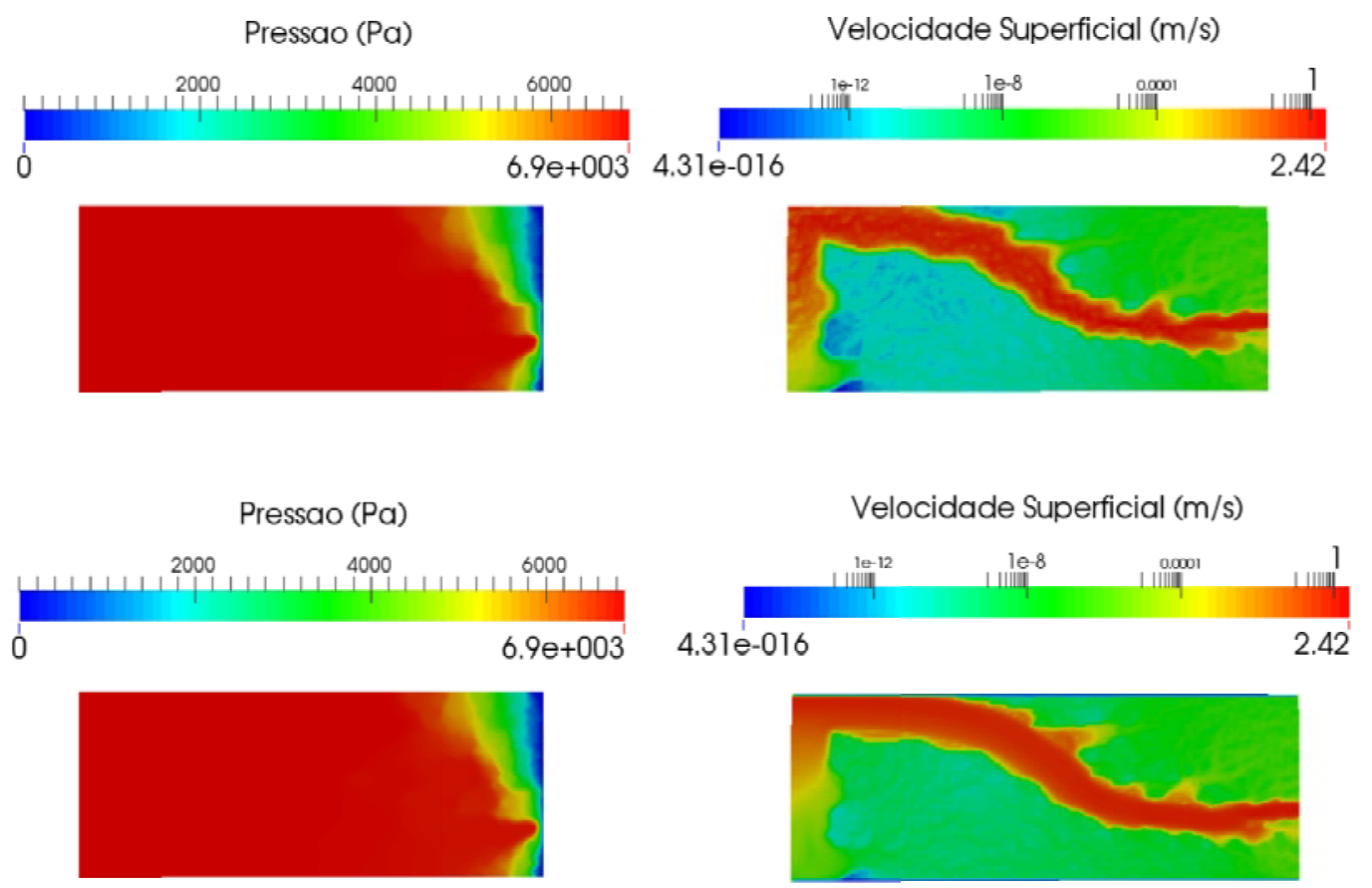

Figura 8.20: Caso 2.3. (a) Campo de pressão (b) Campo de velocidade superficial. Acima HDF e abaixo RPPF.

A figura 8.21 apresenta o perfil de velocidade superficial ao longo da linha vertical no centro do domínio. Fica claro que o modelo baseado na equação de Darcy prevê velocidades maiores na região da fratura do que o modelo HDF. Nota-se também, o perfil mais suave obtido com o modelo RPPF, conforme já mencionado.

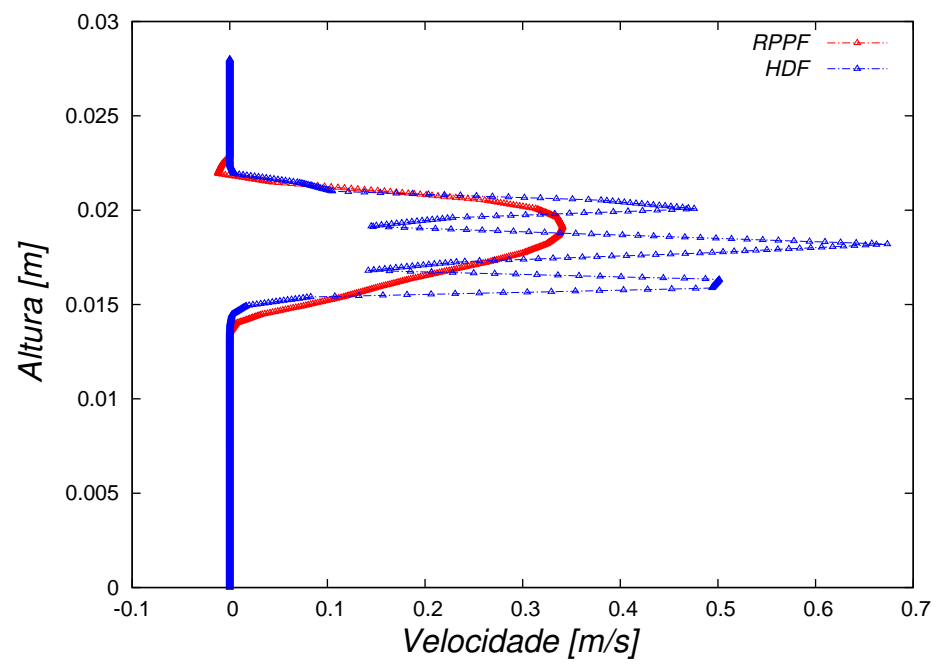

Figura 8.21: Caso 2.3. Perfil de velocidade superficial ao longo da vertical no centro para plug. 


\subsection{4}

\section{Caso 2.4 - Rocha heterogênea 3D}

Como mencionamos, um meio poroso é um meio heterogêneo e sua heterogeneidade é fundamentalmente aleatória. Logo este é naturalmente tridimensional. Com o objetivo de modelar plugs mais reais que os anteriores, um caso tridimensional é resolvido. Nesse exemplo, selecionamos uma região de um reservatório real e similar a um carbonato, para investigar. Somente uma região foi selecionada para ser investigada, pois o reservatório inteiro é muito grande, o que induz a um esforço computacional muito elevado. Para os objetivos do presente trabalho, somente uma região do reservatório, isto é, uma região com dimensões reduzidas, mas com heterogeneidade da permeabilidade real, é suficiente para permitir avaliar o desempenho do modelo RPPF. Vale chamar a atenção que como o paralelepípedo selecionado para o teste é um modelo mais real de um reservatório, este possuindo caminhos preferenciais tridimensionais.

As figuras 8.22 e 8.23 apresentam o campo de permeabilidade do plug 3D do Caso 2.4, utilizando 4 cortes, para melhor visualizar a não uniformidade da permeabilidade.

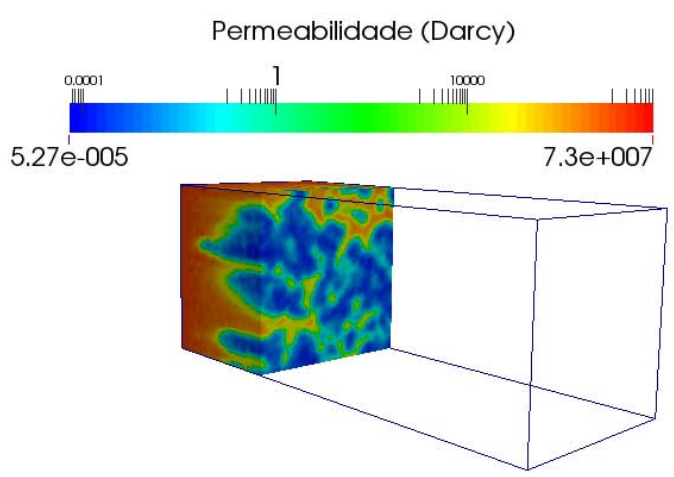

8.22(a): Vista 1

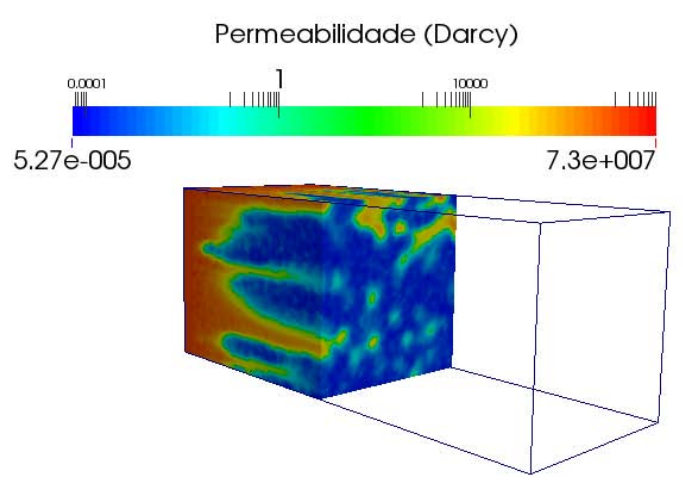

8.22(b): Vista 2

Figura 8.22: Campo de permeabilidade complexo do plug 3D. Caso 2.4 - Vista 1 e 2 . 


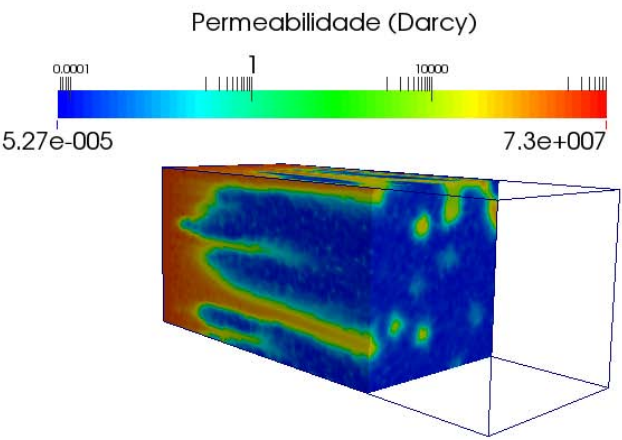

8.23(a): Vista 3

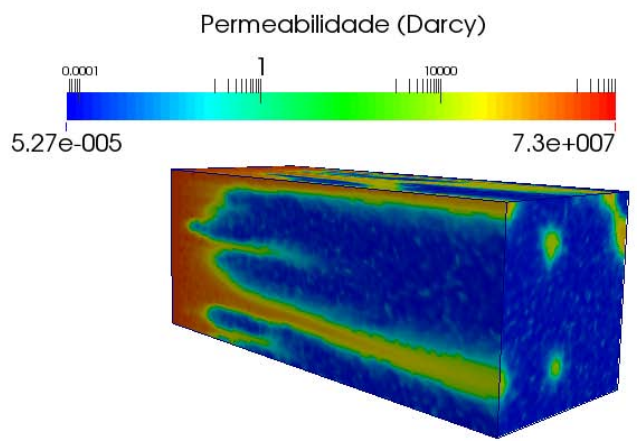

8.23(b): Vista 4

Figura 8.23: Campo de permeabilidade complexo do plug 3D. Caso 2.4 - Vista 3 e 4 .

As figuras 8.24 e 8.25 apresentam o campo de pressão em cortes longitudinais da rocha em relação ao escoamento.

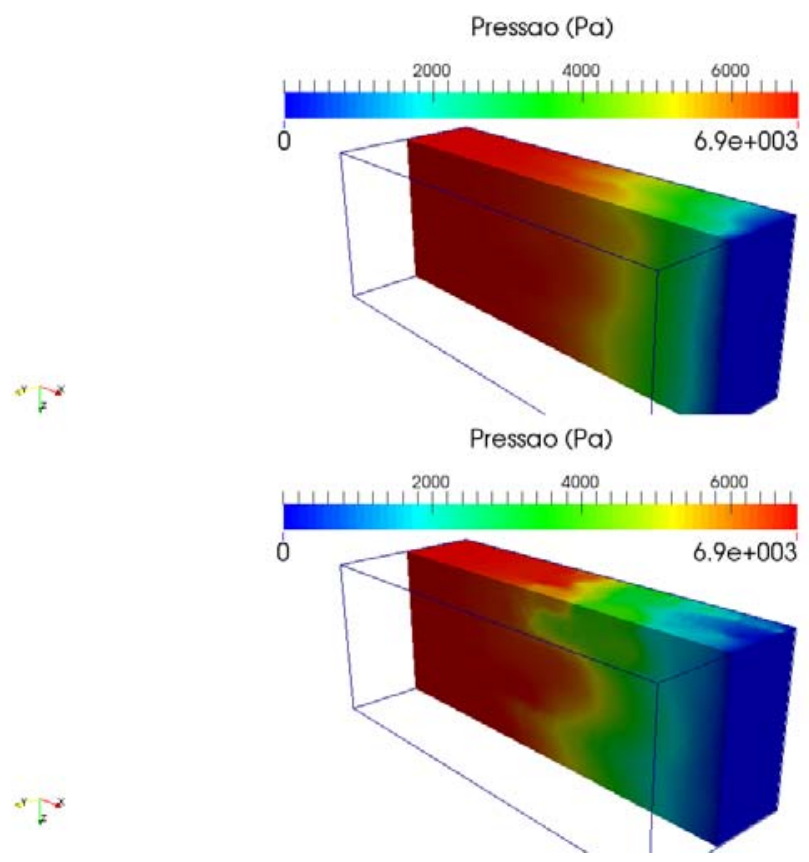

Figura 8.24: Caso 2.4 - Plug 3D. Campo de pressão - Corte longitudinal 1. Acima HDF e abaixo RPPF. 


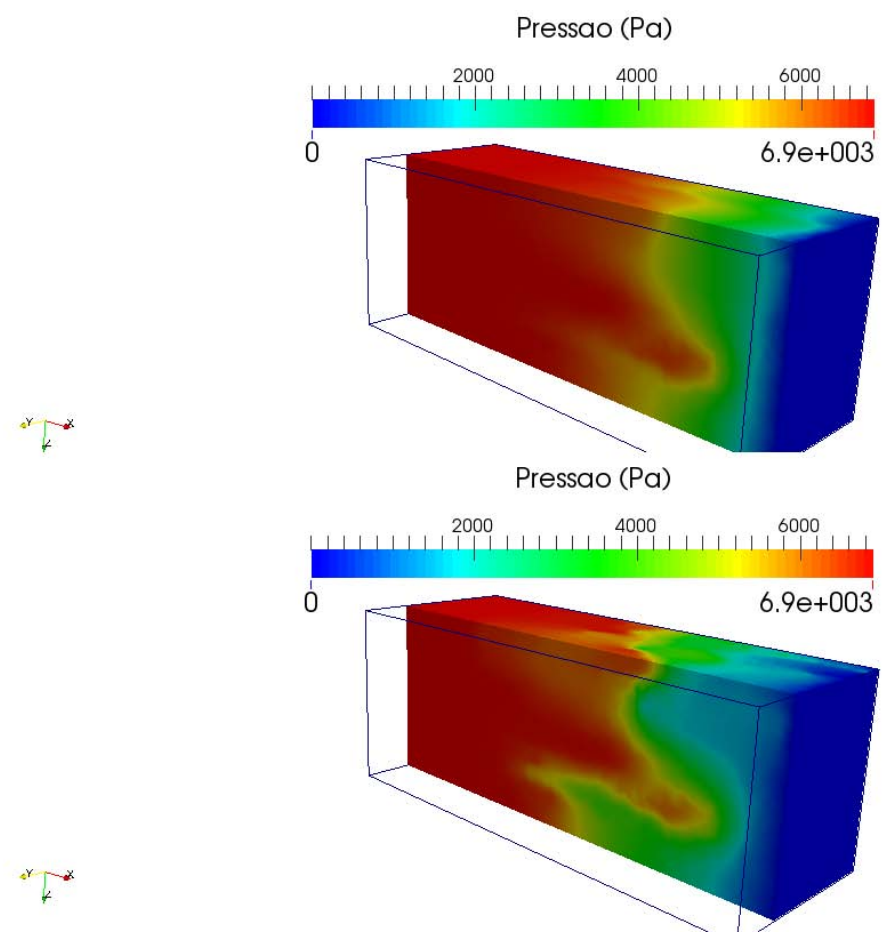

Figura 8.25: Caso 2.4 - Plug 3D. Campo de pressão - Corte longitudinal 2. Acima HDF e abaixo RPPF.

A figura 8.26 apresenta o campo de pressão visto pelas paredes externas do plug.

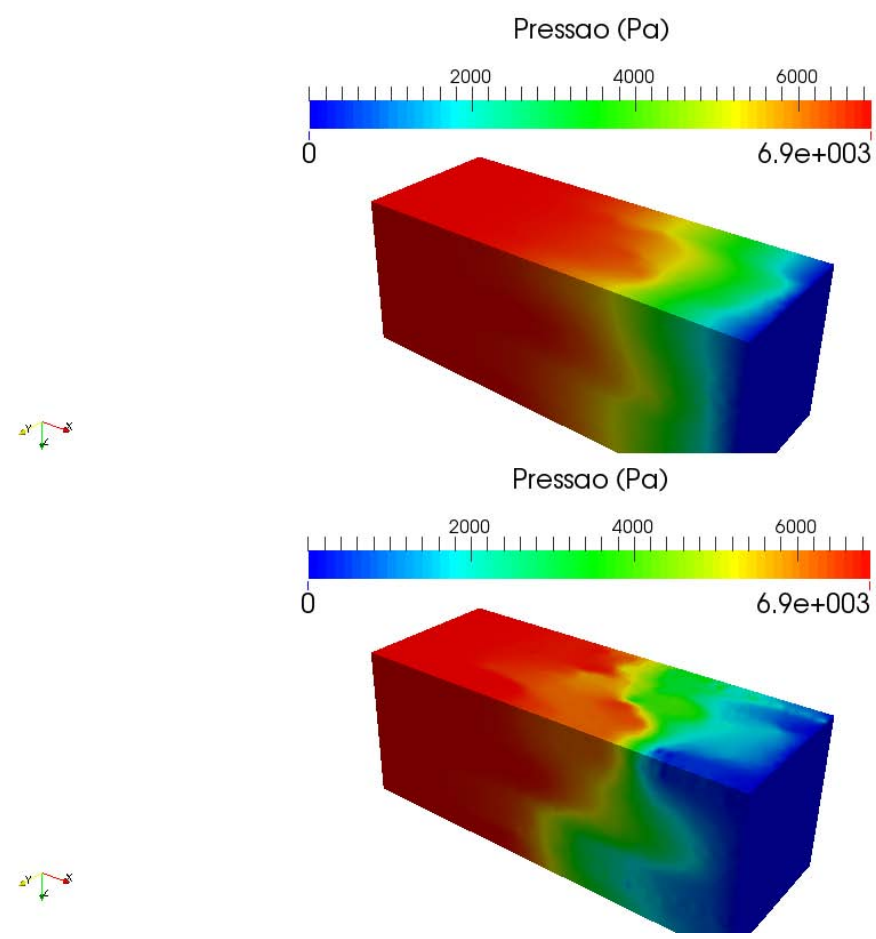

Figura 8.26: Caso 2.4 - Plug 3D. Campo de pressão nas paredes laterais. Acima HDF e abaixo RPPF. 
A figura 8.27 apresenta o campo de pressão em um corte transversal a da rocha em relação ao escoamento.

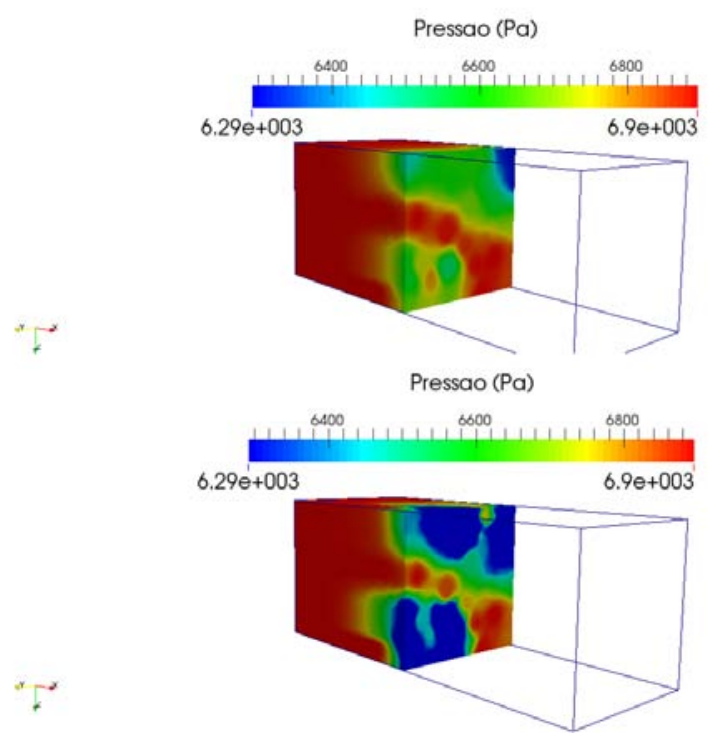

Figura 8.27: Caso 2.4 - Plug 3D. Campo de pressão - Corte transveral. Acima HDF e abaixo RPPF.

Percebe-se que os modelos HDF e RPPF não apresentam as mesmas previsões para os campos de pressão no meio poroso. A aleatoriedade tridimensional da heterogeneidade afeta claramente o campo de pressão quando comparamos os resultados obtidos com os dois modelos.

As figuras 8.28 e 8.29 apresentam o campo de velocidade superficial obtidos com os modelos HDF e RPPF, em cortes longitudinais.

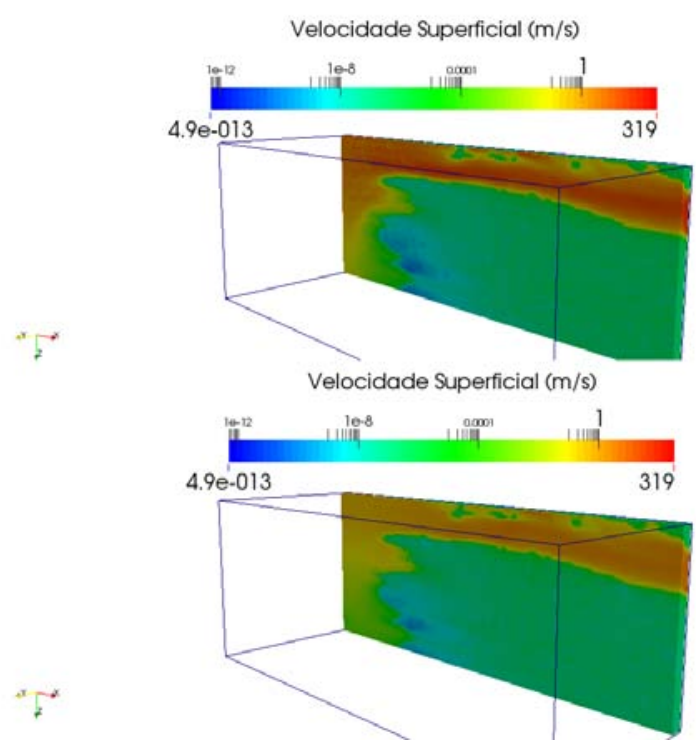

Figura 8.28: Caso 2.4 - Plug 3D. Campo de velocidade superficial - Corte longitudinal 1. Acima HDF e abaixo RPPF. 


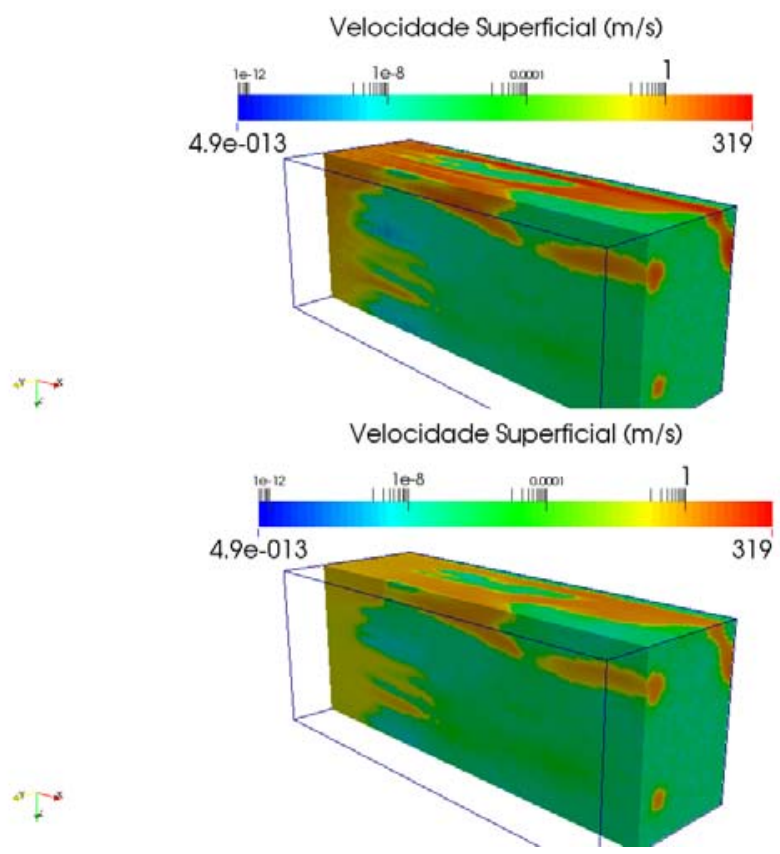

Figura 8.29: Caso 2.4 - Plug 3D. Campo de velocidade superficial - Corte longitudinal 2. Acima HDF e abaixo RPPF.

A figura 8.30 apresenta o campo de velocidades visto pelas paredes externas do plug. Percebe-se que o campo de velocidade do modelo de Darcy tem valores mais altos de velocidade, de forma análoga ao observado nos casos $2 \mathrm{D}$.

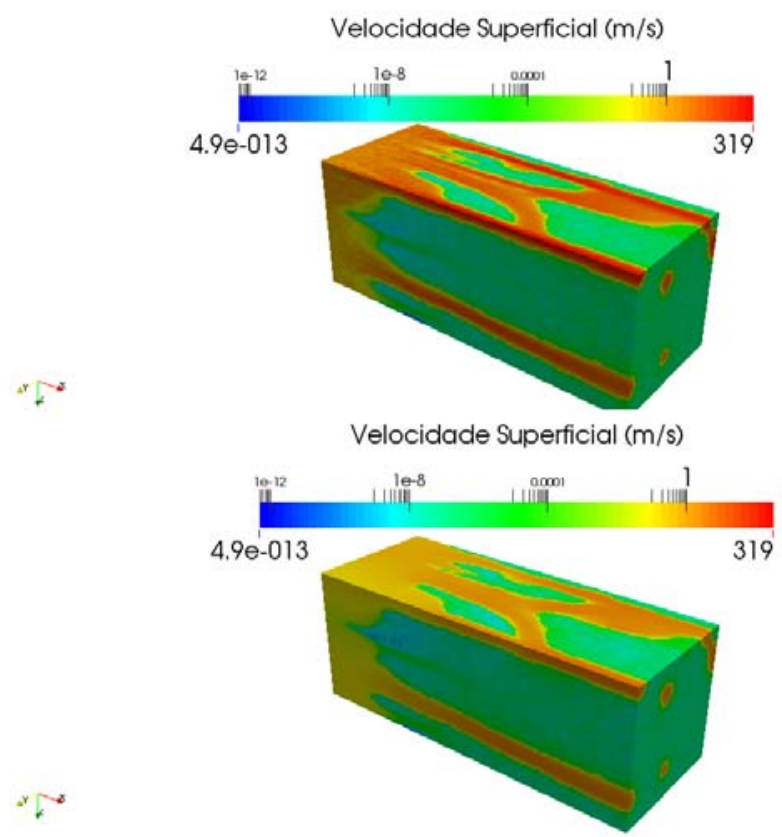

Figura 8.30: Caso 2.4 - Plug 3D. Campo de velocidade superficial visto pelas laterais. Acima HDF e abaixo RPPF. 
A figura 8.31 apresenta o campo de velocidade superficial obtidos com os modelos HDF e RPPF em cortes transversais.

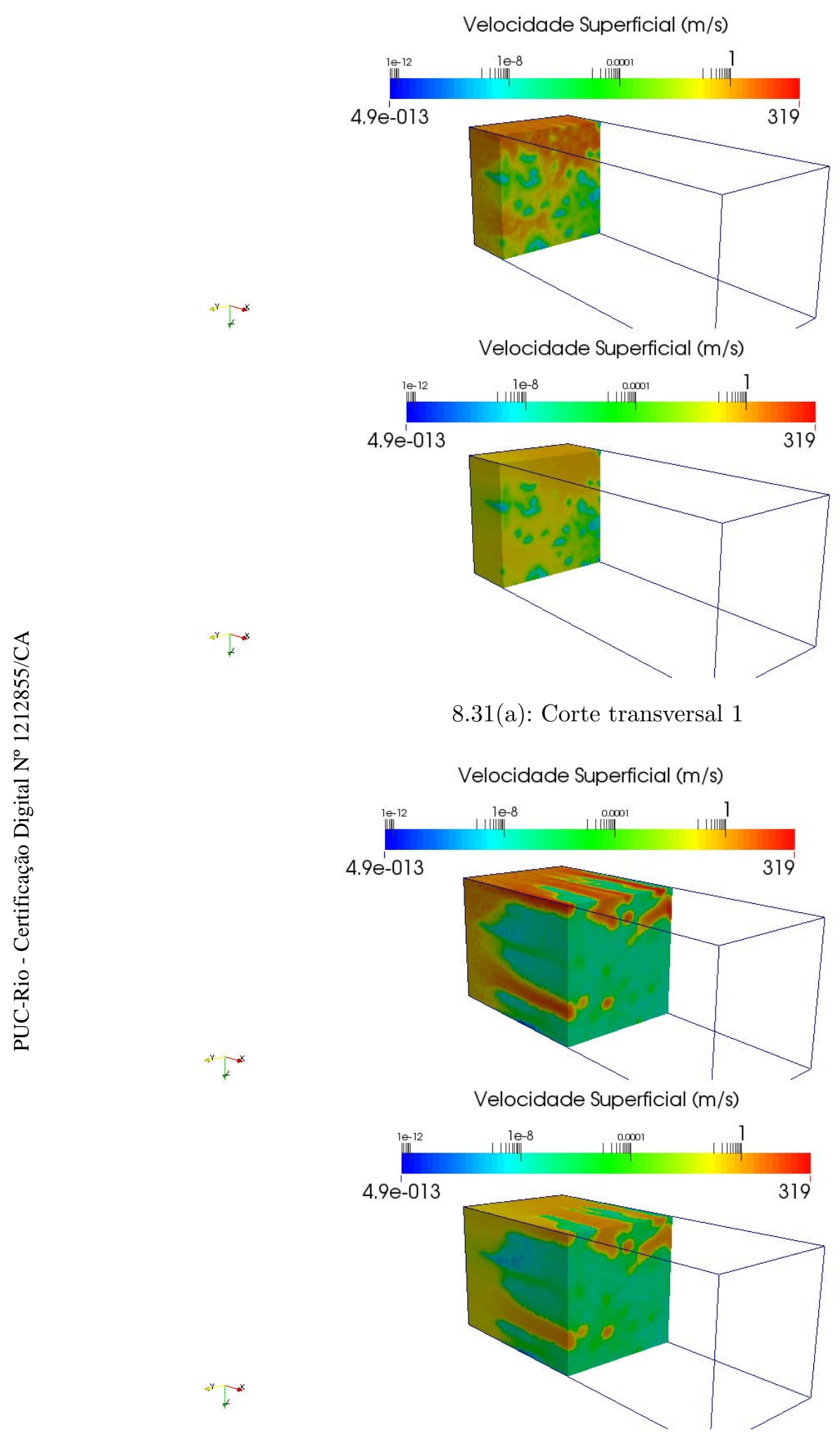

8.31(b): Corte transversal 2

Figura 8.31: Caso 2.4 - Plug 3D. Campo de velocidade superficial (a) Corte transversal 1 (b) Corte transversal 2. Acima HDF e abaixo RPPF. 
Percebe-se que os modelos HDF e RPPF não apresentam as mesmas previsões para os campos de velocidade no meio poroso. A aletoriedade tridimensional da heterogeneidade afeta claramente o campo de velocidade quando comparamos os resultados obtidos com os dois modelos.

\subsection{5}

\section{Comparação da Produção do Plug}

A avaliação precisa da produção de um reservatório é extremamente importante do ponto de vista operacional. Um reservatório com baixa produção pode ser abandonado, ou a necessidade de utilização de métodos secundários ou terciários de extração do óleo podem ser recomendados. Uma avaliação pouco precisa da produção pode levar a prejuízos de milhões de dólares.

Visando avaliar o reflexo das hipóteses simplicadoras do modelo de Darcy na vazão através dos plugs estudados, apresenta-se na tabela 8.7 a vazão mássica na saída do plug para os casos 2.1 a 2.4. Para o Caso 2.1, rocha permeável com fratura, o modelo HDF apresentou uma vazão três vezes superior a vãzo prevista como modelo RPPF. Já para o Caso 2.2, com heterogeneidade em série, o modelo HDF apresentou uma vazõa $45 \%$ maior. O Caso 2.3, que presenta uma combinação de heterogeneidaade em série e fratura, não apresentou campos de pressão e velocidade muito diferentes, mas ainda assim a vazão prevista com o HDF é $32 \%$ superior a prevista com o RPPF. Finalmente, a vazão prevista pelo modelo HDF para o Caso 2.4, plug $3 \mathrm{D}$, foi aproximadamente igual a 8,8 vezes o valor previsto com a ferramenta RPPF.

Tabela 8.7: Produção no Plug. Casos 2.1 a 2.4

\begin{tabular}{|c|c|c|}
\hline & Vazão mássica no plug $(\mathrm{Kg} / \mathrm{s})$ & \\
\hline Caso & $\mathrm{HDF}$ & $\mathrm{RPPF}$ \\
\hline Caso 2.1 & $1,692 \times 10^{-2}$ & $5,109 \times 10^{-3}$ \\
\hline Caso 2.2 & $1,641 \times 10^{-9}$ & $1,123 \times 10^{-9}$ \\
\hline Caso 2.3 & $2,115 \times 10^{-3}$ & $1,607 \times 10^{-3}$ \\
\hline Caso 2.4 & $5,974 \times 10^{-1}$ & $6,800 \times 10^{-2}$ \\
\hline
\end{tabular}

Estes resultados ilustram situações com heterogeneidade complexa, onde o modelo mais completo permite uma contabilização mais adequada da vazão através do meio porosos. A equação de Darcy é consagrada e altamente utilizada na indústria, no entanto, existem situações, como as ilustradas neste trabalho, onde o modelo simplificado de Darcy prevê valores de vazão bem diferentes do que uma modelgem mais geral consegue prever. O modelo HDF somente envolve a solução de uma equação de diferencial, enquando que o 
modelo RPPF resolve 4 equações diferenciais (no caso 3D), e portanto envolve um esforço e custo computacional significativamente maior. Dessa forma, não recomenda-se a utilização do modelo mais complexo em todas as situações. Porém, em situações específicas, com alta heterogeneidade, a acurácia da avaliação da produção de um reservatório compensa esse esforço adicional. 


\section{9 \\ Conclusões}

A previsão da produção de poços tem um papel crucial na engenharia de petróleo. Nessa área específica, tanto a modelagem do escoamento em meios porosos (reservatório) quanto a modelagem do escoamento no poço acoplada ao reservatório são fundamentais para uma boa estimativa na produtividade de poços. Na maioria esmagadora dos casos, a equação de Darcy é a escolha para prever o comportamento do fluxo em rochas petrolíferas. O grande sucesso do uso da equação de Darcy, infelizmente, levou sua aplicação para fora do âmbito dos problemas para os quais esta se aplica.

Os reservatórios carbonáticos, de uma forma geral, apresentam grandes heterogeneidades e anisotropias de propriedades permo-porosas e mecânicas. As porosidades conectadas, vugs e a porosidades de fraturas, encontradas em carbonatos, criam um caminho muito complexo para os fluidos e afetam diretamente a produtividade dos poços, sendo de difícil modelagem para simulação de reservatórios.

A abordagem de Darcy apenas fornece a taxa de fluxo volumétrica como função do gradiente de pressão. Como apresentada na tese, a equação de Darcy contabiliza os efeitos de fricção nos poros com uma estrutura muito especial e específica, sendo que os efeitos friccionais dentro do fluido são esquecidos. Além disso, o fluxo precisa ser suficientemente lento e a equação de Darcy considera o fluxo de fluidos incompressíveis em regime permanente. Isso é contornado na engenharia de reservatórios, por meio da incorporação da conservação de massa e compressibilidade do fluido, resultando numa equação mais completa (equação da difusividade hidráulica), de forma a representar condições de regimes de fluxo mais realistas.

A aplicação da equação de Darcy em simulação numérica em reservatórios carbonáticos deve ser avaliada com cuidado. A presença de vugs e cavernas (cavidades de grandes dimensões), são um problema desafiador em simulação. É importante ressaltar que os vugs e cavernas tem tamanhos variando de centímetros a vários metros e podem impactar a produtividade de um poço. A alta heterogeneidade desse tipo de reservatório torna impeditivo o uso da equação clássica de Darcy. 
O presente trabalho desenvolveu dois solvers: um baseado na equação da difusividade hidráulica e outro baseado na teoria de médias. A modelagem da equação da difusividade hidráulica foi implementada em dois softwares diferentes de CFD: Ansys Fluent e OpenFoam. O modelo baseado na teoria das médias em meio poroso foi implementado no software de CFD OpenFoam.

Investigou-se a produção de poços verticais, verticais fraturados e horizontais em reservatórios homogêneos e heterogêneos para as duas modelagens. A validação das implementações foi feita através de comparação com o software comercial IMEX em casos simplificados. Os casos foram escolhidos de forma que a hipótese de Peacemann (modelo de poço) e a discretização do poço no CFD responderiam da mesma forma. Os poços escolhidos, foram simples (verticais e horizontais) em termos de sua geometria para que esse fator não influenciasse a solução. Ou seja, apesar da versatilidade do CFD na discretização da geometria dos casos, escolheu-se intencionalmete exemplos onde apenas a equação da difusividade hidráulica fosse ser validada.

Com o objetivo de avaliar as limitações da equação de Darcy e entender a necessidade de um modelo mais completo, simulações em plugs foram realizadas para prever o escoamento e campo de pressão em rochas altamente heterôgeneas. Os resultados encontrados mostram que dependendo da heterogeneidade e da pressão imposta, diferentes resultados de produtividade são obtidos, indicando que alguns dos parâmetros comumente desprezados, possuem um papel significativo no escoamento. Portanto, nessas situações, a equação de Darcy não seria uma boa escolha para o cálculo do escoamento em meios porosos.

É importante ressaltar que apesar da análise ser realizada em plugs de centímetros ou metros (e não em um reservatório inteiro) mostra-se que a presente análise não perde a aplicabilidade em relação aos casos práticos de produtividade dos poços. Na verdade, esse tipo de análise traz uma noção maior em que tipo de reservatório a equação simplificada de Darcy pode levar a resultados mal estimados. Os modelos de heterogeneidade permitem um entendimento de quais são as condições onde a equação de Darcy e de teoria de média não prevêem o mesmo resultado de vazão. Ou seja, quais são as permeabilidades e pressão impostas onde os termos desprezados da equação completa (média) são significativos.

Os resultados também ilustram que o modelo mais completo permite uma contabilização mais adequada da vazão através do meio porosos altamente heterogeneos. Apesar da equação de Darcy ser consagrada e altamente utilizada na indústria, existem situações, como as ilustradas neste trabalho, onde o modelo simplifcado de Darcy prevê valores de vazão bem diferentes do que uma modelgem mais geral consegue prever. 
Lembra-se também que a forma como os modelos foram implementados permite que outras equações de estado sejam utilizadas para a representação do fluido. Ou seja, os solvers desenvolvidos permitem o escoamento de gás ou de fluidos mais compressíveis. O termo referente a dilatação do fluido, termo importante em escoamentos compressíveis, foi implentado no modelo de teoria de médias e permite uma contabilização mais realista desses tipos de fluidos.

O presente trabalho representa a continuação de um estudo atual desenvolvido na academia para apresentar a importância de uma equação mais geral na contabilização da produtividade de poços em determinados cenários. Um modelo monofásico foi avaliado, mas é notório que em reservatórios de petróleo a hipótese monofásica simplifica muito o problema. Trabalhos futuros podem ser desenvolvidos nessa linha. O mesmo tipo de processo de upscale pode ser feito para escoamentos com mais de uma fase, avaliando a importância dos termos adicionais quando submetidos a meios porosos altamente heterogêneos.

O fato da equação de difusividade hidráulica e de teoria de média estarem em uma plataforma livre de CFD permite a novos pesquisadores utilizarem os presentes solvers em outros casos de simulação de reservatórios não descritos na tese. A avaliação da produtividade de poços canhoneados, poços multilaterais, poços horizontais ondulados, poços multi fraturados, etc, são alguns exemplos de casos que podem ser simulados utilizando os solvers. O uso de uma plataforma de CFD permite que a geração de geometria e malha sejam feitas customizadas às soluções de novos problemas de simulação de reservatórios, dando mais versatilidade em relação aos simuladores de reservatório.

Outra hipótese empregada na presente tese é o modelo de fluidos newtonianos escoando no reservatório. O processo de média, aplicado a fluidos newtonianos generalizados e não newtonianos em meios porosos altamente heterôgeneos também é de fundamental importância na área de previsão de produtividade através de simulação em poços e reservatórios.

O presente trabalho tem como objetivo fazer uma singela contribuição em um processo contínuo de busca por uma melhor previsão na produtividade de poços de petróleo. Uma melhor estimativa pode representar uma decisão mais asseertiva na escolha do tipo de poço e na decisão de produzir ou não um determinado campo. 


\section{0 Referências bibliográficas}

Abdassah, D.; Ershaghi, I. 1986. Triple-Porosity Systems for Representing Naturally Fractured Reservoirs. SPE Formation Evaluation., DOI: 10.2118/13409-pa.

Adkins, J. E. 1963a. Non-linear diffusion, 2. Constitutive equations for mixtures of isotropic fluids. Phil. Trans. Roy. Soc., A 255, 635-648.

Adkins, J. E. 1963b. Nonlinear diffusion, I. Diffusion flow of mixtures of fluids. Phil. Trans. Roy. Soc., A 255, 607-633.

Altevogt, A. S.; Rolston, D. E.; Whitaker S. 2003. New equations for binary gas transport in porous media; part 1: equation development. Adv. Water Res., 26, 695-715.

Anderson, T. B.; Jackson, R. 1967. A fluid mechanical description of fluidized beds. Equations of motion. Ind. Eng. Chem. Fundamentals 6, 4, 527-539.

Ansys. 2014. Fluent User Guide.

Arbogast, T.; Brunson, D. 2007. A Computational Method for Approximating a Darcy-Stokes System Governing a Vuggy Porous Medium. Computational Geosciences, 11(3), 207-218.

Arbogast, T.; Lehr, H. 2006. Homogenization of a Darcy-Stokes System Modeling Vuggy Porous Media. Computational Geosciences, 10(3), 291-302.

Atkin, R. J.; Craine, R. E. 1976. Continuum theories of mixtures, basic theory and historical development. Quart. J. Appl. Math., 29, 290.

Babu, D. K.; Odeh, A. S. 1989. Productivity of a Horizontal Well. Paper SPE-18298-PA.

Bear, J.; Bachmat, Y. 1990. Introduction to Modelling of Transport Phenomena in Porous Media. Kluwer Academic, Dordrecht.

Bennethum, L.S.; Weinstein, T. 2004. Three pressures in porous media. Transp. Porous Media, 54 (1), 1-34. 
Bi, L.; Qin, G.; Popov P. et al. 2009. An Efficient Upscaling Process Based on a Unified Fine-Scale Multi-Physics Model for Flow Simulation in Naturally Fracture Carbonate Karst Reservoirs. Paper presented at the SPE/EAGE Reservoir Characterization and Simulation Conference, 19-21 October, Abu Dhabi, UAE Society of Petroleum Engineers., DOI: 10.2118/125593-ms.

Bird, R. B.; Stewart, W. E.; Lightfoot E. N. Fenômenos de Transporte. LTC.

Bourgoyne, A. T.; Millheim, K. K.; Chenevert M. E.; Young Jr. 1991. F. S.: Applied Drilling Engineering. Society of Petroleum Engineers, Richardson, TX, USA, 2 nd Printing.

Bowen, R. M. 1976. Theory of Mixtures in Continuum Physics. A.C. Eringen, 3,8 .

Brinkman, H. C. 1947a. A calculation of viscous force exerted by a flowing fluid on a dense swarm of particles. Applied Science Research, A1, 27-34.

Brinkman, H. C. 1947b. On the Permeability of Media Consisting of Closely Packed Porous Particles. Appl. Sci. Res., 81-86.

Brinkman, H. C. 1952. The Viscosity of Concentrated suspensions and Solutions. J. Chem. Phys., 571.

Byrne, M.; Jimenez, M. A.; Chavez J. C. 2009. Predicting Well Inflow Using Computational Fluid Dynamics - Closer to the Truth? SPE 122351.

Byrne, M. T.; Jimenez, M. A.; Rojas E. 2010. Modelling Well Inflow Potential in Three Dimensions Using Computational Fluid Dynamics. SPE 128082.

Byrne, M.; Jimenez, M. A.; Rojas E.; Castillo E. 2011a. Computational Fluid Dynamics for Reservoir and Well Fluid Flow Performance Modelling. SPE 144130 .

Byrne, M.; Jimenez, M. A.; Salimi S. 2011b. Modelling the Near Wellbore and Formation Damage - A Comprehensive Review of Current and Future Options. SPE 144096.

Camacho, V. R.; Vasquez-Cruz, M. A.; Castrejon-Aivar R. et al. 1986. Pressure Transient and Decline Curve Behaviors in Naturally Fractured Vuggy Carbonate Reservoirs. SPE Formation Evaluation., 8(02), 95-112.

Chandra, V.; Hamdi, H.; Corbett P. W. M. ; Geiger S. 2013. Improving Reservoir Characterization and Simulation with Near Wellbore Modeling. SPE 148104. 
Chandra, V.; Hamdi, H.; Corbett P. W. M.; Geiger S. 2011. Improving Reservoir Characterization and Simulation With Near-Wellbore Modeling. SPE 148104.

Cinclo-Ley, S. 1981. Transient pressure analysis for fractured wells. SPE 7490.

CMG. 2016. IMEX User Guide, Computer Modelling Group LTD.

Correia, M. G. 2014. Representação de Reservatórios Carbonáticos Naturalmente Fraturados em Simulação de Reservatórios. Tese de Doutorado, UNICAMP, Campinas.

Crochet, M. J.; Nagdhi, P.M. 1967. Small motions superposed on large static deformations. Acta Mech., 4, 315-335.

Dabbouk, C.; Liaqat, A.; Williams G. et al. 2002. Waterflood in Vuggy Layer of a Middle East Reservoir - Displacement Physics Understood. Paper presented at the Abu Dhabi International Petroleum Exhibition and Conference, Abu Dhabi, United Arab Emirates Society of Petroleum Engineers., DOI: 10.2118/78530-MS.

Darcy, H. P. G. 1856. Les Fontaines Publiques de la Ville de Dijon. Victor Dalmont,Paris.

Dupuit, A. J. E. J. 1963. Etudes Thoriques et Pratiques sur le Mouvement des aux dans les Canaux D6couverts et a Travers les Terrains Permdables. Victor Dalmont,Paris.

Economides, M. J.; Brand, C. W.; Frick T. P. 1996. Well Configurations in Anisotropic Reservoirs. Paper SPE-27980-PA.

Edwards, D. A.; Shapiro, M.; Bar-Yoseph P.; Shapira M. 1990. The influence of reynolds number upon the apparent permeability of spatially periodic arrays of cylinders. Physics of Fluids A : Fluid Dynamics, 2 (1), 45-55.

Fernandes, P. D.; Ferreira, M. G.; Bedrikovetsky P. 2006. Uniformização de fluxo em poços horizontais. Encontro Nacional de Hidráulica de Perfuração e Completação de Poços de Petróleo e Gás,.

Ferreira, J. A. S. L. 2016. Caracterização e modelação de reservatórios carbonatados: estudo de caso baseado em análogos do Jurássico Médio da região de Vale Florido, Maciço Calcário Estremenho (MCE). Tese de Mestrado, Universidade de Lisboa, Lisboa. 
Ferziger, J.; Peric, M. 1995. Computational methods for fluid dynamics. Springer Verlag. [S.l.]: Berlin-New York.

Forchheimer, P. 1901. Wasserbewegung durch Boden. Zeitschrift des Vereines Deutscher Ingenieure, 45, 1736-1741 e 1781-1788.

Furui, K.; Zhu, D.; Hill A. D. 2005. A Comprehensive Skin-Factor Model of Horizontal Well Completion Performance. SPE Prod $\&$ Fac, 20 (3), 207-220.

Ganesan, S.; Poirier, D. R. 1991. Conservation of mass and momentum for the flow of interdendritic liquid during solidification. Metall. Trans. B, 21, $173-181$.

Garcia, J. E. L.; Bianco, L. C. B.; Fernandes P. D. 2010. Apostila da Petrobras de Completação de Poços.

Givler, R. C.; Altobelli, S. A. 1994. A determination of the effective viscosity for the Brinkman-Forchheimer flow model. Journal of Fluid Mechanics, 258, $355-370$.

Gray, W. G.; Leijnse, A.; Kolar R. L.; Blain C. A. 1993. Mathematical tools for changing spatial scales in the analysis of physical systems. CRC Press.

Gray, W. G.; Miller, C. T. 2009. Thermodynamically constrained averaging theory approach for modeling flow and transport phenomena in porous medium systems: 7. Single-phase megascale flow models. Adv. Water Resour., 32, 1121-1142.

Gray, W. G.; Miller, C. T. 2013. A generalization of averaging theorems for porous medium analysis. Adv. Water Resour., 62, 227-237.

Gray, W. G.; Hassanizadeh, S. M. 1989. Averaging theorems and averaged equations for transport of interface properties in multiphase systems. Int. J. Multiphase Flow, 15 (1), 81-95.

Gray, W. G. 1975. A derivation of the equations for multi-phase transport. Chem. Eng. Sci., 30, 229-233.

Green, A. E.; Adkins, J. E. 1964. Non-linear diffusion, 2. Constitutive equations for mixtures of isotropic fluids. Arch. Ration. Mech. Anal., 15, 235-246.

Gulbransen, A. F.; Hauge, V. L.; Lie K. A. 2009. A Multiscale Mixed Finite Element Method for Vuggy and Naturally Fractured Reservoirs. Paper presented at the SPE Reservoir Simulation, DOI: 10.2118/130287-ms. 
Hassanizadeh, M.; Gray, W. G. 1980. General conservation equations for multiphase systems: 3. Constitutive theory for porous media flow. Adv. Water Resourc., 3(1), 25-40.

Hassanizadeh, S. M.; Gray, W. G. 1989. Boundary and interface conditions in porous media. Water Resour. Res., 25 (7), 1705-1715.

Hazen, A. 1893. Some physical properties of sand and gravels with special reference to their use in filtration. Massachusetts State Board of Health, Twenty-fourth Annual Report, 541.

He, J.; Killough, J. E. 2015. A Unified Finite Difference Model for The Simulation of Transient Flow in Naturally Fractured Carbonate Karst Reservoirs. SPE Reservoir Simulation Symposium, 23-25 February, in Houston, Texas, USA.

Hill, A. A.; Rajagopal, K. R.; Vergori L. 2016a. On the stability and uniqueness of the flow of a fluid through a porous medium. Z. Angew. Math. Phys., 1-12.

Hill, A. A.; Rajagopal, K. R.; Vergori L. 2016b. On the Stability and Uniqueness of the Flow of Fluid Through a Porous Medium. ZAMP, Zeitschrift fur Angewandte Mathematik und Physik, 67, 49.

Holzmann, T. 2016. Mathematics, Numerics, Derivations and OpenFOAM. 4 ed. Holzmann CFD.

Howes, F. A.; Whitaker, S. 1985. The spatial averaging theorem revisited. Chemical Engineering Science, 40, 1387-1392.

Hsu, C. T.; Cheng, P. 1990. Thermal dispersion in a porous medium. Int. J. Heat Mass Transfer, 33, 1587-1597.

Huang, H.; Burch, D.; Brown W.; Yin J.; Long T. 2010a. Innovative Technologies Enable Fast, Accurate, and Detailed Completion Evaluation and Well Performance Analysis. SPE 135119.

Huang, Z.; Yao, J.; Li Y. et al. 2010b. Permeability Analysis of Fractured Vuggy Porous Media Based on Homogenization Theory. Science China Technological Sciences, 53(3), 839 -847.

Hubbert, M. K. Darcy's Law and the Field Equations of the Flow of Underground Fluids. Paper prepared for presentation before Darcy Centennial Hydrology Symposium of the International Association of Hydrology held in Dijon. 
Ingeborg, L.; Marcin, K.; Knut-Andreas L. et al. 2010. On the Stokes-Brinkman Equations for Modeling Flow in Carbonate Reservoirs. Paper presented at the 12th European Conference on the Mathematics of Oil Recovery: ECMOR XII, 6-9 September Oxford, UK. European Association of Geoscientists and Engineers., DOI: 10.3997/2214-4609.20144924.

Jackson, A. S.; Rybak, I.; Helmig R.; Gray W. G.; Miller C. T. 2012. Thermodynamically constrained averaging theory approach for modeling flow and transport phenomena in porous medium systems: 9. Transition region models. Adv. Water Resour, 42, 71-90.

Jasak, H. 1996. Error Analysis and Estimation for the Finite Volume Method with Applications to Fluid Flows. PhD Thesis, Imperial College of Science Technology and Medicine, London.

Johansen, T. E.; Khoriakov, V. 2007. Iterative techniques in modeling of multiphase flow in advanced wells and the near well region. Journal of Petroleum Science and Engineering, 58, 49 - 67.

Joshi, S. D. 2007. Petroleum Engineering - Upstream - Horizontal And Multilateral Well Technology. Encyclopedia of Life Support Systems(EOLSS), (http://www.eolss.net).

Kalia, N.; Balakotaiah, V. 2007. Modeling and analysis of Wormhole Formation in Reactive Dissolution of Carbonate Rocks. Chemicam Engineering Science, 62, 919-928.

Kalia N.; Balakotaiah, V. 2009. Effect of Medium Heterogeneiteis on Reactive Dissolution of Carbonates. Chemicam Engineering Science, 64, 376-390.

Kang, Z.; Wu, Y.-S.; Li J. et al. 2006. Modeling Multiphase Flow in Naturally Fractured Vuggy Petroleum Reservoirs. SPE Annual Technical Conference and Exhibition, 24-27 September, San Antonio, Texas, USA Society of Petroleum Engineers, DOI: 10.2118/102356-MS.

Kannan, K.; Rajagopal, K. R. 2008. Flow Through Porous Media due to High Pressure Gradients. Applied Mathematics and Computation, 199, 748-759.

Karakas, M.; Tariq, S. M. 1990. Semiana-lytical Productivity Models for Perforated Completions. SPE 1824\%.

Karakas, M.; Tariq, S. M. 1991. Semianalytical Productivity Models for Perforated Completions. SPE Prod Eng, 6 (1). 
Karimi, M. F.; Durlofsky, L. J. 2012. Accurate resolution of Near Well Effects in Upscaled Models Using Flow Based Unstructuraed Local Grid Refinement. SPE 141675 .

Karimi, M. F; Durlofsky, L.J. 2011. Accurate Resolution of Near-Well Effects in Upscaled Models Using Flow-Based Unstructured Local Grid Refinement. SPE 141675, Presentation at the SPE Reservoir Simulation Symposium, The Woodlands, Texas, USA.

Khvatova, I. E.; Renaud, A.; Golitsina E. et al. 2012. Simulation of Complex Carbonate Field: Double Medium Vs. Single Medium - Kharyaga Field Case. Paper presented at the SPE Russian Oil and Gas Exploration and Production Technical Conference and Exhibition, Moscow, Russia Society of Petroleum Engineers., DOI: 10.2118/160585-MS.

Knupp, P.; Lage, J. L. 1995. Generalization of the Forchheimer-extended Darcy flow model to the tensor permeability case via a variational principle. Journal of FluidMechanics, 299, 97-104.

Kovscek, A.; Cakici, M. 2011. Geologic storage of carbon dioxide and enhanced oil recovery. II Cooptimization of storage and recovery. Energy Convers. Manag., 46(11-12), 1941-1956.

Kruger, E. 1927. Die Grundwasserbewegung. Internationale Mitteilungen fur Bodenkunde, 8, 105.

Lage, J. L. 1998. The fundamental theory of flow through permeable media: from Darcy to turbulence. Transport Phenomena in Porous Media (eds. D.B. Ingham and I. Pop), 1-30.

Laptev, V. 2003. Numerical Solution of Coupled Flow in Plain and Porous Media. PhD Thesis, Technische Universität Kaiserslautern, Kaiserslautern.

Liang, C. 2015. Simulation and Analysis of Wormhole Structure Affected by Mineralogy Heterogeneity in Carbonate Rocks. The Eletronic Journal of Geotechnical Engineering, 20, 12811-12831.

Ling, J. X.; Dybbs, A. 1992. The effect of variable viscosity on forced convection over a flat plate submersed in a porous medium. ASME Journal of Heat Transfer, 114, 1063-1065.

Marle. 1965. Application de la méthode de la thermodynamique des processus irréversible à l'écoulement d'un fluide à travers un milieu poreux. Bulletin RILEM, 29, 1066-1071. 
McGuire, W. J.; Sikora, V. J. 1960. The Effect of Vertical Fractures on Well Productivity. SPE 1618.

Miller, C. T.; Gray, W. G. 2005. Thermodynamically constrained averaging theory approach for modeling flow and transport phenomena in porous medium systems: 2. Foundation. Adv. Water Resour., 28, 181-202.

Moraes, A. O. S. 2013. Analysis of the non-orthogonality correction of finite volume discretization on unstructured meshes. 22ND International Congress of Mechanical Engineering, COBEM.

Munaf, D.; Lee, D.; Wineman A. S.; Rajagopal K. R. 1993. A boundary value problem in groundwater motion analysis-comparisons based on Darcy's law and the continuum theory of mixtures. Mathematical Modeling and Methods in Applied Science, 3, 231-248.

Nakshatrala, K. B.; Rajagopal, K. R. 2009. A numerical study of fluids with pressure dependent viscosity flowing through a rigid porous media. Int. J. Numer. Methods Fluids, 67, 342-368.

Nakshatrala, K. B.; Rajagopal, K. R. 2011. A Numerical Study of Fluids with Pressure-Dependent Viscosity Flowing Through a Rigid Medium. International Journal for Numerical Methods in Fluids, 67, 342-368.

Ni, J.; Beckerann, C. 1991. A volume-averaged two-phase model for transport phenomena during solidification. Metall. Trans. B, 22, 349-361.

Nield, D. A.; Lage, J. L. 1997. Convection effect on the porous medium flow of a fluid with temperature dependent viscosity. ASME Journal of Heat Transfer.

Nolte, K. G.; Economides, M. J. 2000. Reservoir Stimulation. John Wiley and Sons; 3 edition.

Nutting, P. G. 1930. Physical analysis of soil sands. Bulletin of the American Association of Petroleum Geologists, 14, 1337-1349.

Oda, M. 1986. An Equivalent Continuum Model for Coupled Stress and Fluid Flow Analysis in Jointed Rock Masses. Water Resources Research, 22 (13), 1845-1856.

Patankar, S. V. 1981. Numerical heat transfer and fluid flow. [S.l.]: Hemisphere Publishing Corporation. 
Peaceman, D. W. 1978. Interpretation of well-block pressures in numerical reservoir simulation. Soc. Pet. Eng. J., 183-194.

Peaceman, D. W. 1982. Interpretation of well-block pressure in numerical reservoir simulation with nonsquare grid blocks anisotropic permeability. SPE 10528.

Peaceman, D. W. 1983. Interpretation of well-block pressure in numerical reservoir simulation with nonsquare grid blocks anisotropic permeability. SPE Journal, 9, 531-543.

Peaceman, D. W. 1987. Interpretation of well-block pressures in numerical reservoir simulation-part 3: some additional well geometries. SPE 28670, $183-194$.

Peaceman, D. W. 1990. Interpretation of well-block pressures in numerical reservoir simulation - part 3: some additional well geometries. SPE Reservoir Eng. J., 227-232.

Peaceman, D. W. 1995. A New Method for Representing Multiple Wells with Arbitrary Rates in Numerical Reservoir Simulation. Paper SPE 31066, 1-22.

Peaceman, D. W. 2003. A New method for calculating well indexes for multiple wellblocks with arbitrary rates in numerical reservoir simulation. Paper SPE 79687, 1-22.

Peng, X.; Du, Z.; Liang B. et al. 2009. Darcy-Stokes Streamline Simulation for the Tahe-Fractured Reservoir with Cavities. SPE Journal, DOI: 10.2118/107314-PA.

Pomeala, D. C.; Lager, J. L. 1997. Experimental verification of the HazenDarcy flow model for forced convection of a liquid with temperature dependent viscosity. International Journal of Heat and Mass Transfer.

Popov, P.; Qin, G.; Bi L. et al. 2009. Multiphysics and Multiscale Methods for Modeling Fluid Flow through Naturally Fractured Carbonate Karst Reservoirs. SPE Reservoir Evaluation and Engineering., DOI: 10.2118/105378-pa.

Popov, P.; Bi, L.; Efendiev Y. et al. 2007. Multi-Physics and Multi-Scale Methods for Modeling Fluid Flow through Naturally-Fractured Vuggy Carbonate Reservoirs. Paper presented at the SPE Middle East Oil and Gas Show and Conference, Kingdom of Bahrain Society of Petroleum Engineers., DOI: 10.2118/105378-ms. 
Prats. 1961. Effect of Vertical Fractures on Reservoir Behavior - Incompressible Fluid Case. SPE 1575.

Qin, G.; Gong, B.; Bi L. et al. 2011. Multi-Scale and Multi-Physics Methods for Numerical Modeling of Fluid Flow in Fractured Formations. Paper presented at the SPE EUROPEC/EAGE Annual Conference and Exhibition, Vienna, Austria Society of Petroleum Engineers, DOI: 10.2118/143590-ms.

Quintard, M.; Whitaker, S. 1994a. Transport in ordered and disordered porous media i: The cellular average and the use of weighting functions. Transport in Porous Media, 14, 163-177.

Quintard, M.; Whitaker, S. 1994b. Transport in Ordered and Disordered Porous Media I: The Cellular Average and Use of Weighting Functions. Transport in Porous Media, 14, 163-177.

Quintard, M.; Whitaker, S. 1994c. Transport in Ordered and Disordered Porous Media II: Generalized Volume Averaging. Transport in Porous Media, 14, 179-206.

Rajagopal, K. R. 2007. On a Hierarchy Of Approximate Models For Flows of Incompressible Fluids Through Porous Solids. Mathematical Models and Methods in Applied Sciences, 17, 215-252.

Rajagopal, K. R.; Tao, L. World Scientific, Singapore, 1995. Mechanics of Mixtures. Series on Advances in Mathematics and Applied Sciences, 35.

Rajagopal, K. R.; Srinivasan, S. 2014. Flow of fluids through porous media due to high pressure gradients: Part 2-unsteady flows. J. Porous Media, $\mathbf{1 7 ( 9 ) , ~ 7 5 1 - 7 6 2 . ~}$

Roache, P. J. 2002. Code Verification by the method of manufactured solutions. J. Fluids Eng., 124 (1), 4-10.

Rushe, H. 2002. Computational fluid dynamics of dispersed two-phase flows at high phase fractions. Tese (Doutorado), Imperial College of Science, Technology and Medicine, London.

Sitharam, T. G.; Sridevi, J.; Shimizu N. 2001. Practical Equivalent Continuum Characterization of Jointed Rock Masses. International Journal of Rock Mechanics and Mining Sciences, 38(3), 437-448.

Slattery, J. C. 1967. Flow of viscoelastic fluids through porous media. AIChE. J., 13, 1066-1071. 
Smit, G. J. F.; Wilms, J. M.; Dideericks G.P.J. 2011. Two-phase flow modeling for low concentration spherical particle motion through a Newtonian fluid. Appl. Math. Model., 217, 5068-5077.

Soulaine, C. 2012. Modélisation des écoulements dans les garnissages structurés: de l'échelle du pore à l'échelle de la colonne. PhD Thesis, Université de Toulouse, Texas.

Srinivasan. 2016a. A generalized Darcy-Dupuit-Forchheimer Model with Pressure-Dependent Drag Coefficient for Flow Through Porous Media Under Large Pressure Gradients. Transp. Porous Media, 111, 741-750.

Srinivasan, S.; Bonito, A.; Rajagopal K. R. 2013a. Flow of a Fluid Through a Porous Solid due to High Pessure Gradients. Journal of Porous Media, 16, 193-203.

Srinivasan, S.; Bonito, A.; Rajagopal K. R. 2013b. Flow of a fluid through a porous solid due to high pressure gradients. J. Porous Media, 16(3), 193-203.

Srinivasan, S.; Rajagopal, K. R. 2014. A thermodynamic basis for the derivation of the Darcy, Forchheimer and Brinkman models for flows through porous media and their generalizations. Int. J. Non-Linear Mech., 58, $162-166$.

Srinivasan, S.; Rajagopal, K. R. 2016b. On the flow of fluids through inhomogeneous porous media due to high pressure gradients. International Journal of Non-Linear Mechanics, 78, 112-120.

Srinivasan, S.; Rajagopal, K. R. 2016c. On the flow of fluids through inhomogeneous porous media due to high pressure gradients. Int. J. Non-Linear Mech., 78, 112-120.

Srinivasan, S. 2016d. A Generalized Darcy Dupuit Forchheimer Model with Pressure Dependent Drag Coefficient for Flow Through Porous Media Under Large Pressure Gradients. Transport Porous Media, 111, 741-750.

Stanek, V.; Szekely, J. 1974. Three-dimensional flow of fluids through nonuniform packed beds. AIChE Journal, 20, 974-980.

Stauffer, P. H.; Viswanathan, H. S.; Pawar R. J.; Guthrie G. D. 2008. A system model for geologic sequestration of carbon dioxide. Environ. Sci. Technol., 43(3), 565-570. 
Subramanian, S. C.; Rajagopal, K. R. 2007. A Note on the Flow Through Porous Solids at High Pressures. Computers and Mathematics with Applications, 53, 260-275.

Sun, D.; Li, B.; Gladkikh M.; Satti R.; Evans R. 2011. Comparison of Skin Factors for Perforated Completions Calculated with Computational Fluid Dynamics Software and a Semi-Analytical Model. SPE 143663.

Sun, D.; Li, B.; Gladkikh M.; Satti R.; Evans R. 2013. Comparison of Skin Factors for Perforated Completions Calculated with Computational Fluid Dynamics Software and Karakas Tariq Semianalytical Model. SPE 143663, 21.

Szekely, J.; Carr, R. G. 1968. On nonisothermal flow of gases through packed beds. Transactions of the Metallurgical Society of AIME, 242, 918-921.

Vafai, K.; Tien, C. L. 1981. Boundary and inertia effects on flow and heat transfer in porous media. International Journal of Heat and Mass Transfer, 24, 195-203.

Wang, L.; Wang, L. P.; Guo Z.; Mi J. 2015. Volume-averaged macroscopic equation for fluid flow in moving porous media. International Journal of Heat and Mass Transfer, 82, 357-368.

Ward, J. C. 1964. Turbulent flow in porous media. ASCE Journal of the Hydraulics Division, 90, 1-12.

Weng, X.; Kresse, O; Cohen C. E. 2011. Modelling of Hydraulic Fracture Network Propagation in a Naturally Fractured Formation. SPE 140253-MS.

Whitaker, S. 1967. Diffusion and dispersion in porous media. AIChE. J., 13, $420-427$.

Whitaker, S. 1973. The transport equations for multi-phase systems. Chem. Eng. Sci., 28, 139-147.

Whitaker, S. 1986. Flow in porous media: A theoretical derivation of Darcy's law. Transport in Porous Media, 1, 3-25.

Whitaker, S. 1996. The Forchheimer equation: a theoretical development. Transport in Porous Media, 25, 27-61.

Whitaker, S. 1999. The Method of Volume Averaging. Springer Science + Business. 
Wood, B. D. 2007. Inertial effects in dispersion in porous media. Water Resour. Res. W12S16, http://dx.doi.org/10.1029/2006WR005790, 43, 357-368.

Wu, Y.-S.; Ehlig Economides, C. A.; Qin G. et al. 2007. Modeling Multiphase Flow in Naturally Fractured Vuggy Petroleum Reservoirs. SPE Annual Technical Conference and Exhibition, 1-14 November, Anaheim, California, U.S.A. Society of Petroleum Engineers., DOI: 10.2118/110044-ms.

Wu, Y. S.; Qin, G.; Ewing R. E. et al. 2006. A Multiple-Continuum Approach for Modeling Multiphase Flow in Naturally Fractured Vuggy Petroleum Reservoirs. Paper presented at the International Oil and Gas Conference and Exhibition in China, 5-7 December, Beijing, China. Society of Petroleum Engineers., DOI: 10.2118/104173-MS.

Wu, Y. S. 2013. On the Effective Continuum Method for Modeling Multiphase Flow, Multicomponent Transport and Heat Transfer in Fractured Rock. In Dynamics of Fluids in Fractured Rock: American Geophysical Union.

Yang, X. F.; Zheng, Z. Q. C.; Winecki S. ; Eckels S. 2013. Model simulation and experiments of flow and mass transport through a nano-material gas filter. Appl. Math. Model., 37, 9052-9062.

Yao, J.; Huang, Z.; Li Y. et al. 2010. Discrete Fracture-Vug Network Model for Modeling Fluid Flow in Fractured Vuggy Porous Media. Society of Petroleum Engineers., DOI: 10.2118/130287-ms.

Zeboudj, F.; Bahi, L. 2010. Horizontal Well Performance Flow Simulation CFD-Application. SPE 133269.

Zhang, L.; Bryant, S. L.; Jennings J. W. et al. 2004. Multiscale Flow and Transport in Highly Heterogeneous Carbonates. Paper presented at the SPE Annual Technical Conference and Exhibition, 26-29 September, Houston, Texas Society of Petroleum Engineers., DOI: 10.2118/90336-MS.

Zhang, L. W.; Balachandar, S.; Tafti D. K.; Najjar F. M. 1997. Heat transfer enhancement mechanisms in inline and staggered parallel-plate fin heat exchangers. ASCE Journal of the Hydraulics Division, 40, 2307-2325. 